A Wet-chemical Approach to Perovskitie and Fluorite-type Nanoceramics

- Synthesis and Processing -
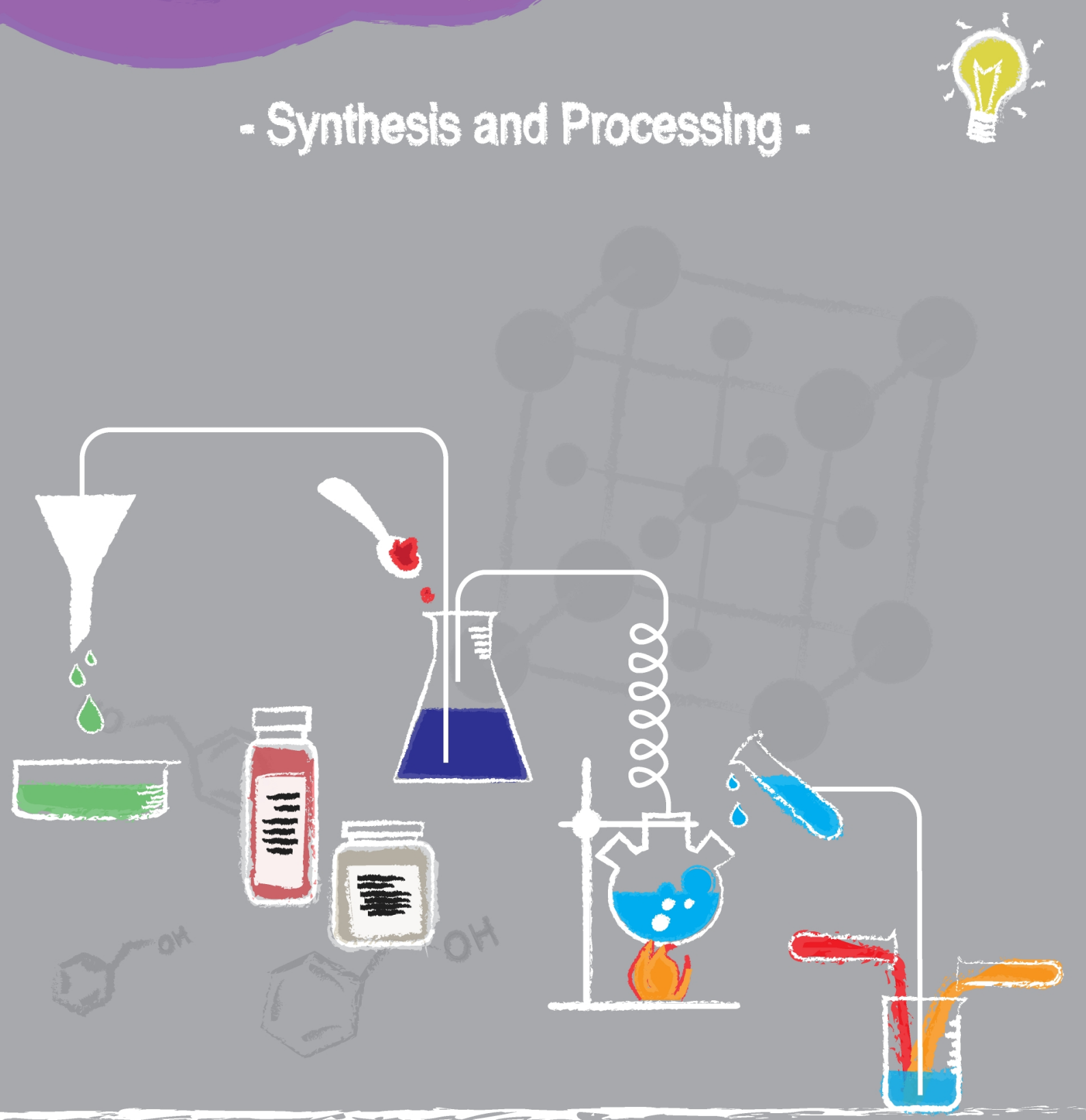

Sjoerd A. Veldhuis 



\section{A WET-CHEMICAL APPROACH TO PEROVSKITE AND FLUORITE-TYPE NANOCERAMICS}

\section{- SYNTHESIS AND PROCESSING -}




\section{Ph.D. Committee}

\section{Chairman and Secretary}

Prof. dr. ir. J.W.M. Hilgenkamp University of Twente

\section{Promotor}

Prof. dr. ir. J.E. ten Elshof

University of Twente

\section{Members}

Prof. dr. ir. J. Huskens

University of Twente

Prof. dr. ir. A. Nijmeijer

University of Twente

Prof. dr. M. van Bael

Hasselt University

Prof. S. Guillemet-Fritsch

University Paul Sabatier, Toulouse

Prof. dr. ir. L. Lefferts

University of Twente

\section{Referent}

Dr. B.A. Boukamp

University of Twente

The research described in this thesis was carried out within the Inorganic Materials Science group, Department of Science and Technology and the MESA+ Institute for Nanotechnology at the University of Twente. This work is financially supported by the Advanced Dutch Energy Materials program (ADEM).

A Wet-chemical Approach to Perouskite and Fluorite-type Nanoceramics Ph.D. thesis, University of Twente, Enschede, The Netherlands Copyright (C) 2015 by Sjoerd A. Veldhuis Printed by CPI Royal Wöhrmann, Zutphen, The Netherlands ISBN: 978-90-365-3824-4

DOI: $10.3990 / 1.9789036538244$ 


\title{
A WET-CHEMICAL APPROACH TO PEROVSKITE AND FLUORITE-TYPE NANOCERAMICS
}

\section{- SYNTHESIS AND PROCESSING -}

\section{PROEFSCHRIFT}

\author{
Ter verkrijging van \\ de graad van doctor aan de Universiteit Twente \\ op gezag van de rector magnificus, \\ Prof. dr. H. Brinksma \\ volgens het besluit van het College voor Promoties \\ in het openbaar te verdedigen \\ op woensdag 4 maart 2015 om 16.45 uur
}

door

Sjoerd Antonius Veldhuis

geboren op 03-07-1982

te Almelo 
Dit proefschrift is goedgekeurd door de promotor

Prof. dr. ir. J.E. ten Elshof 


\section{Table of Contents}

$\begin{array}{ll}\text { 1. Introduction } & 1\end{array}$

1.1 Solid Oxide Fuel Cells ....................................................................................... 2

1.2 Sol-gel Chemistry ............................................................................................

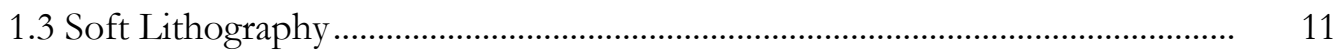

1.4 Scope of the Thesis ...................................................................................... 15

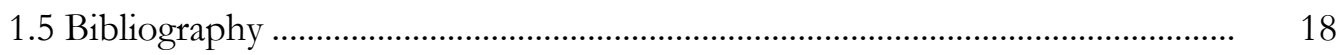

2. The Formation of Nano-crystalline Barium Titanate in Benzyl 23 Alcohol at Room Temperature

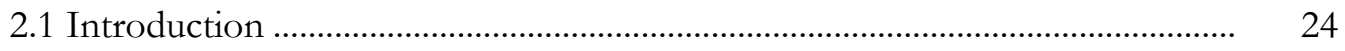

2.2 Experimental Section ................................................................................... 25

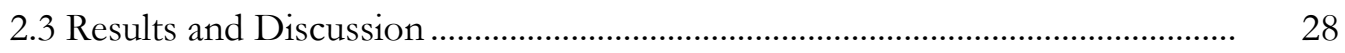

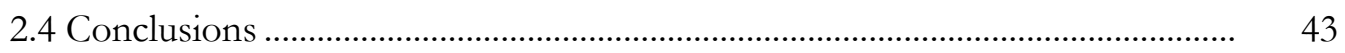

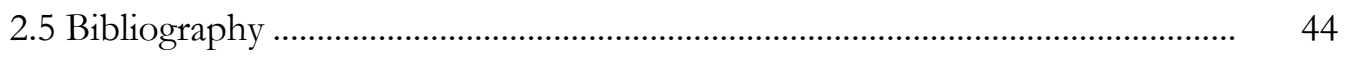

2.6 Supporting Information .................................................................................. 47

3. Kinetics of Barium Titanate Nanocrystal Formation in Benzyl 51 Alcohol

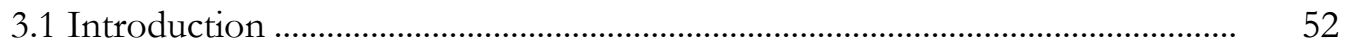

3.2 Model Independent Data Analysis ................................................................... 53

3.3 Experimental Section ................................................................................... 56

3.4 Results and Discussion ................................................................................. 58

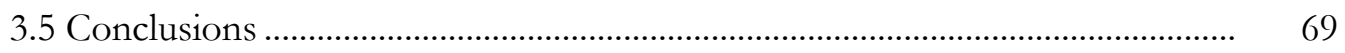

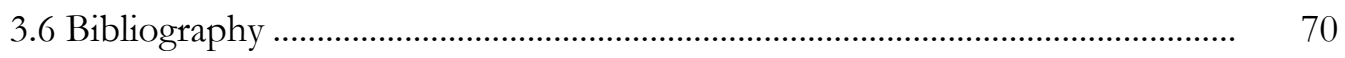

3.7 Supporting Information .................................................................................. 73 

doped Barium Zirconate - A Structural Study

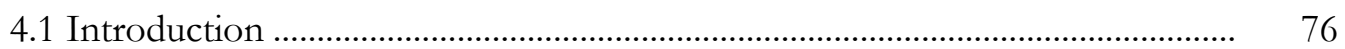

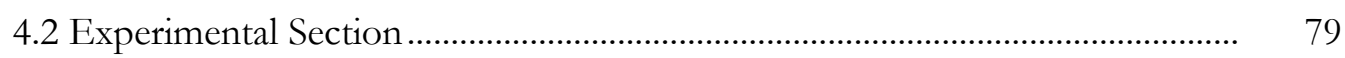

4.3 Results and Discussion ................................................................................ 82

4.4 Conclusions .......................................................................................... 89

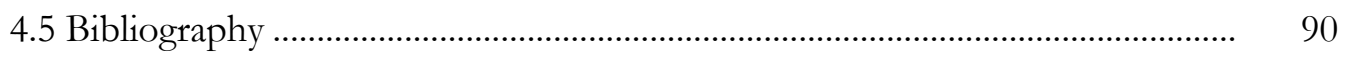

5. A Facile Method for the Density Determination of Ceramic Thin 93 Films using X-ray Reflectivity

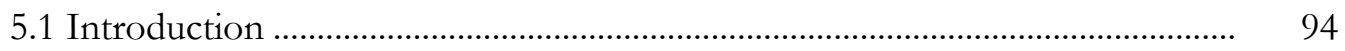

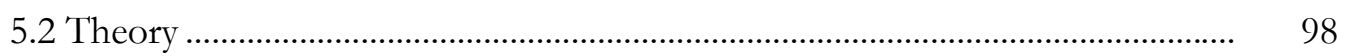

5.3 Experimental Section................................................................................. 104

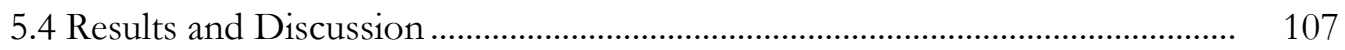

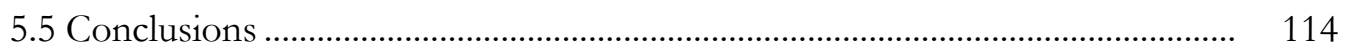

5.6 Bibliography ……........................................................................................ 115

6. Rapid Densification of Sol-gel Derived Yttria-stabilized Zirconia 117 Thin Films

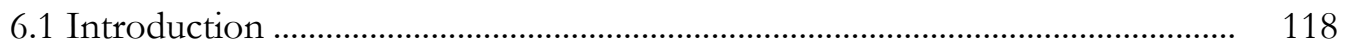

6.2 Experimental Section ............................................................................... 119

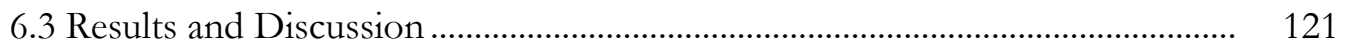

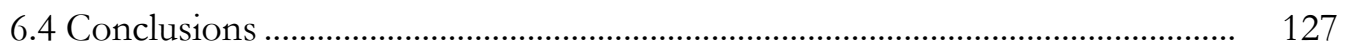

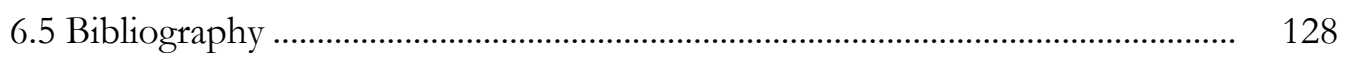

7. Concentration Dependence on the Shape and Size of Sol-gel De- 131 rived Yttria-stabilized Zirconia Features using Soft Lithographic Patterning

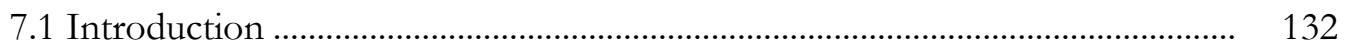

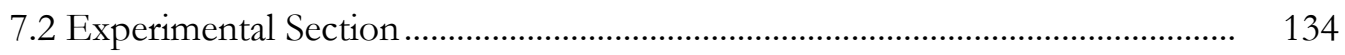

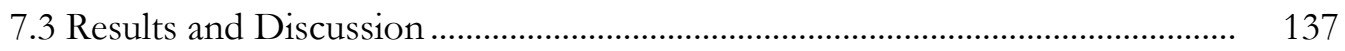

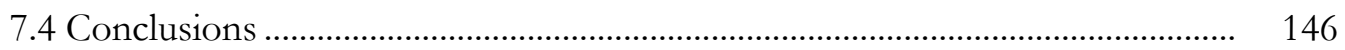

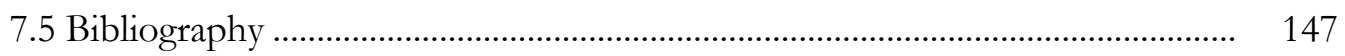


8.1 General Conclusions ................................................................................... 150

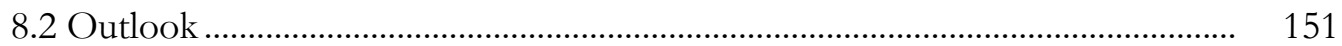

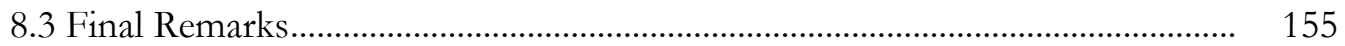

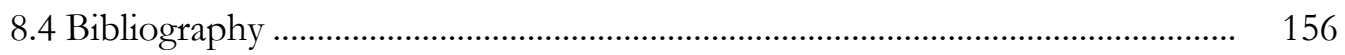

$\begin{array}{ll}\text { Summary } & 157\end{array}$

$\begin{array}{ll}\text { Samenvatting } & 161\end{array}$

$\begin{array}{ll}\text { List of Publications } & 165\end{array}$

$\begin{array}{ll}\text { Acknowledgments } & 167\end{array}$

$\begin{array}{ll}\text { Dankwoord } & 171\end{array}$ 



\title{
Introduction
}

\begin{abstract}
A general introduction to solid oxide fuel cells, sol-gel chemistry, and soft lithographic patterning is presented. A special emphasis is on the various facets of sol-gel chemistry, since it forms the experimental 'backbone' of all the experimental work described. The research is mainly focussed on the facile and low-temperature synthesis of materials used in fuel cell or energy storage applications. The chapter is concluded with an outline and the scope of the thesis.
\end{abstract}


The current global energy demand is ever growing, while at a staggering rate the fossil fuel reserves are diminishing. With the extensive use of these non-renewable energy source, the impact on the environment is extensive. In order to be able to supply the energy demand in the (near) future, new and more environmentally friendly alternative energy sources are necessary. Although research on materials for renewable energy receives a lot of global attention, new breakthroughs are necessary to become (more) independent of the use of fossil fuels. Currently existing technologies are being improved, while fundamental research on new (better) materials is explored. Besides solar, wind, and water energy, fuel cells are also used as an alternative energy source. The latter technology, in particular the solid oxide fuel cell (SOFC), offers great possibilities, due to its high efficiency.

\subsection{Solid Oxide Fuel Cells}

\subsubsection{Working Principle}

The SOFC is an electrochemical device capable of converting chemical energy into electrical energy, and consists of three main components: cathode, electrolyte, and anode (see Figure 1.1).

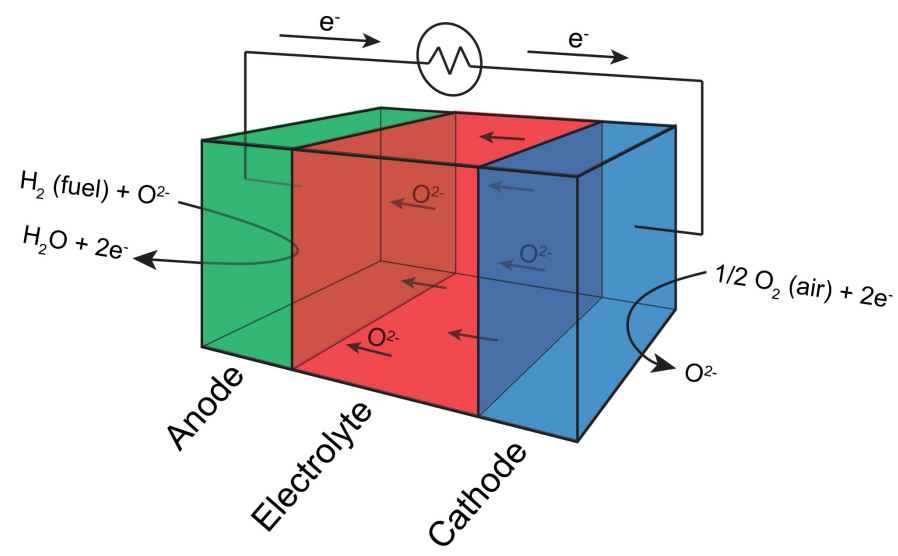

Figure 1.1 Schematic representation of the active components of a fuel cell.

The oxidant (air) is reduced at the cathode into oxygen ions (Eq. (1.1)). These subsequently diffuse through the gas impermeable electrolyte layer, and react at the anode interface with the fuel (Eq. (1.2)). 


$$
\begin{gathered}
\frac{1}{2} \mathrm{O}_{2}+2 \mathrm{e}^{-} \longrightarrow \mathrm{O}^{2-} \\
\mathrm{H}_{2}+\mathrm{O}^{2-} \longrightarrow \mathrm{H}_{2} \mathrm{O}+2 \mathrm{e}^{-} \text {(+ heat) }
\end{gathered}
$$

The overall reaction of the fuel cell can thus be described as:

$$
\mathrm{H}_{2}+\frac{1}{2} \mathrm{O}_{2} \longrightarrow \mathrm{H}_{2} \mathrm{O}
$$

Under a constant supply of oxidant and fuel, the produced electrical energy can, theoretically, be used infinitely. Since ionic conduction through the electrolyte membrane is a thermodynamically activated process, fuel cells often operate at high temperatures, ranging 800-1000 ${ }^{\circ} \mathrm{C}$. The chosen temperature depends on the chosen electrolyte material. $^{[1]}$ Under high temperature conditions, a high fuel-to-electricity efficiency conversion is obtained, without the emission of polluting side products. ${ }^{[2-4]}$ In addition, the excess heat may be used to help maintain the high temperatures, or in combined heat and power applications. The high operational temperatures, however, result in longer start-up times, higher material costs, and material degradation, which contribute to a reduced life time of the cell. The characteristics of the individual components are discussed below.

\subsubsection{Cathode}

The cathode electrode comprises of an interconnected pore network in which the oxygen reduction reaction can take place. For this reason, the cathode must be catalytically active towards the reduction of oxygen and exhibit a high ionic conductivity to transport the ions towards the electrolyte membrane. Often mixed ionic and electric conducting oxides (MIEC) are used. The reduction of oxygen only occurs at the triple-phase boundary (TPB), where the cathode, electrolyte, and air meet. Furthermore, the structure should be stable under the high operating temperatures and have a matching thermal expansion coefficient with the electrolyte. State-of-the-art cathodes are: lanthanum strontium manganite (LSMO) and lanthanum strontium cobalt ferrite (LSCF). 


\subsubsection{Electrolyte}

The electrolyte, positioned between the cathode and anode, is a gas-impermeable membrane through which the oxygen ions diffuse. Its general requirements for usage are high ionic conductivity, low electronic conductivity, and good mechanical, chemical, and thermal stability under both oxidizing and reducing conditions. ${ }^{[1,5]}$ Three of the most commonly used electrolyte materials are: yttria-stabilized zirconia (YSZ), gadolinium-doped ceria (CGO), and magnesium-doped lanthanum gallate (LSGM). ${ }^{[5]} \mathrm{A}$ pathway for oxygen ions to diffuse is created by the incorporation of lower valency ions in the crystal lattice. Consequently, oxygen vacancies are created due to charge compensation, through which the ionic transport is possible. For example, the oxygen vacancies in YSZ are created by the introduction of $\mathrm{Y}^{3+}$ ions in the fluorite $\mathrm{ZrO}_{2}$ lattice:

$$
\mathrm{Y}_{2} \mathrm{O}_{3} \longrightarrow 2 \mathrm{Y}_{\mathrm{Zr}}^{\prime}+3 \mathrm{O}_{\mathrm{O}}^{\mathrm{x}}+\mathrm{V}_{\mathrm{O}}^{\bullet \bullet}
$$

Where Kröger-Vink notation is used, in which $\mathrm{Y}_{\mathrm{Zr}}^{\prime}, \mathrm{O}_{\mathrm{O}}^{\mathrm{x}}$, and $\mathrm{V}_{\mathrm{O}}^{\bullet \bullet}$ are the yttrium atom on a $\mathrm{Zr}$-site, a lattice oxygen, and an oxygen vacancy, respectively.

\section{Proton Conduction}

The working principle of a proton conducting electrolyte is equal to an oxygen ion conducting electrolyte, except that the charge carriers are different. Protons are transported from the anode electrode interface through the membrane either via hydrogen bond formation and cleavage of the oxygen atoms in the lattice due to rotational movement and reorientation (Grotthuss mechanism), ${ }^{[6,7]}$ or via a 'vehicle' mechanism. In the latter mechanism, the protons are transported with bigger species, e.g. with water as $\mathrm{H}_{3} \mathrm{O}^{+}$. The conductivity is then dependent on the diffusivity of the 'vehicle' species. ${ }^{[6-8]}$ The hydroxyl defects are created by hydration, according to:

$$
\mathrm{H}_{2} \mathrm{O}+\mathrm{O}_{\mathrm{O}}^{\mathrm{x}}+\mathrm{V}_{\mathrm{O}}^{\bullet \bullet} \longrightarrow 2 \mathrm{OH}_{\mathrm{O}}^{\bullet}
$$

where, $\mathrm{OH}_{\mathrm{O}}^{\bullet}$ is the hydroxyl defect. Due to a change in charge carrier (i.e. protons instead of oxygen ions), the half-reactions at the anode and cathode electrode interfaces of a proton conducting fuel cell are, respectively:

$$
\mathrm{H}_{2} \longrightarrow 2 \mathrm{H}^{+}+2 \mathrm{e}^{-} \text {(+heat) }
$$




$$
\frac{1}{2} \mathrm{O}_{2}+2 \mathrm{H}^{+}+2 \mathrm{e}^{-} \longrightarrow \mathrm{H}_{2} \mathrm{O}
$$

\subsubsection{Anode}

Analogous to the cathode, the anode electrode exhibits a porous nature which should be catalytically active towards (in this case) the fuel oxidation. In addition, it should be mechanically stable and good electronically conducting. The most commonly used material for anodes is the Ni/YSZ cermet.

\subsubsection{Challenges}

Although SOFCs are capable of producing a high power output with high chemical-toenergy efficiency, the high operational costs hinder the economic feasibility of a more widespread usage. Especially the high operating temperatures and the material's degradation severely affect the fuel cell life time. A reduction of the operating temperature to intermediate temperatures $\left(400-700{ }^{\circ} \mathrm{C}\right)$, however, enables the use of cheaper materials (e.g. stainless steel), and concurrently reduces the thermal stress in the system. ${ }^{[5]}$ Furthermore, the reduced operational temperature gives opportunities for portable power generation by using e.g. micro-SOFCs. ${ }^{[9,10]}$ A major problem however, is that the reduced temperature leads to an increased Ohmic resistance in the electrolyte membrane, and a reduction of the overall ionic conductivity. This can be compensated by e.g. decreasing the electrolyte film thickness. For example, a decrease of film thickness from $15 \mu \mathrm{m}$ to $500 \mathrm{~nm}$ for a $10 \mathrm{~mol} \%$ YSZ electrolyte, allowed for the reduction of operational temperature from 700 to $525^{\circ} \mathrm{C}$ (for an area-specific resistance of $0.15 \Omega \cdot \mathrm{cm}^{2}$ ). ${ }^{[2]}$

To address these technological challenges, a significant amount of research is focused on developing new materials that can be used at intermediate temperatures and on the improvement of the currently used materials. Thin electrolyte films are currently prepared using a wide array of deposition techniques, like e.g. pulsed laser deposition (PLD),${ }^{[11,12]}$ spin coating, ${ }^{[13]}$ spray casting, ${ }^{[14]}$ and sputtering techniques. ${ }^{[15]}$ In addition, back-etching procedures (used in MEMS technology) are employed to increase the surface area of the electrolyte membrane,$^{[16-18]}$ and thus increasing the TPB length. Compared to a flat electrolyte geometry, a corrugated membrane showed a substantially improved performance at $450^{\circ} \mathrm{C} \cdot{ }^{[17,18]}$ 


\subsection{Sol-gel Chemistry (of transition metal alkoxides)}

In general, sol-gel chemistry comprises the formation of colloidal suspensions of solid particles in a liquid phase (sol), and their transformation to an integrated network (gel). It is a popular synthetic route for the preparation of nano-crystalline metal oxide powders and thin films, due to its low cost, versatility in material's choice, and reaction control on small length scales.

\subsubsection{Basic Principles}

\section{Hydrolysis and Condensation}

In the initial stage of sol formation, the metal alkoxide precursor is hydrolyzed after a reaction with water, followed by a sequence of polymerization reactions. In the simplest case, for $\mathrm{Si}$ alkoxides, the hydrolysis and condensation reactions are two distinct reactions. ${ }^{[19]}$ The hydrolysis can be written as:

$$
\equiv \mathrm{M}-\mathrm{OR}+\mathrm{H}_{2} \mathrm{O} \longrightarrow \equiv \mathrm{M}-\mathrm{OH}+\mathrm{ROH}
$$

Depending on the reactive groups involved in the condensation reactions, polymerization proceeds via either oxolation or alkoxolation, respectively:

$$
\begin{aligned}
& \equiv \mathrm{M}-\mathrm{OH}+\mathrm{HO}-\mathrm{M} \equiv \longrightarrow \equiv \mathrm{M}-\mathrm{O}-\mathrm{M} \equiv+\mathrm{H}_{2} \mathrm{O} \\
& \equiv \mathrm{M}-\mathrm{OH}+\mathrm{RO}-\mathrm{M} \equiv \longrightarrow \equiv \mathrm{M}-\mathrm{O}-\mathrm{M} \equiv+\mathrm{ROH}
\end{aligned}
$$

For coordinatively saturated metals, the hydrolysis and condensation reactions are believed to follow a $\mathrm{S}_{\mathrm{N}} 2$ reaction scheme, involving the nucleophilic attack of the free electrons of water, proton transfer, and subsequent removal of either an alcohol or water. ${ }^{[20,21]}$ Unlike for Si alkoxides, the hydrolysis and condensation reactions for transition metal alkoxides $(\mathrm{M}=\mathrm{Ti}$ or $\mathrm{Zr})$ constitute of a single step reaction in which poly-oxocomplexes are rapidly formed. ${ }^{[22-25]}$ The greater reactivity of transition metal alkoxides towards nucleophilic agents like $\mathrm{H}_{2} \mathrm{O}$ is the cause of the enhanced reaction kinetics. ${ }^{[1]}$ 
Table 1.1 The electronegativity $\left(E_{N}\right)$, partial charge $\left(\delta_{\mathrm{M}}\right)$, coordination number $(\mathrm{N})$ - oxidation state $(\mathrm{Z})$ of $\mathrm{Si}$, $\mathrm{Ti}$ and $\mathrm{Zr}$, and the overall reactivity of the corresponding metal alkoxides. ${ }^{[20,26]}$

\begin{tabular}{lcccl}
\hline Precursor & $\boldsymbol{E}_{\mathbf{N}}$ & $\boldsymbol{\delta}_{\mathbf{M}}$ & $\mathbf{N}-\mathbf{Z}$ & Gel formation rate \\
\hline $\mathrm{Si}\left(\mathrm{O}^{\prime} \mathrm{Pr}\right)_{4}$ & 1.74 & +0.32 & 0 & Very slow \\
$\mathrm{Ti}\left(\mathrm{O}^{\prime} \mathrm{Pr}\right)_{4}$ & 1.32 & +0.60 & 2 & Fast \\
$\mathrm{Zr}\left(\mathrm{O}^{\prime} \mathrm{Pr}\right)_{4}$ & 1.29 & +0.64 & 3 & Fast \\
\hline
\end{tabular}

\subsubsection{Chemical Modification}

The precursor reactivity can be influenced by one or more factors: (1) steric hindrance of the surrounding ligands; (2) the ability to increase the oxidation state of the complex; and (3) the effective charge on the metal. ${ }^{[20,26]}$ The effect of the latter two parameters is shown in Table 1.1. The higher effective partial charge and lower electronegativity on the $\mathrm{Ti}$ or $\mathrm{Zr}$ metal centers in comparison to $\mathrm{Si}$, increase the susceptibility of a nucleophilic attack, and thus the hydrolysis/condensation reactions, i.e. $\mathrm{Zr}>\mathrm{Ti}>>\mathrm{Si}^{\left[{ }^{[2]}\right.}$

To allow for easier handling and greater control over the process, metal alkoxide precursors are often chemically modified. Enhanced reactivity can be achieved by changing the: (1) the inductive effect; (2) chelating effect; and (3) bridging effect of the ligands.

\section{Inductive Effect of the Ligand}

The inductive effect of the ligand, caused by its size and electron attractive/repulsive characteristics, influence the reactivity. The partial charge model as proposed by Livage et al. enables the calculation of the average electronegativity of a particular ligand, and the effect on the partial charge of the metal atom: ${ }^{[2,26]}$

$$
\delta_{\mathrm{Ti}}=\frac{\bar{\chi}-\chi_{\mathrm{Ti}}^{0}}{k \sqrt{\chi_{\mathrm{Ti}}^{0}}}
$$

Here, $\delta_{\mathrm{Ti}}$ is the partial charge on Ti, $k$ the Pauling's electronegativity constant, $\bar{\chi}$ the mean electronegativity of the ligand, and $\chi_{\mathrm{Ti}}^{0}$ the electronegativity of a neutral Ti atom. The alkoxide reactivity in a homologous series thus decreases according to $\operatorname{Ti}\left(\mathrm{O}^{n} \mathrm{Me}\right)_{4}$ $>\operatorname{Ti}\left(\mathrm{O}^{n} \mathrm{Et}\right)_{4}>\operatorname{Ti}\left(\mathrm{O}^{n} \mathrm{Pr}\right)_{4}$ etc. 


\section{Chelating Effect of the Ligand}

The reactivity of metal alkoxide is greatly enhanced by changing the binding mode of the ligand. An increase in the number of donor groups in the ligand (bidentate or multidentate) that are able to form a bond with the central atom, effectively increases the coordination number of the complex. Popular chelating ligands are e.g. $\beta$-ketonates, carboxylic acids, and functional alcohols like acetylacetone, acetic acid, and 2-methoxyethanol. ${ }^{[22-24,27-29]}$ The bidentate binding of these modifiers has been extensively studied using a wide range of spectroscopic techniques such as Fourier transform infrared (FTIR), nuclear magnetic resonance (NMR), X-ray absorption near-edge spectroscopy (XANES), and extended X-ray absorption fine-structure spectroscopy (EXAFS). Modification of a monomeric $\mathrm{Ti}\left(\mathrm{O}^{2} \mathrm{Pr}\right)_{4}$ precursor ${ }^{[30]}$ with glacial acetic acid, led to an exothermic reaction and an expansion of coordination number from $\mathrm{N}=4$ to $6 .{ }^{[31]}$ Concurrently, the frequency separation between the symmetric and asymmetric vibration of (-COO) confirmed the bidentate binding of the acetate ligand to the Ti atom. ${ }^{[28]}$ In addition, modification of the $\mathrm{Ti}(\mathrm{O} P r){ }_{4}$ precursor with acetic acid increased the gelation time from mere seconds to several months. ${ }^{[28]}$ Primary zirconium alkoxides like $\mathrm{Zr}\left(\mathrm{O}^{n} \mathrm{Pr}\right)_{4}$ or $\mathrm{Zr}\left(\mathrm{O}^{n} \mathrm{Bu}\right)_{4}$, on the other hand, form dimeric structures and have a coordination number $\mathrm{N}=6 .{ }^{[32]}$ Contrary to Ti alkoxides, only monodentate binding modes were found for $\mathrm{Zr}$ alkoxides after modification with acetic acid. ${ }^{[33]}$ Terminal alkoxy groups could only be substituted by acetate due to the dimeric $\mathrm{Zr}-\mathrm{Zr}$ unit. Addition of acetylacetone, however, instantly led to the formation of monomeric $\mathrm{Zr}(\mathrm{acac})_{4}$ species, in which $\mathrm{Zr}$ expanded its coordination state to $\mathrm{N}=8 \cdot{ }^{[33]}$ Besides binding to one single atom, multidentate ligands also have the ability to bridge between two metal centers. This opens the possibility to form complexes containing different metal atoms while using only one type of ligand. Single-source precursors, ${ }^{[24,34-36]}$ which allow for greater control of reactant stoichiometry, may thus be obtained. Control over the hydrolysis, condensation, and gel formation greatly depends on the nature of the alkoxide (monomeric, dimeric etc.) and the choice of modifier. Moreover, the manner in which the sol is processed eventually determines the optimal combination of both.

\subsubsection{Gel Formation}

As a result of ongoing hydrolysis and condensation reactions, the length of the polymer chains and the viscosity of the sol-gel precursor increases concurrently. The clusters 
grow to such an extent, that eventually different branches link, and a continuous 3D network is formed. This point is marked by the rapid increase of the viscosity (i.e. gel point). The time of gelation can be determined by monitoring the rheological changes using a viscometer. ${ }^{[37]}$ Although for slow gelling systems the gel point may be accurately determined, significant discrepancies arise for rapid gelation. From the changes in viscosity, a distinction between types of polymer growth can be observed using e.g the mass-fractal growth (MFG), or near-linear growth (NLG) models. ${ }^{[38,39]}$

\section{Aging of Gels}

The formation of an infinitely large cluster does not mark the end of all condensation processes. Within the gel, the polymeric chains still enjoy a certain degree of freedom, and additional bonds are formed. During this aging stage, the viscoelasticity of the gel is further reduced, until a more rigid gel is formed. The liquid precursor, trapped within the pores of the gel, are slowly expelled by contraction. This process, driven by the reduction of surface energy (i.e. shrinkage gel), is called syneresis. It is believed that syneresis follows the same pathway as the condensation reactions that lead to gelation, see Eq. (1.5)-(1.6). ${ }^{[19]}$ Finally, due to the increased stiffness as a result of aging, the gel is often unable to dissipate the stress caused by the shrinkage, and cracks in the monolithic gel may appear.

\section{Drying}

The first stages of drying are marked by the volume reduction of the gel, in which the volume linearly decreases by the volume of evaporated solvent; up to one-tenth of its original size ${ }^{[40]}$ During this stage, the solid gel surface is still covered by a liquid film. However, once the gel is exposed, an energetically more favorable solid-vapor interface appears. In order to reduce the internal energy of the gel, the liquid phase is expelled from its interior by capillary pressure; the solid-liquid interface is reinstated. The capillary pressure in the liquid $(P)$ is related to the curvature of the formed meniscus $(r)$ by: ${ }^{[19}$, 40]

$$
P=\frac{2 \gamma_{\mathrm{LV}} \cos \theta}{r}
$$


where $\gamma_{\mathrm{LV}}$ is the interfacial energy of the liquid-vapor interface, and $\theta$ the contact angle between the liquid phase and the pore wall. For a liquid retained in a cylindrical-shaped pore of radius $a$, the meniscus radius is $r=-a / \cos \theta$. If $\theta=0^{\circ}$, the liquid film is completely covering the gel's surface, whereas if $\theta=90^{\circ}$ the liquid is not wetting the surface. As the drying proceeds, the viscoelasticity of the gel is further reduced by shrinkage through syneresis, resulting in a decreased meniscus radius. Once the meniscus is equal to the pore radius, no more liquid is expelled.

Due to the relatively low permeability of water in gels, the liquid pressure is higher close to the surface than the interior of the gel. Consequently, cracks form due to different shrinkage rates caused by the pressure gradient. To circumvent cracks to appear during the drying stage, painstakingly low drying rates are necessary to dissipate the pressure gradient within the gel. Likewise, the problem may be overcome by aging the sol precursor prior to drying. The greater strength of the polymer network is able to reduce chances of fracture.

\subsubsection{Sol-gel Processing}

One of the major advantages of sol-gel chemistry is that a wide variety of microstructures is obtained by merely changing the processing conditions or techniques. A schematic overview of various processing procedures and their effect on the obtained morphologies is presented in Figure 1.2.

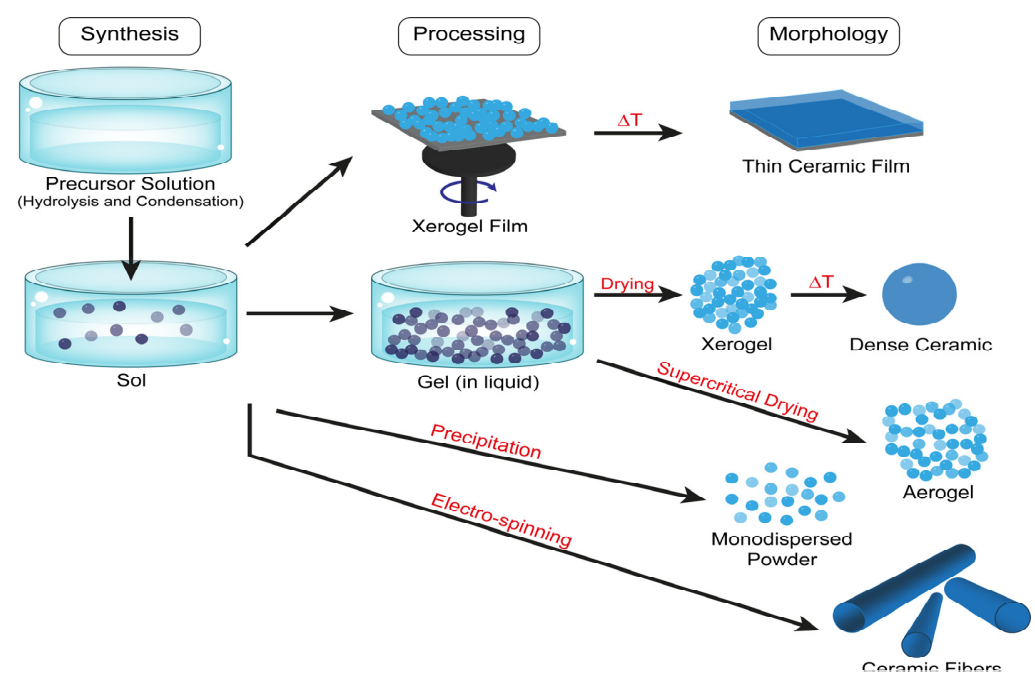

Figure 1.2 Schematic overview of the various morphologies obtained using sol-gel processing. 


\subsection{Soft Lithography}

\subsubsection{Introduction to Lithographic Patterning}

The recent trend towards the miniaturization of devices and individual components resulted in new fabrication methods to pattern materials in the sub-micrometer range. Among these methods, photolithography has been the most extensively used technique in industry. Photolithography employs stencil masks for the patterning of photosensitive polymers (or photoresists). The exposed and non-exposed areas are subsequently changed by UV illumination. The obtained chemical contrast is then used to e.g. selectively etch one phase or to attach new moieties. Usually, multiple processing steps are necessary to manufacture the required devices structures. The high costs of equipment (used under clean room conditions) are considered the major drawback of photolithography, and more cost-effective methods for patterning devices were investigated. Among these methods, soft lithography has gained considerable attention due to its low cost, simplicity, and flexibility regarding size, shape of the patterned materials. ${ }^{[41-43]}$

\subsubsection{Basics of Soft Lithography}

\section{Mold Preparation and Characteristics}

In soft lithography, elastomeric molds (or stamps) with arranged relief structures are used to obtain patterned microstructures. Soft poly(dimethylsiloxane) (PDMS) stamps are prepared by pouring a mixture of the polymer and cross-linking agent over a Si master with pre-defined features. A solid stamp is obtained by heating at elevated temperatures $\left(<70^{\circ} \mathrm{C}\right)$ and subsequent cross-linking via the hydrosilylation reaction. ${ }^{[44]}$

In addition to the ease of mold preparation, the use of PDMS stamps has several other important advantages: ${ }^{[41]}$ (1) the low interfacial energy of the PDMS $\left(\gamma_{\mathrm{SV}}=\right.$ $\left.21.6 \mathrm{mN} \cdot \mathrm{m}^{-1}\right)^{[45]}$ enables easy release from the Si master after molding, and in particular, the patterned structures. (2) No swelling under humid conditions. (3) Due to its natural porosity, gases permeate easily through the mold. (4) Good thermal stability (to 186 $\left.{ }^{\circ} \mathrm{C}\right)$. (5) The PDMS stamp is optically transparent, which enables visual inspection during pattern preparation, and (6) due to its elasticity, conformal contact between mold and substrate is made, and patterning on non-planar surfaces is viable.

On the other hand, the use of PDMS as stamp material also entails several drawbacks that could limit the extent in which soft lithography will be used as a general approach for microfabrication. 
Firstly, the high solubility of nonpolar solvents like dichloromethane ${ }^{[46]}$ and $\mathrm{C}_{5}-\mathrm{C}_{7}$ alkanes $^{[46,47]}$ in PDMS micropores give rise to enormous swelling, and consequently the loss of conformal contact between stamp and substrate. Secondly, the elasticity and softness of the material limits the aspect ratios and dimensions of the relief patterns that can be used (Figure 1.3). Replication without pattern distortion is feasible when the dimensions of $h, d$, and $l$ are in the range of $0.2-20,0.5-200$, and $0.5-200 \mu \mathrm{m}$, respectively. ${ }^{[41,48]}$

\section{Types of Soft Lithography}

The various types of soft lithographic patterning can be categorized in two main groups: (1) the mold is used to modify the surface of the substrate (i.e. chemical contrast), using e.g. oxygen plasma or self-assembled monolayers (SAMSs). (2) The patterns are directly obtained from the mold. ${ }^{[43]}$ From the molding-based techniques, three are discussed below with respect to the patterning of ceramic materials (see Figure 1.4 for a schematic overview):

(a)

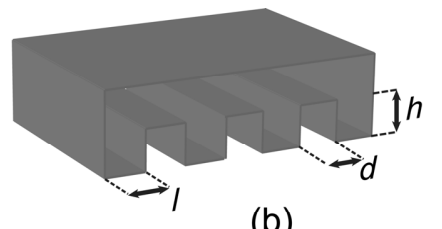

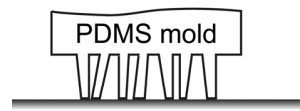

$(d<<h)$ $(d>>h)$

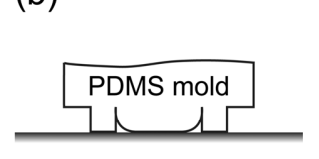

Figure 1.3 Schematic illustration of the limited range of aspect ratios for successful pattern replication: (a) buckling of protruding pillars for high aspect ratio features; (b) sagging due to compressive forces between stamp and substrate for low aspect ratio features with large spacing.

\subsubsection{Microtransfer Molding ( $\mu$ TM)}

A liquid precursor is applied on the patterned surface of the PDMS stamp with $\mu$ TM. ${ }^{[4]}$ The excess material is removed by e.g. spin coating (a) or with a jet of $\mathrm{N}_{2}$. The mold filled with precursor solution - is then gently placed on the substrate (b) and cured at elevated temperatures. The final structures are obtained by mold removal (c) and additional heat treatment (d). The technique provides a facile procedure for the patterning of interconnected or isolated features on non-planar surfaces. Also, it allows the use of 
a variety of precursor solutions, like e.g. polymers, ${ }^{[49]}$ sol-gel precursors, ${ }^{[50,51]}$ ceramicloaded colloidal suspensions. ${ }^{[52,53]}$ Nonetheless, residual layers between the patterned features can form if the excess material is incompletely removed (a), and additional etching steps may be required to attain isolated features. Which, in turn, may damage the uniformity (and surface morphology) of the patterned structures. For this reason, optimization of the precursor solution is necessary for successful replication. The current limits of lateral resolution achieved by $\mu$ TM are $<500 \mathrm{~nm}$. ${ }^{[50,54]}$

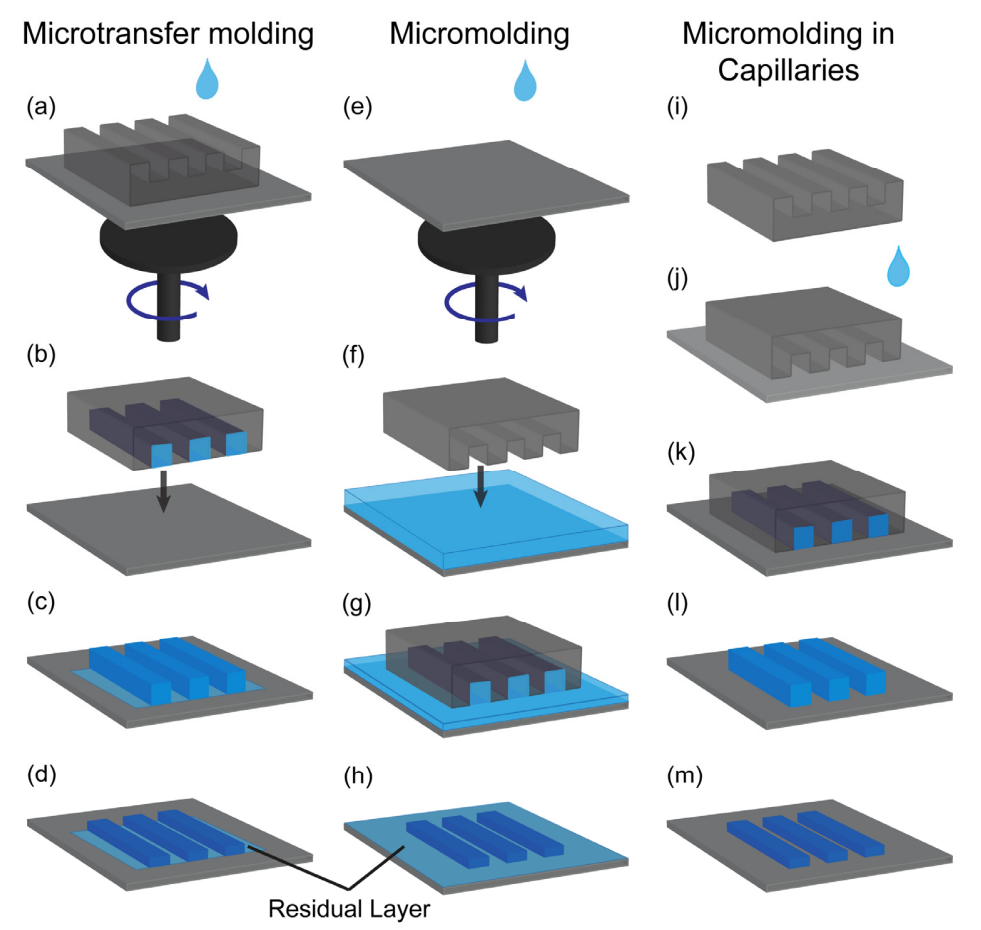

Figure 1.4 Three different types of molding-based soft lithography: (a)-(d) microtransfer molding; (e)-(h) micromolding, and (i)-(m) micromolding in capillaries.

\subsubsection{Micromolding}

Micromolding provides perhaps the easiest route towards nanopatterned structures. A thin precursor film is applied on the substrate's surface by e.g. spincoating (e), or just by depositing a droplet of precursor. Subsequently, the mold is placed on the substrate (f) and the liquid is forced into the formed microchannels. To ensure conformal contact and reduce the formation of a residual layer, the liquid precursor should dewet on the stamp's surface. ${ }^{[5]}$ In addition, soaking the stamp with solvent prior to placement on 
the substrate, may also result in a residual-free pattern, although this remains difficult to achieve. ${ }^{[56]}$ Further drying (g), mold removal, and additional heat treatment (h) result in the final pattern formation. The drying rate can be enhanced by increasing the temperature to approximately $60^{\circ} \mathrm{C}$. Above this temperature, the PDMS detaches from the surface and loss of conformal contact may result in the spreading of the not yet dried solution. Application of pressure on the mold circumvents this problem, and higher drying temperatures are achieved. ${ }^{[5]}$ Depending on the geometry and dimension of the mold, too much applied pressure may result in buckling or sagging (see Figure 1.3).

\subsubsection{Micromolding in Capillaries (MIMIC)}

With MIMIC, ${ }^{[45]}$ the elastomeric stamp is gently placed on a cleaned substrate. If necessary, the hydrophilicity of the stamp may be enhanced by oxygen plasma treatment, prior to placing on the substrate (i). To improve adhesion, the mold is softly pressed to ensure conformal contact. A drop of precursor solution is placed at the openings of the microchannels formed between the mold and substrate (j). Subsequently, capillary suction forces the precursor to fill the channels $(\mathrm{k})$. Lack of conformal contact results in incomplete filling or the spreading of precursor (i.e. film formation). After complete filling, the precursor inside the microchannels is dried at elevated temperatures, and subsequently the mold is released from the substrate (l). Further heat treatment results in densification and shrinkage of the as-patterned features, after which the final structures are obtained $(\mathrm{m})$.

One of the main advantages of MIMIC over e.g. micromolding and $\mu \mathrm{TM}$ is that a residual layer is avoided, and the desired architectures are readily obtained. A drawback however, is that a network of interconnected microchannels is necessary to completely fill the stamp; fabrication of isolated features with MIMIC is thus not realizable. Moreover, only precursors with sufficiently low viscosity (to enable complete filling of the stamp) can be used for patterning. The rate $\mathrm{d} z / \mathrm{d} t$ in which the microchannels are filled, is inversely proportional to the viscosity of the liquid phase $\eta:^{[45]}$

$$
\frac{\mathrm{d} \tau}{\mathrm{d} t}=\frac{R \cdot \gamma_{\mathrm{LV}} \cdot \cos \theta}{4 \eta ₹}=\frac{R \cdot\left(\gamma_{\mathrm{LV}}-\gamma_{\mathrm{LS}}\right)}{4 \eta ₹}
$$

Here, $z$ is the penetration length of the capillary, $R$ the hydraulic radius of the channels, $\theta$ the contact angle of the precursor's meniscus inside the microchannels, and $t$ is time. 
The surface tensions of the precursor and air, PDMS wall and air, and PDMS wall and precursor are $\gamma_{\mathrm{LV}}, \gamma_{\mathrm{SV}}$, and $\gamma_{\mathrm{SL}}$, respectively.

The use of sol-gel precursors in combination with MIMIC often results in the formation of double peak features, ${ }^{[57,58]}$ where the height at the edges of the patterns are higher than in the center. It results from the more rapid drying of the precursor sol in the corners of the stamp, since these areas have a higher surface-to-volume ratio than elsewhere under the mold. ${ }^{[57]}$ Slower drying, however, reduces the effect of double peak formation.

\subsection{Scope of the Thesis}

This thesis is comprised of six research chapters, in which the low-temperature, wetchemical approach to various functional inorganic oxide materials is described. The main focus of this research is to control the material's synthesis from liquid precursor to metal oxide powder or thin film; while understanding its formation mechanism. In addition, the synthetic approaches should be compatible with deposition techniques that allow for the upscaling to larger deposited surface areas. The research focuses mainly on the preparation and patterning of fluorite-type yttria-stabilized zirconia (YSZ) thin films and the synthesis of perovskite-type barium titanate (BTO) and yttriumdoped barium zirconate (BZY) nanocrystalline powders, respectively. Throughout the thesis, sol-gel chemistry is used as a versatile route to prepare nanocrystalline metal oxides.

The YSZ thin films are used as thin film electrolyte material in solid oxide fuel cell applications. The reduction of thin film thickness enables lower operational temperatures, and thus the use of cheaper materials. However, the preparation of a gasimpermeable thin electrolyte film remains a major challenge. In addition, the lower ionic conductivity at intermediate temperatures needs to be addressed.

Barium titanate is used as a high- $k$ dielectric material in multilayer ceramic capacitors (MLCC), however, the commercially used tape-casting method has reached its limit of downscaling. In order to comply with the current trend of miniaturization, this research is focused on new synthetic routes to yield finer starting powders and compatible deposition techniques. 
Due to its refractory nature, the sintering of proton conducting BZY only occurs at very high temperatures. As a consequence, element evaporation and segregation occurs, resulting in a loss of conductivity. The preparation of nanocrystalline BZY might overcome the currently faced challenges, as lower sintering temperatures are expected. In order to achieve all of the above, a better understanding of the underlying chemistry and formation mechanisms is necessary.

In Chapter 2 and 3 the reaction mechanism of the low-temperature $\left(23-78{ }^{\circ} \mathrm{C}\right)$ one-pot synthesis of $\mathrm{BaTiO}_{3}$ (BTO) is described. In Chapter 2 the formation of the crystalline phase was studied by investigating the stability and interaction of the precursors with each other and the solvent. In addition, computational models were used to explain the experimental data.

The influence of temperature, water amount, and precursor concentration and stoichiometry on the BTO formation kinetics were described in Chapter 3. Time-resolved small-angle X-ray scattering (SAXS), X-ray diffraction (XRD), and high-resolution transmission electron microscopy (HR-TEM) were used to gain insight in nucleation, growth, and crystallization phenomena.

This gained knowledge was used to expand this facile approach for the synthesis of other perovskite ceramics, and the incorporation of dopants. In Chapter 4 the synthesis and characterization of proton-conducting yttrium-doped barium zirconate $\left(\mathrm{BZY} ; \mathrm{BaZr}_{\mathrm{x}} \mathrm{Y}_{1-\mathrm{x}} \mathrm{O}_{3-\delta}\right)$ is presented.

A method to measure the thin film density of sol-gel derived YSZ was described in Chapter 5. This facile approach is based on X-ray reflectivity (XRR) in which electron density of the material is determined by the critical angle (of total external reflection). The method describes the mathematical calculation of a so-called psendo-critical angle. Calibration curves, illustrating the correlation between simulated XRR curves and their corresponding pseudo-critical angles, were used to determine the density of the prepared thin films.

In Chapter 6, the abovementioned method was used to investigate the densification behavior of YSZ thin films. In particular, the effect of dopant concentration, heating rates, temperatures, and substrate choice on the final density was studied. Dense thin films are the key requirement for fuel cell applications, since fuel and oxidant need to be separated by the electrolyte membrane. Underlining, once more, the necessity of the method described in Chapter 5. 
The reduction of the overall electrolyte film thickness to $<5 \mu \mathrm{m}$, has led to an increased performance for SOFCs operating at intermediate temperatures. Which eventually might lead to better economic feasibility for use in e.g. portable energy storage applications. In my opinion, an additional increase of electrolyte surface area will lead to a higher possibility of oxygen ion formation, and thus enhanced properties. To this end, the soft-lithographic patterning of ionically conducting YSZ patterns is described in Chapter 7. A combination of sol-gel chemistry and micromolding in capillaries (MIMIC) was used to obtain isolated features with aspects ratios of $\sim 1$. Both methods comprise a low-cost, and up-scalable approach with great flexibility regarding shape and composition. The combined knowledge of Chapter 5, 6, and 7 may result in the successful fabrication of gas-impermeable thin film electrolytes with increased surface area and, hopefully, signify a step towards the increased commercial implementation of SOFC technology. In Chapter 8, general conclusions are drawn, and an outlook for future research and synthesis strategies is presented. 


\subsection{Bibliography}

[1] S. M. Haile, Fuel cell materials and components. Acta Mater. 2003, 51, 5981-6000.

[2] B. C. H. Steele, A. Heinzel, Materials for fuel-cell technologies. Nature 2001, 414, 345-352.

[3] A. J. Jacobson, Materials for solid oxide fuel cells. Chem. Mater. 2010, 22, 660-674.

[4] S. J. Litzelman, J. L. Hertz, W. Jung, H. L. Tuller, Opportunities and challenges in materials development for thin film solid oxide fuel cells. Fuel Cells 2008, 8, 294-302.

[5] J. W. Fergus, Electrolytes for solid oxide fuel cells. J. Power Sources 2006, 162, 30-40.

[6] K.-D. Kreuer, Proton Conductivity: Materials and Applications. Chem. Mater. 1996, 8, 610641.

[7] F. M. M. Snijkers, A. Buekenhoudt, J. Cooymans, J. J. Luyten, Proton conductivity and phase composition in BaZr0.9Y 0.1O3- $\delta$. Scripta Mater. 2004, 50, 655-659.

[8] T. Norby, M. Widerøe, R. Glöckner, Y. Larring, Hydrogen in oxides. Dalton Trans. 2004, 3012-3018.

[9] D. Beckel, A. Bieberle-Hütter, A. Harvey, A. Infortuna, U. P. Muecke, M. Prestat, J. L. M. Rupp, L. J. Gauckler, Thin films for micro solid oxide fuel cells. J. Power Sources 2007, 173, 325-345.

[10] Z. Shao, S. M. Haile, J. Ahn, P. D. Ronney, Z. Zhan, S. A. Barnett, A thermally self-sustained micro solid-oxide fuel-cell stack with high power density. Nature 2005, 435, 795-798.

[11] H. S. Noh, H. Lee, B. K. Kim, H. W. Lee, J. H. Lee, J. W. Son, Microstructural factors of electrodes affecting the performance of anode-supported thin film yttria-stabilized zirconia electrolyte $(\sim 1 \mu \mathrm{m})$ solid oxide fuel cells. J. Power Sources 2011, 196, 7169-7174.

[12] X. Chen, N. J. Wu, L. Smith, A. Ignatiev, Thin-film heterostructure solid oxide fuel cells. Appl. Phys. Lett. 2004, 84, 2700-2702.

[13] K. Chen, Z. Lü, N. Ai, X. Huang, Y. Zhang, X. Xin, R. Zhu, W. Su, Development of yttriastabilized zirconia thin films via slurry spin coating for intermediate-to-low temperature solid oxide fuel cells. J. Power Sources 2006, 160, 436-438.

[14] P. Charpentier, P. Fragnaud, D. M. Schleich, E. Gehain, Preparation of thin film SOFCs working at reduced temperature. Solid State Ionics 2000, 135, 373-380.

[15] H. Huang, M. Nakamura, P. Su, R. Fasching, Y. Saito, F. B. Prinz, High-performance ultrathin solid oxide fuel cells for low-temperature operation. J. Electrochem. Soc. 2007, 154, B20-B24. [16] C. C. Chao, C. M. Hsu, Y. Cui, F. B. Prinz, Improved solid oxide fuel cell performance with nanostructured electrolytes. ACS Nano 2011, 5, 5692-5696.

[17] P. C. Su, C. C. Chao, J. H. Shim, R. Fasching, F. B. Prinz, Solid oxide fuel cell with corrugated thin film electrolyte. Nano Lett. 2008, 8, 2289-2292. 
[18] J. H. Shim, C. C. Chao, H. Huango, F. B. Prinz, Atomic layer deposition of yttria-stabilized zirconia for solid oxide fuel cells. Chem. Mater. 2007, 19, 3850-3854.

[19] C. J. Brinker, G. W. Scherer, Sol-gel science: the physics and chemistry of sol-gel processing, Academic Press, Inc, San Diego, CA 1990.

[20] J. Livage, M. Henry, C. Sanchez, Sol-gel chemistry of transition metal oxides. Prog. Solid State Chem. 1988, 18, 259-341.

[21] C. Sanchez, J. Livage, M. Henry, F. Babonneau, Chemical modification of alkoxide precursors. J. Non-Cryst. Solids 1988, 100, 65-76.

[22] U. Schubert, Chemical modification of titanium alkoxides for sol-gel processing. J. Mater. Chem. 2005, 15, 3701-3715.

[23] U. Schubert, Organically modified transition metal alkoxides: Chemical problems and structural issues on the way to materials syntheses. Acc. Chem. Res. 2007, 40, 730-737.

[24] V. G. Kessler, G. I. Spijksma, G. A. Seisenbaeva, S. Håkansson, D. H. A. Blank, H. J. M. Bouwmeester, New insight in the role of modifying ligands in the sol-gel processing of metal alkoxide precursors: A possibility to approach new classes of materials. J. Sol-Gel Sci. Technol. 2006, 40, 163179

[25] V. G. Kessler, The chemistry behind the sol-gel synthesis of complex oxide nanoparticles for bio-imaging applications. J. Sol-Gel Sci. Technol. 2009, 51, 264-271.

[26] J. Livage, C. Sanchez, Sol-gel chemistry. J. Non-Cryst. Solids 1992, 145, 11-19.

[27] G. I. Spijksma, H. J. M. Bouwmeester, D. H. A. Blank, V. G. Kessler, Stabilization and destabilization of zirconium propoxide precursors by acetylacetone. Chem. Commun. 2004, 10, 18741875.

[28] S. Doeuff, M. Henry, C. Sanchez, J. Livage, Hydrolysis of titanium alkoxides: Modification of the molecular precursor by acetic acid. J. Non-Cryst. Solids 1987, 89, 206-216.

[29] R. W. Schwartz, Chemical solution deposition of perovskite thin films. Chem. Mater. 1997, 9, 2325-2340.

[30] F. Babonneau, S. Doeuff, A. Leaustic, C. Sanchez, C. Cartier, M. Verdaguer, XANES and EXAFS Study of Titanium Alkoxides. Inorg. Chem. 1988, 27, 3166-3172.

[31] J. Livage, C. Sanchez, M. Henry, S. Doeuff, The chemistry of the sol-gel process. Solid State Ionics 1989, 32-33, 633-638.

[32] D. Peter, T. S. Ertel, H. Bertagnolli, EXAFS study of zirconium alkoxides as precursor in the sol-gel process: I. Structure investigation of the pure alkoxides. J. Sol-Gel Sci. Technol. 1994, 3, 91 99. 
[33] D. Peter, T. S. Ertel, H. Bertagnolli, EXAFS study of zirconium alkoxides as precursors in the sol-gel process: II. The influence of the chemical modification. J. Sol-Gel Sci. Technol. 1995, 5, 514.

[34] L. G. Hubert-Pfalzgraf, Heterometallic aggregates as intermediates on the molecular routes to multicomponent oxides. MRS Proceedings 1992, 271, 15-25.

[35] M. Veith, S. Mathur, N. Lecerf, V. Huch, T. Decker, H. P. Beck, W. Eiser, R. Haberkorn, Sol-gel synthesis of nano-scaled $\mathrm{BaTiO} 3, \mathrm{BaZrO} 3$ and $\mathrm{BaTi0} 0.5 \mathrm{Zr} 0.5 \mathrm{O} 3$ oxides via single-source alkoxide precursors and semi-alkoxide routes. J. Sol-Gel Sci. Technol. 2000, 17, 145-158.

[36] N. Y. Turova, The Chemistry of Metal Alkoxides, Kluwer Academic Publishers, Dordrecht, The Netherlands 2002.

[37] T. M. Stawski, S. A. Veldhuis, R. Besselink, H. L. Castricum, G. Portale, D. H. A. Blank, J. E. Ten Elshof, Nanoscale structure evolution in alkoxide-carboxylate sol-gel precursor solutions of barium titanate. Journal of Physical Chemistry C 2011, 115, 20449-20459.

[38] E. J. A. Pope, J. D. Mackenzie, Theoretical modelling of the structural evolution of gels. J. Non-Cryst. Solids 1988, 101, 198-212.

[39] A. Brasseur, B. Michaux, R. Pirard, O. Van Cantfort, J. P. Pirard, A. J. Lecloux, Rheological Characterization of BaTiO3 Sol-Gel Transition. J. Sol-Gel Sci. Technol. 1997, 9, 5-15.

[40] G. W. Scherer, Theory of drying. J. Am. Ceram. Soc. 1990, 73, 3-14.

[41] Y. Xia, G. M. Whitesides, Soft lithography. Annu. Rev. Mater. Sci. 1998, 28, 153-184.

[42] Y. Xia, J. A. Rogers, K. E. Paul, G. M. Whitesides, Unconventional Methods for Fabricating and Patterning Nanostructures. Chem. Rev. 1999, 99, 1823-1848.

[43] J. E. ten Elshof, S. U. Khan, O. F. Göbel, Micrometer and nanometer-scale parallel patterning of ceramic and organic-inorganic hybrid materials. J. Eur. Ceram. Soc. 2010, 30, 1555-1577. [44] S. J. Clarson, J. A. Semlyen, Siloxane Polymers, Prentice Hall, 1993.

[45] E. Kim, Y. Xia, G. M. Whitesides, Micromolding in capillaries: Applications in materials science. J. Am. Chem. Soc. 1996, 118, 5722-5731.

[46] D. P. Brennan, A. Dobley, P. J. Sideris, S. R. J. Oliver, Swollen poly(dimethylsiloxane) (PDMS) as a template for inorganic morphologies. Langmuir 2005, 21, 11994-11998.

[47] J. N. Lee, C. Park, G. M. Whitesides, Solvent Compatibility of Poly(dimethylsiloxane)-Based Microfluidic Devices. Anal. Chem. 2003, 75, 6544-6554.

[48] E. Delamarche, H. Schmid, B. Michel, H. Biebuvck, Stability of molded polydime thylsiloxane microstructures. Adv. Mater. 1997, 9, 741-746. 
[49] X. M. Zhao, Y. Xia, G. M. Whitesides, Fabrication of three-dimensional micro-structures: microtransfer molding. Adv. Mater. 1996, 8, 837-840.

[50] S. U. Khan, O. F. Göbel, D. H. A. Blank, J. E. Ten Elshof, Patterning lead zirconate titanate nanostructures at sub-200-nm resolution by soft confocal imprint lithography and nanotransfer molding. ACS Applied Materials and Interfaces 2009, 1, 2250-2255.

[51] C. Fernández-Sánchez, V. J. Cadarso, M. Darder, C. Domínguez, A. Llobera, Patterning high-aspect-ratio sol-gel structures by microtransfer molding. Chem. Mater. 2008, 20, 2662-2668.

[52] D. Zhang, B. Su, T. W. Button, Preparation of concentrated aqueous alumina suspensions for soft-molding microfabrication. J. Eur. Ceram. Soc. 2004, 24, 231-237.

[53] M. G. Holthaus, L. Treccani, K. Rezwan, Comparison of micropatterning methods for ceramic surfaces. J. Eur. Ceram. Soc. 2011, 31, 2809-2817.

[54] P. M. Moran, F. F. Lange, Microscale lithography via channel stamping: Relationships between capillarity, channel filling, and debonding. Appl. Phys. Lett. 1999, 74, 1332-1334.

[55] C. Marzolin, S. P. Smith, M. Prentiss, G. M. Whitesides, Fabrication of glass microstructures by micro-molding of sol-gel precursors. Adv. Mater. 1998, 10, 571-574.

[56] O. F. Göbel, D. H. A. Blank, J. E. T. Elshof, Thin films of conductive zno patterned by micromolding resulting in nearly isolated features. ACS Applied Materials and Interfaces 2010, 2, 536543.

[57] C. R. Martin, I. A. Aksay, Topographical evolution of lead zirconate titanate (PZT) thin films patterned by micromolding in capillaries. J. Phys. Chem. B 2003, 107, 4261-4268.

[58] S. Seraji, Y. Wu, N. E. Jewell-Larson, M. J. Forbess, S. J. Limmer, T. P. Chou, G. Cao, Patterned microstructure of sol-gel derived complex oxides using soft lithography. Adv. Mater. 2000, $12,1421-1424$. 



\title{
The Formation of Nano-Crystalline Barium Titanate in Benzyl Alcohol at Room Temperature*
}

\begin{abstract}
Nano-crystalline barium titanate (8-10 nm crystallite size) was prepared at temperatures of $23-78{ }^{\circ} \mathrm{C}$ through reaction of a modified titanium alkoxide precursor in benzyl alcohol with barium hydroxide octahydrate. The room temperature formation of a perovskite phase from solution is associated with the use of benzyl alcohol as solvent medium. The formation mechanism was elucidated by studying the stability and interaction of each precursor with the solvent and with each other using various experimental characterization techniques. Density Functional Theory (DFT) computational models which agreed well with my experimental data could explain the formation of the solid phase. The stability of the Ti precursor was enhanced by steric hindrance exerted by phenylmethoxy ligands that originated from the benzyl alcohol solvent. Electron microscopy and X-ray diffraction indicated that the crystallite sizes were independent of the reaction temperature. Crystal growth was inhibited by the stabilizing phenylmethoxy groups present on the surface of the crystallites.
\end{abstract}

${ }^{*}$ This chapter has been accepted for publication in: S.A. Veldhuis, W.J.C. Vijselaar, T.M. Stawski, and J.E. ten Elshof, Inorganic Chemistry 2014, 53 (24), 13188-13196. 


\subsection{Introduction}

Barium titanate (BTO) is used as a high- $k$ dielectric material in multi-layer ceramic capacitors (MLCC). The industrial trend towards miniaturization leads to ever smaller feature sizes. Commercially used tape casting methods have reached their ultimate limits in terms of downscaling layer thicknesses, so that finer starting powders and compatible off-contact deposition techniques are necessary to enable further miniaturization.

In the last decades, many wet-chemical synthesis routes have been developed to form homogeneous, nanometer-sized BTO particles of high purity. ${ }^{[1-3]}$ Among these methods, sol-gel processing received much attention because of its simplicity, low cost, and control over the composition on a molecular level. However, a disadvantage is that often high post-processing temperatures are needed to crystallize the amorphous body into the desired BTO perovskite phase, causing phase inhomogeneity and rapid crystallite growth. The alkoxide-hydroxide precipitation method, ${ }^{[4-6]}$ however, is known to form crystalline BTO at temperatures $<100{ }^{\circ} \mathrm{C}$, making additional heat treatment unnecessary. ${ }^{[4-8]}$

Transition metal alkoxides such as $\mathrm{Zr}$, and $\mathrm{Ti}$ alkoxides are highly reactive towards nucleophilic reagents like $\mathrm{H}_{2} \mathrm{O} .^{\left[{ }^{[9]}\right.}$ Their reactivity can be influenced by one or more factors: (1) steric hindrance by the ligand; (2) the ability to increase the oxidation state of the complex; and (3) the effective charge on the metal. Livage et al. showed the impact of the latter two parameters on gel formation for a range of transition metal alkoxides. ${ }^{[10,11]}$ Gel formation occurs most rapidly for alkoxides with the highest polarizability and the highest tendency to expand their coordination number, i.e. $\mathrm{Zr}>\mathrm{Ti}>>$ Si. Due to their high reactivity, metal alkoxides are often chemically modified by ligand exchange to lower their reactivity and allow easier handling. ${ }^{[9,12-14]}$ It is therefore important to know the effect of chemical modification on the stability of the alkoxide and its susceptibility towards hydrolysis.

Most of these synthesis routes use titanium (IV) iso-propoxide in combination with barium hydroxide octahydrate under strongly basic conditions. Unlike for Si alkoxides, the hydrolysis and condensation reactions for transition metal alkoxides $(\mathrm{M}=\mathrm{Ti}$ or $\mathrm{Zr}$ ) constitute of a single step reaction in which well-defined poly-oxocomplexes are near-instantly formed. ${ }^{[15-18]}$ The amount of water present in the system and the speed of addition are crucial to control the process. An excess of water causes too rapid hydrolysis and may lead to formation of $\left[\mathrm{Ti}(\mathrm{OH})_{n}\right]^{(4-n)+}$ species $^{[19]}$ or direct precipitation of 
amorphous $\mathrm{TiO}_{2},{ }^{[9]}$ crystallite growth, ${ }^{[8,20]}$ and agglomeration. ${ }^{[7]}$ In order to achieve full control over the hydrolysis-condensation reaction, a good understanding of the underlying chemistry is needed. ${ }^{[9]}$

In this report we describe the formation of nano-crystalline BTO powder (8$10 \mathrm{~nm}$ diameter) at temperatures between 23 and $78{ }^{\circ} \mathrm{C}$. As reported earlier by Stawski et al., a modified Ti alkoxide precursor in benzyl alcohol in the presence of barium hydroxide octahydrate was used in the synthesis. ${ }^{[8,21]}$ Niederberger $e t$ al. also showed the importance and active role of benzyl alcohol in the nonaqueous synthesis of BTO. ${ }^{[3]}$ However, the two reactions proceed via fundamentally different pathways, i.e. hydrolytic in my case versus non-hydrolytic in the case of Niederberger et al. In my hydrolytic solgel synthesis, the reactivity of the $\left[\mathrm{Ti}(\mathrm{OR})_{4}\right]$ precursor is reduced by the benzyl alcohol solvent via ligand exchange, without impeding the hydrolysis-condensation reactions at these low temperatures. Essentially, the alkoxide precursor is hydrolyzed by hydrated water that is released from barium hydroxide octahydrate upon mild heating.

To elucidate the formation mechanism, we studied the stability and interaction of both precursors with the solvent and with each other using simplified density functional theory (DFT) calculations, and compared the results with my experimental data.

\subsection{Experimental Section}

\subsubsection{Chemicals and Materials}

Titanium (IV) iso-propoxide $\left.\left(\operatorname{Ti}\left[\left(i-\mathrm{OC}_{3} \mathrm{H}_{7}\right)\right]_{4}\right), 99.999 \%\right)$, barium hydroxide octahydrate $\left(\mathrm{Ba}(\mathrm{OH})_{2} \cdot 8 \mathrm{H}_{2} \mathrm{O}, 98.0 \%\right)$, and 2-propanol (99.5\%) were purchased from Sigma-Aldrich. Benzyl alcohol (99.0\%) was acquired from Acros. All chemicals were used as-received from the suppliers without any further purification. Both titanium (IV) iso-propoxide and benzyl alcohol were stored and handled in a water-free environment $(<0.1 \mathrm{ppm}$ $\left.\mathrm{H}_{2} \mathrm{O}\right)$.

\subsubsection{Formation of Crystalline BTO}

A stoichiometric amount of $\mathrm{Ba}(\mathrm{OH})_{2} \cdot 8 \mathrm{H}_{2} \mathrm{O}$ was added to a $0.2 \mathrm{~mol} \cdot \mathrm{dm}^{-3}$ solution of titanium (IV) iso-propoxide in benzyl alcohol. While stirring, the reaction mixture was heated to $35,45,60$, or $75{ }^{\circ} \mathrm{C}$, whereas one mixture was held at $23{ }^{\circ} \mathrm{C}$ (the constant 
temperature of the lab). After reaction, the as-synthesized powder was centrifuged using a Heraeus Labofuge 300 centrifuge at $8000 \mathrm{rpm}$ for $30 \mathrm{~min}$. The supernatant benzyl alcohol phase was removed by decantation and replaced with $15 \mathrm{~mL}$ of 2-propanol. Subsequently, the as-prepared powder was redispersed in 2-propanol and the centrifuging/redispersion steps were repeated. Finally, the dispersion of as-synthesized BTO powder in 2-propanol was poured into a Petri dish and dried at room temperature for 24 h under a constant flow of $\mathrm{N}_{2}$ to prevent $\mathrm{BaCO}_{3}$ formation.

\subsubsection{Sample Characterization}

\section{X-Ray Diffraction (XRD)}

Samples synthesized between $23-78{ }^{\circ} \mathrm{C}$ were characterized with $\mathrm{X}$-ray powder diffraction to confirm the formation of the crystalline $\mathrm{BaTiO}_{3}$ perovskite phase using a Bruker D2 Phaser (Bruker AXS, Delft, The Netherlands) with a LYNXEYETM detector. Samples were measured typically from $2 \theta=25-90^{\circ}$, with step sizes of $0.02^{\circ}$ and $1 \mathrm{~s}$ per step. Time-resolved X-ray diffraction was performed to determine the first formation of crystalline phase at temperature between $45-150{ }^{\circ} \mathrm{C}$. At intervals of 2-15 min samples were taken from the reaction vessel, and measured using an X'Pert Powder Pro (PANalytical, Almelo, The Netherlands) with a 1D PIXcel detector. Scans from $2 \theta=27-35^{\circ}$ of the (110) peak were measured with step sizes of $0.026^{\circ}$ and $600 \mathrm{~s}$ per step. The patterns were further analyzed using the X'Pert Highscore Plus software package (version 3.0e).

\section{Thermogravimetric Analysis \& Differential Scanning Calorimetry (TGA/DSC)}

Weight loss due to dehydration of barium hydroxide octahydrate was measured isothermally using Netzsch STA 449 F3 simultaneous TGA/DSC (Netzsch, Selb, Germany) at $25,35,45,50,60$, and $70{ }^{\circ} \mathrm{C}$. Samples were placed in Pt cups and heated at a constant heating rate of $5^{\circ} \mathrm{C} \cdot \mathrm{min}^{-1}$ in technical air $\left(\mathrm{N}_{2} / \mathrm{O}_{2}=80 / 20\right.$; flow rate $\left.60 \mathrm{~mL} \cdot \mathrm{min}^{-1}\right)$ to the desired temperature, and held at that temperature for 2-24 h until 7 moles of hydrated water had been released and barium hydroxide monohydrate had formed. All samples were measured at least 3 times in order to determine the experimental error. The weight percentage of benzyl alcohol associated with the presence of a covalently bonded capping layer on the surface of the BTO particles was determined for as-prepared samples, synthesized at $78{ }^{\circ} \mathrm{C}$, and for samples heat-treated at $250{ }^{\circ} \mathrm{C}$ for $24 \mathrm{~h}$ 
(bp. benzyl alcohol $205^{\circ} \mathrm{C}$ ). Samples were placed in Pt cups and heated to $900{ }^{\circ} \mathrm{C}$, using the abovementioned conditions.

\section{Electron Microscopy Analysis}

Samples were investigated by transmission electron microscopy (TEM, $400 \mathrm{keV}$, FEI Instruments, Eindhoven, The Netherlands) and further analyzed using the ImageJ processing software package (version $1.47 \mathrm{q}){ }^{[22]}$ Crystallite size distributions of selected samples were based on images containing at least 200 different crystallites and recorded at lower magnification.

\section{Small-Angle X-ray Scattering (SAXS)}

SAXS experiments were performed on the Dutch-Belgium beam line (BM-26B) of the ESRF in Grenoble, France. ${ }^{[23]}$ The samples were irradiated with a X-ray beam energy of $16 \mathrm{keV}(\lambda=0.0776 \mathrm{~nm})$ and measured using a $2 \mathrm{D}$ gas-filled proportional detector (512x512 pixels). The recorded scattering vector magnitude was $0.13<q<8.2 \mathrm{~nm}^{-1}$. $1 \mathrm{D}$ scattering curves obtained from $2 \mathrm{D}$ patterns are plotted as a function of the absolute $q$-scale with respect to the center of diffraction (i.e. with respect to the beam-stop). The vertical and horizontal $q$-scale values of the $2 \mathrm{D}$ scattering patterns are relative values with respect to the $(\mathrm{x}, \mathrm{y})=(0,0)$ pixel of the detector. Small quantities of the individual and mixed precursors were measured in sealed glass capillaries ( $\varnothing=1.5 \mathrm{~mm}$; glass no. 50; Hilgenberg, Malsfeld, Germany) at different temperatures between 45 and $90{ }^{\circ} \mathrm{C}$.

\subsubsection{Computational Modeling}

Consecutive Ligand Exchange Titanium (IV) iso-propoxide and Benzyl Alcohol The model phenylmethoxy ligand $\left(-\mathrm{OCH}_{2} \mathrm{Ph}\right)$ of the benzyl alcohol was created in Spartan'10, and subsequently the equilibrium geometry at ground state was found by energy minimization using a Hartree-Fock 6-31G* basis set. The ligand was taken to be a singly charged anion in singlet state. Subsequently, the ligand was placed at $4 \mathrm{~nm}$ from the Ti core of $\left[\mathrm{Ti}\left(\mathrm{O}^{\prime} \mathrm{Pr}\right)_{4}\right]$. In 50 steps, the ligand was moved to the vicinity of the Ti atom (to $1.9 \mathrm{~nm}$ distance), and concurrently, the iso-propoxide ligand was removed. For every step, the minimum conformation energy was calculated using the energy profile in the ground state, with the semi-empirical AM1 method. In the simulation, the oxygen of the phenylmethoxy group binds with the Ti atom of the alkoxide. All simulations were 
performed in a polarizable benzyl alcohol continuum using the SM8 solvation calculation. ${ }^{[24]}$ Coordination expansion of the monomeric $\left[\mathrm{Ti}\left(\mathrm{O}^{2} \mathrm{Pr}\right)_{4}\right]$ species was not taken into account during the simulations, since the electronegative phenyl groups of the benzyl alcohol solvent are thought to effectively shield the Ti-core (see Section 2.3.2).

\section{Electronegativity Changes of the Central Ti-atom}

The minimum energy states of all possible ligand exchange complexes (i.e. $\left[\mathrm{Ti}(\mathrm{O} / \mathrm{Pr})_{4}\right]$, $\left[\mathrm{Ti}(\mathrm{O} / \mathrm{Pr})_{3}\left(\mathrm{OCH}_{2} \mathrm{Ph}\right)\right], \quad\left[\mathrm{Ti}(\mathrm{O} / \mathrm{Pr})_{2}\left(\mathrm{OCH}_{2} \mathrm{Ph}\right)_{2}\right], \quad\left[\mathrm{Ti}(\mathrm{O} / \mathrm{Pr})\left(\mathrm{OCH}_{2} \mathrm{Ph}\right)_{3}\right], \quad$ and $\left.\left[\mathrm{Ti}\left(\mathrm{OCH}_{2} \mathrm{Ph}\right)_{4}\right]\right)$ in benzyl alcohol were calculated with a Hartree-Fock 6-31G* basis set and the SM8 solvation calculation. ${ }^{[2]}$ The complexes were taken to be charge neutral and in singlet state. A minimum bond length between the phenylmethoxy ligand and the Ti core of $1.95 \mathrm{~nm}$ was found.

\subsection{Results and Discussion}

\subsubsection{The Dehydration of Barium Hydroxide Octabydrate}

The amount of water present in the system during the alkoxide-hydroxide precipitation reaction influences the rate of hydrolysis, and consequently the size and morphology of the powders. ${ }^{\left[{ }^{2} 20\right]}$ To control the reaction, the release of water from the Ba precursor was monitored using isothermal thermogravimetric measurements. The weight loss of samples was recorded at constant temperatures below the melting point of $\mathrm{Ba}(\mathrm{OH})_{2} \cdot 8 \mathrm{H}_{2} \mathrm{O}$, i.e. $78^{\circ} \mathrm{C}$. Figure 2.1 a shows a typical dehydration curve obtained from a measurement performed at $25{ }^{\circ} \mathrm{C}$. From the start of the measurement linear weight loss with time was observed until an equivalent mass of 7 moles $\mathrm{H}_{2} \mathrm{O}$ water had been released. The time necessary for complete dehydration varied between approximately 1 and $19 \mathrm{~h}$, at isothermal temperatures of $70^{\circ} \mathrm{C}$ and $25^{\circ} \mathrm{C}$, respectively. The phase of the final powder was identified as $\mathrm{Ba}(\mathrm{OH})_{2} \cdot \mathrm{H}_{2} \mathrm{O}$ using XRD (data not shown), which agreed well with the observed weight loss. The $\mathrm{Ba}(\mathrm{OH})_{2} \cdot 8 \mathrm{H}_{2} \mathrm{O}$ phase showed no signs of melting at any temperature. ${ }^{25]}$ The dehydration was governed by evaporation of water and was modeled by a zero-th order reaction, as shown in Equation 2.1 to Equation 2.3 , where $k_{1}$ is the rate constant, and $t$ is time. 


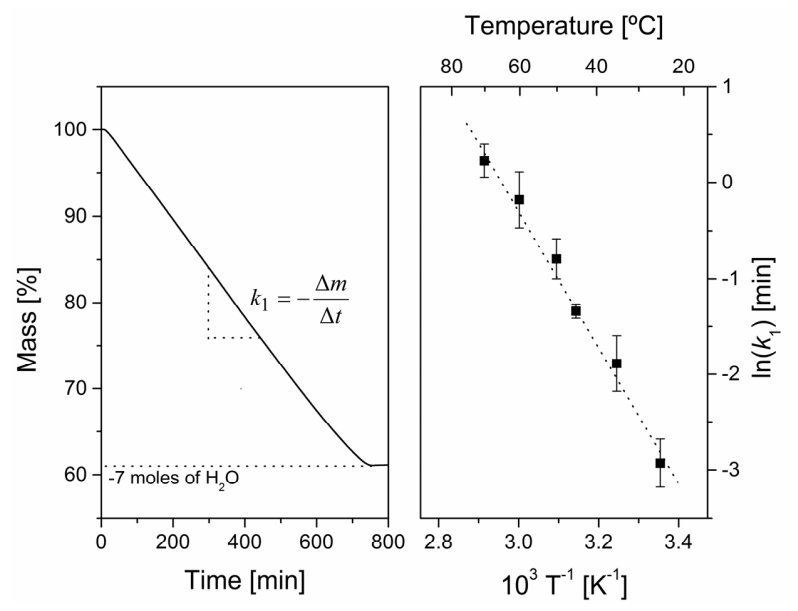

Figure 2.1 (a) Isothermal dehydration of barium hydroxide octahydrate precursor at $25{ }^{\circ} \mathrm{C}$ as measured with TGA/DSC. After dehydration, 7 moles of $\mathrm{H}_{2} \mathrm{O}$ were lost and barium hydroxide monohydrate was obtained. Reaction constant $k_{1}$ was determined by the slope of weight loss versus time. (b) Arrhenius representation of reaction constant $k_{1}$ determined from isothermal measurements at $25,35,45,50,60$, and $70{ }^{\circ} \mathrm{C}$.

$$
\begin{gathered}
\mathrm{Ba}(\mathrm{OH})_{2} \cdot 8 \mathrm{H}_{2} \mathrm{O} \stackrel{k_{1}}{\longrightarrow} \mathrm{Ba}(\mathrm{OH})_{2} \cdot \mathrm{H}_{2} \mathrm{O}+7 \mathrm{H}_{2} \mathrm{O} \\
\frac{\partial\left[\mathrm{Ba}(\mathrm{OH})_{2} \cdot 8 \mathrm{H}_{2} \mathrm{O}\right]}{\partial t}=-k_{1} \\
\frac{\left[\mathrm{Ba}(\mathrm{OH})_{2} \cdot 8 \mathrm{H}_{2} \mathrm{O}\right]}{\left[\mathrm{Ba}(\mathrm{OH})_{2} \cdot \mathrm{H}_{2} \mathrm{O}\right]_{0}}=-k_{1} \cdot t
\end{gathered}
$$

Figure 2.1b shows the exponential behavior of the rate constants obtained from the isothermal TGA measurements. The activation energy for the dehydration of barium hydroxide octahydrate to its monohydrate phase is $E_{\mathrm{A}} \sim 54.7 \pm 3.3 \mathrm{~kJ} \cdot \mathrm{mol}^{-1}$ and was calculated from the slope. Zero-th order dehydration kinetics has also been observed for dehydration of other hydrated materials. ${ }^{[26-28]}$ The thermogravimetric experiments show that sufficient water can be released at $25^{\circ} \mathrm{C}$ to initiate the hydrolysis reaction of the titanium alkoxide precursor. 

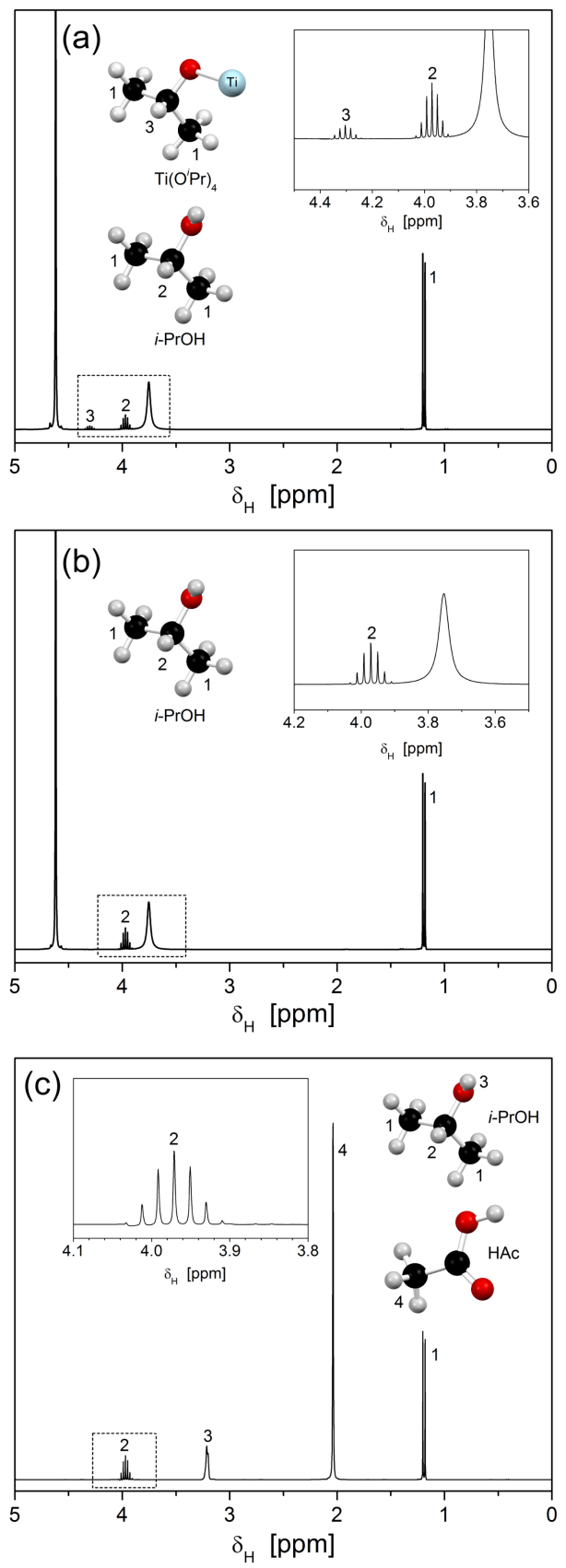

Figure $2.2{ }^{1} \mathrm{H}$ NMR spectra of (a) partially stabilized [ $\left.\mathrm{Ti}\left(\mathrm{O}^{2} \mathrm{Pr}\right)_{4}\right]$ precursor in benzyl alcohol at RT; i.e. $\left[\mathrm{Ti}\left(\mathrm{O}^{i} \mathrm{Pr}\right)\left(\mathrm{OCH}_{2} \mathrm{Ph}\right)_{3}\right]$; (b) $\left[\mathrm{Ti}\left(\mathrm{O}^{i} \mathrm{Pr}\right)_{4}\right]$ stabilized by complete ligand exchange of the phenylmethoxy ligands; (c) fully stabilized $\left[\mathrm{Ti}\left(\mathrm{O}^{i} \mathrm{Pr}\right)_{4}\right]$ precursor with acetate ligands at RT. The measurement resolution is too low to observe an $\mathrm{OH}$-signal of free iso-propanol in (a) and (b). 


\subsubsection{Stability of Titanium (IV) iso-propoxide in Bensyl Alcohol}

\section{Ligand Exchange}

The hydrolytic stability of the highly reactive Ti alkoxide was enhanced by ligand exchange of the phenylmethoxy ligands from the parent solvent, that the precursor solution could be handled under ambient conditions. ${ }^{[8]}$ Similar to hydrolysis-condensation reactions, the consecutive ligand exchanges are thought to follow a series of $\mathrm{S}_{\mathrm{N}} 2$ reaction steps, ${ }^{[9,10]}$ resulting in the overall reaction:

$$
\left[\mathrm{Ti}\left(\mathrm{O}^{i} \mathrm{Pr}\right)_{4}\right]+\mathrm{n} \mathrm{ROH} \longrightarrow\left[\mathrm{Ti}\left(\mathrm{O}^{i} \mathrm{Pr}\right)_{4-\mathrm{n}}(\mathrm{OR})_{\mathrm{n}}\right]+\mathrm{n} \operatorname{PrOH} \quad \text { Eq. (2.4) }
$$

${ }^{1} \mathrm{H}$ NMR measurements (Bruker AV $600 \mathrm{MHz}$, Wormer, The Netherlands) were performed on solutions of $\left[\mathrm{Ti}^{2}\left(\mathrm{O}^{2} \mathrm{Pr}\right)_{4}\right]$ in benzyl alcohol to characterize the ligand exchange process. The ligand exchange can be followed by the change in chemical shift of the characteristic septet $(-\mathrm{CH})$ of the iso-propoxide ligand (bound to Ti) and iso-propanol (exchanged ligand) from approximately $\delta_{\mathrm{H}}=4.4 \mathrm{ppm}$ to $\delta_{\mathrm{H}}=3.9 \mathrm{ppm}$, respectively (Figure 2.2). At room temperature both septets were present, indicating partial ligand exchange and formation of $\left[\mathrm{Ti}(\mathrm{O} \mathrm{Pr})\left(\mathrm{OCH}_{2} \mathrm{Ph}\right)_{3}\right]$, which is in accordance with the findings of Stawski et al. ${ }^{[8]}$ After heating the mixture to $100{ }^{\circ} \mathrm{C}$, only the septet of iso-propanol at $\delta_{\mathrm{H}}=3.9 \mathrm{ppm}$ was present, showing that full ligand exchange had taken place. These results were compared with the analogous ligand exchange process using acetate ligands. Acetate ligands are frequently used as bidentate ligands to stabilize metal alkoxide precursors. ${ }^{[10,12,13]}$ Figure $2.2 \mathrm{c}$ shows that at RT all ligands are already exchanged. The bidentate binding of the acetate to the $\mathrm{Ti}$ atom and reduced steric hindrance make it energetically favorable to exchange all ligands. Doeuff et al. showed with FTIR that acetic acid acts as a chelating and bridging ligand. ${ }^{[13]}$ Due to this unidentate binding behavior of acetic acid, polymeric titanium acetate species were formed, without any OR groups attached to Ti. My ${ }^{1} \mathrm{H}$ NMR data agrees well with the abovementioned findings, showing that all -OR groups are present as iso-propanol.

To obtain insight into the ligand exchange process at RT, the exchange reaction summarized by Equation 2.4 were simulated by DFT. The transition state energy, the Gibbs free energy of the product relative to the starting composition, the partial charge on the Ti atom, and the chemical structure at equilibrium were calculated in a polarizable benzyl alcohol solvent matrix, see Table 2.1 and Figure 2.3 (and Supporting Information). A clear trend was observed in the ligand exchange processes. For every consecutive 
exchange, the transition state energy increased (i.e. increased activation energy), probably due to steric hindrance by the negatively charged phenyl groups of the phenylmethoxy ligands. As a result, the free energy change of the system upon exchange of the fourth ligand is not favorable $(\Delta G \sim 0)$, and this agrees well with the NMR data, which indicate that only 3 ligands are exchanged at RT.

Table 2.1 Energy data obtained from the computational ligand exchange simulations. The activation energy $\left(E_{A}\right)$ and Gibbs free energy $(\Delta G)$ are calculated for both phenylmethoxy and acetate ligand exchange reactions.

\begin{tabular}{lcccc}
\hline & \multicolumn{2}{c}{ Phenylmethoxy ligand } & \multicolumn{2}{c}{ Acetate ligand } \\
\# Ligand Exchange & $E_{\mathrm{A}}\left[\mathrm{kJ} \cdot \mathrm{mol}^{-1}\right]$ & $\Delta \mathrm{G}\left[\mathrm{kJ} \cdot \mathrm{mol}^{-1}\right]$ & $E_{\mathrm{A}}\left[\mathrm{kJ} \cdot \mathrm{mol}^{-1}\right]$ & $\Delta \mathrm{G}\left[\mathrm{kJ} \cdot \mathrm{mol}^{-1}\right]$ \\
\hline First & 21.6 & -57.4 & 26.0 & -52.1 \\
Second & 39.9 & -26.4 & 33.5 & -48.8 \\
Third & 64.6 & -14.9 & 36.7 & -44.7 \\
Fourth & 100.0 & -1.9 & 39.1 & -41.5 \\
\hline
\end{tabular}

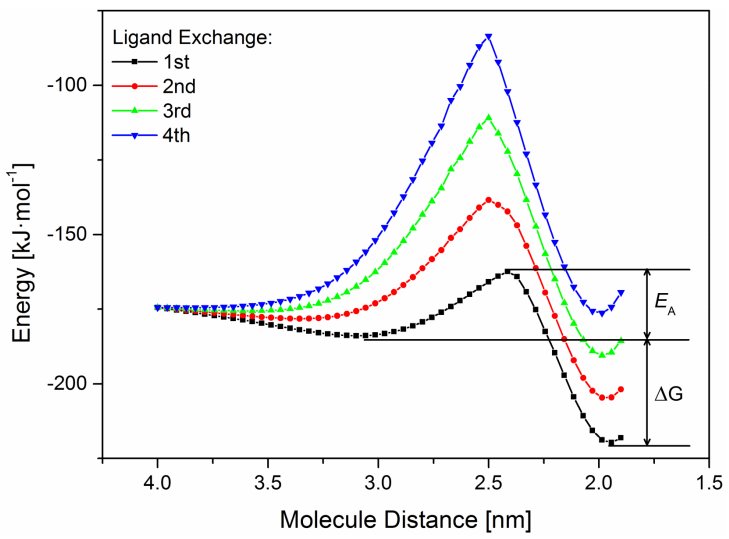

Figure 2.3 Calculated energy profiles of the four consecutive phenylmethoxy ligand exchanges, and the distance between the approaching benzyl alcohol molecule and the Ti core. For every exchange, the activation energy increases, whereas the Gibbs free energy decreases to almost zero.

These results were compared to the same process involving acetate ligands. Although the simulations of the acetate ligand exchange also showed a small increase in activation energy (Table 2.1), ligand exchange remained favorable at RT for all four exchange reactions $(\Delta G<0)$. This can be explained by the smaller steric hindrance of acetate ligands 
in comparison to phenylmethoxy ligands, and the results are in good agreement with the data from the ${ }^{1} \mathrm{H}$ NMR measurements.

\section{Partial Charge}

The abovementioned results suggest that the Ti precursor is stabilized against hydrolysis by steric hindrance and the electronegativity of the phenyl groups. However, ligand exchange may also influence the partial charge of the Ti atom and, thus, the intrinsic reactivity of the complex. Several models to calculate the partial charge of a central atom in a complex have been proposed. The simplest model takes only the electronegativity of the direct neighboring atoms into account. The partial charge is then calculated by:

$$
\delta_{\mathrm{Ti}}=V_{\mathrm{Ti}}-\left[L_{\mathrm{Ti}}+\sum \frac{\chi_{\mathrm{Ti}}}{\chi_{\mathrm{Ti}}+\chi_{\mathrm{O}}} \cdot B_{\mathrm{O}}\right]
$$

Here, $\delta_{\mathrm{Ti}}$ is the partial charge on the central Ti atom, $V_{\mathrm{Ti}}$ the number of valence electrons of $\mathrm{Ti}$, and $L_{\mathrm{Ti}}$ the number of lone pair electrons involved, $\chi_{\mathrm{Ti}}$ and $\chi_{\mathrm{O}}$ are the electronegativities of the Ti and $\mathrm{O}$ atoms, respectively, and $B_{\mathrm{O}}$ is the number of electrons involved in the bond.

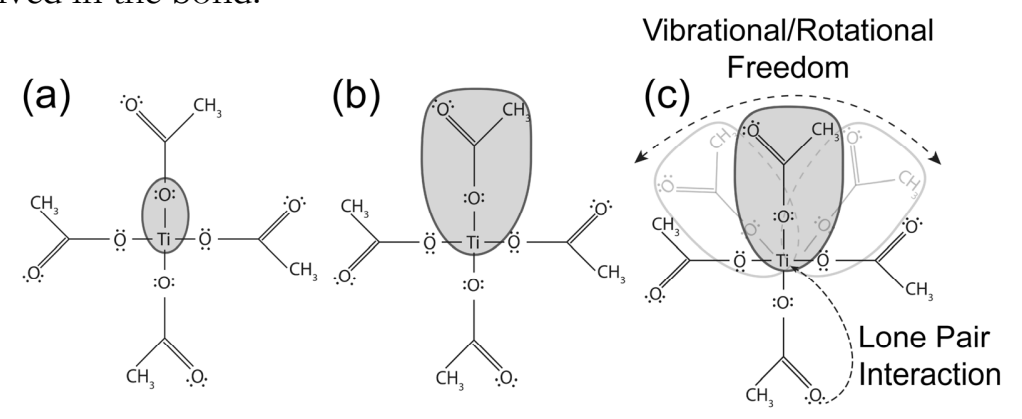

Figure 2.4 Schematic representation of the partial charge calculation on the central $\mathrm{Ti}$ atom of the $\left[\mathrm{Ti}\left(\mathrm{O}^{i} \mathrm{Pr}\right)_{4}\right]$ precursor. (a) The electronegativity of only the surrounding oxygen atoms are taken into account; (b) inductive effects of the surrounding ligands are included, as described by Livage et al.: ${ }^{[10,11]}$ (c) proposed model in which inductive effects as well as rotational/vibrational effects of the surrounding ligands are included.

Although the model takes the electronegativity of the direct neighboring oxygen atoms into account, inductive effects of the complete ligand are neglected, as shown in Figure 2.4a. Livage et al. introduced a more complex model in which the inductive effects of all ligands are taken into account, see Figure 2.4b. ${ }^{[10,11]}$ 
The partial charge on the $\mathrm{Ti}$ atom is calculated using the average electronegativity of every ligand:

$$
\delta_{\mathrm{Ti}}=\frac{\bar{\chi}-\chi_{\mathrm{Ti}}^{0}}{k \sqrt{\chi_{\mathrm{Ti}}^{0}}}
$$

where $\bar{\chi}$ and $\chi_{\mathrm{Ti}}^{0}$ are the mean electronegativity of the ligand and the neutral Ti atom, respectively, and $k$ is Pauling's electronegativity constant (set at $k=1.36) .{ }^{[10]}$

Table 2.2 Overview of the effect of consecutive ligand exchange on the partial charge of the Ti atom. The results are based on Equation 2.5, Equation 2.6, and my simulations, respectively. Note: the absolute values should not be compared between models, only the trend within a model should be compared.

\begin{tabular}{lcccccc}
\hline & \multicolumn{2}{c}{ Electronegativity } & \multicolumn{2}{c}{ Livage } & \multicolumn{2}{c}{ Simulation } \\
& $-\mathrm{OCH}_{2} \mathrm{Ph}$ & $-\mathrm{O}(\mathrm{CO}) \mathrm{CH}_{3}$ & $-\mathrm{OCH}_{2} \mathrm{Ph}$ & $-\mathrm{O}(\mathrm{CO}) \mathrm{CH}_{3}$ & $-\mathrm{OCH}_{2} \mathrm{Ph}$ & $-\mathrm{O}(\mathrm{CO}) \mathrm{CH}_{3}$ \\
\hline$\left[\mathrm{Ti}\left(\mathrm{O}^{\prime} \mathrm{Pr}\right)_{4}\right]$ & 1.81 & 1.81 & 0.61 & 0.61 & 2.02 & 2.02 \\
{$\left[\mathrm{Ti}\left(\mathrm{O}^{\prime} \mathrm{Pr}\right)_{3}(\mathrm{OR})\right]$} & 1.81 & 1.81 & 0.62 & 0.65 & 2.02 & 1.37 \\
{$\left[\mathrm{Ti}\left(\mathrm{O}^{\prime} \mathrm{Pr}\right)_{2}(\mathrm{OR})_{2}\right]$} & 1.81 & 1.81 & 0.63 & 0.66 & 2.03 & 1.29 \\
{$\left[\mathrm{Ti}\left(\mathrm{O}^{\prime} \mathrm{Pr}\right)(\mathrm{OR})_{3}\right]$} & 1.81 & 1.81 & 0.64 & 0.67 & 2.04 & 1.25 \\
{$\left[\mathrm{Ti}(\mathrm{OR})_{4}\right]$} & 1.81 & 1.81 & 0.64 & 0.69 & 2.05 & 1.19 \\
\hline
\end{tabular}

Although the second model includes the effect of the complete ligand, the conformation in which these ligands are attached cannot be predicted. My computational model for ligand exchange was able to include that effect too, and the rotational and vibrational effects of the phenylmethoxy ligand on the partial charge could be calculated (Figure 2.4c). The results of the different models are summarized in Table 2.2. For the sake of comparison, the effect of the acetate ligand on the partial charge is also shown. Since the numerical value of the partial charge is calculated differently by each model, only trends within the same model should be compared. Furthermore, the simulations assume the $\left[\mathrm{Ti}^{2}\left(\mathrm{O}^{2} \mathrm{Pr}\right)_{4}\right]$ precursor to remain monomeric prior to and after ligand exchange, ${ }^{[10,29]}$ in accordance with literature data that suggest that the $\left[\mathrm{Ti}\left(\mathrm{O}^{2} \mathrm{Pr}\right)_{4}\right]$ precursor does not form dimeric or oligomeric species, nor does it expand its coordination number, in contrast to $\left[\mathrm{Ti}(\mathrm{OEt})_{4}\right]$ and $\left[\mathrm{Ti}\left(\mathrm{O}{ }^{n} \mathrm{Bu}\right)_{4}\right] \cdot{ }^{[10,29]}$

As expected, the model described by Equation 2.5 did not predict changes in the partial charge as a result of ligand exchange. The other two models predicted only a slight increase of the partial charge on the Ti atom, implying that the phenylmethoxy 
ligands do not contribute significantly to an increased stability towards hydrolysis. ${ }^{[16]}$ On the other hand, a clear decrease in partial charge was observed for the acetate ligand, indicating that bidentate binding of the acetate effectively reduces the overall reactivity of the metal alkoxide/acetate. The stability of both the phenylmethoxy and acetate stabilized precursors was further investigated by adding a small amount of water at RT. Whereas the latter solution was stable for days, the phenylmethoxy stabilized solution turned opaque within minutes. These results thus indicate, that the Ti precursor is not stabilized by a partial charge decrease of the central Ti atom, but rather by the shielding of the phenylmethoxy ligands (i.e. steric hindrance). Figure 2.5 illustrates the effective encapsulation of the Ti center by ligands for the state with the lowest conformational energy. Concurrently, the low miscibility of water with benzyl alcohol may also have contributed to the lower reactivity of the Ti precursor.
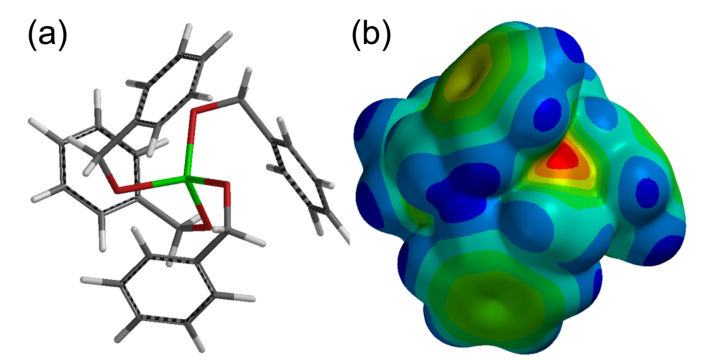

Figure 2.5 (a) 3D view and (b) electrostatic potential map of the optimized $\left[\mathrm{Ti}\left(\mathrm{OCH}_{2} \mathrm{Ph}\right)_{4}\right]$ structure, i.e. after complete ligand exchange.

\subsubsection{Interaction Between the Ti and Ba Precursors}

Small-angle X-ray scattering (SAXS) and diffraction experiments were performed to study the structural evolution of BTO from the observed interactions between the Ti alkoxide and the Ba precursor in benzyl alcohol. Essentially, SAXS probes local electron density fluctuations of a sample by X-ray scattering at very small angles, which makes it possible to extract structural information on length scales up to $500 \mathrm{~nm}$ (typically $<200$ $\mathrm{nm}) .{ }^{[30,31]}$ The scattered intensity is measured as a function of the modulus of the scattering vector $q\left(\mathrm{~nm}^{-1}\right)$ :

$$
q=\frac{4 \pi}{\lambda} \sin \theta
$$


where $\lambda$ is the wavelength $(\mathrm{nm})$ of the incident beam, and the scattering angle is $2 \theta$. Suspensions of $\mathrm{Ba}(\mathrm{OH})_{2} \cdot 8 \mathrm{H}_{2} \mathrm{O}$ in benzyl alcohol were investigated at elevated temperatures to determine the effect of heating on the crystal structure and the release of hydrate water. Figure 2.6 shows SAXS data of samples heated between 60 and $90{ }^{\circ} \mathrm{C}$. A clear correlation peak is observed at $q \sim 3.9 \mathrm{~nm}^{-1}$ for samples heated at $60{ }^{\circ} \mathrm{C}$, which is interpreted as a Bragg peak associated with the $\mathrm{Ba}-\mathrm{Ba}$ distance in the (101) plane of the $\mathrm{Ba}(\mathrm{OH})_{2} \cdot 8 \mathrm{H}_{2} \mathrm{O}$ crystal (ICSD \# 33741), ${ }^{[32]}$ see Supporting Information Figure S2.3.

(a)

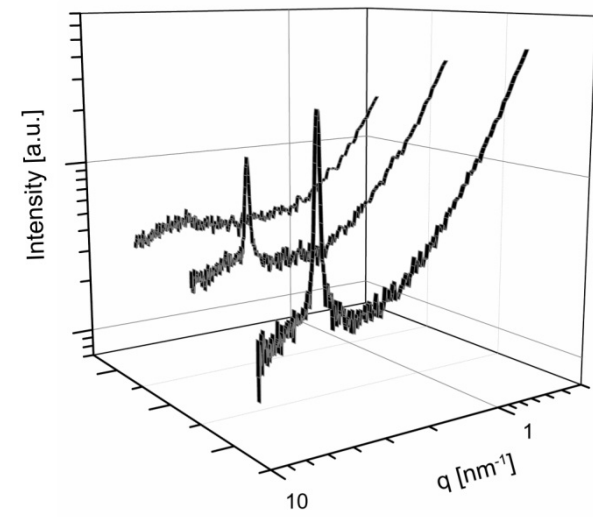

(c)

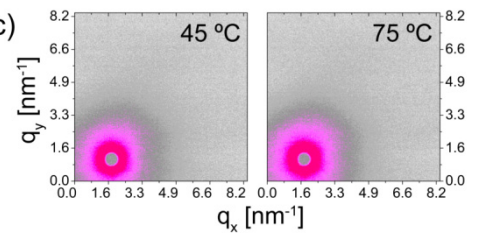

(b)
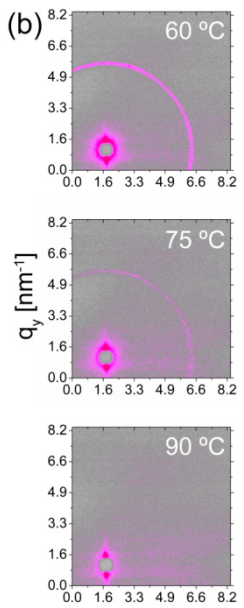

$\mathrm{q}_{\mathrm{x}}\left[\mathrm{nm}^{-1}\right]$

Figure 2.6 (a) Small angle X-ray diffraction pattern of barium hydroxide octahydrate at different temperatures. Samples measured below the melting point of $78^{\circ} \mathrm{C}$ exhibit a diffraction peak at $q \sim 3.9 \mathrm{~nm}^{-1}$, correlated to the crystal structure of the Ba precursor. (b) 2D representation of the recorded pattern. (c) $2 \mathrm{D}$ small angle X-ray diffraction pattern of a titanium (IV) iso-propoxide and barium hydroxide octahydrate mixture in benzyl alcohol at 45 and $75{ }^{\circ} \mathrm{C}$, respectively. The correlation peak at $q \sim 3.9 \mathrm{~nm}^{-1}$ disappeared well below the melting point of the $\mathrm{Ba}$ precursor; the long range order in the crystal is lost in the presence of the Ti precursor.

In the proximity of its melting point, the diffraction peak was still observed. However, the intensity was lower, suggesting that the processes of decomposition of crystal structure and release of hydrated water was taking place. Above the melting temperature, the 
characteristic peak at $q \sim 3.9 \mathrm{~nm}^{-1}$ was not visible, indicating that the long range order of the crystal structure was absent.

The interaction between the $\mathrm{Ba}$ and Ti precursors was investigated by addition of titanium (IV) iso-propoxide to a $\mathrm{Ba}(\mathrm{OH})_{2} \cdot 8 \mathrm{H}_{2} \mathrm{O}$ suspension in benzyl alcohol. Where the Ba precursor in benzyl alcohol clearly showed a Bragg diffraction below $78{ }^{\circ} \mathrm{C}$, no rings were observed in the $2 \mathrm{D}$ detector image after [ $\left[\mathrm{Ti}(\mathrm{O} / \mathrm{Pr})_{4}\right]$ had been added to the suspension, see Figure 2.6c. Even at $45^{\circ} \mathrm{C}$, the long range order of $\mathrm{Ba}(\mathrm{OH})_{2} \cdot 8 \mathrm{H}_{2} \mathrm{O}$ was lost in the presence of the $\mathrm{Ti}$ alkoxide, showing that even at these low temperatures a strong interaction exists between the two precursors.

The interaction between the precursors, combined with the loss of hydrated water from the $\mathrm{Ba}(\mathrm{OH})_{2} \cdot 8 \mathrm{H}_{2} \mathrm{O}$ (as described in Section 2.3.1), thus imply that all reaction conditions for the formation of crystalline BTO are present, even at room temperature.

\subsubsection{RT Formation of Nano-crystalline BTO}

\section{Reaction Pathway}

Syntheses with $\mathrm{Ba}(\mathrm{OH})_{2} \cdot 8 \mathrm{H}_{2} \mathrm{O}$ (insoluble) and $\left[\mathrm{Ti}\left(\mathrm{O}^{2} \mathrm{Pr}\right)_{4}\right]$ in benzyl alcohol were performed at various temperatures between 23 and $78^{\circ} \mathrm{C}$. Within minutes a white precipitate formed in the solution, indicating that a reaction between the two precursors was taking place. Scanning electron microscopy/energy-dispersive X-ray spectroscopy $(\mathrm{SEM} / \mathrm{EDX})$ in combination with XRD confirmed that short reaction times yielded Xray amorphous $\mathrm{TiO}_{\mathrm{x}}$. Reaction times between 2.5 months and 30 min were necessary for crystalline BTO (Figure 2.7) to form between 23 and $78{ }^{\circ} \mathrm{C}$, respectively.

The exponential trend in the Arrhenius representation of the inverse crystallization time versus temperature (Figure 2.7b) shows that the formation of the perovskite phase is driven by the same kinetic processes in the temperature regime of $45-150{ }^{\circ} \mathrm{C}$. The relatively low value of the activation energy, i.e. $E_{\mathrm{A}} \sim 65.2 \pm 3.5 \mathrm{~kJ} \cdot \mathrm{mol}^{-1}$, implies that the process may be governed by diffusion, possibly by diffusion of $\mathrm{Ba}^{2+}$ into the amorphous $\mathrm{TiO}_{\mathrm{x}}$ matrix. At temperatures $<45^{\circ} \mathrm{C}$, different rate-limiting factors seem to play a role in the crystallization reaction, with an activation energy $>200 \mathrm{~kJ} \cdot \mathrm{mol}^{-1}$. Two possible mechanisms have been proposed in literature for the formation of crystalline BTO, both based on the hydrothermal synthesis route: (1) in-situ transformation or via (2) dissolution-precipitation. ${ }^{[33]}$ However, based on the experiments presented 
here, I cannot distinguish between these two mechanisms and more dedicated timeresolved work should be carried out to elucidate the earliest stages of crystalline BTO phase formation (see Chapter 3).

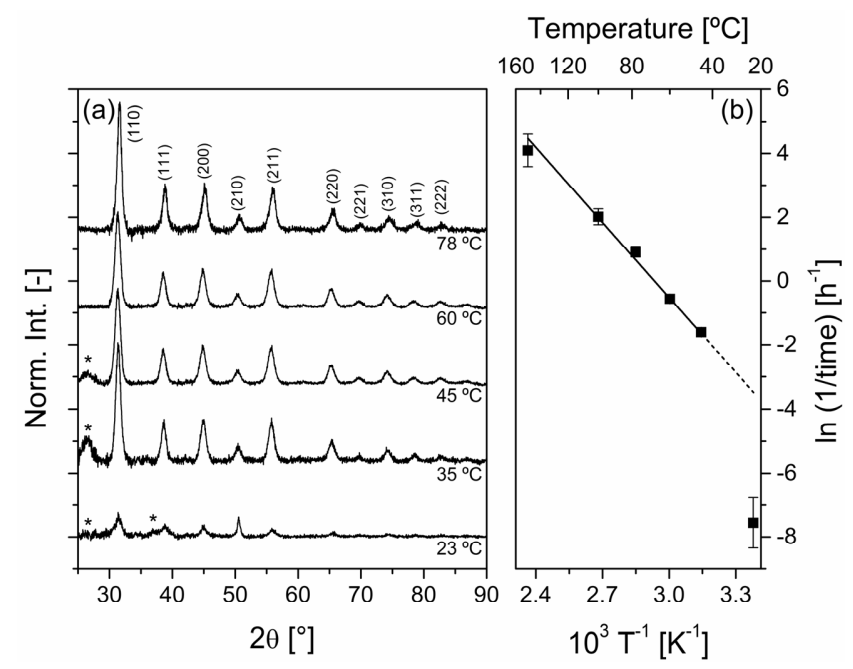

Figure 2.7 (a) XRD pattern of crystalline BTO powder synthesized at temperatures of 23$78^{\circ} \mathrm{C}$. A minor $\mathrm{BaCO}_{3}$ impurity was present for $\mathrm{BTO}$ prepared at temperatures $<45^{\circ} \mathrm{C}$. The baseline was subtracted from all patterns and then renormalized to the maximum intensity of the (110) peak at $2 \theta \sim 31.4^{\circ}$ (offset between the patterns: 0.6). (b) Arrhenius representation of the inverse time of first crystalline phase formation and temperature. A linear trend is observed for temperatures between $45-150{ }^{\circ} \mathrm{C}$.

\section{Crystallite Formation and Size}

The as-synthesized powders were characterized by XRD and TEM, see Figure 2.8. Peak broadening analysis of the (111) peak at $2 \theta \sim 38.9^{\circ}$ showed that no significant changes in peak width were observed, i.e. no significant crystallite growth occurred, regardless of reaction temperature. The average crystallite sizes were estimated to be approximately 8-10 nm using the Scherrer equation. The sample synthesized at $23{ }^{\circ} \mathrm{C}$ however, showed equally sized crystalline regions embedded in an amorphous matrix (Figure 2.8a). This might be caused by additional energy barriers dominant in the low reaction temperature regime (Figure 2.7b), and reaction times longer than 2.5 months are needed to further crystallize the sample at RT. The crystallites formed at temperatures between 35 and $78{ }^{\circ} \mathrm{C}$ showed a high degree of crystallinity (Figure 2.8b-d). 


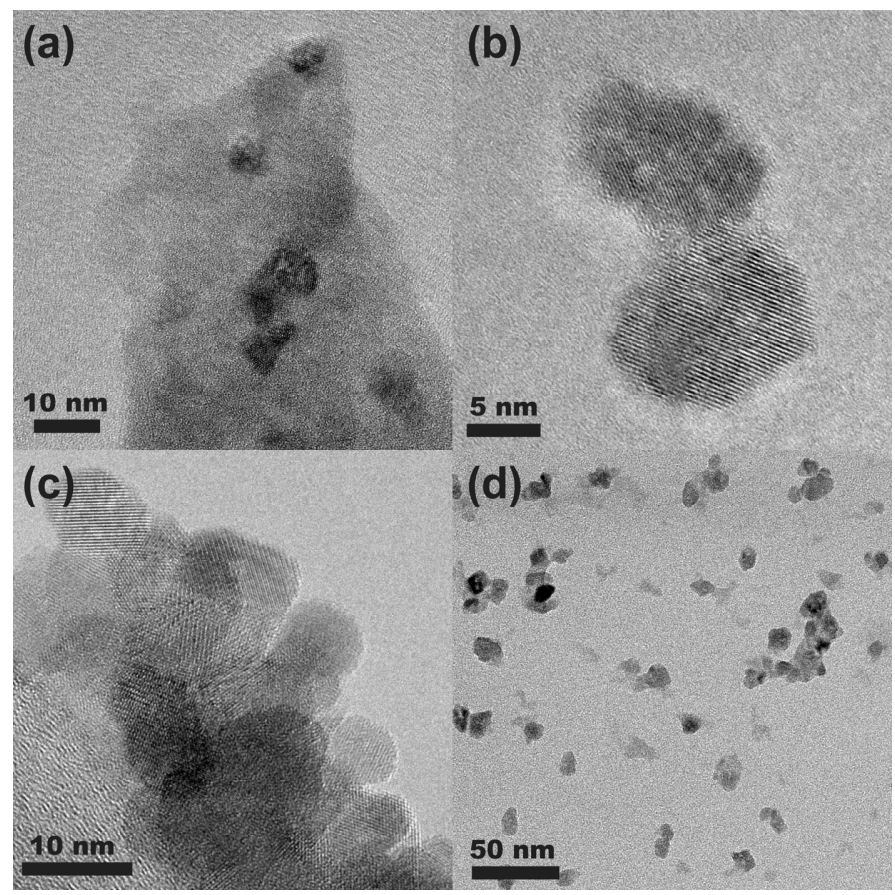

Figure 2.8 HRTEM images of BTO synthesized at different temperatures. (a) $23^{\circ} \mathrm{C}$; crystalline BTO embedded in an amorphous matrix; (b) $45^{\circ} \mathrm{C}$; (c) $60^{\circ} \mathrm{C}$, and (d) $60{ }^{\circ} \mathrm{C}$. Overview recorded at lower magnification. Sample placed on a Lacey support grid.

Crystallite size distributions of BTO synthesized at temperatures between $23{ }^{\circ} \mathrm{C}$ and 78 ${ }^{\circ} \mathrm{C}$ revealed that the reaction temperature had no influence on the final crystallite size of the powder. An average final size of approximately 7-9 $\mathrm{nm}$ was determined for all samples from TEM images recorded at lower magnification (see Figure 2.9). This value is in good agreement to the approximate size calculated from peak broadening in the $\mathrm{XRD}$ pattern in the same temperature range.

Another series of experiments was carried out to investigate if crystallite growth could be influenced by introducing new precursor material to the reaction mixture. After heating the reactants at $150{ }^{\circ} \mathrm{C}$ for $2 \mathrm{~h}$, the mixture containing crystalline BTO was cooled down to RT. Equal amounts of new Ba and Ti precursor material was added, and subsequently the mixture was heated again at $150{ }^{\circ} \mathrm{C}$ for $2 \mathrm{~h}$. A single-step synthesis of $4 \mathrm{~h}$ at $150^{\circ} \mathrm{C}$ was carried out as a control experiment. The BTO powders obtained from both experiments were investigated by XRD and TEM, see Figure 2.10. Both experiments yielded crystallites of equal size and morphology. Although we showed that 
the crystallite size increases with increasing the amount of water in previous work, ${ }^{[8]}$ the abovementioned experiments show that the newly introduced precursor material (i.e. more water present) does not lead to additional crystallite growth, but rather to the formation of new nuclei. So the question can be raised why these crystallites all grow to approximately the same size of 7-9 nm, and not larger? My hypothesis is that benzyl alcohol plays a crucial role in the limited growth of the particles, and that it acts as a capping layer on the BTO crystallites' surface (see Figure 2.11). Niederberger et al. introduced benzyl alcohol as solvent to provide good control over particle shape in the nonaqueous synthesis of $\mathrm{BTO}, \mathrm{TiO}_{2}$ and other metal oxide nanoparticles. ${ }^{[34,35]}$ However, the particle size in their nonaqueous approach is determined mainly by the concentration of Ti precursor. ${ }^{[34]}$

I hypothesized that since the surface curvature of small crystallites is higher compared to large crystallites, the packing density of benzyl alcohol molecules on the BTO surface is probably lower (Figure 2.11 ), and $\left[\mathrm{Ti}\left(\mathrm{O}^{2} \mathrm{Pr}\right)_{4}\right]$ can more easily approach the surface hydroxyl groups. As the crystallites grow to their final size of approximately 7-9 $\mathrm{nm}$, the surface curvature is reduced, and the packing of benzyl alcohol molecules on its surface becomes denser. Due to the density of the electronegative phenyl groups on the surface, BTO nanoparticles become effectively shielded from further growth. Cooke et al. showed that benzyl alcohol plays an important role in the formation of $\mathrm{TiO}_{2}$ nanotubes from carbon nanotubes (CNTs). ${ }^{[36]} \mathrm{The}^{\mathrm{TiO}}{ }_{2}$ nanotubes were fully covered by benzyl alcohol molecules, preferably parallel to the surface, while the phenyl rings were able to undergo $\pi-\pi$ stacking with the CNTs. If I consider benzyl alcohol molecules as hard spheres covering the BTO crystallites' surface without any interaction with its surroundings, then the surface area occupied by 1 molecule $\left(\sim 37 \AA^{2}\right)$ can be estimated from the molecular weight $\left(108.14 \mathrm{~g} \cdot \mathrm{mol}^{-1}\right)$ and density $\left(1.045 \mathrm{~g} \cdot \mathrm{cm}^{-3}\right)$ of benzyl alcohol. For non-agglomerated, fully covered BTO crystallites, the surface organic phenylmethoxy monolayer would then contain approximately $5 \%$ of the total mass of a BTO crystallite. 


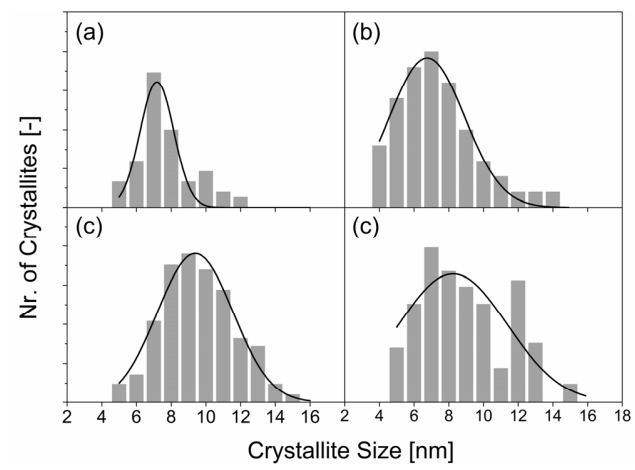

Figure 2.9 Crystallite size distribution of BTO powder obtained after synthesis at (a) $23{ }^{\circ} \mathrm{C}$, (b) $35^{\circ} \mathrm{C}$, (c) $60^{\circ} \mathrm{C}$ and (d) $150{ }^{\circ} \mathrm{C}$. Crystallite sizes were calculated from at least 200 crystallites from TEM images recorded at lower magnification.
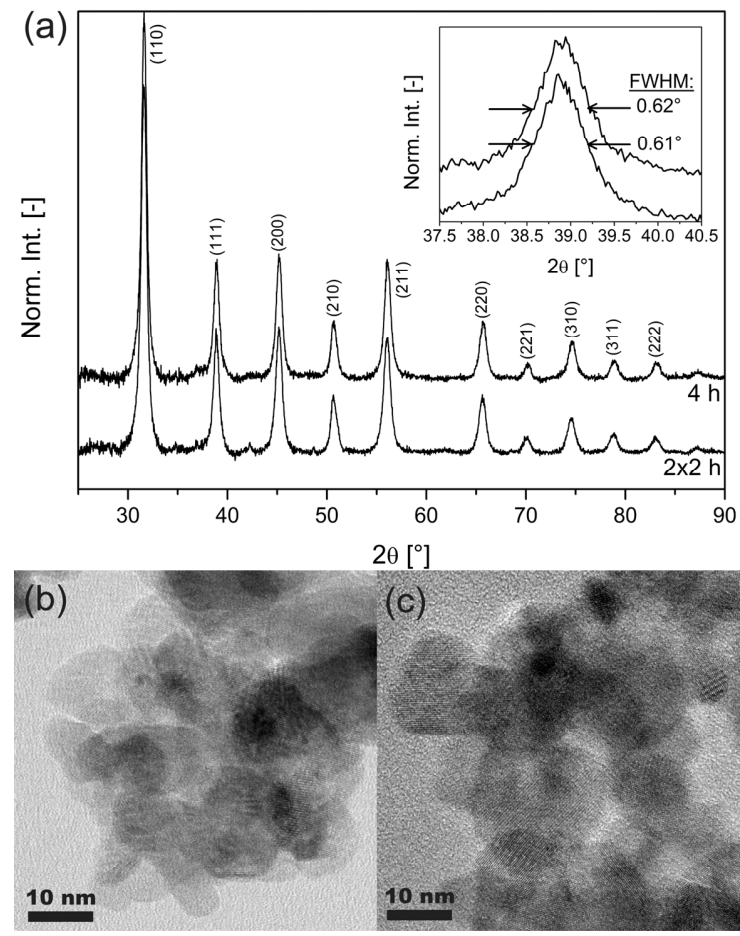

Figure 2.10 (a) XRD pattern of BTO synthesized for $2 \times 2 \mathrm{~h}$ and $4 \mathrm{~h}$ at $150{ }^{\circ} \mathrm{C}$. No difference in FWHM, and thus crystallite size, are observed. (b)-(c) TEM images of BTO synthesized for $2 \times 2 \mathrm{~h}$ and $4 \mathrm{~h}$ at $150{ }^{\circ} \mathrm{C}$, respectively, show equal crystallite sizes and morphology. Note: the synthesis denoted at $2 \times 2 \mathrm{~h}$ comprises a regular $2 \mathrm{~h}$ synthesis at $150{ }^{\circ} \mathrm{C}$. After cooling the reaction mixture to $\mathrm{RT}$, new precursor material was added and subsequently heated again for $2 \mathrm{~h}$ at $150^{\circ} \mathrm{C}$. 
(a)

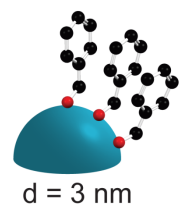

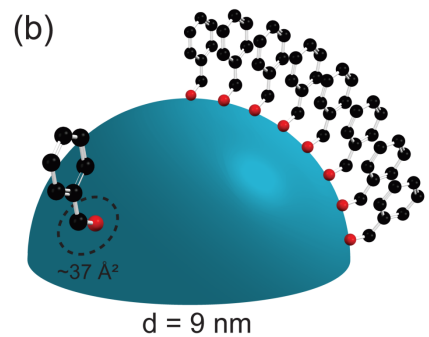

Figure 2.11 Schematic representation of benzyl alcohol molecules attached to BTO surface for different particle diameters. (a) $3 \mathrm{~nm}$ : high surface curvature - low packing density; (b) 9 $\mathrm{nm}$ : low surface curvature - high packing density. The space occupied by one benzyl alcohol on the BTO surface is $\sim 37 \AA^{2}$. Effects such as molecule-molecule interactions, molecule rotations, electronegativity of the side groups, stacking etc., were not taken into account.

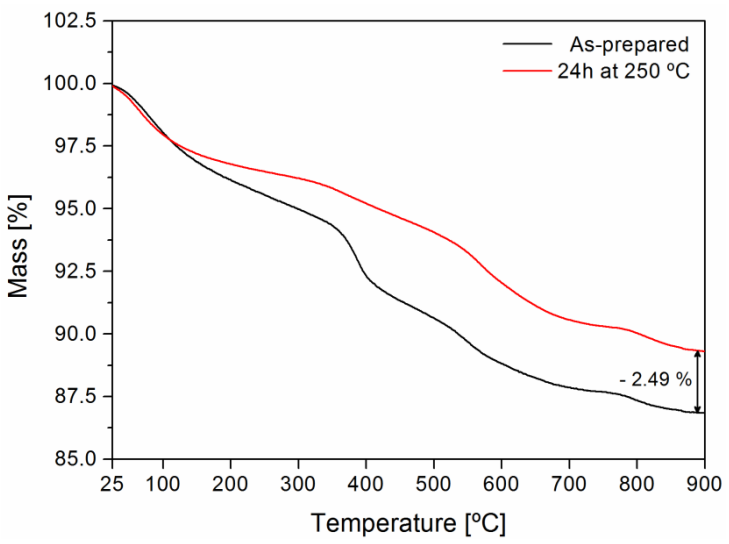

Figure 2.12 Thermogravimetric analysis of a BTO sample synthesized at $60{ }^{\circ} \mathrm{C}$ (red line), and after heat treatment at $250{ }^{\circ} \mathrm{C}$ for $24 \mathrm{~h}$ (black line). The weight loss of $\sim 7.5 \%$ between 400 and $700{ }^{\circ} \mathrm{C}$ is probably due to loss of organic moieties such as unreacted alkoxide precursors, and the curing of hydroxyl defects. Since the samples were heated dynamically, mass loss is typically observed at higher temperatures than normal for processes like e.g. adsorbed/chemisorbed water.

Thermogravimetric analysis of BTO powders heat-treated at $250{ }^{\circ} \mathrm{C}$ for $24 \mathrm{~h}$, i.e. above the boiling point of $205^{\circ} \mathrm{C}$ of benzyl alcohol, and as-prepared samples showed a weight difference of approximately $2.5 \%$, see Figure 2.12 . This value is fairly close to the estimated weight loss, and indicates that benzyl alcohol may indeed have been present on as-prepared samples. ${ }^{[37]}$ I also observed that the color of as-prepared BTO changed from a slightly yellowish to white upon heat treatment at $250{ }^{\circ} \mathrm{C}$. This also indicates that an organic moiety was initially attached to the surface of the crystallites. 


\subsection{Conclusions}

Nano-sized crystalline barium titanate powders were successfully synthesized at very low temperatures $\left(23-78{ }^{\circ} \mathrm{C}\right)$ through an alkoxide-hydroxide precipitation reaction of a modified titanium alkoxide precursor in benzyl alcohol and barium hydroxide octahydrate. My experimental results and simple computational models show that benzyl alcohol plays a crucial role throughout the reaction, from the mixing and modification of the precursor to the formation and growth of the crystalline phase. The phenylmethoxy ligands from the solvent medium stabilized the Ti precursor by steric hindrance, and allowed its subsequent controlled hydrolysis from the hydrated water released by the Ba precursor. The formation of the crystalline phase was dependent on the reaction temperature, and associated with the diffusivity of the $\mathrm{Ba}^{2+}$ ions into the amorphous $\mathrm{TiO}_{\mathrm{x}}$ matrix. The crystallite sizes, however, were found to be independent of the reaction temperatures. I hypothesized that crystal growth beyond a certain size was hampered by the stabilizing phenylmethoxy groups on the surface of the crystallites. 


\subsection{Bibliography}

[1] P. P. Phule, S. H. Risbud, Low-temperature synthesis and processing of electronic materials in the BaO-TiO2 system. J. Mater. Sci. 1990, 25, 1169-1183.

[2] C. Pithan, D. Hennings, R. Waser, Progress in the synthesis of nanocrystalline BaTiO3 powders for MLCC. Int. J. Appl. Ceram. Technol. 2005, 2, 1-14.

[3] M. Niederberger, G. Garnweitner, N. Pinna, M. Antonietti, Nonaqueous and halide-free route to crystalline $\mathrm{BaTiO} 3, \mathrm{Sr} T i \mathrm{O} 3$, and $(\mathrm{Ba}, \mathrm{Sr}) \mathrm{TiO} 3$ nanoparticles via a mechanism involving $\mathrm{C}-\mathrm{C}$ bond formation. J. Am. Chem. Soc. 2004, 126, 9120-9126.

[4] R. N. Viswanath, S. Ramasamy, Preparation and ferroelectric phase transition studies of nanocrystalline BaTiO3. Nanostruct. Mater. 1997, 8, 155-162.

[5] S. Yoon, S. Baik, M. G. Kim, N. Shin, Formation mechanisms of tetragonal barium titanate nanoparticles in alkoxide-hydroxide sol-precipitation synthesis. J. Am. Ceram. Soc. 2006, 89, 18161821.

[6] M. H. Frey, D. A. Payne, Synthesis and processing of barium titanate ceramics from alkoxide solutions and monolithic gels. Chem. Mater. 1995, 7, 123-129.

[7] S. S. Flaschen, An aqueous synthesis of barium titanate. J. Am. Chem. Soc. 1955, 77, 6194.

[8] T. M. Stawski, S. A. Veldhuis, O. F. Göbel, J. E. Ten Elshof, D. H. A. Blank, Effects of reaction medium on the phase synthesis and particle size evolution of BaTiO3. J. Am. Ceram. Soc. 2010, 93, 3443-3448.

[9] C. J. Brinker, G. W. Scherer, Sol-gel science: the physics and chemistry of sol-gel processing, Academic Press, Inc, San Diego, CA 1990.

[10] J. Livage, M. Henry, C. Sanchez, Sol-gel chemistry of transition metal oxides. Prog. Solid State Chem. 1988, 18, 259-341.

[11] J. Livage, C. Sanchez, Sol-gel chemistry. J. Non-Cryst. Solids 1992, 145, 11-19.

[12] C. Sanchez, J. Livage, M. Henry, F. Babonneau, Chemical modification of alkoxide precursors. J. Non-Cryst. Solids 1988, 100, 65-76.

[13] S. Doeuff, M. Henry, C. Sanchez, J. Livage, Hydrolysis of titanium alkoxides: Modification of the molecular precursor by acetic acid. J. Non-Cryst. Solids 1987, 89, 206-216.

[14] M. Nabavi, S. Doeuff, C. Sanchez, J. Livage, Chemical modification of metal alkoxides by solvents: A way to control sol-gel chemistry. J. Non-Cryst. Solids 1990, 121, 31-34.

[15] V. G. Kessler, The chemistry behind the sol-gel synthesis of complex oxide nanoparticles for bio-imaging applications. J. Sol-Gel Sci. Technol. 2009, 51, 264-271. 
[16] V. G. Kessler, G. I. Spijksma, G. A. Seisenbaeva, S. Håkansson, D. H. A. Blank, H. J. M. Bouwmeester, New insight in the role of modifying ligands in the sol-gel processing of metal alkoxide precursors: A possibility to approach new classes of materials. J. Sol-Gel Sci. Technol. 2006, 40, 163179.

[17] U. Schubert, Organically modified transition metal alkoxides: Chemical problems and structural issues on the way to materials syntheses. Acc. Chem. Res. 2007, 40, 730-737.

[18] U. Schubert, Chemical modification of titanium alkoxides for sol-gel processing. J. Mater. Chem. 2005, 15, 3701-3715.

[19] T. Sugimoto, X. Zhou, A. Muramatsu, Synthesis of uniform anatase TiO2 nanoparticles by gel-sol method: 1. Solution chemistry of $\mathrm{Ti}(\mathrm{OH}) \mathrm{n}(4-\mathrm{n})+$ complexes. J. Colloid Interface Sci. 2002, 252, 339-346.

[20] S. Yoon, S. Baik, M. G. Kim, N. Shin, I. Kim, Synthesis of tetragonal barium titanate nanoparticles via alkoxide-hydroxide sol-precipitation: Effect of water addition. J. Am. Ceram. Soc. 2007, 90, 311-314.

[21] T. M. Stawski, S. A. Veldhuis, O. F. Göbel, E. Podstawka-Proniewicz, J. E. Ten Elshof, Electron microscopy study of intragranular nanoporosity and the occurrence of local structural disorder in cubic $\mathrm{BaTiO} 3$ nanopowders from alkoxidehydroxide precipitation process. Ceram. Int. 2012, 38, 6911-6917.

[22] C. A. Schneider, W. S. Rasband, K. W. Eliceiri, NIH Image to ImageJ: 25 years of image analysis. Nat. Methods 2012, 9, 671-675.

[23] W. Bras, I. P. Dolbnya, D. Detollenaere, R. Van Tol, M. Malfois, G. N. Greaves, A. J. Ryan, E. Heeley, Recent experiments on a combined small-angle/wide-angle X-ray scattering beam line at the ESRF. J. Appl. Crystallogr. 2003, 36, 791-794.

[24] A. V. Marenich, R. M. Olson, C. P. Kelly, C. J. Cramer, D. G. Truhlar, Self-consistent reaction field model for aqueous and nonaqueous solutions based on accurate polarized partial charges. J. of Chem. Theory Comput. 2007, 3, 2011-2033.

[25] H. D. Lutz, W. Eckers, H. Christian, B. Engelen, Hydrates of barium hydroxide. Preparation, thermal decomposition and X-ray data. Thermochim. Acta 1981, 44, 337-343.

[26] Y. Sakata, S. Shiraishi, M. Otsuka, Characterization of dehydration and hydration behavior of calcium lactate pentahydrate and its anhydrate. Colloids Surf., B 2005, 46, 135-141.

[27] N. Koga, Y. Suzuki, T. Tatsuoka, Thermal dehydration of magnesium acetate tetrahydrate: Formation and in situ crystallization of anhydrous glass. J. Phys. Chem. B 2012, 116, 14477-14486. 
[28] P. R. Perrier, S. R. Byrn, Dehydration of glucuronamide hydrate. Confirmation of the predicted influence of crystal packing on dehydration reactions. J. Org. Chem. 1982, 47, 4677-4680.

[29] F. Babonneau, S. Doeuff, A. Leaustic, C. Sanchez, C. Cartier, M. Verdaguer, XANES and EXAFS Study of Titanium Alkoxides. Inorg. Chem. 1988, 27, 3166-3172.

[30] W. Bras, An SAXS/WAXS Beamline at the ESRF and Future Experiments. J. Macromol. Sci., Phys. 1998, 37, 557-565.

[31] N. Stribeck, X-Ray Scattering of Soft Matter, Springer Berlin Heidelberg, Berlin 2007.

[32] M. Sacerdoti, V. Bertolasi, V. Ferretti, C. Accorsi, A redetermination of the crystal structure of barium hydroxide octahydrate $\mathrm{Ba}(\mathrm{OH}) 2 \cdot 8 \mathrm{H} 2 \mathrm{O}$. Z. Kristallogr. 1990, 192, 111-118.

[33] J. O. Eckert Jr, C. C. Hung-Houston, B. L. Gersten, M. M. Lencka, R. E. Riman, Kinetics and mechanisms of hydrothermal synthesis of barium titanate. J. Am. Ceram. Soc. 1996, 79, 2929-2939. [34] M. Niederberger, M. H. Bartl, G. D. Stucky, Benzyl alcohol and titanium tetrachloride - A versatile reaction system for the nonaqueous and low-temperature preparation of crystalline and luminescent titania nanoparticles. Chem. Mater. 2002, 14, 4364-4370.

[35] M. Niederberger, N. Pinna, J. Polleux, M. Antonietti, A general soft-chemistry route to perovskites and related materials: Synthesis of $\mathrm{BaTiO} 3, \mathrm{BaZrO} 3$, and $\mathrm{LiNbO} 3$ nanoparticles. Angew. Chem. Int. Ed. 2004, 43, 2270-2273.

[36] D. J. Cooke, D. Eder, J. A. Elliott, Role of benzyl alcohol in controlling the growth of TiO2 on carbon nanotubes. J. Phys. Chem. C 2010, 114, 2462-2470.

[37] K. Page, T. Proffen, M. Niederberger, R. Seshadri, Probing local dipoles and ligand structure in BaTiO3 nanoparticles. Chem. Mater. 2010, 22, 4386-4391. 


\subsection{Supporting Information}

\subsubsection{Computational Modeling - Phenylmethoxy Ligand Exchange}

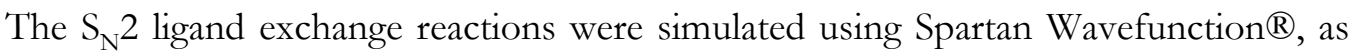
described in Section 2.2.4 of the main text. Energy profiles of the four consecutive ligand exchanges were derived for both the phenylmethoxy and acetate ligand exchange reactions. The activation energy $\left(E_{A}\right)$ and Gibbs free energy $(\Delta G)$ were calculated from the obtained energy profiles.

For every consecutive ligand exchange, an energy profile was derived. In the simulation, the phenylmethoxy ligand approached the $\left[\mathrm{Ti}\left(\mathrm{O}^{2} \mathrm{Pr}\right)_{4}\right]$ precursor. For every reaction coordinate (i.e. the distance between the oxygen atom of the nucleophile and the central Ti atom), the structure was optimized, and the total energy of the system calculated (see Figure S2.1). After an initial minimum energy during the approach of the phenylmethoxy ligand, a maximum energy state was reached, from which $E_{\mathrm{A}}$ could be derived. At this point, the Ti atom had expanded its coordination number, and the reaction intermediate was formed. Subsequently, ligand exchange took place, and the isopropoxide ligand moved away from the Ti atom. A minimum energy state was reached from which $\Delta G$ could be derived. For every following ligand exchange, the activation energy increased, due to less rotational freedom and more steric hindrance of the phenylmethoxy ligands compared to the original iso-propoxide ligands (see Figure S2.2 and Table 2.1 in the main text). As a result, no Gibbs free energy was gained after the third exchange; more energy is needed to overcome the energy barrier. Although the simulations did not take the chelating/bidentate binding of the acetic acid into account, the results coincided well with ${ }^{1} \mathrm{H}$ NMR measurements described in Section 2.3.2 of the main text. 


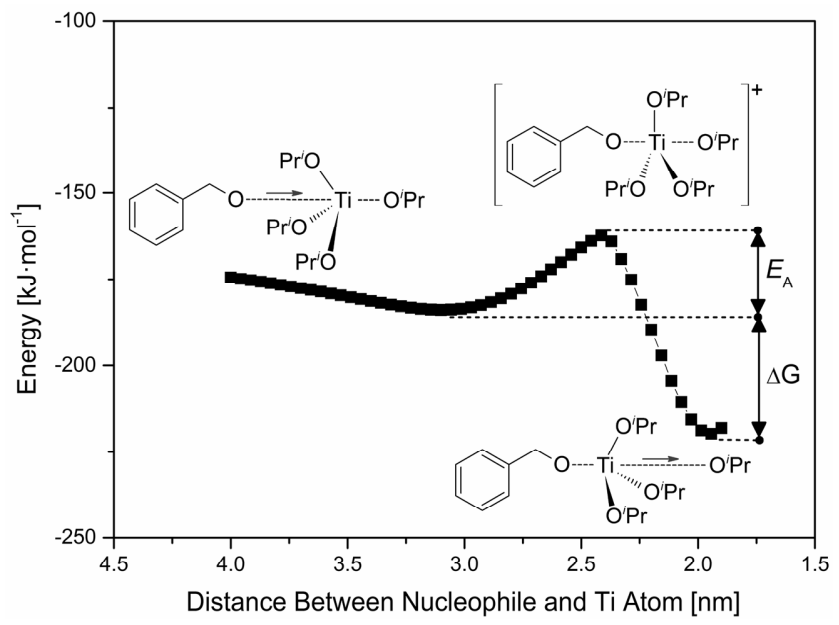

Figure S2.1 Calculated energy profile derived from the first simulated ligand exchange reaction between $\left[\mathrm{Ti}^{2}\left(\mathrm{O}^{2} \mathrm{Pr}\right)_{4}\right]$ and the phenylmethoxy ligand from the parent solvent.

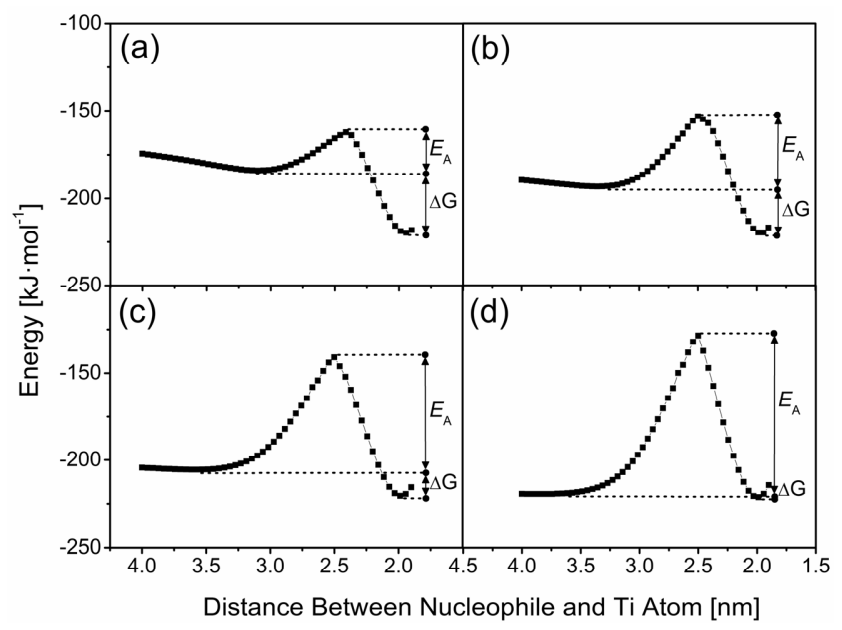

Figure S2.2 Four calculated energy profiles derived from the simulated ligand exchange reactions between the $\left[\mathrm{Ti}^{2}\left(\mathrm{O}^{2} \mathrm{Pr}\right)_{4}\right]$ precursor and the phenylmethoxy ligand of the benzyl alcohol. Graphs (a)-(d) correspond to the consecutive ligand exchange reactions as summarized by Equation 2.4 in the main text. 


\subsubsection{Crystal Structure of $\mathrm{Ba}(\mathrm{OH})_{2} \cdot 8 \mathrm{H}_{2} \mathrm{O}$}

The $d$-spacing of $16.09 \AA$, corresponding to the Bragg reflection $q \sim 3.9 \mathrm{~nm}^{-1}$ from the SAXS measurements, is related to the $\mathrm{Ba}-\mathrm{Ba}$ distance within the (101) crystal plane of $\mathrm{Ba}(\mathrm{OH})_{2} \cdot 8 \mathrm{H}_{2} \mathrm{O}$ (ICSD \# 33741)..$^{[\mathrm{S} 1]}$ The crystal has a monoclinic space group P $21 / \mathrm{c}$ (nr. 14), with cell parameters: $\mathrm{a}=9.274(2) \AA, \mathrm{b}=9.260(2) \AA, \mathrm{c}=11.817(3) \AA, \alpha=\gamma=$ $90^{\circ}$, and $\beta=98.95(2)^{\circ}$.

(a)

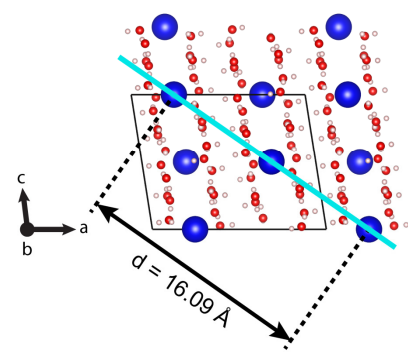

(b)

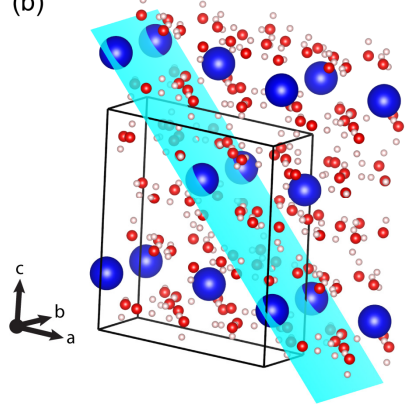

Figure S2.3 Two representations of the $\mathrm{Ba}(\mathrm{OH})_{2} \cdot 8 \mathrm{H}_{2} \mathrm{O}$ crystal. (a) side view; (b) $3 \mathrm{D}$ view. The (101) crystal plane in which the $d$-spacing of $16.09 \AA$ was found, is highlighted in light blue. The images were made using the VESTA software package (version 3). ${ }^{[\text {[S2] }}$

\section{Bibliography}

[S1] M. Sacerdoti, V. Bertolasi, V. Ferretti, C. Accorsi, A redetermination of the crystal structure of barium hydroxide octahydrate $\mathrm{Ba}(\mathrm{OH}) 2 \cdot 8 \mathrm{H} 2 \mathrm{O}$. Z. Kristallogr. 1990, 192, 111-118.

[S2] K. Momma, F. Izumi, VESTA 3 for three-dimensional visualization of crystal, volumetric and morphology data. J. Appl. Crystallogr. 2011, 44, 1272-1276. 



\title{
Kinetics of Barium Titanate Nanocrystal Formation in Benzyl Alcohol
}

\begin{abstract}
Time-resolved small-angle X-ray scattering and X-ray diffraction were successfully employed to elucidate the reaction mechanism of barium titanate nanocrystal formation in benzyl alcohol below $78^{\circ} \mathrm{C}$. The amorphous-to-crystalline transformation is predominantly determined by the total amount of water released from the barium hydroxide octahydrate precursor, and different rate-limiting regimes were found. Sufficiently high water concentrations enabled rapid succession of nucleation, crystallization, and growth events, and the formation rate was only limited by the dehydration rate of the Ba precursor. Water lean conditions resulted in impeded gel formation, and only gradual nucleation, crystallization, and growth process was observed. As a result of an improved understanding of the effect of varying reaction conditions, elementary boundary conditions could be set up for better control of the barium titanate nanocrystal synthesis.
\end{abstract}




\subsection{Introduction}

Barium titanate (BTO) is a technologically important material, which finds its application mainly in multi-layer ceramic capacitors (MLCC) as a high- $k$ dielectric material. In order to comply with the current industrial trend towards device miniaturization, new synthesis routes yielding finer (monodisperse) starting powders are necessary to overcome the down-scaling limits of the commercially used tape-casting techniques.

In the last decades, wet-chemical synthesis routes have received much attention since highly pure, nanometer-sized BTO can be formed at low temperatures with control on the molecular level. ${ }^{[1-10]}$ However, the question how reaction parameters influence the formation of these particles remains unanswered.

In several studies, performed under hydrothermal conditions, it was attempted to describe the underlying formation mechanism. Two main pathways have been described: (1) in-situ transformation, ${ }^{[1-14]}$ and (2) dissolution-precipitation. ${ }^{[15-20]}$ The first model assumes the reaction of $\mathrm{Ba}^{2+}$ ions with $\mathrm{TiO}_{2}$, forming a core-shell structure. Crystallite growth proceeds via the diffusion of $\mathrm{Ba}^{2+}$ through a $\mathrm{TiO}_{2}$ shell until the titania core is depleted. The other mechanism is based on the local dissolution of $\mathrm{TiO}_{2}$ into hydrolyzed Ti species and the subsequent reaction with $\mathrm{Ba}^{2+}$ ions in their vicinity. Although evidence is found in favor of both mechanisms, discrepancies between the various studies exist, and comparison remains challenging due to the variation in precursors and reaction conditions.

In this chapter, I report the effect of varying reaction conditions (concentration, temperature, water content, and precursor stoichiometry) on the reaction rate and mechanism of BTO nanoparticle formation; prepared via alkoxide-hydroxide precipitation in benzyl alcohol under near ambient conditions (see Chapter 2). Coprecipitation reactions involve concomitant nucleation, growth, and coarsening processes, in which the individual reaction processes are obscured. ${ }^{[21]}$ Moreover, the fundamental difference between my nonaqueous synthetic approach and the aqueous hydrothermal syntheses of BTO obstructs direct comparison with the reaction mechanisms described above.

The amorphous-to-crystalline phase transition of barium titanate was monitored using time-resolved small/wide angle X-ray scattering (SAXS/WAXS) and X-ray diffraction (XRD). The effect of varying reaction conditions on the nucleation, crystallization, and growth phenomena during synthesis were derived using form-free and/or model independent analysis method of SAXS curves. The rate and extent of crystalline 
phase formation was found to be predominantly determined by the amount of water present. Conversely, for off-stoichiometric precursor ratios a more complex relationship between reaction parameters exists. Besides the total water concentration, also changes in diffusion length between $\mathrm{Ba}^{2+}$ ions and $\mathrm{Ti}$ atoms were found to control the crystallization rate.

\subsection{Model Independent Data Analysis}

\subsubsection{Small-angle X-ray Scattering}

A sample, which is either particulate or bicontinuous (nonparticulate) in nature and at the same time exhibits nanometer-range electronic density variations, will scatter photons from the monochromatic collimated X-ray beam that passes through this sample. These density fluctuations may arise from a homogeneous suspension of particles (with electron density $\rho$ ) in a solvent matrix of different electron density, $\rho_{0}$, or similarly from porosity within a particle. The recorded scattering intensity, $I(q)$, is proportional to the square of electron density difference, $(\Delta \rho)^{2}$, between the particles and the solvent matrix. Conventionally, $I(q)$ is plotted versus the magnitude of the scattering vector, $q$, and is related to the scattering angle $(2 \theta)$ and the wavelength $(\lambda)$ of the incident beam via:

$$
q=\frac{4 \pi}{\lambda} \sin \theta
$$

For particulate systems the scattered intensity can be expressed as a product of the number density of particles, $N$, the scattering contrast, $(\Delta \rho)^{2}$, particle volume, $V$, and a single particle form factor $P(q)$.

$$
I(q)=N \cdot(\Delta \rho)^{2} \cdot V^{2} \cdot P(q)
$$

One can also define $I_{0}=N \cdot(\Delta \rho)^{2} \cdot V^{2}$ as a convenient parameter to scale the form factor against the scattered intensity, since $P(q \rightarrow 0)=1$. Typically, form factors express the shape of individual scatterers and the appropriate $P(q)$ functions are derived for a variety of simple geometries. ${ }^{[22,23]}$ Furthermore, more complicate assemblies of particles are often referred to as form factors, like e.g. mass-fractal aggregates, ${ }^{[2]}$ or polymer coils, ${ }^{[23]}$ as long as the individual assemblies are non-interacting and monodisperse in 
nature. Here, the entire assembly is treated as a single particle in which the form factor describes its internal structure. In a common case (such as considered in here), when the shape of particles is approximated by spheres of radius, $R$ the form factor $P(q)$ product is expressed as:

$$
P(q, R)=\left(3 \frac{\sin (q R)-q R \cdot \cos (q R)}{(q R)^{3}}\right)^{2}
$$

For polydisperse spherical particles, however, Eq. (3.3) is no longer valid, and the size distribution function $D(r)$ has to be included in the expression for the form factor. The averaged form factor of spheres is then given by Eq. (3.4):

$$
\langle P(q, \bar{R}, \sigma)\rangle=\frac{\int_{0}^{\infty} D(q, \bar{R}, \sigma) P(q, r) r^{3 d} d r}{\int_{0}^{\infty} D(q, \bar{R}, \sigma) r^{3 d} d r}
$$

where $\bar{R}$ denotes the averaged radius, and $\sigma$ is the variance of the distribution. The parameter $d$ takes either values of 0,1 , or 2 . Depending on the value of $d$, the average radius yields the intensity, volume (mass), or number weighted value of $\bar{R}$, respectively. In such case, $I_{0}$ is described as $I_{0}=N \cdot(\Delta \rho)^{2} \cdot\left\langle V^{2}\right\rangle$, where $\left\langle V^{2}\right\rangle$ denotes the distribution-averaged squared volume of a spherical particle, because $\langle P(q \rightarrow 0\rangle=1$.

In order to characterize a system of polydisperse spherical particles, typically, a certain form of $D(r)$ is assumed and the values of $\overline{\mathrm{R}}$ and $\sigma$ are obtained from fitting the expression to the intensity data. The choice of a particular $D(r)$ function is usually limited to only a small number of mathematical expressions, which may potentially describe a given physical phenomenon. In quickly evolving and highly polydisperse systems, a simple form of $D(r)$ is often not expected, and multimodal distributions have to be considered. A form-free distribution would then be far more useful for that kind of particulate systems. This can be achieved by e.g. the structure interference methods and their Monte Carlo derivatives. ${ }^{[25,26]}$ Pauw et al. have recently released a software package that allows for the finding of form-free size distribution histograms. ${ }^{[27]}$ 


\subsubsection{Scattering Invariant}

Most of the scattering functions are based on assumptions regarding the particle shape (i.e. $P(q)$ ). The scattering invariant (or Porod invariant) is only dependent on the total scattering volume, and thus remains constant for a given concentration. ${ }^{28]}$ Consequently, the extent of the total particle volume evolution during synthesis can be monitored. The scattering invariant, $Q_{i n n}$, is determined by:

$$
Q_{i n v}=\int_{0}^{\infty} q^{2} \cdot I(q) d q
$$

The high intensity measured at low $q$, caused by scattering of the largest particles (i.e. large volume contribution), is thus normalized by multiplying with $q^{2}$. Additionally, the average scattering length $\langle L\rangle$, scattering surface $\langle A\rangle$, and scattering volume (or Porod volume) $V_{p}$, of the investigated system are determined using the scattering invariant:

$$
\begin{gathered}
\langle L\rangle=\frac{\pi}{Q_{i n v}} \cdot \int_{0}^{\infty} q \cdot I(q) d q \\
\langle A\rangle=\frac{2 \pi}{Q_{i n v}} \cdot \int_{0}^{\infty} I(q) d q \\
V_{p}=\frac{2 \pi^{2}}{Q_{i n v}} \cdot I_{0}
\end{gathered}
$$

Although the calculation of the invariant is straightforward, in practice it is difficult to measure from $q \rightarrow 0$ to $q \rightarrow \infty$. If I consider the measured $q$-range as: $q_{\mathrm{L}}<q<q_{\mathrm{H}}$, the contributions at $q_{L} \rightarrow 0$ and $q_{L} \rightarrow \infty$ can be extrapolated using the Guinier approximation $^{[22]}$ and Porod's law, ${ }^{[28]}$ respectively. In this manner, good estimates of $Q_{i n \nu}$ can be determined. A representation of the number density of the emerging phase (with changing electron density contrast) is obtained by replacing $I_{0}$ by $N \cdot(\Delta \rho)^{2} \cdot\left\langle V^{2}\right\rangle$ in Eq. (3.8), resulting in $Q_{i n v}=2 \pi^{2} \cdot N \cdot(\Delta \rho)^{2} \cdot\langle V\rangle$. Subsequent division by $I_{0}$ leads to:

$$
N \cdot(\Delta \rho)^{2}=\frac{1}{4 \pi^{4}} \cdot \frac{Q_{i n v}{ }^{2}}{I_{0}}
$$




\subsection{Experimental Section}

\subsubsection{Chemicals and Materials}

Titanium (IV) iso-propoxide $\left.\left(\mathrm{Ti}\left[\left(i-\mathrm{OC}_{3} \mathrm{H}_{7}\right)\right]_{4}\right), 99.999 \%\right)$, barium hydroxide octahydrate $\left(\mathrm{Ba}(\mathrm{OH})_{2} \cdot 8 \mathrm{H}_{2} \mathrm{O}, 98.0 \%\right)$, and 2-propanol (99.5\%) were purchased from Sigma-Aldrich. Benzyl alcohol (99.0\%) was acquired from Acros. All chemicals were used as-received from the suppliers without any further purification. Both titanium (IV) iso-propoxide and benzyl alcohol were stored and handled in a water-free environment $(<0.1 \mathrm{ppm}$ $\left.\mathrm{H}_{2} \mathrm{O}\right)$.

\subsubsection{Formation of Crystalline BTO}

Stoichiometric amounts of barium hydroxide octahydrate were added to 0.05-0.2 $\mathrm{mol} \cdot \mathrm{dm}^{-3}$ solutions of titanium (IV) iso-propoxide in benzyl alcohol. While stirring, the reaction mixture was heated to $78{ }^{\circ} \mathrm{C}$. At various time intervals, samples were taken from the reaction vessel and thermally quenched to stop the reaction. Subsequently, the samples were stored at $-18{ }^{\circ} \mathrm{C}$. The samples measured by X-ray diffraction (XRD), were centrifuged using a Sigma 1-14 centrifuge at $14800 \mathrm{rpm}$ for $15 \mathrm{~min}$. The supernatant benzyl alcohol phase was removed, the sample was rinsed with 2-propanol, dried in air, and subsequently measured with XRD. More information on the synthesis can be found elsewhere (see Chapter 2). ${ }^{[7]}$

\section{Influence Reaction Parameters}

The effect of various experimental conditions on the reaction mechanism was investigated at $78^{\circ} \mathrm{C}$ by changing the $\left[\mathrm{Ti}\left(\mathrm{O}^{2} \mathrm{Pr}\right)_{4}\right]$ precursor concentration $(0.05,0.075,0.1$, and $\left.0.2 \mathrm{~mol} \cdot \mathrm{dm}^{-3}\right)$, the Ba:Ti ratio $(0.5: 1,1: 1$, and $2: 1)$, and the water content $\left(\left[\mathrm{H}_{2} \mathrm{O}\right] /[\mathrm{Ti}]=\right.$ $h=3.5,7$ and 14). Also, the effect of pre-hydrolysis (i.e. water was added to the Ti precursor solution prior to $\mathrm{Ba}(\mathrm{OH})_{2} \cdot 8 \mathrm{H}_{2} \mathrm{O}$ addition) with an equivalent of 14 moles $\mathrm{H}_{2} \mathrm{O}$ per Ti was investigated.

\subsubsection{Sample Characterization}

\section{Time-resolved X-ray Diffraction}

The synthesized samples were characterized with X-ray powder diffraction (Cu K $\alpha$ irradiation) to confirm the formation of the crystalline $\mathrm{BaTiO}_{3}$ phase using an $\mathrm{X}$ 'Pert 
Powder Pro (PANalytical, Almelo, The Netherlands) with a 1D PIXcel detector. Scans from $2 \theta=27-35^{\circ}$ of the (110) peak were measured with step sizes of $0.026^{\circ}$ and $600 \mathrm{~s}$ per step. The patterns were further analyzed using the X'Pert Highscore Plus software package (version 3.0e).

\section{Time-resolved Small Angle X-ray Scattering (SAXS)}

SAXS experiments were performed on the Dutch-Belgian beam line (BM-26B) of the European Synchrotron Radiation Facility (ESRF) in Grenoble, France. ${ }^{[29]}$ The X-ray beam energy $(16 \mathrm{keV} ; \lambda=0.0776 \mathrm{~nm})$ was positioned on the corner of a $2 \mathrm{D}$ Pilatus $1 \mathrm{M}$ detector to maximize the range of scattering angles. Ag behenate was used to calibrate the absolute scattering vector $q$-range $\left(\mathrm{nm}^{-1}\right)$ in my experiments. The detector was placed at a distance of $1.5 \mathrm{~m}$ from the sample, which allowed us to record the effective scattering vector magnitude in the range of $0.16<q<6.96 \mathrm{~nm}^{-1}$. Samples were measured in sealed glass capillaries ( $\varnothing=1.5 \mathrm{~mm}$; glass no. 50; Hilgenberg, Malsfeld, Germany) at room temperature. The absolute scattered intensity for all samples was calibrated with distilled water. ${ }^{[30]}$ The absolute scattered intensity was not determined for experiments performed at 45 and $150{ }^{\circ} \mathrm{C}$, and the values for $\mathrm{N} \cdot(\Delta \rho)^{2},\langle A\rangle / V_{p}$, and $\langle L\rangle$ may deviate slightly. The data were only used to demonstrate the observed trends. For all measurements, the scattering of an empty capillary was subtracted as a background signal.

\section{Particle Size Distribution (PSD)}

Form-free particle size distributions were obtained from the scattering curves using the Monte Carlo based software package McSAS. ${ }^{[27]}$ All scattering curves were fitted in a range of $0.16<q<6.96 \mathrm{~nm}^{-1}$, using a convergence criterion of 5, with 25 calculating repetitions, and 200 contributions (see Supporting Information for exemplary fits).

\section{High-Resolution Transmission Electron Microscopy (HR-TEM)}

Samples were investigated by high-resolution transmission electron microscopy (HRTEM; Philips CM300ST-FEG) with an acceleration voltage of $285 \mathrm{keV}$ using a Gatan Ultrascan 1000 CCD camera and further analyzed using the ImageJ processing software package (version $1.47 \mathrm{q}) \cdot{ }^{[31]}$ 
Selected-area electron diffraction (SAED) images were acquired with 5-10 s exposure time (10 frames) from typical areas of approximately $0.9 \times 0.9 \mu \mathrm{m}^{2}$ and $0.2 \times 0.2 \mu \mathrm{m}^{2}$ for [Ti] $\leq 0.075 \mathrm{~mol} \cdot \mathrm{dm}^{-3}$ and $[\mathrm{Ti}] \geq 0.1 \mathrm{~mol} \cdot \mathrm{dm}^{-3}$, respectively.

\subsection{Results and Discussion}

\subsubsection{General Overview}

The extent of crystalline BTO phase formation was followed by measuring the increase of the integrated (110) peak area at $2 \theta \sim 31.3^{\circ}$, see Figure 3.1a. As the crystallization process started, both the bulk crystalline volume and crystallite sizes increased rapidly, after which both reached a plateau. In addition, the combination of SAXS/WAXS allowed also for the monitoring of structural changes in the amorphous stage, yielding greater insight in the formation of the crystalline phase. Figure $3.1 \mathrm{~b}$ shows time-resolved SAXS curves for a reaction performed at $78{ }^{\circ} \mathrm{C}$. The correlation peak at $q \sim 2.4 \mathrm{~nm}^{-1}$ shows an instantaneous shift to $q \sim 1.8 \mathrm{~nm}^{-1}$ upon appearance of a crystalline phase $(t=$ $20 \mathrm{~min}$; blue curves). After 40 min of reaction, a further shift to $q \sim 1.3 \mathrm{~nm}^{-1}$ is observed for the correlation peak. Concurrently, the scattered intensity of the system increased by a factor of $\sim 1.4$. Extended reaction times showed a further shift of the correlation peak to lower scattering angles, until a constant value of $q \sim 0.3 \mathrm{~nm}^{-1}$ was reached. At the end of the reaction, the absolute scattered intensity was a factor of $\sim 33$ higher than at the time of amorphous-to-crystalline transition. Moreover, a large linear regime is visible in the range $0.4<q<2.7 \mathrm{~nm}^{-1}$.

In a Kratky plot (Figure 3.1c), the scattering angle $q$ is plotted versus $q^{2} \cdot I(q)$, where the high contribution in scattered intensity of the largest particles (at low- $q$ ) is normalized. Here, also a distinct difference between the amorphous (black curves) and crystalline phase (blue curves) was observed.

Integration of the data in Figure 3.1c corrected by the extrapolation based on the Guinier approximation for the low- $q$ regime for $0<q<0.16 \mathrm{~nm}^{-1}$ and the extrapolation based on the Porod law for the high- $q$ regime for $6.96<q<\infty \mathrm{nm}^{-1}$ (see Section 3.2.2) yielded the scattering invariant, see Figure 3.1d. Initially, a rapid increase of the scattering invariant was observed. This increase in total scattering volume is most likely related to the growth of crystallites, since a shift of the correlation peak from $q \sim 2.4$ to 
$0.3 \mathrm{~nm}^{-1}$ was observed (Figure 3.1b). After $t \sim 450 \mathrm{~min}$, a plateau was reached, and no further changes in the scattering volume occurred, implying that further crystallite growth did not occur beyond this time. A closer look at Figure 3.1b shows quite different slopes in $I(q)$ for $q<0.2 \mathrm{~nm}^{-1}$. The rather steep increase in $I(q)$ during the first 60 min of the reaction suggests the existence of a large network or gel (with dimensions far greater than observable in the measured $q$-range) in which nucleation and growth of crystallites occurred. In the time interval from 75-150 min, however, the slope was absent, and only small changes in the position of the correlation peak were observed. This suggests that the large network ceased to exist and no significant crystallite growth occurred beyond this time. The sharp inclination observed $>300$ min may be interpreted as clustering of crystallites to aggregate sizes beyond the experimental $q$-range. The presence of a correlation peak at $q \sim 0.3 \mathrm{~nm}^{-1}$, however, suggests that crystallites did not grow further through coalescence, but rather through clustering of discrete crystallites. This agrees well with results from a previous study in which no growth beyond $10 \mathrm{~nm}$ sized crystallites was observed due to the presence of a dense capping layer on the crystallites' surface (see Chapter 2.3.4). In addition, the near-constant values for $Q_{i n v}$ for reaction times $>300$ min proved that no further changes in the scattering volume occurred (Figure 3.1d).
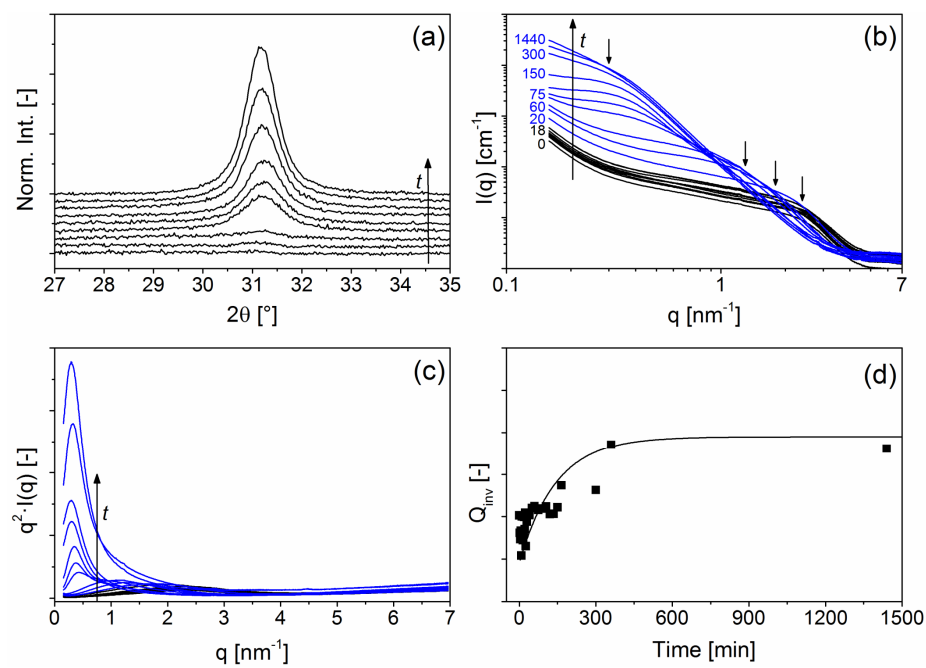

Figure 3.1 Time-resolved data obtained from a reaction performed at $78^{\circ} \mathrm{C}$. (a) Evolution of (110) peak area; (b) Shift of correlation peak to lower $q$ due to transformation from an amorphous (black line) to a crystalline (blue line) phase; correlation peak maxima are indicated by arrows; (c) Kratky plot; (d) scattering invariant as a function of time. 


\subsubsection{Nucleation and Growth}

\section{Particle Size Distribution}

Figure 3.2 shows the particle size distribution (PSD) obtained from SAXS curves for different initial concentrations. It provides insight in the overall reaction pathway. In the early stages of the process, the appearance of a great number of tiny crystallites (1$3 \mathrm{~nm})$ was observed. These sizes coincide well with the sizes obtained from the corresponding position of the correlation peaks in Figure 3.1b (for $1.3<q<2.4 \mathrm{~nm}^{-1}$ ). As the concentration was decreased from 0.2 to $0.075 \mathrm{~mol} \cdot \mathrm{dm}^{-3}$, the total number of smallest crystallites reduced, and crystallization times increased from 20 to 120 minutes, respectively. No crystallization time could be determined for the lowest concentration, due to the lack of a sufficient amount of large crystallites. The reduction of the total number of smallest crystallites does not only depend on the decrease in concentration, but most likely also on the availability of water for hydrolysis. The final crystallite sizes (mean value) for $0.05,0.075,0.1$, and $0.2 \mathrm{~mol} \cdot \mathrm{dm}^{-3}$ were $4.0,5.6,6.4$, and $10.0 \mathrm{~nm}$, respectively.

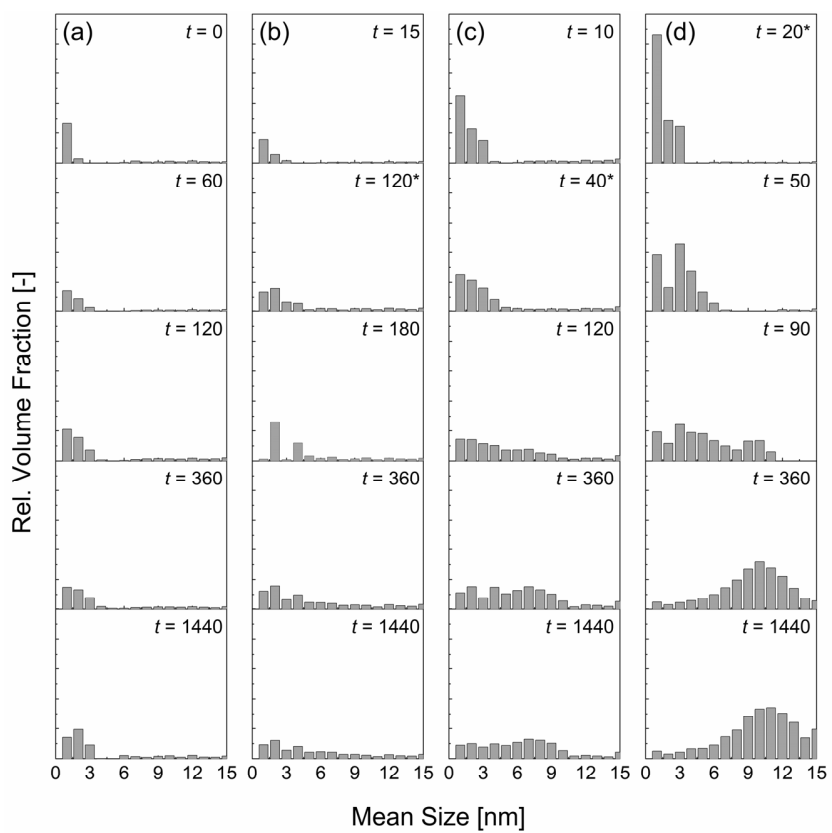

Figure 3.2 Particle size distributions obtained by fitting SAXS curves with the McSAS software, for experiments performed at $78{ }^{\circ} \mathrm{C}$ with a concentration of (a) 0.05 ; (b) 0.075 ; (c) 0.1 ; and (d) $0.2 \mathrm{~mol} \cdot \mathrm{dm}^{-3}$. The time values (in min) denoted with an asterisk correspond to the appearance of the crystalline phase in XRD and WAXS. The y-axes are all equally scaled. 


\section{Phase Formation}

Complementary to the PSD, HR-TEM was used to visualize the size and morphology of the synthesized crystallites (Figure 3.3). After $24 \mathrm{~h}$ of reaction, only a handful of very small crystallites, embedded in an amorphous Ti-based matrix, were formed at 0.05 $\mathrm{mol} \cdot \mathrm{dm}^{-3}$. The amorphous nature of the Ti-based matrix was confirmed with electron diffraction (see Figure 3.3a). At $0.075 \mathrm{~mol} \cdot \mathrm{dm}^{-3}$ more BTO crystallites were formed, however, they were still embedded in an amorphous matrix. Due to the increased amount of crystalline material, a polycrystalline diffraction pattern was obtained (see Figure 3.3b and Supporting Information). A further increase in concentration led to the disappearance of the amorphous network and subsequent growth of the volume fraction of crystalline particles (see Figure 3.3c-d).

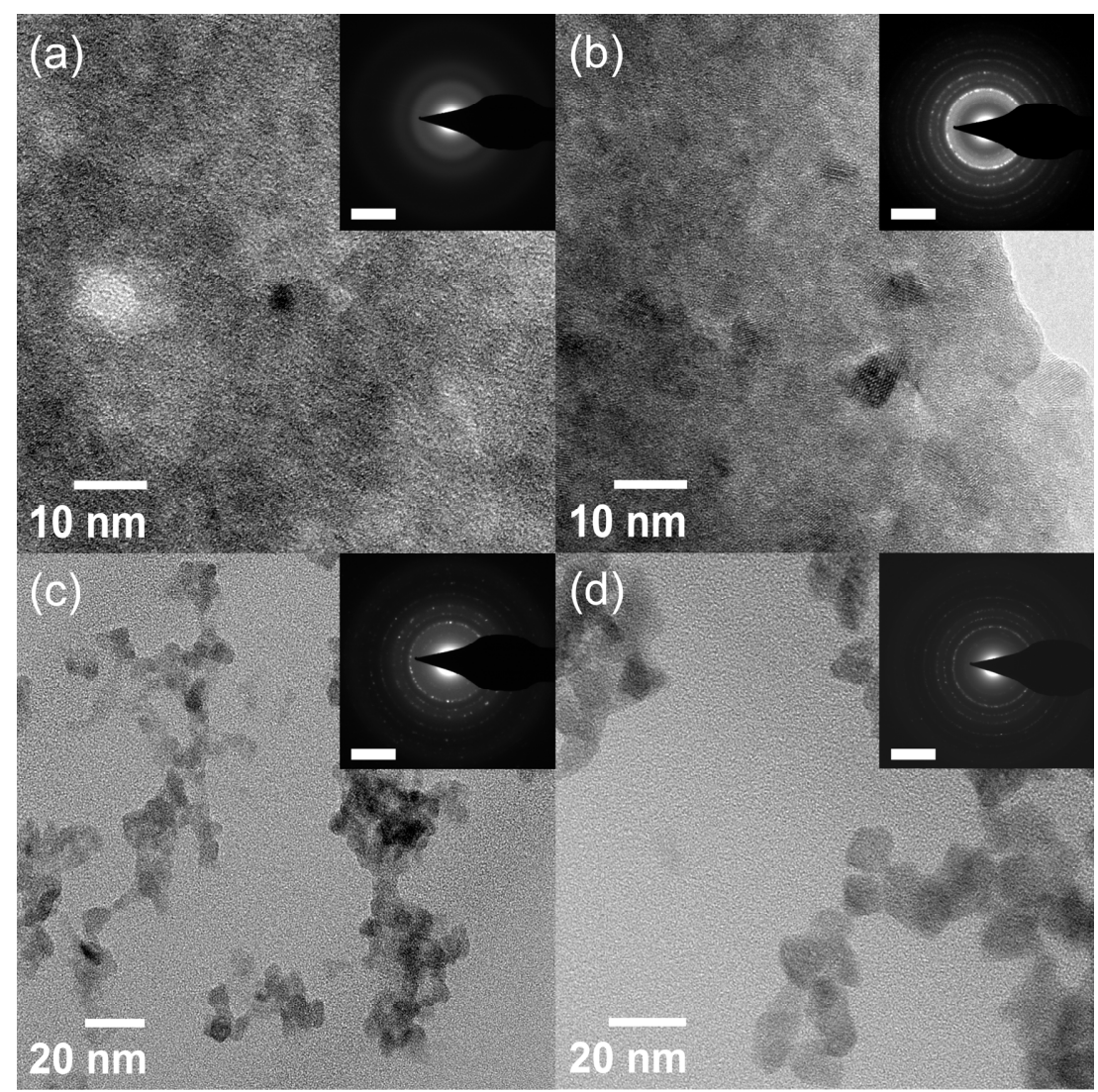

Figure 3.3 HR-TEM images of BTO prepared at $78{ }^{\circ} \mathrm{C}$ for $24 \mathrm{~h}$ using various concentrations: (a) 0.05 ; (b) 0.075 ; (c) 0.1 ; and (d) $0.2 \mathrm{~mol} \cdot \mathrm{dm}^{-3}$. Insets are SAED patterns acquired from typical areas as shown in the images; all scale bars are of $4 \mathrm{~nm}^{-1}$ length. 
MacLaren et al. also observed the consumption of a hydrous Ti gel after prolonged heating at $80{ }^{\circ} \mathrm{C}$ under hydrothermal conditions, ${ }^{[13]}$ albeit that the Ba precursor in their study was dissolved in water, and thus an enormous excess was available for the hydrolysis of Ti. The nano-sized BTO crystals initially formed within the amorphous matrix and subsequently coalesced into larger single crystals after the collapse of the gel. Viviani et al. observed the growth of spherical crystalline particles $(<10 \mathrm{~nm})$ at the expense of larger amorphous particles (ca. 100-200 nm). ${ }^{[32]}$ A crystalline phase was only found in the sub-10 nm-sized particles. The disappearance of the Ti gel in my samples ([Ti] $>0.1$ $\mathrm{mol} \cdot \mathrm{dm}^{-3}$ ) suggests that crystallite growth also occurs at the expense of the amorphous phase. Moreover, prolonged irradiation of the focused electron beam on a single spot induced the crystallization of very small BTO crystallites (observed in sample [Ti] = $0.05 \mathrm{~mol} \cdot \mathrm{dm}^{-3}$; data not shown), suggesting that $\mathrm{Ba}^{2+}$ ions were present within the gel matrix. Given the porous nature of these hydrolyzed Ti networks, high concentrations of adsorbed $\mathrm{Ba}^{2+}$ ions may be expected on the gel's surface. ${ }^{[13,33]}$ Favorable conditions to crystallize may therefore be dependent on the availability of sufficiently high Ba concentrations within the amorphous network. ${ }^{[34]}$

\section{Scattering Invariant}

The scattering invariant provides access to several parameters that enable a better understanding of the nucleation and growth process of BTO in benzyl alcohol. The specific surface area, defined as the ratio between $\langle A\rangle$ and $V_{p}$ provides a measure of the appearance of small nuclei (large $\langle A\rangle / V_{p}$ ) and their subsequent growth into larger clusters/crystallites (low $\langle A\rangle / V_{p}$ ). The number density changes of the emerging new phase(s) can be monitored via Eq. (3.9). Figure 3.4 shows an overview of these parameters in relation to the average crystallite size and scattering length $\langle L\rangle$, Eq. (3.6). The highest measured concentration $\left(0.2 \mathrm{~mol} \cdot \mathrm{dm}^{-3}\right.$; Figure $\left.3.4 \mathrm{~d}\right)$ shows the rapid emergence of a vast number of stable primary clusters, as witnessed by the fast increase in both $N \cdot(\Delta \rho)^{2}$ and $\langle A\rangle / V_{p}$, and their subsequent growth. The peak for $N \cdot(\Delta \rho)^{2}$ at $\sim 65 \mathrm{~min}$ coincides with the disappearance of the gel matrix and the sudden shift of the correlation peak from $q \sim 1.3$ to $0.3 \mathrm{~nm}^{-1}$ (Figure 3.1b). Due to the high growth rate, these larger $10 \mathrm{~nm}$-sized crystallites are thus most likely formed through the aggregation and/or coalescence of smaller crystallites. The rapid decrease implies a strong reduction of the contribution of $N$ in the product $N \cdot(\Delta \rho)^{2}$, in which the scattering contrast be- 
tween the newly evolved phase and the supernatant liquid presumably reached its maximum value. Additionally, the fast decay observed for $\langle A\rangle / V_{p}$ at $\sim 105 \mathrm{~min}$ also explains the loss of surface-to-volume ratio due to rapid crystallite growth well. The surface area of as-formed aggregates was still large, due to the surface area contribution of the individual crystals. Over time, this contribution was reduced as a result of particle smoothening, leading to a decrease of $\langle A\rangle$. The fact that $\langle A\rangle / V_{p}$ decayed $\sim 40$ min later than $N \cdot(\Delta \rho)^{2}$ may thus be explained by the time necessary to create smooth crystallites. A plateau was reached for both parameters after crystal growth stopped. For the lowest concentration $\left(0.05 \mathrm{~mol} \cdot \mathrm{dm}^{-3}\right.$; Figure $\left.3.4 \mathrm{a}\right)$ no real nucleation burst of primary particles (amorphous or crystalline) was observed. The rather gradual change in specific surface area suggests the appearance and dissolution of small (unstable) clusters, until their precipitation onto larger (more stable) clusters. ${ }^{[35]}$ However, no (real) growth beyond $4 \mathrm{~nm}$-sized (in diameter) crystallites was observed. At intermediate concentrations (0.075-0.1 $\mathrm{mol} \cdot \mathrm{dm}^{-3}$; Figure $\left.3.4 \mathrm{~b}-\mathrm{c}\right)$ precipitation and growth of stable crystallites through coalescence or Ostwald ripening was favored, and a peak for $N \cdot(\Delta \rho)^{2}$ (Figure $3.4 \mathrm{~b}-\mathrm{c})$, albeit less sharp and high than for $0.2 \mathrm{~mol} \cdot \mathrm{dm}^{-3}$, was observed.
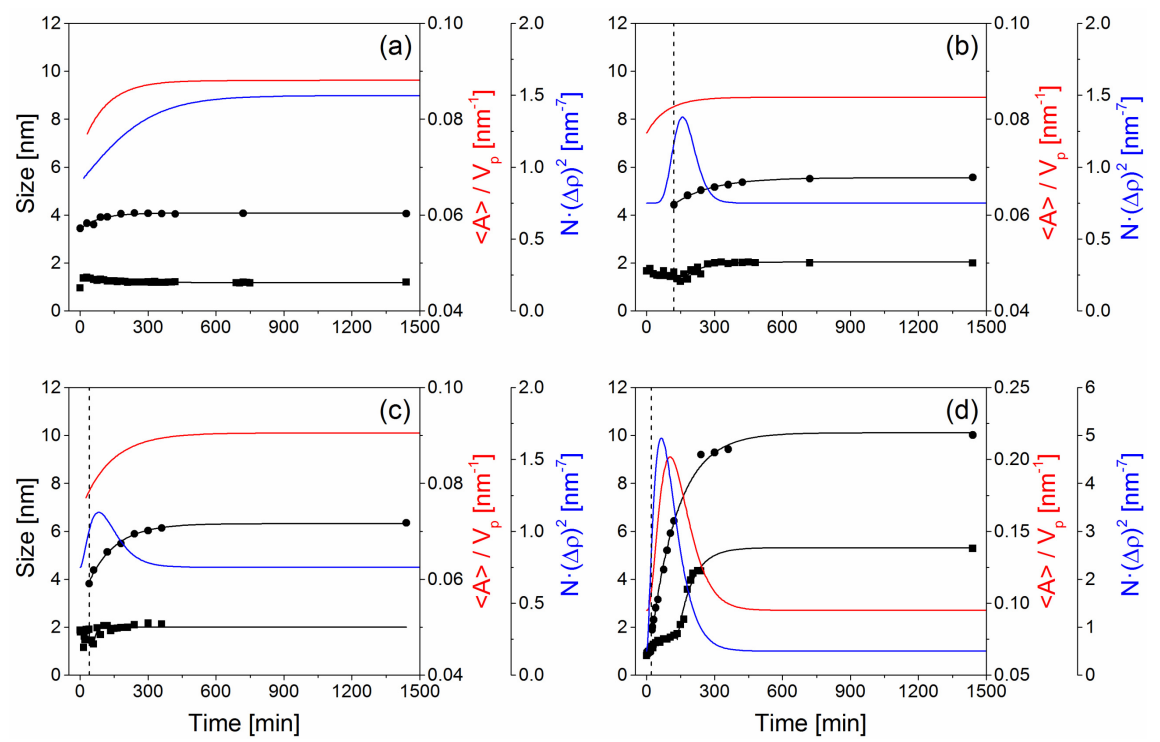

Figure 3.4 Schematic overview of the mean crystallite size (black circles), scattering length $\langle L\rangle$ (black squares), specific surface area $\left\langle A>/ V_{p}\right.$ (in $\mathrm{nm}^{-1}$; red line), and the product of particle number and scattering density $N \cdot(\Delta \rho)^{2}$ (in $\mathrm{nm}^{-7}$; blue line) for (a) 0.05 ; (b) 0.075 ; (c) 0.1 ; and (d) $0.2 \mathrm{~mol} \cdot \mathrm{dm}^{-3}$. The dashed vertical lines represent the times of crystallization determined by $\mathrm{XRD}$, and serve only as a guide to the eye. 

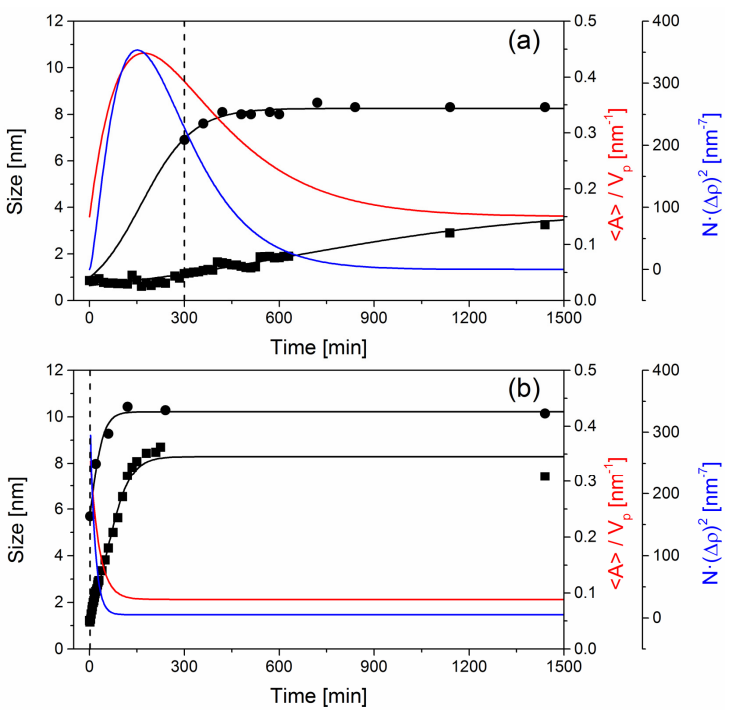

Figure 3.5 Schematic overview of the mean crystallite size (black circles), scattering length $\langle L\rangle$ (black squares), specific surface area $\left\langle A>/ V_{p}\right.$ (in $\mathrm{nm}^{-1}$; red line), and $N \cdot(\Delta \rho)^{2}$ (in $\mathrm{nm}^{-7}$; blue line) for reactions performed at (a) $45^{\circ} \mathrm{C}$; and (b) $150{ }^{\circ} \mathrm{C}$. [Ti] $=0.2 \mathrm{~mol} \cdot \mathrm{dm}^{-3}$. The dashed vertical lines represent the times of crystallization determined by XRD, and serve only as a guide to the eye.

\subsubsection{Varying Reaction Conditions}

\section{Temperature Dependence $\left([\mathrm{Ti}]=0.2 \mathrm{~mol} \cdot \mathrm{dm}^{-3}\right)$}

My previous study on $\mathrm{BaTiO}_{3}$ formation in benzyl alcohol showed that the crystallization process was thermally activated (see Figure 2.7). An activation energy for crystallization of $E_{\mathrm{A}}=65.2 \mathrm{~kJ} \cdot \mathrm{mol}^{-1}$ was found in the temperature range $45-150{ }^{\circ} \mathrm{C}$. This is slightly higher than $E_{\mathrm{A}}=55.1 \mathrm{~kJ} \cdot \mathrm{mol}^{-1}\left(150-200{ }^{\circ} \mathrm{C}\right)$ found for the crystallization of BTO from a hydrothermal reaction using a hydrous amorphous titania precursor. ${ }^{[18]}$ Figure 3.5 shows the effect of temperature on the nucleation and phase formation of BTO. Changes in temperature affected the rate of crystal water release from the $\mathrm{Ba}$ hydroxide precursor (zero-th order; see Figure 2.1). Although equal of amounts of water are released, the dehydration is faster at higher temperatures, and thus nucleation and crystallization rates were affected. At lower temperatures, nucleation and growth took place over a longer period of time due to the slower release of water, whereas at high temperatures, the reaction proceeded very rapidly. Similar trends found for the reaction performed at $78{ }^{\circ} \mathrm{C}$ (Figure 3.4d) indicate that the rates of hydrolysis and subsequent crystallization and growth are indeed determined by the release rate of water. Moreover, 
thermogravimetric analysis at various temperatures from my previous study showed that the formation of a crystalline phase takes approximately 2 times longer than the dehydration of barium hydroxide octahydrate (see Chapter 2.3.4).

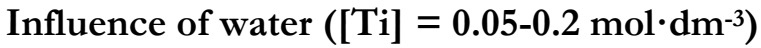

The concentration of water present in the system has a profound influence on the manner in which the reaction proceeds. An excess of water may lead to uncontrolled precipitation and growth of crystallites, ${ }^{[36,37]}$ while a lack of water may result in no reaction at all. The barium hydroxide octahydrate precursor was used for the controlled release of 7 moles of water per mole of Ba during heating (i.e. independent of the starting concentration). Thus, the reduction of the overall Ti precursor concentration from 0.2 to $0.05 \mathrm{~mol} \cdot \mathrm{dm}^{-3}$ effectively reduced the overall water concentration in the system from 2.46 to 0.63 vol $\%$, respectively, while keeping $h=\left[\mathrm{H}_{2} \mathrm{O}\right]:[\mathrm{Ti}]=7$. The zero-th order dehydration reaction of the $\mathrm{Ba}$ precursor ensured equal water release rates for all investigated concentrations, although the total water concentration available for hydrolysis was 4 times higher for $0.2 \mathrm{~mol} \cdot \mathrm{dm}^{-3}$ than for $0.05 \mathrm{~mol} \cdot \mathrm{dm}^{-3}$. Figure 3.6 a shows that an increased Ti concentration led to reduced crystallization times and increased mean crystallite sizes (red and black squares, respectively). From Figure 3.6a it is evident that not the ratio $\left[\mathrm{H}_{2} \mathrm{O}\right]:[\mathrm{Ti}]$, but rather the total water concentration determines the rate of crystallization (also see Table 3.1 for an overview of all reaction conditions and crystallization times). To investigate this issue further, two additional experiments were performed: (1) the water content of a reaction performed with [Ti] $=0.1 \mathrm{~mol} \cdot \mathrm{dm}^{-3}$ was carefully adjusted from 1.25 to $2.46 \mathrm{vol} \%$ ( $h=7$ to 14 , respectively); (2) a reaction was performed with [Ti] $=0.4 \mathrm{~mol} \cdot \mathrm{dm}^{-3}\left(4.80 \mathrm{vol} \% \mathrm{H}_{2} \mathrm{O} ; h=7\right)$. The influence of the increase of $h$ by a factor 2 , and the influence of the total water concentration on the crystallization time, respectively, was determined. In both experiments it was found that a crystalline phase started to appear after $\sim 20 \mathrm{~min}$. Thus, independent of the precursor concentration and h, comparable times for crystallization were found as for [Ti] $=0.2$ $\mathrm{mol} \cdot \mathrm{dm}^{-3}$. Above a critical water concentration of $2.46 \mathrm{vol} \%$, the crystallization proceeded seemingly via a zero-th order reaction rate, corresponding to the dehydration rate of barium hydroxide octahydrate. Moreover, crystallization was not affected by the shorter diffusion length of the reactive species for [Ti] $=0.4 \mathrm{~mol} \cdot \mathrm{dm}^{-3}$ compared to 0.2 $\mathrm{mol} \cdot \mathrm{dm}^{-3}$. 
Table 3.1 Overview of the influence of reaction conditions on the crystallization time.

\begin{tabular}{|c|c|c|c|c|c|}
\hline $\begin{array}{c}\text { Concentration } \\
{\left[\mathrm{mol}^{\cdot} \mathrm{dm}^{-3}\right]}\end{array}$ & $\begin{array}{c}{[\mathrm{Ba}]:[\mathrm{Ti}]} \\
{[-]} \\
\end{array}$ & $\mathrm{H}_{2} \mathrm{O}$ added & $\begin{array}{c}\boldsymbol{h} \\
{[-]} \\
\end{array}$ & $\begin{array}{c}\mathrm{H}_{2} \mathrm{O} \text { concentration } \\
{[\mathrm{vol} \%]}\end{array}$ & $\begin{array}{c}\text { Crystallization time } \\
\text { [min] }\end{array}$ \\
\hline 0.05 & 1 & - & 7 & 0.63 & n.d. \\
\hline 0.075 & 1 & - & 7 & 0.94 & 120 \\
\hline 0.1 & 1 & - & 7 & 1.25 & 40 \\
\hline 0.2 & 1 & - & 7 & 2.46 & 20 \\
\hline 0.1 & 1 & Yes & 14 & 2.46 & 22 \\
\hline 0.4 & 1 & - & 7 & 4.80 & 20 \\
\hline 0.2 & 2 & - & 14 & 4.80 & 10 \\
\hline 0.2 & 0.5 & - & 3.5 & 1.25 & $>720$ \\
\hline 0.2 & 0.5 & Yes & 7 & 2.46 & 40 \\
\hline 0.2 & 0.375 & Yes & 7 & 2.46 & 123 \\
\hline
\end{tabular}

n.d.: not determined

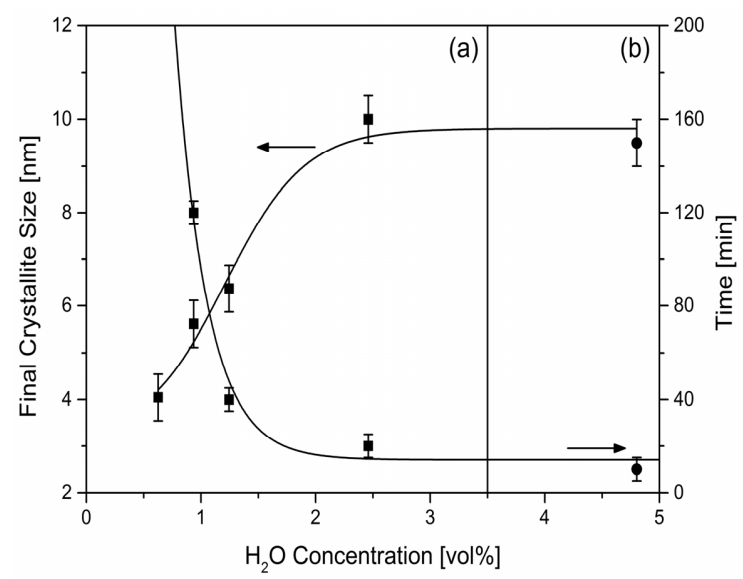

Figure 3.6 Influence of the overall volume percentage of water on the crystallization time and final mean crystallite size (determined by PSD from SAXS curves). (a) Varying concentration $\left([\right.$ Ti $\left.]=0.05-0.2 \mathrm{~mol} \cdot \mathrm{dm}^{-3}\right)$; (b) precursor stoichiometry Ba:Ti $=2: 1$ (with [Ti $]=0.2 \mathrm{~mol} \cdot \mathrm{dm}^{-3}$.

Note: the crystallization time of [Ti] $=0.05 \mathrm{~mol} \cdot \mathrm{dm}^{-3}$ in (a) could not be determined.

This implies that the gel formation rate (through subsequent hydrolysis and condensation reactions) is rate-limiting, rather than the flux or diffusion of $\mathrm{Ba}^{2+}$ ions. For [Ti] $=$ $0.1 \mathrm{~mol} \cdot \mathrm{dm}^{-3}$, below the water threshold, the amorphous network formation was impeded by the lower supply of water. Although the hydrolysis and condensation reactions are expected to be very rapid in the presence of water, ${ }^{[36]}$ the diffusion of water molecules towards to reactive $\mathrm{Ti}$ species was limiting the reaction rate. The crystalline phase was formed after $40 \mathrm{~min}$; exactly twice as long as for [Ti] $=0.2 \mathrm{~mol} \cdot \mathrm{dm}^{-3}$. At [Ti $]<0.1$ 
$\mathrm{mol} \cdot \mathrm{dm}^{-3}$, the time of crystal formation was not linearly related to the precursor concentration. Hence, the crystallization reaction was presumably limited by both the diffusion rate of water molecules and of $\mathrm{Ba}^{2+}$ ions.

\section{Influence Ba:Ti Stoichiometry $\left([\mathrm{Ti}]=\mathbf{0 . 2} \mathrm{mol} \cdot \mathrm{dm}^{-3}\right)$}

An increased Ba:Ti ratio of 2:1 $\left(4.80 \mathrm{vol} \% \mathrm{H}_{2} \mathrm{O} ; h=14\right)$ had no significant effect on the final crystallite size (Figure 3.6b; black circle), but it reduced the crystallization time from 20 to $10 \mathrm{~min}$ (red circle), respectively. Although an excess of Ba was present, only an equimolar amount participates in the BTO formation reaction. Since the water concentration is sufficiently high, the reduction in crystallization time was thus linked to the decrease of the diffusive path length of $\mathrm{Ba}^{2+}$ ions. In later stages of the reaction, the excess of $\mathrm{Ba}$ resulted in the formation of secondary phases, such as $\mathrm{BaCO}_{3}$.

The more water lean conditions when $\mathrm{Ba}: \mathrm{Ti}=0.5: 1\left(1.25 \mathrm{vol} \% \mathrm{H}_{2} \mathrm{O} ; h=3.5\right)$ led to a crystallization time $>720 \mathrm{~min}$ (Table 3.1). Although the water concentration was equal to that in a stoichiometric reaction performed at [Ti] $=0.1 \mathrm{~mol} \cdot \mathrm{dm}^{-3}$, the crystallization was significantly slower. The crystallization rate is determined by a correlation between the water concentration, $h$, precursor stoichiometry and flux of water, rate of gel formation, and flux of $\mathrm{Ba}^{2+}$ ions, respectively. To clarify this relationship, the water concentration in reaction mixtures with two sub-stoichiometric Ba:Ti ratios, namely 0.5:1 (1.25 vol\% $\left.\mathrm{H}_{2} \mathrm{O} ; h=3.5\right)$ and $0.375: 1\left(0.94 \mathrm{vol}^{2} \mathrm{H}_{2} \mathrm{O} ; h=2.6\right)$, was carefully adjusted to $2.46 \mathrm{vol} \%$ (i.e. the water amount normally present for $\mathrm{Ba}: \mathrm{Ti}=1: 1 ; b=$ 7). Effectively, both reactions should yield an equivalent amount of BTO as performed under stoichiometric conditions using [Ti] $=0.1$ and $0.075 \mathrm{~mol} \cdot \mathrm{dm}^{-3}$, respectively. My hypothesis was confirmed by the near-identical reaction rates that were found for the water-adjusted reactions compared to the latter reactions performed under stoichiometric conditions (see Table 3.1). Provided that sufficient water is supplied for hydrolysis and gel formation, the crystallization times are determined predominantly by the lower flux of $\mathrm{Ba}^{2+}$ ions and the longer diffusion length towards the $\mathrm{Ti}$ atoms.

\subsubsection{Rate-limiting Regimes}

An overview of the dependencies of the investigated reactions conditions on the ratelimiting regimes for crystal formation is presented in Figure 3.7. Three regimes have been identified in which (1) the gel formation (red area), (2) the water or $\mathrm{Ba}^{2+}$ flux (blue 
area), and (3) a combination of both (green area) are the rate-limiting factors. For reactions performed under stoichiometric precursor ratios, the crystallization rate is determined by the amount of water and the rate at which it is released from the barium hydroxide octahydrate. For [Ti] $\geq 0.2 \mathrm{~mol} \cdot \mathrm{dm}^{-3}$ sufficient water is provided by the $\mathrm{Ba}$ precursor and crystal formation is limited by the dehydration of the Ba precursor, and thus the rate of gel formation. At lower concentrations, the distance between water molecules to the reactive $\mathrm{Ti}$ atoms, and thus the diffusion of water, rather than the formation of an amorphous network is rate-limiting.

For reactions performed with off-stoichiometric precursor ratios, the rate of crystallization is not only determined by the absolute water concentration, but also by $h$. The hydrolysis and condensation reactions are severely impeded at $h<7$. In addition, variations in the $\mathrm{Ba}$ :Ti ratio change the diffusion length of $\mathrm{Ba}^{2+}$, and thus also influence the rate at which crystals are formed.
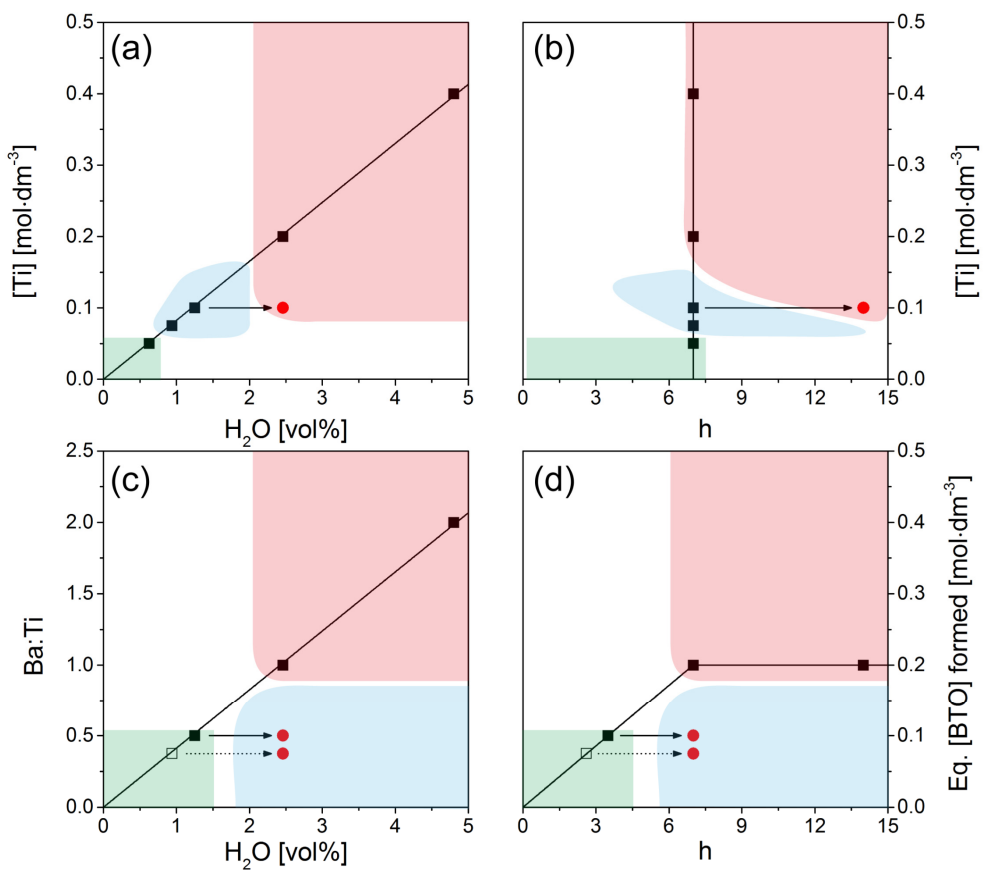

Figure 3.7 Overview of rate-limiting regimes for reactions performed under (a)-(b) stoichiometric, and (c)-(d) off-stoichiometric precursor conditions. The red, blue, and green areas represent the regimes in which the gel formation rate, water concentration, and a combination of both are the rate-limiting conditions, respectively. The red circles indicate the reactions performed with adjusted water concentrations. 


\subsection{Conclusions}

The reaction mechanism and kinetics of BTO phase formation in benzyl alcohol at temperatures below $78{ }^{\circ} \mathrm{C}$ were elucidated successfully by employing time-resolved SAXS and XRD measurements. The effect of precursor concentration, reactant stoichiometry, and temperature on the amorphous-to-crystalline transformation was described in detail. It was established that BTO nanocrystal formation is a thermally activated process.

For stoichiometric reactions $\left([\mathrm{Ba}]:[\mathrm{Ti}]=1 ; h=7\right.$ ) performed at $78^{\circ} \mathrm{C}$, the total amount of water released from the barium hydroxide octahydrate precursor was the key factor in the rate of crystalline phase formation. Sufficiently high water concentrations enabled a quick succession of the nucleation, crystallization, and growth events. The rate of BTO nanocrystal formation was only limited by the dehydration rate of the $\mathrm{Ba}$ precursor, and thus by the formation of an amorphous gel network. Water lean conditions resulted in impeded gel formation and only a gradual nucleation, growth, and crystallization process was observed.

For reactions performed under off-stoichiometric precursor ratios, not only the total water concentration, but also $b$ determined the reaction rate. In addition, it was found that the changes in the diffusion length between $\mathrm{Ba}^{2+}$ ions and the reactive $\mathrm{Ti}$ atom affected the kinetics.

A better understanding of the effect of modified reaction parameters on the synthesis of nanocrystals enable to set up elementary boundary conditions for improved control over the reaction. 


\subsection{Bibliography}

[1] S. O'Brien, L. Brus, C. B. Murray, Synthesis of monodisperse nanoparticles of barium titanate: Toward a generalized strategy of oxide nanoparticle synthesis. J. Am. Chem. Soc. 2001, 123, 1208512086.

[2] M. Niederberger, G. Garnweitner, N. Pinna, M. Antonietti, Nonaqueous and halide-free route to crystalline $\mathrm{BaTiO} 3, \mathrm{SrTiO} 3$, and $(\mathrm{Ba}, \mathrm{Sr}) \mathrm{TiO} 3$ nanoparticles via a mechanism involving $\mathrm{C}-\mathrm{C}$ bond formation. J. Am. Chem. Soc. 2004, 126, 9120-9126.

[3] X. Wang, J. Zhuang, Q. Peng, Y. Li, A general strategy for nanocrystal synthesis. Nature 2005, 437, 121-124.

[4] C. Pithan, D. Hennings, R. Waser, Progress in the synthesis of nanocrystalline BaTiO3 powders for MLCC. Int. J. Appl. Ceram. Technol. 2005, 2, 1-14.

[5] R. L. Brutchey, D. E. Morse, Template-free, low-temperature synthesis of crystalline barium titanate nanoparticles under bio-inspired conditions. Angewandte Chemie - International Edition 2006, 45, 6564-6566.

[6] C. W. Beier, M. A. Cuevas, R. L. Brutchey, Room-temperature synthetic pathways to barium titanate nanocrystals. Small 2008, 4, 2102-2106.

[7] T. M. Stawski, S. A. Veldhuis, O. F. Göbel, J. E. Ten Elshof, D. H. A. Blank, Effects of reaction medium on the phase synthesis and particle size evolution of BaTiO3. J. Am. Ceram. Soc. 2010, 93, 3443-3448.

[8] T. M. Stawski, S. A. Veldhuis, O. F. Göbe, E. Podstawka-Proniewicz, J. E. Ten Elshof, Electron microscopy study of intragranular nanoporosity and the occurrence of local structural disorder in cubic BaTiO3 nanopowders from alkoxidehydroxide precipitation process. Ceram. Int. 2012, 38, 6911-6917.

[9] Y. Gao, V. V. Shvartsman, A. Elsukova, D. C. Lupascu, Low-temperature synthesis of crystalline BaTiO3 nanoparticles by one-step "organosol"-precipitation. J. Mater. Chem. 2012, 22, 1757317583.

[10] F. A. Rabuffetti, R. L. Brutchey, Structural evolution of BaTiO3 nanocrystals synthesized at room temperature. J. Am. Chem. Soc. 2012, 134, 9475-9487.

[11] W. Hertl, Kinetics Of Barium-Titanate Synthesis. J. Am. Ceram. Soc. 1988, 71, 879-883.

[12] M. Z. C. Hu, V. Kurian, E. A. Payzant, C. J. Rawn, R. D. Hunt, Wet-chemical synthesis of monodispersed barium titanate particles - Hydrothermal conversion of TiO2 microspheres to nanocrystalline BaTiO3. Powder Technol. 2000, 110, 2-14. 
[13] I. MacLaren, C. B. Ponton, A TEM and HREM study of particle formation during barium titanate synthesis in aqueous solution. J. Eur. Ceram. Soc. 2000, 20, 1267-1275.

[14] X. Wang, B. I. Lee, M. Z. Hu, E. A. Payzant, D. A. Blom, Mechanism of nanocrystalline BaTiO3 particle formation by hydrothermal refluxing synthesis. Journal of Materials Science: Materials in Electronics 2003, 14, 495-500.

[15] A. T. Chien, J. S. Speck, F. F. Lange, A. C. Daykin, C. G. Levi, Low temperature/low pressure hydrothermal synthesis of barium titanate: powder and heteroepitaxial thin films. J. Mater. Res. 1995, 10, 1784-1789.

[16] J. O. Eckert Jr, C. C. Hung-Houston, B. L. Gersten, M. M. Lencka, R. E. Riman, Kinetics and mechanisms of hydrothermal synthesis of barium titanate. J. Am. Ceram. Soc. 1996, 79, 2929-2939. [17] P. Pinceloup, C. Courtois, J. Vicens, A. Leriche, B. Thierry, Evidence of a dissolution-precipitation mechanism in hydrothermal synthesis of barium titanate powders. J. Eur. Ceram. Soc. 1999, 19, 973-977.

[18] R. I. Walton, F. Millange, R. I. Smith, T. C. Hansen, D. O'Hare, Real time observation of the hydrothermal crystallization of barium titanate using in situ neutron powder diffraction. J. Am. Chem. Soc. 2001, 123, 12547-12555.

[19] J. Moon, E. Suvaci, A. Morrone, S. A. Costantino, J. H. Adair, Formation mechanisms and morphological changes during the hydrothermal synthesis of $\mathrm{BaTiO} 3$ particles from a chemically modified, amorphous titanium (hydrous) oxide precursor. J. Eur. Ceram. Soc. 2003, 23, 2153-2161.

[20] L. Qi, B. I. Lee, P. Badheka, D. H. Yoon, W. D. Samuels, G. J. Exarhos, Short-range dissolution-precipitation crystallization of hydrothermal barium titanate. J. Eur. Ceram. Soc. 2004, 24, 35533557.

[21] B. L. Cushing, V. L. Kolesnichenko, C. J. O'Connor, Recent advances in the liquid-phase syntheses of inorganic nanoparticles. Chem. Rev. 2004, 104, 3893-3946.

[22] A. Guinier, G. Fournet, C. B. Walker, K. L. Yudowitch, Small-angle scattering of X-rays, Vol. 14, Wiley New York, 1955.

[23] J. S. Pedersen, Analysis of small-angle scattering data from colloids and polymer solutions: Modeling and least-squares fitting. Adv. Colloid Interface Sci. 1997, 70, 171-210.

[24] J. Teixeira, Small-angle scattering by fractal systems. J. Appl. Crystallogr. 1988, 21, 781-785.

[25] H. G. Krauthäuser, W. Lennartz, G. Nimtz, Real-Space Distributions from Small-Angle Scattering Data: Structure Interference Method versus Indirect Transformation Method. J. Appl. Crystallogr. 1996, 29, 7-15. 
[26] S. Martelli, P. E. Di Nunzio, Particle size distribution of nanospheres by Monte Carlo fitting of small angle x-ray scattering curves. Part. Part. Syst. Char. 2002, 19, 247-255.

[27] B. R. Pauw, J. S. Pedersen, S. Tardif, M. Takata, B. B. Iversen, Improvements and considerations for size distribution retrieval from small-angle scattering data by Monte Carlo methods. $J$. Appl. Crystallogr. 2013, 46, 365-371.

[28] G. Porod, in Small angle X-ray scattering, (Eds: O. Glatter, O. Kratky), Academic Press, London 1982, 17-51.

[29] W. Bras, I. P. Dolbnya, D. Detollenaere, R. Van Tol, M. Malfois, G. N. Greaves, A. J. Ryan, E. Heeley, Recent experiments on a combined small-angle/wide-angle X-ray scattering beam line at the ESRF. J. Appl. Crystallogr. 2003, 36, 791-794.

[30] L. Fan, M. Degen, S. Bendle, N. Grupido, J. Ilavsky, The absolute calibration of a smallangle scattering instrument with a laboratory X-ray source. J. Phys. Conf. Ser. 2010, 247.

[31] C. A. Schneider, W. S. Rasband, K. W. Eliceiri, NIH Image to ImageJ: 25 years of image analysis. Nat. Methods 2012, 9, 671-675.

[32] M. Viviani, M. T. Buscaglia, A. Testino, V. Buscaglia, P. Bowen, P. Nanni, The influence of concentration on the formation of $\mathrm{BaTiO} 3$ by direct reaction of $\mathrm{TiCl} 4$ with $\mathrm{Ba}(\mathrm{OH}) 2$ in aqueous solution. J. Eur. Ceram. Soc. 2003, 23, 1383-1390.

[33] D. Hennings, G. Rosenstein, H. Schreinemacher, Hydrothermal preparation of barium titanate from barium-titanium acetate gel precursors. J. Eur. Ceram. Soc. 1991, 8, 107-115.

[34] J. A. Kerchner, J. Moon, R. E. Chodelka, A. A. Morrone, J. H. Adair, Vol. 681, 1998, 106119.

[35] R. Viswanatha, D. D. Sarma, in Nanomaterials Chemistry, Wiley-VCH Verlag GmbH \& Co. KGaA, 2007, 139-170.

[36] C. J. Brinker, G. W. Scherer, Sol-gel science: the physics and chemistry of sol-gel processing, Academic Press, Inc, San Diego, CA 1990.

[37] T. Sugimoto, X. Zhou, A. Muramatsu, Synthesis of uniform anatase TiO2 nanoparticles by gel-sol method: 1. Solution chemistry of $\mathrm{Ti}(\mathrm{OH}) \mathrm{n}(4-\mathrm{n})+$ complexes. J. Colloid Interface Sci. 2002, 252, 339-346. 


\subsection{Supporting Information}

\subsubsection{Particle Size Distribution with McSAS Software Package}
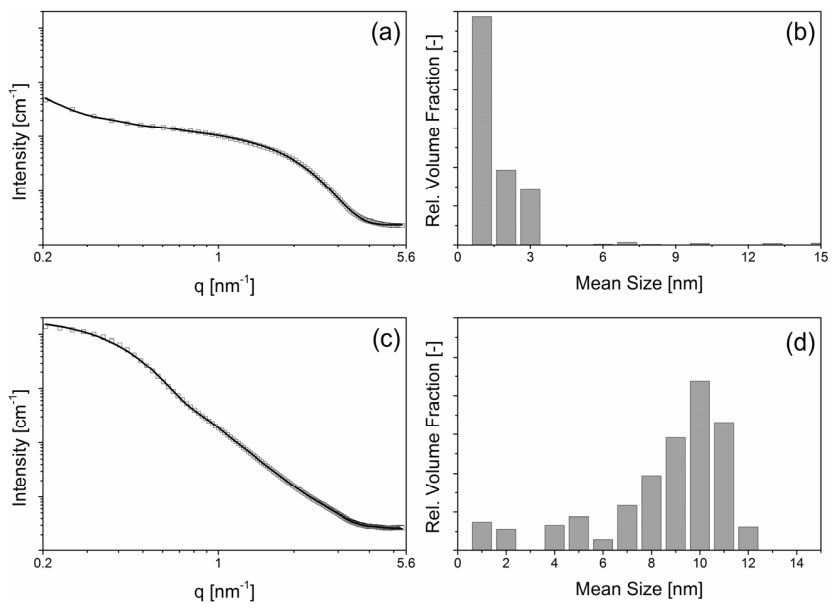

Figure S3.1 Examples of scattering curves fitted with the McSAS software package, ${ }^{[\mathrm{S} 1]}$ and the corresponding particle size distributions for a synthesis performed at $78{ }^{\circ} \mathrm{C}$. Samples taken at different time intervals: (a)-(b) $t=4 \mathrm{~min}$, and (c)-(d) $t=1440 \mathrm{~min}$, respectively.

\subsubsection{Selected-Area Electron Diffraction}

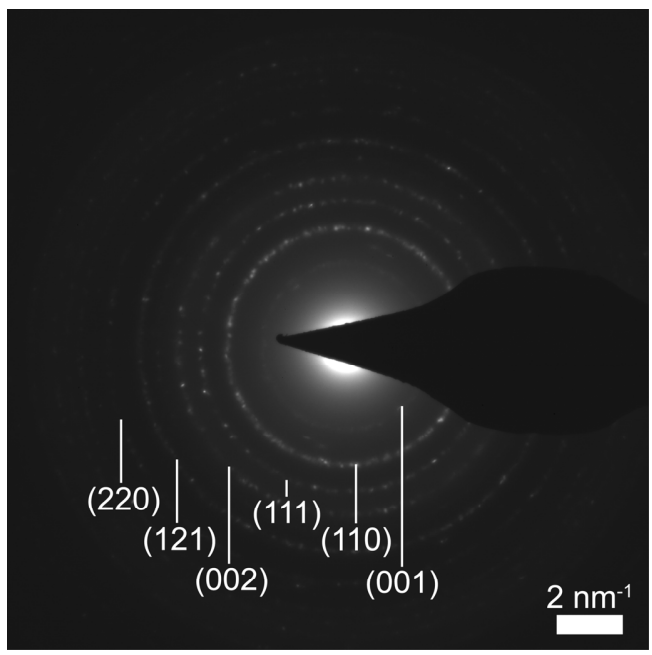

Figure S3.2 Selected-area electron diffraction (SAED) pattern acquired with $5 \mathrm{~s}$ exposure time (10 frames) from an area of approximately $0.2 \times 0.2 \mu \mathrm{m}^{2}$ (at $285 \mathrm{keV}$ ). Polycrystalline BTO was formed at $78{ }^{\circ} \mathrm{C}$ using [Ti] $=0.2 \mathrm{~mol} \cdot \mathrm{dm}^{-3}$. The corresponding crystal lattice planes are presented. 


\section{Bibliography}

[S1] B. R. Pauw, J. S. Pedersen, S. Tardif, M. Takata, B. B. Iversen, Improvements and considerations for size distribution retrieval from small-angle scattering data by Monte Carlo methods. J. Appl. Crystallogr. 2013, 46, 365-371. 


\title{
The Low-Temperature Synthesis of Proton Conducting Yttrium-doped Barium Zirconate - A Structural Characterization
}

\begin{abstract}
Proton conducting yttrium-doped barium zirconate was prepared via a low-temperature wet-chemical synthesis in benzyl alcohol. The synthesis yielded a highly sinter-active nano-crystalline phase, and densification was achieved at much lower temperatures than for bulk samples. A maximum density of $95.6 \%$ was achieved after sintering for $24 \mathrm{~h}$ at $1350{ }^{\circ} \mathrm{C}$. Although no secondary phases were formed after sintering, yttrium segregation at the grain boundaries was observed with transmission electron microscopy. Furthermore, a lack of grain growth during sintering, resulting in a large grain boundary contribution on the total proton conductivity was recorded. A maximum proton conductivity of $1.6 \cdot 10^{-4} \mathrm{~S} \cdot \mathrm{cm}^{-1}$ was achieved at $600{ }^{\circ} \mathrm{C}$ in wet $\mathrm{H}_{2}$ atmosphere.
\end{abstract}




\subsection{Introduction}

Perovskite oxide materials $\left(\mathrm{ABO}_{3}\right)$ have attracted considerable attention since Iwahara et al. discovered high proton conductivity in some members of this family in the $1980 \mathrm{~s}^{\left[{ }^{[1]}\right.}$ In particular, $\mathrm{B}$-site doped barium cerates $\left(\mathrm{BaCe}_{\mathrm{x}} \mathrm{M}_{1-\mathrm{x}} \mathrm{O}_{3-\delta}\right)$ and barium zirconates $\left(\mathrm{BaZr}_{\mathrm{x}} \mathrm{M}_{1-\mathrm{x}} \mathrm{O}_{3-\delta}\right)$ respectively, where $\left.\mathrm{M}=\mathrm{Y}, \mathrm{La}, \mathrm{Sc}, \mathrm{Yb}, \mathrm{Gd}\right)$ are among the most thoroughly investigated ones. Although doped barium cerates have superior proton conducting properties over zirconates and are of comparable mechanical strength, their chemical instability in $\mathrm{CO}_{2}$ containing atmospheres, i.e. easy formation of $\mathrm{BaCO}_{3},{ }^{\left[{ }^{[2}\right.} \mathrm{fa}-$ vors the use of doped barium zirconates. This ceramic material is a promising candidate as electrolyte material in fuel cells operating at intermediate temperatures (500-700 $\left.{ }^{\circ} \mathrm{C}\right) .{ }^{[3,4]}$

A high proton conductivity can be obtained by introducing dopants of lower valency such as $\mathrm{Y}^{3+}$ ions onto regular 4+ lattice sites. Point defects with a negative effective charge are thus formed and oxygen vacancies are incorporated into the perovskite lattice due to charge compensation. ${ }^{[5,6]}$ Exposure of the formed yttrium-doped barium zirconate (BZY) to humid atmospheres then results in the formation of hydroxyl defects, see Eq. (4.1), and thus in a pathway for proton transfer.

$$
\mathrm{H}_{2} \mathrm{O}+\mathrm{O}_{\mathrm{O}}^{\mathrm{x}}+\mathrm{V}_{\mathrm{O}}^{\bullet \bullet} \Leftrightarrow 2 \mathrm{OH}_{\mathrm{O}}^{\bullet}
$$

where, $\mathrm{O}_{\mathrm{O}}^{\mathrm{x}}, \mathrm{V}_{\mathrm{O}}^{\bullet \bullet}$, and $\mathrm{OH}_{\mathrm{O}}^{\bullet}$ are the oxygen atoms in the crystal lattice, the oxygen vacancies, and hydroxyl defects, respectively. Protons are transferred either via hydrogen bond formation and cleavage of the oxygen-hydrogen bonds in the lattice due to rotational movement and reorientation (Grotthuss mechanism), ${ }^{[7,8]}$ or via a 'vehicle' mechanism. In the latter mechanism, the protons are transported with bigger species, e.g. with water in the form of $\mathrm{H}_{3} \mathrm{O}^{+}$. The conductivity is then dependent on the diffusivity of the 'vehicle' species. ${ }^{[7]}$

The refractory nature of BZY ceramics contributes to processing challenges due to the very high sintering temperatures $\left(1600-1700{ }^{\circ} \mathrm{C}\right)$ that are needed to obtain fully dense bodies. Therefore, finding suitable anode supports that can withstand these high temperatures without degradation remains a challenge. Furthermore, the materials properties are closely related to the synthesis method and its subsequent heat treatment, and many attempts have been made to improve either of these steps in order to lower 
the sintering temperature. Sintering aids, e.g. $\mathrm{ZnO}$ and $\mathrm{NiO}$, are commonly used in the solid state reaction of $\mathrm{BaCO}_{3}, \mathrm{ZrO}_{2}$, and $\mathrm{Y}_{2} \mathrm{O}_{3}$ to form BZY. ${ }^{[10-15]}$ These sintering aids form sub-phases, and liquid phase sintering and densification is observed at temperatures of approximately $200-300{ }^{\circ} \mathrm{C}$ lower than without the use of sintering aids. ${ }^{[14]}$ However, only small amounts $(<1 \mathrm{at} \%)$ can be used without affecting the conductivity of the samples, ${ }^{[12,13]}$ due to the diffusion of the sub-phases into the grain boundary (GB). Other sintering aids such as $\mathrm{TiO}_{2}, \mathrm{MgO}, \mathrm{Mo}, \mathrm{Al}_{2} \mathrm{O}_{3}$, and $\mathrm{Bi}_{2} \mathrm{O}_{3}$ have been tested, but also resulted in an increased activation energy. ${ }^{[16]}$

As an alternative to solid state syntheses, wet-chemical synthesis routes, such as a reversed micellar process, ${ }^{[2]}$ sol-gel methods, ${ }^{[17-19]}$ and chemical solution precipitations ${ }^{[20]}$ are described. Although nano-crystalline ceramics are obtained at relatively low temperatures when employing the wet-chemical syntheses, it is quite problematic to obtain a pure single phase at these temperatures, ${ }^{[2]}$ and higher temperatures are often needed. Depending on the synthesis route, the additional heat treatment may lead to $\mathrm{BaO}$ evaporation. ${ }^{[10,11]}$ The resulting A-site deficiency may then cause the formation of secondary phases such as $\mathrm{BaCO}_{3}, \mathrm{Y}_{2} \mathrm{O}_{3}$, and $\mathrm{ZrO}_{2}$ at the grain boundaries, ${ }^{[3,10,12]}$ although this is not always observed. ${ }^{[11]}$ Also, yttrium incorporation on the A-site is observed. The cubic perovskite structure is maintained due to charge compensation from loss of oxygen vacancies, ${ }^{[21]}$ according to:

$$
2 \mathrm{Ba}_{\mathrm{Ba}}^{\mathrm{x}}+\mathrm{V}_{\mathrm{O}}^{\bullet \bullet}+\mathrm{Y}_{2} \mathrm{O}_{3} \Leftrightarrow 2 \mathrm{BaO}+\mathrm{O}_{\mathrm{O}}^{\mathrm{x}}+2 \mathrm{Y}_{\mathrm{Ba}}^{\bullet}
$$

where $\mathrm{Ba}_{\mathrm{Ba}}^{\mathrm{x}}$ and $\mathrm{Y}_{\mathrm{Ba}}^{\bullet}$ are the barium atoms in the lattice and the yttrium atoms incorporated on the A-site, respectively. Conductivity thus decreases as a result of reduction in the oxygen vacancy concentration, as shown in Eq. (4.2). To compensate for possible barium deficiency on the A-site, an excess of $\mathrm{BaCO}_{3}$ is often added on top and around of a BZY pellet during the sintering step. ${ }^{[8,22]}$ Table 4.1 gives an overview of the effect of various synthesis routes and sintering conditions on the final density and conductivity. It is evident that low synthesis and processing temperatures (while keeping full control over the stoichiometry) are paramount to obtain high quality ceramics suitable for fuel cell applications. Here I describe a low-temperature synthesis of nano-crystalline $\mathrm{BaZr}_{0.8} \mathrm{Y}_{0.2} \mathrm{O}_{3-\delta}(\mathrm{BZY} 20)$ and its full characterization and structural development. I observed that the synthesized nano-crystalline powders are highly sinter-active and dense bodies $\left(\rho_{\text {rel }}=95.6 \%\right)$ were obtained at relatively low sintering temperatures. By carefully 
controlling the reaction conditions, the evolution of secondary phases was suppressed. However, yttrium enrichment at the grain boundaries was observed.

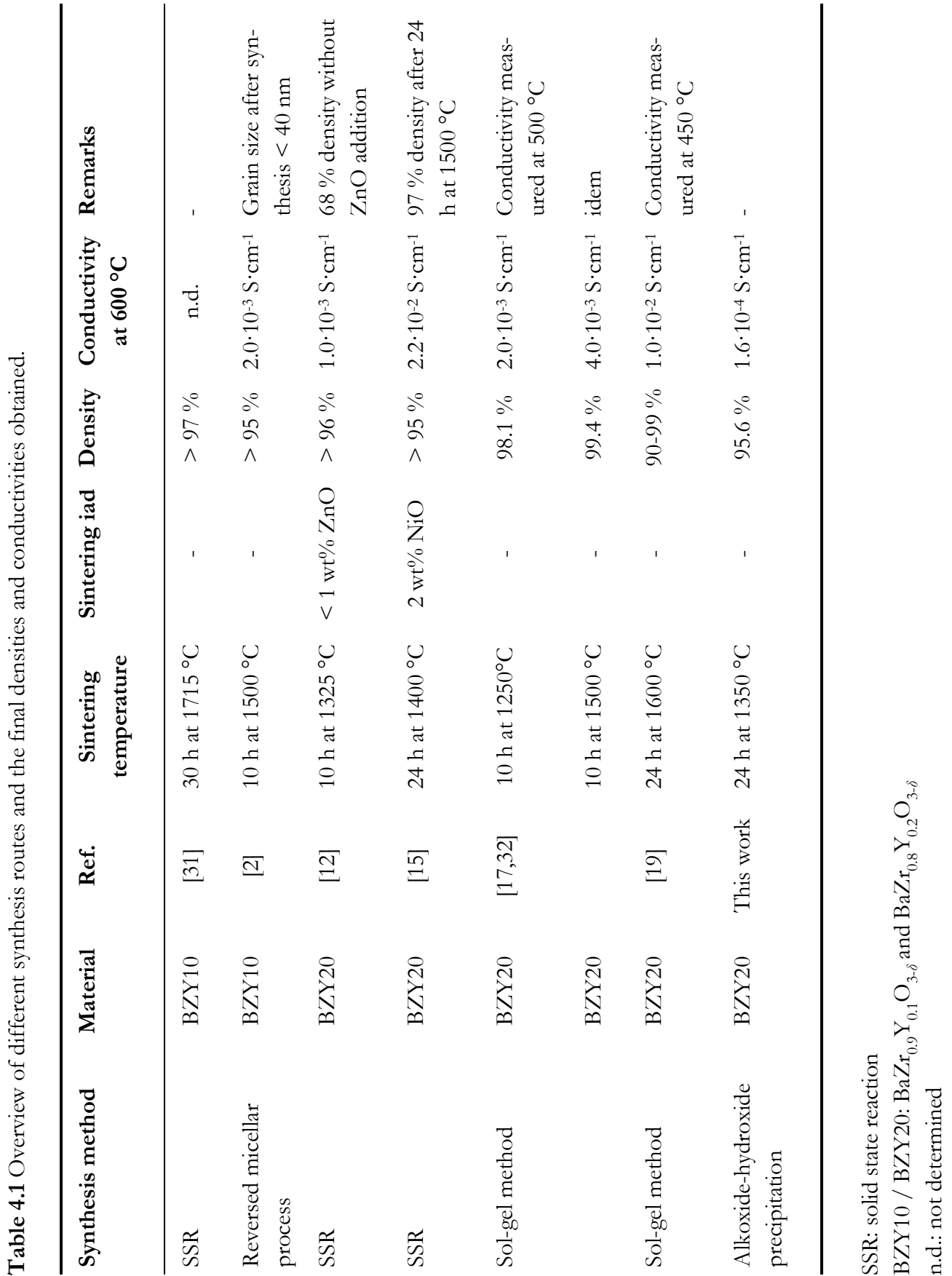




\subsection{Experimental Section}

\subsubsection{Chemicals and Materials}

Zirconium (IV) $n$-propoxide $\left(\mathrm{Zr}\left[\left(\mathrm{OC}_{3} \mathrm{H}_{7}\right)\right]_{4}\right), 70 \mathrm{w} / \mathrm{w} \%$ in propanol) and yttrium (III) iso-propoxide $\left(\mathrm{Y}\left[\left(\mathrm{OC}_{3} \mathrm{H}_{7}\right)\right]_{3}\right), 25 \mathrm{w} / \mathrm{w} \%$ in toluene) were purchased from Alfa Aesar GmbH and ABCR GmbH \& Co. KG, respectively. Benzyl alcohol (> 99.0 \%), 2-propanol $(99.5 \%)$, and barium hydroxide octahydrate $\left(\mathrm{Ba}(\mathrm{OH})_{2} \cdot 8 \mathrm{H}_{2} \mathrm{O},>98.0 \%\right)$ were acquired from Sigma-Aldrich. All chemicals were used as received from the suppliers without any further purification. Due to their high reactivity, the zirconium (IV) npropoxide and yttrium (III) iso-propoxide solutions were stored and handled in a waterfree environment $\left(<0.1 \mathrm{ppm}_{2} \mathrm{O}\right)$.

\subsubsection{Synthesis of Nano-crystalline BZY2O}

\section{Metal-alkoxide Precursor Solution}

A solution of $0.2 \mathrm{~mol} \cdot \mathrm{dm}^{-3}$ zirconium (IV) $n$-propoxide in benzyl alcohol was prepared. While stirring, a diluted solution of yttrium (III) iso-propoxide in $15 \mathrm{~mL}$ toluene was added to this solution so that the resulting ratio [Zr] to [Y] was 4:1, and a clear yellowish solution was obtained. Due to the extreme reactivity of yttrium (III) iso-propoxide, the reaction vessel was heated to $150{ }^{\circ} \mathrm{C}$ and subsequently cooled to RT in water-free environment to remove all trace amounts of water. The solution was stirred in inert atmosphere for $2 \mathrm{~h}$ to ensure good mixing of the metal alkoxide precursors. The stabilized solution was then sealed and subsequently transferred to atmospheric conditions, where it was heated for $4 \mathrm{~h}$ and $24 \mathrm{~h}$ at $100{ }^{\circ} \mathrm{C}$ under reflux conditions. The samples are denoted BZY1 and BZY2, respectively. After full ligand exchange (see Chapter 2), the mixture was cooled down to room temperature.

\section{Reflux Synthesis}

A stoichiometric amount of barium hydroxide octahydrate was added to the cooled precursor solution under vigorous stirring, so that the resulting molar ratio was Ba:Zr:Y $=5: 4: 1$. Subsequently, the reaction mixture was heated under atmospheric conditions in an oil bath and kept at $150^{\circ} \mathrm{C}$ for $20 \mathrm{~h}$ (BZY1) or $48 \mathrm{~h}$ (BZY2), respectively, under refluxing conditions. Barium zirconate (undoped), $\mathrm{BaZrO}_{3}(\mathrm{BZ})$, was synthesized as a phase reference sample under the same conditions as mentioned above. A stoichiometric ratio of $[\mathrm{Ba}]$ and $[\mathrm{Zr}]$ was used. 


\section{Drying of As-synthesized Powder}

The as-synthesized powder was centrifuged using a Heraeus Labofuge 300 for 15 min at $8000 \mathrm{rpm}$. The benzyl alcohol phase was removed by decantation and replaced with $15 \mathrm{~mL}$ of 2-propanol. Subsequently, the as-prepared powder was re-dispersed in 2-propanol and centrifuged again for $15 \mathrm{~min}$ at $8000 \mathrm{rpm}$. The abovementioned procedure of solvent replacement and re-dispersion was followed again. Finally, the dispersion of as-synthesized BZ or BZY powder in 2-propanol was poured into a petri dish and dried in an oven at $100{ }^{\circ} \mathrm{C}$ for $12 \mathrm{~h}$. The dried powders were then heat treated for $24 \mathrm{~h}$ at 250 , 450,850 , and $1000{ }^{\circ} \mathrm{C}$ in air, with heating and cooling rates of $5^{\circ} \mathrm{C} \cdot \mathrm{min}^{-1}$. Below 1000 ${ }^{\circ} \mathrm{C}$, no significant structural differences between BZY1 and BZY2 were observed.

\subsubsection{Powder Characterization}

\section{X-ray Diffraction (XRD)}

Samples were measured with X-ray powder diffraction to confirm the formation of barium zirconate, the incorporation of yttrium in the lattice for the BZY samples, and for a possible secondary phase formation using a PANalytical X'Pert Pro with a PIXcel 1D detector (PANalytical, Almelo, The Netherlands). Samples were typically measured from $2 \theta=20-90^{\circ}$, with step sizes of $0.026^{\circ}$ and $400 \mathrm{~s}$ per step. The patterns were further analyzed using the X'Pert Highscore Plus software package (version 3.0e). ICDD-card \# 06-0399 was used as a reference for the determination of the lattice parameters.

\section{Thermogravimetric Analysis \& Differential Scanning Calorimetry}

Samples were measured using a Netzsch STA 449 F3 simultaneous TGA/DSC (Netzsch, Selb, Germany). Information on the amount of water adsorption, amorphous phase, organic residues and crystallization temperature could be derived by heating the samples in Pt cups at a constant heating rate of $5{ }^{\circ} \mathrm{C} \cdot \mathrm{min}^{-1}$ to $900{ }^{\circ} \mathrm{C}$ in air $\left(\mathrm{N}_{2} / \mathrm{O}_{2}=\right.$ $80 / 20)$ or dry nitrogen.

\section{Dilatometry}

The densification behavior of powders annealed for $24 \mathrm{~h}$ at $450^{\circ} \mathrm{C}$ were measured using a Netzsch DIL 402C Dilatometer (Netzsch, Selb, Germany). The samples (pellets) were heated at a constant rate of $2{ }^{\circ} \mathrm{C} \cdot \mathrm{min}^{-1}$ to $1350{ }^{\circ} \mathrm{C}$, and held at this temperature for 24 h. Then, the samples were cooled to RT at $2{ }^{\circ} \mathrm{C} \cdot \mathrm{min}^{-1}$. Prior to the measurement, the 
samples were filtered using a $125 \mu \mathrm{m}$ sieve, and pellets of the filtered powders (diameter $10 \mathrm{~mm}$ ) were first uniaxially and subsequently isostatically pressed for 3 min at 500 bar and $6 \mathrm{~min}$ at 4000 bar, respectively. The green and final density of the pressed and sintered pallets, respectively, were determined by the water displacement method.

\section{Electron Microscopy}

A top-view of a polished sample was investigated by scanning electron microscopy (HRSEM; Zeiss Merlin at $1.4 \mathrm{kV}$ ). The sample was polished using Minimet 1000 with a Trident $^{\mathrm{TM}} \varnothing 73 \mathrm{~mm}$ PSA microcloth disc (Buehler, Lake Bluff, USA) for $60 \mathrm{~min}$ at 50 $\mathrm{rpm}$, and subsequently annealed for $1 \mathrm{~h}$ at $1250{ }^{\circ} \mathrm{C}$ in $\mathrm{N}_{2}$ (heating and cooling rates of $\left.2{ }^{\circ} \mathrm{C} \cdot \mathrm{min}^{-1}\right)$. Grain boundary regions were investigated with high-resolution transmission electron microscopy (HR-TEM; Philips CM300ST-FEG) with an acceleration voltage of $300 \mathrm{keV}$ using a Gatan Ultrascan 1000 CCD camera. Selected areas were analyzed with energy-dispersive X-ray spectroscopy (EDX) using an acceleration voltage of 280 $\mathrm{keV}$ (acquisition time of $100 \mathrm{~s}$ ). An ellipsoid-shaped beam ( $2.2 \mathrm{~nm}$ width; 10-15 nm length) was created by astigmatism, in order to measure a complete grain boundary. For quantification, the $\mathrm{Zr}-\mathrm{K}$ and $\mathrm{Y}-\mathrm{K}$ lines, and Ba-L line at approximately 15.7, 14.9, and $32.1 \mathrm{keV}$, respectively, were used.

\section{Proton Conductivity Measurements}

The proton conductivity of selected samples was measured using electrochemical impedance spectroscopy (EIS). Samples were measured from $1 \mathrm{MHz}$ to $1 \mathrm{~Hz}$ with an ac voltage amplitude of $50 \mathrm{mV}$, using an Autolab PGSTAT 128N (Metrohm Autolab B.V., Utrecht, The Netherlands). Au electrodes were applied using gold paste (MaTeck conducting paste 85 -Au, Jülich, Germany), and subsequently annealed in static air at 900 ${ }^{\circ} \mathrm{C}$ for $2 \mathrm{~h}$ (heating and cooling rates of $2{ }^{\circ} \mathrm{C} \cdot \mathrm{min}^{-1}$ ). Samples were measured in a temperature range of $450-600{ }^{\circ} \mathrm{C}$ in wet $\mathrm{H}_{2}$ atmosphere $\left(\mathrm{H}_{2} / \mathrm{N}_{2}=3 / 97 ; \mathrm{pH}_{2} \mathrm{O}=0.030\right.$ atm). 


\subsection{Results and Discussion}

\subsubsection{Synthesis of BZ and BZY20}

The incorporation of yttrium in the barium zirconate lattice is crucial to create the oxygen vacancies necessary for good proton conductivity. Figure 4.1a shows XRD patterns of BZ and BZY annealed at temperatures between 150-1000 ${ }^{\circ} \mathrm{C}$. Except for a minor $\mathrm{BaCO}_{3}$ impurity, observed in some of the samples, no secondary phases were formed. Furthermore, the peaks of the as-prepared BZY are shifted to lower diffraction angles compared to as-prepared BZ, indicating that yttrium is fully incorporated in the lattice. For increasing annealing temperatures, a shrinkage of the lattice volume (i.e. peak shift to higher diffraction angles) and minor crystallite growth was observed (see Figure 4.1b). In addition, the lattice volume of the synthesized BZY is significantly larger than found for prepared and bulk BZ powders. The fact that my prepared BZ has larger lattice parameters than the reported bulk value (ICDD-card \# 06-0399) may indicate the incorporation of internal pores or $\mathrm{OH}$ defects, which are an intrinsic effect of the alkoxide-hydroxide precipitation method. Small nano-sized pores were also found in $\mathrm{BaTiO}_{3}$ grains prepared using a similar synthetic pathway. ${ }^{[23]}$ Although normally undesirable, these additional hydroxyl defects may lead to enhanced proton conduction, as more sites are available for proton transport than normally achieved by only doping with lower valency ions. Cervera et al. utilized this phenomenon beneficially in the doublealkoxide synthesis of a fully hydrated $\mathrm{BaScO}_{2}(\mathrm{OH})$ perovskite, ${ }^{[24]}$ and reported the highest proton conductivity so far $\left(1.7 \cdot 10^{-2} \mathrm{~S} \cdot \mathrm{cm}^{-1}\right.$ at $\left.500{ }^{\circ} \mathrm{C}\right)$.

\subsubsection{Effect Heat Treatment}

\section{Thermogravimetric Analysis}

The as-prepared and annealed samples were further analyzed using a combination of thermogrivametric analysis (TGA) and differential scanning calorimetry (DSC), see Figure 4.2. For samples heat treated $<250{ }^{\circ} \mathrm{C}$ a significant mass loss was observed at $\sim 420$ ${ }^{\circ} \mathrm{C}$, which can be attributed to the oxidation of organic residues. The additional mass loss at approximately $240{ }^{\circ} \mathrm{C}$ is only found for the as-prepared samples, and is related to the loss of phenylmethoxy ligands (i.e. from the parent alcohol) attached to the particles (see Chapter 2). 

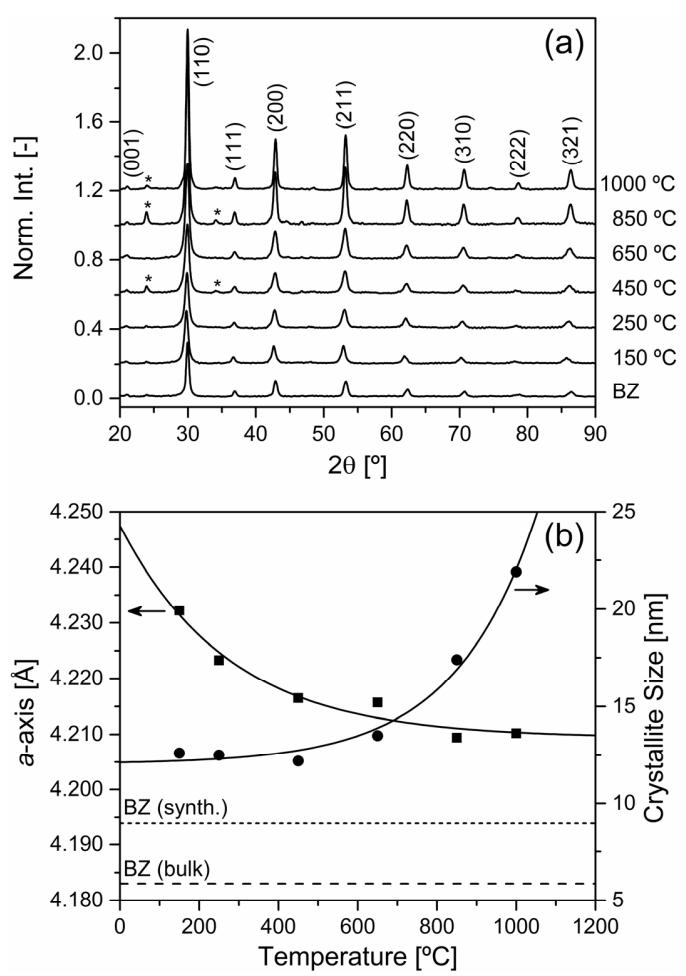

Figure 4.1 (a) XRD patterns of as-prepared and annealed BZY20 powders. As-prepared BZ sample is added as a reference. (b) The effect of annealing temperature on the cubic $p m \overline{3} m$ cell parameters and crystallite size of the synthesized BZY20. The dotted/dashed lines represent the a-axis length of BZ synthesized using the described synthesis and annealed for $24 \mathrm{~h}$ at 1000 ${ }^{\circ} \mathrm{C}$, and of bulk $\mathrm{BaZrO}_{3}$ (ICDD-card \# 06-0399), respectively.
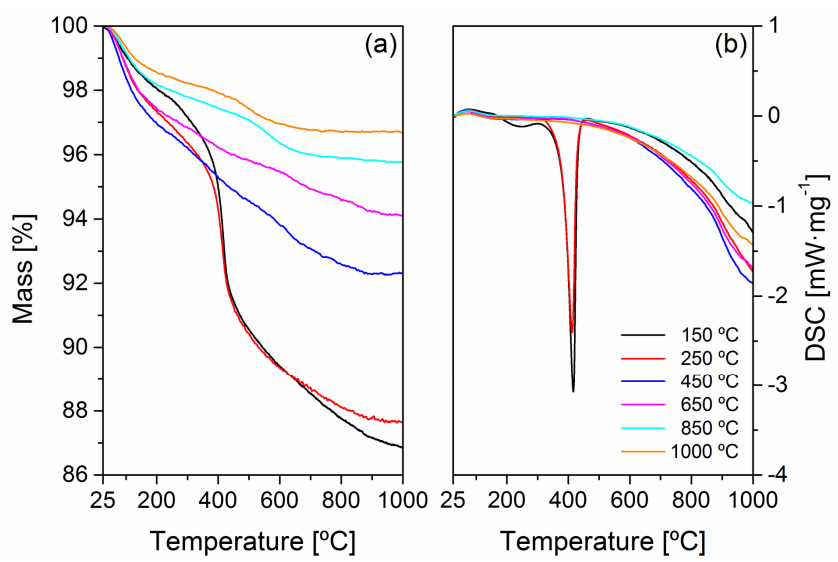

Figure 4.2 (a) Thermogravimetric and (b) calorimetric analysis of an as-prepared sample and samples heat-treated in synthetic air $\left(\mathrm{N}_{2} / \mathrm{O}_{2}=80 / 20\right)$ for $24 \mathrm{~h}$ at temperatures between 250$1000{ }^{\circ} \mathrm{C}$, respectively. 


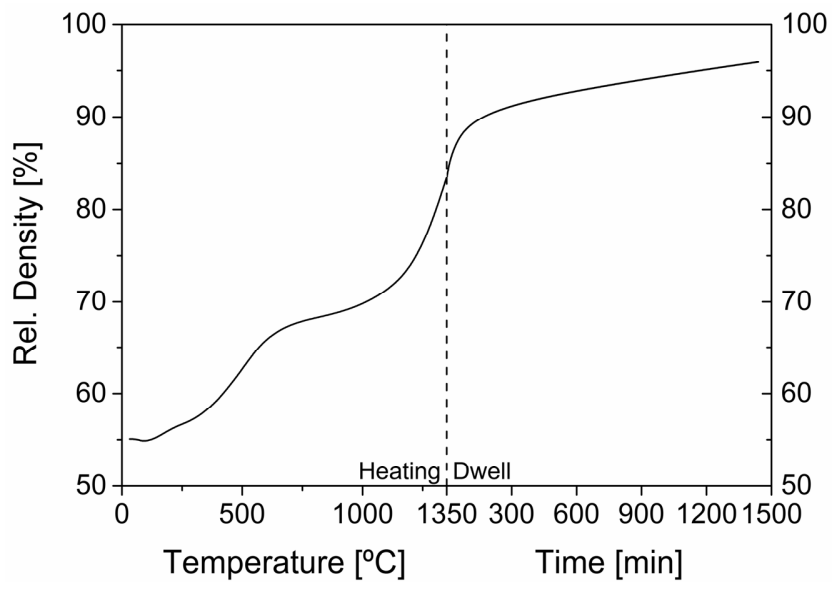

Figure 4.3 Densification behavior of BZY20 sample heated at $1350{ }^{\circ} \mathrm{C}$ for $24 \mathrm{~h}$ with heating/cooling rates of $2{ }^{\circ} \mathrm{C} \cdot \mathrm{min}^{-1}$. The 'bump' observed in the heating stage $\left(600-1000{ }^{\circ} \mathrm{C}\right)$, could be the result of a reorganization of the pore structure.

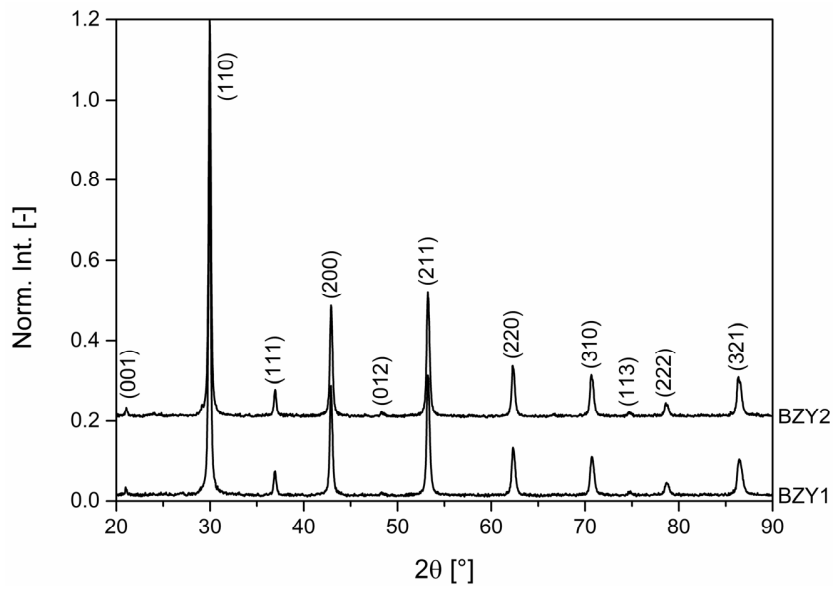

Figure 4.4 XRD patterns of BZY1 and BZY2 after sintering for $24 \mathrm{~h}$ at $1350{ }^{\circ} \mathrm{C}$ in $\mathrm{N}_{2}$ atmosphere. No secondary phases were observed.

\section{Dilatometry \& Sintering}

The densification behavior of samples heat-treated for $24 \mathrm{~h}$ at $450{ }^{\circ} \mathrm{C}$ was determined using dilatometry, as shown in Figure 4.3. A final density of $\rho_{\text {rel }}=95.6 \%$ was achieved after sintering the nanocrystalline BZY for $24 \mathrm{~h}$ at $1350{ }^{\circ} \mathrm{C}$. In the low temperature regime of approximately $120-350{ }^{\circ} \mathrm{C}$ a slow linear densification is observed, which resulted in a relative density increase of $\sim 3 \%$. The heating stage between 350 and 1000 ${ }^{\circ} \mathrm{C}$ is characterized by a 'bump' and an increased densification of $c a .12 \%$. The latter 
may be due to the reorganization of the pore structure within the material, curing, or perhaps the dehydration of the sample (as observed with TGA).

Compressed pellets of BZY1 and BZY2 were sintered for $24 \mathrm{~h}$ at $1350{ }^{\circ} \mathrm{C}$ in $\mathrm{N}_{2}$ atmosphere with an excess BZY powder to prevent $\mathrm{Ba}$ evaporation. X-ray diffraction showed that the pellets were composed of phase pure BZY; no secondary phases were present after the heat treatment (see Figure 4.4). Remarkably, only minor crystallite growth was observed for both samples. Final crystallite sizes of 43 and $40 \mathrm{~nm}$, respectively, were determined from the peak broadening of the (110) peak using the Scherrer equation. The calculated lattice parameters agree well with the plateau value of approximately $4.21 \AA$ as presented in Figure 4.1b.

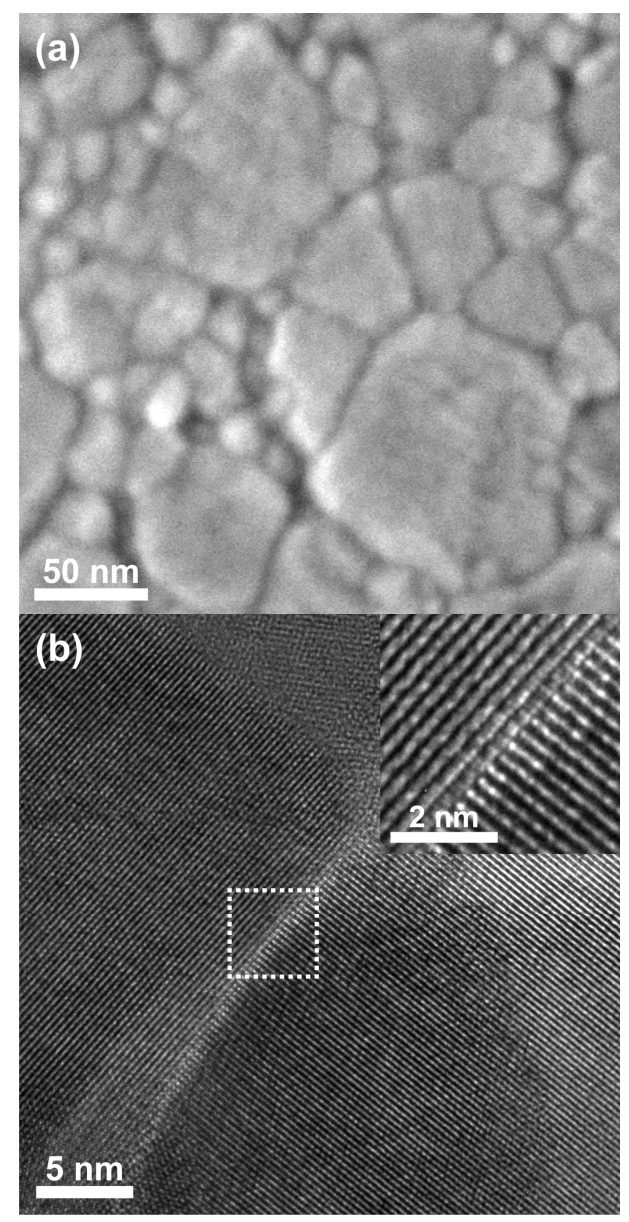

Figure 4.5 Electron microscopy images of a BZY2 pellet annealed for $24 \mathrm{~h}$ at $1350{ }^{\circ} \mathrm{C}$ in $\mathrm{N}_{2}$. (a) HR-SEM of polished (bulk) sample; (b) HR-TEM of a grain boundary region. 
Scanning electron microscopy revealed that the interior of the pellet (= bulk) consisted of particles ranging 10-120 $\mathrm{nm}$ in diameter (Figure 4.5a). The average crystallite sizes, calculated from the XRD patterns, were thus determined mainly by the much larger volume of the larger crystallite fraction, rather than by the more common smaller fraction. The presence of the ultrafine grains accounts for a significant GB surface area, and may thus have a negative effect on the overall proton conductivity (i.e. large grain boundary contribution). HR-TEM showed that the GB region is free of defects (Figure $4.5 \mathrm{~b})$, and a sharp transition between the crystal planes of two adjacent crystallites was observed. Besides the large GB surface area, the formation of a space charge layer may have a negative effect on the GB conductivity. A positive GB core can be formed due to oxygen vacancy segregation, and consequently, acceptor dopant accumulation. ${ }^{[25]}$ This leads to a depletion of protons in its vicinity. ${ }^{[26,27]}$ The degree to which this occurs is influenced by the sintering conditions and the dopant mobility under these conditions. $^{[25]}$
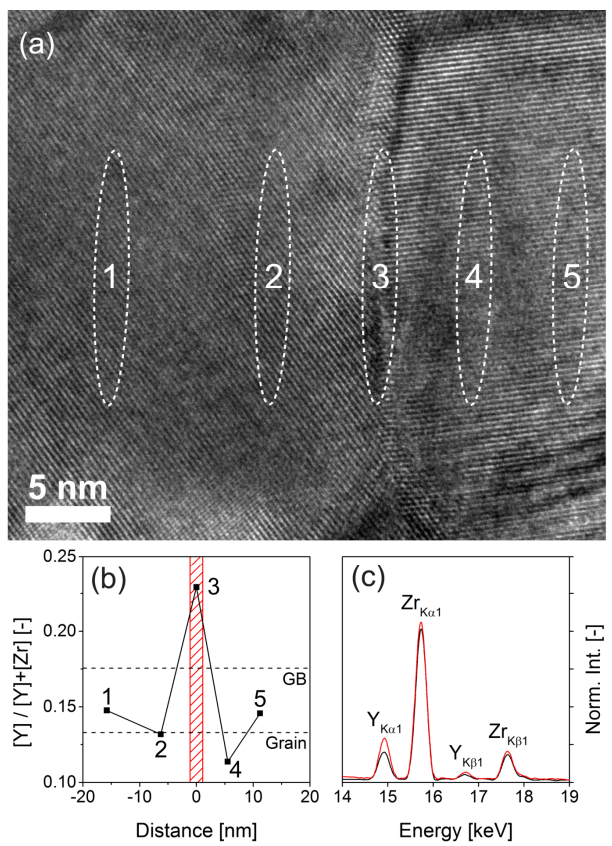

Figure 4.6 (a) HR-TEM image of grain boundary region after sintering for $24 \mathrm{~h}$ at $1350{ }^{\circ} \mathrm{C}$ in $\mathrm{N}_{2}$. (b) The Y concentration in the ellipsoid-shaped areas in (a) measured with EDX. The dotted lines indicate the average $\mathrm{Y}$ concentration at the GB and grain interior, respectively, measured from at least 5 different regions. (c) EDX spectra obtained from the GB (red line) and grain interior (black line), respectively. 
Energy-dispersive X-ray spectroscopy (EDX) on various grain boundaries and grain interiors showed that a subtle Y accumulation at the GB occurred (see Figure 4.6). Due to the standard measurement error and the small number of investigated GBs, the absolute values may deviate from the real value. However, for all measured areas a slight Y enrichment was found at the grain boundary.

\subsubsection{Performance}

The proton conduction of the sintered pellets was measured during cooling from 600$450{ }^{\circ} \mathrm{C}$ in wet atmosphere $\left(3 \% \mathrm{H}_{2}\right.$ in $\mathrm{N}_{2} ; \mathrm{pH}_{2} \mathrm{O}$ is $\left.0.030 \mathrm{~atm}\right)$. Typical impedance spectra, obtained in this temperature range, are presented in Figure 4.7. Prior to fitting the recorded impedance spectra with the 'Equivalent Circuit for Windows' software package, ${ }^{[28]}$ the data were validated using the Kramers-Kronig transformation test. ${ }^{[2]}$ From the fitted curves, the conductivity was calculated according to:

$$
\sigma=\frac{d}{R \cdot A}
$$

where, $d$ and $A$ are the sample thickness, and electrode surface area, respectively. $\mathrm{R}$ is either the bulk, GB, or total resistance.

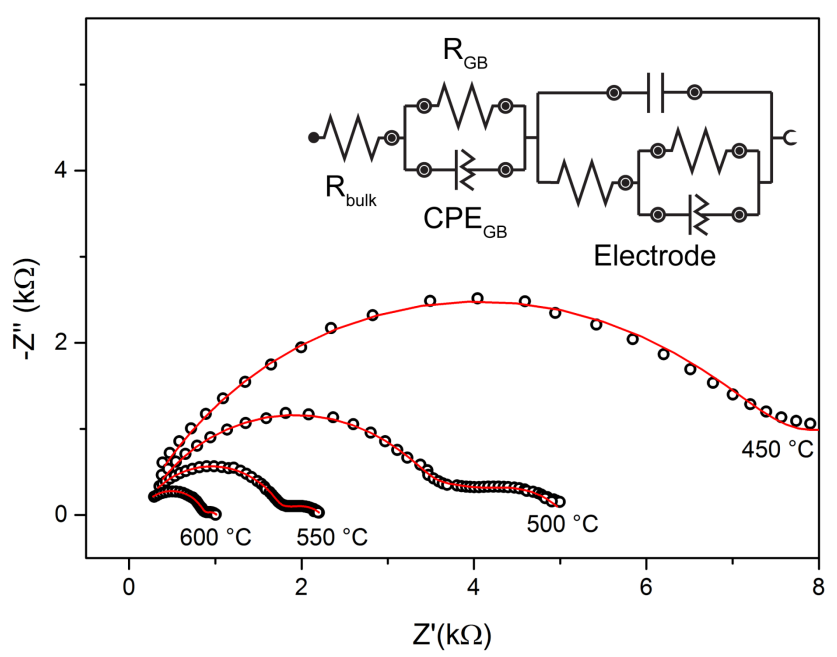

Figure 4.7 Typical Nyquist representation of the BZY impedance spectra measured in the range of $450-600{ }^{\circ} \mathrm{C}$. Data were fitted according to the shown equivalent circuit. 
Table 4.2 Proton conductivity measured at $600^{\circ} \mathrm{C}$ and activation energies.

\begin{tabular}{cccccc}
\hline Sample & \multicolumn{3}{c}{ Conductivity $\left[\mathbf{S} \cdot \mathbf{c m}^{-1}\right]$} & \multicolumn{2}{c}{ Activation Energy [eV] } \\
& Bulk & GB & Total & GB & Total \\
\hline BZY1 & $9.4 \cdot 10^{-4}$ & $1.4 \cdot 10^{-4}$ & $1.2 \cdot 10^{-4}$ & $0.84 \pm 0.03$ & $0.79 \pm 0.02$ \\
BZY2 & $9.3 \cdot 10^{-4}$ & $2.0 \cdot 10^{-4}$ & $1.6 \cdot 10^{-4}$ & $0.70 \pm 0.02$ & $0.65 \pm 0.03$ \\
\hline
\end{tabular}

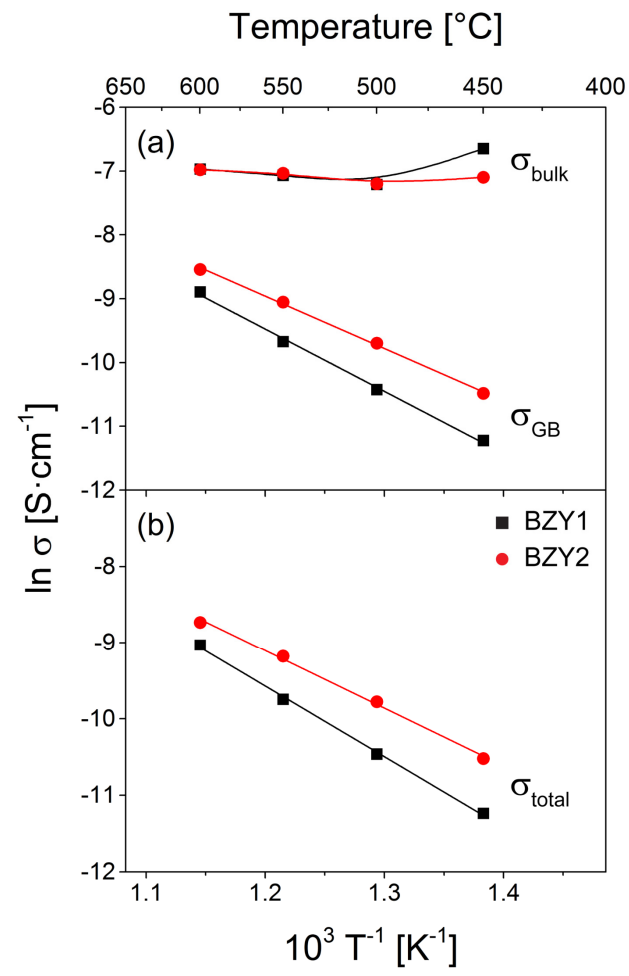

Figure 4.8 Arrhenius representation of: (a) the bulk and grain boundary conductivity; (b) the total proton conductivity for BZY1 (black squares) and BZY2 (red circles), respectively. Both samples have a relative density of approximately $94 \%$.

An overview of the maximum conductivities, measured at $600{ }^{\circ} \mathrm{C}$, is presented in Table 4.2. Although the bulk conductivity is near the reported values in Table 4.1, the total conductivity was mainly determined by the low GB conductivity. The slight distortion in the semicircle, observed in the Nyquist plot (Figure 4.7), may be related to inhomogeneities in the sample's composition (e.g. secondary phases) or the microstructure. ${ }^{[26]}$ Since the total amount of secondary phases was below the XRD detection limit, it is 
unlikely that they caused the distortion. The effect may rather be explained by the large GB area due to the presence of many ultrafine grained crystallites, and the observed Y enrichment at the GB. Based on the current measurements, however, it cannot be concluded which of the two is predominantly governing the low GB conductivity. Figure 4.8 shows the Arrhenius representation of the measured bulk, GB, and the total conductivity. The bulk conductivity for the BZY1 and BZY2 samples are equal above 500 ${ }^{\circ} \mathrm{C}$. At $450{ }^{\circ} \mathrm{C}$, an increase of the bulk conductivity was observed for both samples. Although the nature of this increase was not investigated, hydration (i.e. water uptake) of the proton conducting oxide, and consequently hydroxyl formation are thermodynamically more favorable at lower temperatures. ${ }^{[3]}$ The GB and total conductivity of $\mathrm{BZY} 2$ are higher than that of BZY1 in the measured temperature range. Also, the activation energy for both the GB and total conductivity, calculated from the slope, is lower for BZY2 (see Table 4.2). Most likely, this is related to the longer time the $\mathrm{Zr}$ and $\mathrm{Y}$ precursor were mixed prior to the reaction ( $24 \mathrm{~h}$ versus $4 \mathrm{~h}$, respectively), resulting in a more homogeneous dopant distribution. The activation energies correspond well with the reported values in literature. ${ }^{[2,11,30]}$

\subsection{Conclusions}

The low-temperature synthesis of proton conducting yttrium-doped barium zirconate in benzyl alcohol was presented. Due to the nano-sized grains, rapid densification was observed at lower temperatures than common used during solid state sintering. A maximum relative density of $\sim 95.6 \%$ was achieved after sintering for $24 \mathrm{~h}$ at $1350{ }^{\circ} \mathrm{C}$. The as-sintered material exhibited defect-free grain boundaries, with a sharp transition between two adjacent grains. The total conductivity was mainly determined by the grain boundary contribution, which was caused by the $\mathrm{Y}$ enrichment at the grain boundaries and the presence of ultrafine grains $(10-20 \mathrm{~nm})$ after the sintering procedure. A maximum proton conductivity of $1.6 \cdot 10^{-4} \mathrm{~S} \cdot \mathrm{cm}^{-1}$ was achieved at $600{ }^{\circ} \mathrm{C}$ in wet $\mathrm{H}_{2}$ atmosphere. Longer precursor intermixing resulted in a more homogeneous dopant distribution, and consequently in a lower activation energy and higher grain boundary conductivity. 


\subsection{Bibliography}

[1] H. Iwahara, T. Esaka, H. Uchida, N. Maeda, Proton conduction in sintered oxides and its application to steam electrolysis for hydrogen production. Solid State Ionics 1981, 3-4, 359-363.

[2] Z. Khani, M. Taillades-Jacquin, G. Taillades, M. Marrony, D. J. Jones, J. Rozière, New synthesis of nanopowders of proton conducting materials. A route to densified proton ceramics. $J$. Solid State Chem. 2009, 182, 790-798.

[3] K. D. Kreuer, Proton-Conducting Oxides. Annual Review of Materials Research 2003, 33, 333359.

[4] E. Fabbri, D. Pergolesi, E. Traversa, Materials challenges toward proton-conducting oxide fuel cells: A critical review. Chem. Soc. Rev. 2010, 39, 4355-4369.

[5] N. Bonanos, Oxide-based protonic conductors: point defects and transport properties. Solid State Ionics 2001, 145, 265-274.

[6] Y. Yamazaki, P. Babilo, S. M. Haile, Defect chemistry of yttrium-doped barium zirconate: A thermodynamic analysis of water uptake. Chem. Mater. 2008, 20, 6352-6357.

[7] K.-D. Kreuer, Proton Conductivity: Materials and Applications. Chem. Mater. 1996, 8, 610641.

[8] F. M. M. Snijkers, A. Buekenhoudt, J. Cooymans, J. J. Luyten, Proton conductivity and phase composition in BaZr0.9Y0.1O3-ס. Scripta Mater. 2004, 50, 655-659.

[9] T. Norby, M. Widerøe, R. Glöckner, Y. Larring, Hydrogen in oxides. Dalton Trans. 2004, 3012-3018.

[10] C. Peng, J. Melnik, J. L. Luo, A. R. Sanger, K. T. Chuang, BaZr0.8Y0.2O3- $\delta$ electrolyte with and without $\mathrm{ZnO}$ sintering aid: Preparation and characterization. Solid State Ionics 2010, 181, $1372-$ 1377.

[11] P. Babilo, S. M. Haile, Enhanced sintering of yttrium-doped barium zirconate by addition of ZnO. J. Am. Ceram. Soc. 2005, 88, 2362-2368.

[12] S. Tao, J. T. S. Irvine, Conductivity studies of dense yttrium-doped BaZrO3 sintered at 1325 ${ }^{\circ}$ C. J. Solid State Chem. 2007, 180, 3493-3503.

[13] S. Tao, J. T. S. Irvine, A stable, easily sintered proton-conducting oxide electrolyte for moderate-temperature fuel cells and electrolyzers. Adv. Mater. 2006, 18, 1581-1584.

[14] J. Tong, D. Clark, L. Bernau, M. Sanders, R. O'Hayre, Solid-state reactive sintering mechanism for large-grained yttrium-doped barium zirconate proton conducting ceramics. J. Mater. Chem. 2010, 20, 6333-6341. 
[15] J. Tong, D. Clark, M. Hoban, R. O'Hayre, Cost-effective solid-state reactive sintering method for high conductivity proton conducting yttrium-doped barium zirconium ceramics. Solid State Ionics 2010, 181, 496-503.

[16] S. B. C. Duval, P. Holtappels, U. Stimming, T. Graule, Effect of minor element addition on the electrical properties of BaZr0.9Y0.1O3-ס. Solid State Ionics 2008, 179, 1112-1115.

[17] R. B. Cervera, Y. Oyama, S. Yamaguchi, Low temperature synthesis of nanocrystalline proton conducting BaZr0.8Y0.2O3- $\delta$ by sol-gel method. Solid State Ionics 2007, 178, 569-574.

[18] D. Gao, R. Guo, Yttrium-doped barium zirconate powders synthesized by the gel-casting method. J. Am. Ceram. Soc. 2010, 93, 1572-1575.

[19] Y. Yamazaki, R. Hernandez-Sanchez, S. M. Haile, High total proton conductivity in largegrained yttrium-doped barium zirconate. Chem. Mater. 2009, 21, 2755-2762.

[20] F. Boschini, A. Rulmont, R. Cloots, B. Vertruyen, Rapid synthesis of submicron crystalline barium zirconate $\mathrm{BaZrO} 3$ by precipitation in aqueous basic solution below $100^{\circ} \mathrm{C}$. J. Eur. Ceram. Soc. 2009, 29, 1457-1462.

[21] Y. Yamazaki, C. K. Yang, S. M. Haile, Unraveling the defect chemistry and proton uptake of yttrium-doped barium zirconate. Scripta Mater. 2011, 65, 102-107.

[22] P. Babilo, T. Uda, S. M. Haile, Processing of yttrium-doped barium zirconate for high proton conductivity. J. Mater. Res. 2007, 22, 1322-1330.

[23] T. M. Stawski, S. A. Veldhuis, O. F. Göbel, E. Podstawka-Proniewicz, J. E. Ten Elshof, Electron microscopy study of intragranular nanoporosity and the occurrence of local structural disorder in cubic $\mathrm{BaTiO} 3$ nanopowders from alkoxidehydroxide precipitation process. Ceram. Int. 2012, 38, 6911-6917.

[24] R. B. Cervera, S. Miyoshi, Y. Oyama, Y. E. Elammari, T. Yagi, S. Yamaguchi, Perovskitestructured $\mathrm{BaScO} 2(\mathrm{OH})$ as a novel proton conductor: Heavily hydrated phase obtained via lowtemperature synthesis. Chem. Mater. 2013, 25, 1483-1489.

[25] M. Shirpour, B. Rahmati, W. Sigle, P. A. Van Aken, R. Merkle, J. Maier, Dopant segregation and space charge effects in proton-conducting $\mathrm{BaZrO} 3$ perovskites. Journal of Physical Chemistry C 2012, 116, 2453-2461.

[26] C. Kjølseth, H. Fjeld, Ø. Prytz, P. I. Dahl, C. Estournès, R. Haugsrud, T. Norby, Spacecharge theory applied to the grain boundary impedance of proton conducting BaZr0.9Y0.1O3- $\delta$. Solid State Ionics 2010, 181, 268-275.

[27] M. Shirpour, R. Merkle, J. Maier, Evidence for space charge effects in Y-doped BaZrO3 from reduction experiments. Solid State Ionics 2012, 216, 1-5. 
[28] B. A. Boukamp, University of Twente/WisseQ, The Netherlands (C1985-2005.

[29] B. A. Boukamp, A Nonlinear Least Squares Fit procedure for analysis of immittance data of electrochemical systems. Solid State Ionics 1986, 20, 31-44.

[30] S. Ricote, N. Bonanos, H. J. Wang, B. A. Boukamp, Conductivity study of dense BaZr0.9Y0.1O(3 - $\delta)$ obtained by spark plasma sintering. Solid State Ionics 2012, 213, 36-41.

[31] H. G. Bohn, T. Schober, Electrical conductivity of the high-temperature proton conductor BaZr0.9Y0.1O2.95. J. Am. Ceram. Soc. 2000, 83, 768-772.

[32] R. B. Cervera, Y. Oyama, S. Miyoshi, K. Kobayashi, T. Yagi, S. Yamaguchi, Structural study and proton transport of bulk nanograined Y-doped $\mathrm{BaZrO} 3$ oxide protonics materials. Solid State Ionics 2008, 179, 236-242. 


\title{
A Facile Method for the Density Determination of Ceramic Thin Films using X-ray Reflectivity*
}

\begin{abstract}
A fast and non-destructive method based on X-ray reflectivity was developed to determine the density of sol-gel derived ceramic thin films, without prior assumptions on the microstructure of the system. The thin film density is calculated from the critical angle $\theta_{c}$, i.e. the maximum angle at which total external reflection is still observed, which becomes increasingly difficult for imperfect films. I propose a simple numerical approach, instead of laborious fitting procedures, to determine the thin film density. A pseudocritical angle, $\theta_{\mathrm{pc}}$, was defined by the first minimum in the $3^{\text {rd }}$ derivative of the reflectivity curves. The measured samples were compared with calibration curves obtained from simulations with changing film densities. Although the absolute positions of $\theta_{c}$ and $\theta_{\mathrm{pc}}$ are different, similar shifts are observed with changing density. The accuracy of the described method was validated by determining the density of single crystal substrates $\left(\rho_{\text {rel }}=100 \%\right)$ and by Rutherford backscattering spectroscopy in combination with scanning electron microscopy. Varying sample size, film thickness, and film/interface roughness of yttria-stabilized zirconia films were found to have no influence on the final calculated density.
\end{abstract}

${ }^{*}$ This chapter has been published in: S.A. Veldhuis, P. Brinks, T.M. Stawski, O.F. Göbel, and J.E. ten Elshof, Journal of Sol-Gel Science and Technology 2014, 71, (1), 118-128. 


\subsection{Introduction}

Material properties of thin films are strongly affected by their microstructure, and for many applications it is crucial to optimize the deposition and thermal treatment conditions to control parameters such as film thickness, crystallinity and orientation, density, and surface roughness. Most of these parameters can be quantified by standard analytical techniques such as scanning and transmission electron microscopy (SEM/TEM), $\mathrm{X}$-ray diffraction (XRD), and atomic force microscopy (AFM). However, the density of thin films is difficult to quantify experimentally. In this chapter, I propose a simple and accurate method to determine the film density of ceramic thin films. The method, based on well-established and easily accessible techniques, is demonstrated by the experimental determination of the density of single crystals and polycrystalline thin films. There are several known methods of density determination, each with their own advantages and disadvantages as outlined below, but the method I propose here is applicable to all types of ceramic thin films, and is even suitable for use on a routinely basis by virtue of its simplicity, while it does not require prior knowledge of the microstructure of the system under investigation.

The best known example of density determination is Archimedes' method. However, it is not applicable to thin films since the volume displacement caused by a film is too small to be accurately determined. More common is to analyze a film crosssection by SEM. The film density can be calculated from the ratio of particles and pores as determined from the local variation in optical contrast. Often, laborious computer procedures are needed. ${ }^{[1,2]}$ The underlying assumption is that the fraction of surface area covered by pores and particles in the $2 \mathrm{D}$ cross-section is equivalent to their volume fractions in 3D, which may not always be the case.

An alternative strategy is to determine the film thickness or the mean particle diameter and compare it with the thickness of a fully sintered film or the mean diameter of a fully sintered particle, respectively. ${ }^{[3,4]}$ The difference can be described as the entrapment of pores, and the relative density $\rho_{\text {rel }}$ is calculated from:

$$
\rho_{\text {rel }}=100-\left[\left(\frac{d_{\text {film }}-d_{\text {dense }}}{d_{\text {dense }}}\right) * 100 \%\right] \text { or } \rho_{\text {rel }}=\left(\frac{d_{\exp }^{3}-d_{0}^{3}}{d_{\exp }^{3}}\right) * 100 \%
$$


where $d_{\text {film }}, d_{\text {dense }}, d_{\text {exp }}$, and $d_{0}$ are the thin film thickness of the measured and a fully dense film, and the experimental and theoretical (= dense) mean particle diameter, respectively. This implies that prior knowledge on the densification behavior of the film is necessary. Besides, this technique is also destructive to the sample.

The Swanepoel method is a non-destructive method that can be used to accurately determine $\left(<1 \%\right.$ error) both the film thickness and density. ${ }^{[5-7]}$ The calculations are based on the transmittance spectrum of a thin film on an optically transparent substrate. The experiments are simple, but the different models that are needed to fit the data can lead to varying refractive indexes, and thus to varying densities. ${ }^{[6]}$ Moreover, in general the data cannot be extrapolated to other (non-transparent) substrates, since strain caused by differences in thermal expansion coefficients between film and substrate affects the densification behavior of the thin films. ${ }^{[8,9]}$

Rutherford backscattering spectroscopy (RBS) is a common, non-destructive technique for thin film analysis. It is based on the recoil of high energy (1-2 MeV) $\mathrm{He}^{2+}$ ions off a sample's surface under a well-defined angle, and can be used to obtain information on element stoichiometry and either film thickness or density. Also, it can be used to measure impurities, and for depth profiling. Although nearly all elements of the periodic table $(Z>6)$ can be detected, it is not equally sensitive for all elements (error $1-5 \%$ ). Lastly, the relatively high experimental costs prohibits its use as routine analysis technique.

Ellipsometry is another non-destructive optical technique that is often used for thin film analysis. The reflectance of a polarized light beam that irradiates a sample is measured. Optical constants and thin film thickness are determined indirectly by measuring the amplitude and phase difference between two reflected beams. However, only in the simplest case of an infinitely homogenous thick film, the optical constants and film thickness can be determined directly. In all other cases the amplitude and phase difference are calculated via iterative modeling procedures. In general, one can accurately determine the density with ellipsometry, but a combination of complex models is necessary to fully describe the investigated sample, since the used parameters have no direct (universal) physical meaning. ${ }^{[10]}$

Another well-established and non-destructive technique for thin film analysis is $\mathrm{X}$-ray reflectivity (XRR); a versatile method that can be used for crystalline, amorphous, and even liquid samples. ${ }^{[11,12]}$ An X-ray beam impinges the thin film surface at a 
low angle of incidence. Below the critical angle of total reflection, $\theta_{c}$, the surface acts as a mirror, and the beam is totally reflected. At angles larger than $\theta_{c}$, the measured beam intensity rapidly drops and film thickness, roughness, and chemical composition can be obtained by fitting the full reflectivity curve with well-known models. ${ }^{[11-13]}$ The value of the critical angle determined by the curve fit is directly related to the electron density, which is proportional to the average thin film mass density. Although this technique is widely used in thin film analysis of films grown by chemical vapor deposition (CVD) or pulsed laser deposition (PLD), it is not often used in the field of sol-gel and other wet chemistry-derived ceramic thin films. ${ }^{[14-16]}$

An overview of all of the abovementioned techniques is presented in Table 5.1. I was interested in developing a high throughput, high accuracy method. And although RBS measurements qualify with respect to accuracy, the technique is rather expensive for routine analyses of large numbers of samples. I therefore chose XRR for density determination, since the measurements are fast and easy to perform using standard laboratory diffractometers. The theory behind the models is well-understood, which simplifies data analysis. In general the method assumes an isotropic film, but a density gradient can be taken into account. ${ }^{[17]}$

As was mentioned above, XRR is often used for thin films grown with physical vapor deposition techniques. Since these films are typically stoichiometric and of high density, the reflectivity curves are only partially fitted at angles $>\theta_{c}$ to determine the thickness and the interface roughness. Consequently, the calculated densities obtained via these partial fits are rather inaccurate and may deviate largely from the real density values. Since the thickness, microstructure, and roughness of sol-gel and other ceramic thin films are usually evaluated during the optimization of the deposition process, e.g. from SEM images on cross sections and AFM, only an accurate determination of the critical angle or inflection point is additionally needed to determine the density of the thin film.

In this chapter I describe a simple and quick numerical approach to accurately determine the inflection point of X-ray reflectivity curves. With this method I determined the density of sol-gel derived yttria stabilized zirconia (YSZ) films. The method was validated by measuring the density of sapphire and zinc oxide single crystal substrates $\left(\rho_{\text {theoretical }}=100 \%\right)$ and RBS measurements, and was subsequently extended to thin films deposited on a substrate. It is demonstrated below that film thickness, surface 
roughness, and choice of substrate have no apparent effect on the final calculated density. The key advantage of my approach is that an often very challenging complete curve fit is not required.

Table 5.1 Overview of available methods for the density determination and their properties.

\begin{tabular}{|c|c|c|c|c|}
\hline Technique & Based on & Error & Advantages & Disadvantages \\
\hline Archimedes & $\begin{array}{l}\text { Volume displace- } \\
\text { ment }\end{array}$ & n.d. & Simple, fast & Not applicable for thin films \\
\hline \multirow[t]{2}{*}{ SEM } & $\begin{array}{l}\text { Contrast particles / } \\
\text { pores }\end{array}$ & n.d. & Widely applicable & $\begin{array}{l}\text { Assumes fraction } 2 \mathrm{D} \text { cross-section } \\
\text { is equivalent in } 3 \mathrm{D} \text {, laborious pro- } \\
\text { cessing }\end{array}$ \\
\hline & $\begin{array}{l}\text { Difference in film } \\
\text { thickness dense / } \\
\text { porous }\end{array}$ & n.d. & Simple & $\begin{array}{l}\text { Knowledge of densification behav- } \\
\text { ior necessary }\end{array}$ \\
\hline Swanepoel & Refractive index & $<1 \%$ & $\begin{array}{l}\text { Non-destructive, simple, fast, } \\
\text { film thickness }\end{array}$ & $\begin{array}{l}\text { Only valid for transparent sub- } \\
\text { strates, applicable for films }<300 \\
\mathrm{~nm}\end{array}$ \\
\hline RBS & $\begin{array}{l}\text { Recoil } \mathrm{He}^{2+} \text { ions } \\
\text { off sample surface }\end{array}$ & $1-5 \%$ & $\begin{array}{l}\text { Non-destructive, whole peri- } \\
\text { odic table }(Z>6) \text { covered, } \\
\text { stoichiometry, depth-profil- } \\
\text { ing, film thickness }\end{array}$ & $\begin{array}{l}\text { Not sensitive to all elements, ex- } \\
\text { pensive, slow }\end{array}$ \\
\hline Ellipsometry & $\begin{array}{l}\text { Reflectance of a } \\
\text { polarized light } \\
\text { beam }\end{array}$ & $<1 \%$ & $\begin{array}{l}\text { Non-destructive, fast, high } \\
\text { resolution, film thickness }\end{array}$ & $\begin{array}{l}\text { Indirect, difficult data interpreta- } \\
\text { tion (via modeling) }\end{array}$ \\
\hline XRR & $\begin{array}{l}\text { Total external re- } \\
\text { flection under low } \\
\text { incidence angles }\end{array}$ & $<1 \%$ & $\begin{array}{l}\text { Non-destructive, fast, small } \\
\text { number of fitting parame- } \\
\text { ters, film thickness / rough- } \\
\text { ness }\end{array}$ & $\begin{array}{l}\text { Difficult to determine the density } \\
\text { of imperfect films }\end{array}$ \\
\hline
\end{tabular}




\subsection{Theory}

\subsubsection{General}

$\mathrm{X}$-ray reflectivity or reflectometry is an X-ray technique that is based on the scattering effects of smooth surfaces measured at very low angles of incidence. It was first described by Compton in $1923 .{ }^{[18]}$ He found that the density of metal substrates was related to a so-called critical angle. Due to the low angles of incidence, the penetration depth of the X-rays is low and only structural information of the top surface is obtained, which can be extrapolated for completely homogeneous films. Moreover, below the critical angle, it leads to the phenomenon of total external reflection for smooth films, where the angle of incidence equals the angle of reflectance, $\theta_{i}=\theta_{r}$ (see Figure 5.1a).

(a)

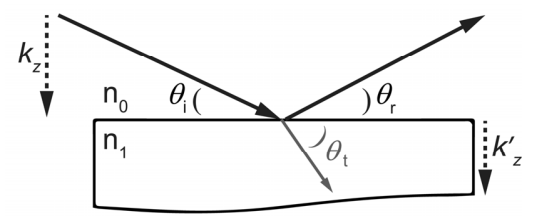

(b)

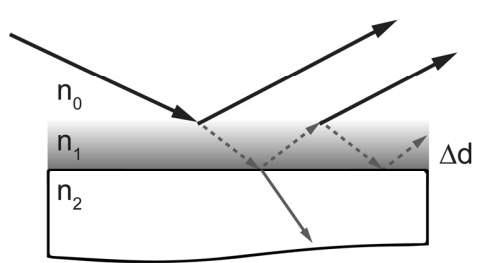

Figure 5.1 Schematic representation of the reflection and transmission of a film of infinite (substrate) and finite (thin film) thickness. (a) an X-ray beam impinges the surface of a polished substrate on very low angle, $\theta_{\mathrm{i}}, \theta_{\mathrm{r}}$ and $\theta_{\mathrm{t}}$ are the angle of incidence, reflection, and refraction (transmittance), respectively. The vertical wave vectors of the incident and transmitted beam are described by $k_{z}$ and $k_{z}^{\prime}$, respectively; (b) as the X-ray beam impinges a finite thin film (thickness $\Delta \mathrm{d}$ ), a phase shift related to the difference in refractive index between film and substrate is observed, and an infinite sequence of reflections is possible.

Another surface phenomenon, refraction, is observed when the X-ray beam passes from one medium to another, and is described by Snell-Descartes' law:

$$
\frac{\cos \theta_{i}}{\cos \theta_{t}}=\frac{n_{1}}{n_{0}}
$$


where $\theta_{i}, \theta_{t}, n_{0}$, and $n_{1}$ are the angles of incidence and refraction, and the refractive indices of media ' 0 ' and ' 1 ', respectively. X-ray reflectivity measures the angles with respect to the sample's surface instead of its normal, therefore, cosines are used. Since the refractive index of air $\left(=n_{0}\right)$ is 1 , the expression can be written as:

$$
\cos \theta_{i}=n_{1} \cdot \cos \theta_{t}
$$

This technique does not rely on diffraction, and for this reason amorphous films can also be investigated.

\subsubsection{Refractive Index of X-rays \& Critical Angle}

The refractive index of X-rays in media is slightly smaller than unity. The complex refractive index can be described as a deviation from unity with a real dispersive part (associated with density and chemical composition) and an imaginary dissipative part (associated with absorption effects):

$$
n=1-\delta-i \beta
$$

Here $\delta$ and $\beta$ are the dispersive and dissipative part of the refractive index, respectively, and can be described as:

$$
\begin{gathered}
\delta=\frac{\lambda^{2} r_{e}}{2 \pi} \rho_{e} \\
\beta=\frac{\lambda}{4 \pi} \mu
\end{gathered}
$$

where $\lambda$ is the X-ray wavelength (typically $1.5418 \AA$ for $\mathrm{Cu} \mathrm{K} \alpha$ ), $r_{e}$ the classical electron radius $\left(2.818 \cdot 10^{-15} \mathrm{~m}\right), \rho_{e}$ the electron density, and $\mu$ the attenuation coefficient. The latter is related to the material's density via the mass attenuation coefficient $\mu / \rho$ (in $\mathrm{cm}^{2 \cdot} \mathrm{g}^{-1}$ ), and can be found in the International Tables of Crystallography. ${ }^{[19]}$ The dispersive part $\delta$ has typically values in the range of $10^{-5}$ to $10^{-6}$, for the dissipative part $\beta$ the values are approximately an order of magnitude smaller. The deviation from unity caused by the imaginary dissipative part is so small, that it is often neglected, i.e. $\beta=0$. The expression for the refractive index is then described by: 


$$
n=1-\delta
$$

Since the transmittance into the material then equals zero, the relationship, after derivation, between the angle of incidence and the real dispersive part can be written as:

$$
\theta_{t}=\sqrt{\theta_{i}^{2}-2 \delta}=0
$$

and total external reflection can only be observed under very small angles, when $\theta_{i}^{2}<$ $2 \delta$ is still valid. The critical angle of total external reflection is thus described by $\theta_{\mathrm{c}} \approx \sqrt{2 \delta}$, which usually lies in the range of $0.1-0.4^{\circ}$ for $\mathrm{Cu} \mathrm{K} \alpha$ irradiation. For materials with known stoichiometry, the mass density of the measured material $\rho_{m}$ is directly calculated from $\rho_{e}$ in Eq. (5.5):

$$
\rho_{m}=\frac{\rho_{e} \cdot A}{N_{\mathrm{A}} \cdot Z}
$$

Here $\rho_{m}$ and $\rho_{e}$ are the mass and electron density, $N_{\mathrm{A}}$ Avogadro's number, $A$ the atomic weight, and $Z$ the atomic number. This equation, however, can only be used for mono-atomic materials. For more complex structures such as fluorite or perovskite materials, the mass density may be calculated using the sum of the individual atoms in the unit cell. ${ }^{[11]}$

\subsubsection{Fresnel Reflectivity}

An X-ray beam can be described as a propagating wave; the magnitude and direction in which the beam propagates is described by wave vectors for the incident, reflected, and transmitted waves. The wave vectors describe the X-ray beam's behavior when propagating through media with different refractive indices:

$$
\frac{I_{r}}{I_{0}}=\left|r_{s} \cdot r_{p}\right| \approx\left|r^{2}\right|=\left|\frac{k_{z}-k_{z}^{\prime}}{k_{z}+k_{z}^{\prime}}\right|^{2}
$$

The Fresnel coefficients, $r$, are calculated for the electric field of the beam perpendicular (s-polarization) and parallel (p-polarization) to the scattering plane. Since the difference between s- and p-polarization is small, it is often neglected. The ratio of total reflected 
and incident intensity of the measured sample, $I_{r} / I_{0}=1$, is thus the product of the calculated coefficients, see Eq. (5.10). Here $k_{z}$ and $k_{z}^{\prime}$ are the vertical components of the wave vectors of the incident and transmitted beam (for the s-polarized electric field), respectively, as shown in Figure 5.1a.

\subsubsection{Parratt's Formalism}

\section{Homogenous Media of Infinite Thickness}

The reflection of smooth and homogenous media can be calculated by substitution of Snell-Descartes' law into the Fresnel equations. ${ }^{[20]}$ In view of Eq. (5.11) and Eq. (5.12), the ratio of reflected and incident intensity of the beam is only dependent on the critical angle, $\theta_{\mathrm{c}}$, and the absorption of X-rays in the medium, $\beta / \delta$.

$$
\begin{aligned}
& \frac{I_{r}}{I_{0}}=\left|r^{2}\right|=\frac{\left[b-\left(\frac{\theta_{i}}{\theta_{c}}\right) \sqrt{2}(b-1)\right]^{\frac{1}{2}}}{\left[b+\left(\frac{\theta_{i}}{\theta_{c}}\right) \sqrt{2}(b-1)\right]^{\frac{1}{2}}} \\
& h=\left(\frac{\theta_{i}}{\theta_{c}}\right)+\left\{\left[\left(\frac{\theta_{i}}{\theta_{c}}\right)^{2}-1\right]+\left(\frac{\beta}{\delta}\right)^{2}\right\}^{\frac{1}{2}}
\end{aligned}
$$

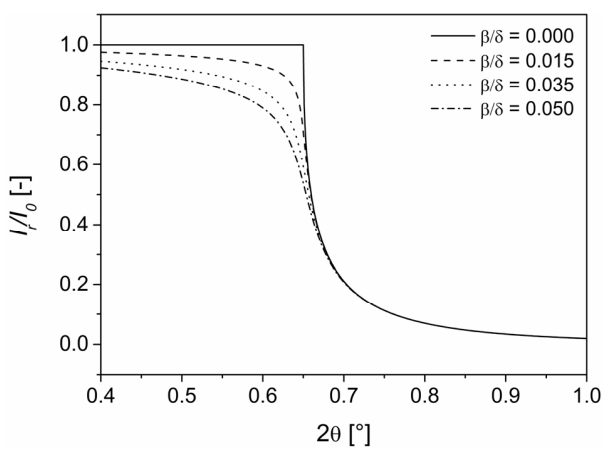

Figure 5.2 Simulated reflectivity curves according to Parratt's formalism, see Eq. (5.11) and Eq. (5.12), with a fixed critical angle of $\theta_{c}=0.65^{\circ}$. At increasing layer imperfection, the absorption of X-rays into the films increases, and thus the coefficient $\beta / \delta$ increases. The determination of the critical angle of total external reflection then becomes increasingly difficult. 
Figure 5.2 shows the calculated reflectivity of a homogeneous medium (bulk) with a smooth top surface at a fixed critical angle of $0.65^{\circ}$, according to the abovementioned formulas. When the sample acts as a perfect mirror, all the incident beam's energy is reflected below the critical angle and $I_{r} / I_{0}=1$. The critical angle is easily determined as the angle where an abrupt decrease of intensity occurs. With increasing interface imperfection or surface roughness, the absorption of X-rays into the film (and thus $\beta / \delta$ ) increases, and a gradual decrease in the beam's intensity is also observed below the critical angle, i.e. $I_{r} / I_{0}<1$. As a result, an abrupt intensity drop at the critical angle does not occur, which makes its experimental determination challenging. Although in absolute terms both $\beta$ and $\delta$ are dependent on the material's stoichiometry and density, the ratio $\beta / \delta$ does not change with varying density, see Eq. (5.5) and (5.6).

\section{Thin Film(s) on a Substrate}

In more complex cases than the reflectivity of a substrate or an infinitely thick film, e.g. thin films on a substrate, multilayers, and superlattices, Parratt's formalism can be used in a recursive manner. The Fresnel coefficients of the individual interfaces (starting from the substrate) are used to calculate the reflectivity according to:

$$
r_{j, j+1}=\frac{k_{z, j}-k_{z, j+1}}{k_{z, j}+k_{z, j+1}}
$$

For a thin film on a substrate as depicted in Figure 5.1b, the Fresnel coefficients are calculated for the film-substrate and air-film interface, from which the total reflected intensity can be calculated:

$$
\frac{I_{r}}{I_{0}}=\frac{r_{0,1}^{2}+r_{1,2}^{2}+2 \cdot r_{0,1}^{2} \cdot r_{1,2}^{2} \cdot \cos 2 k_{z, 1} \cdot d}{1+r_{0,1}^{2} \cdot r_{1,2}^{2}+2 \cdot r_{0,1}^{2} \cdot r_{1,2}^{2} \cdot \cos 2 k_{z, 1} \cdot d}
$$

Here $r_{0,1}$ and $r_{1,2}$ are the Fresnel coefficients of the air-film and film-substrate interface, respectively, and $d$ is the film thickness. The reflected beam intensity is thus reduced by reflection at the separate interfaces and absorption in the individual layers (incorporated in the wave vectors of Eq. 5.13). ${ }^{[1]}$

Figure 5.3 shows simulated reflectivity curves based on Parratt's recursive formalism, and illustrates the effect of changes in the film density, thickness, and roughness 
on the shape of the curve. An increase in the film density results in a shift of the complete curve towards higher angles, as shown in Figure 5.3a. A change in the film thickness results in a phase shift, the cosine term in Eq. (5.14), and is related to the difference in refractive index between the thin film and the substrate. Oscillations are observed in the reflectivity curve (for $\theta>\theta_{c}$ ) as a result of this phase shift, and an infinite sequence of reflections is possible, see Figure 5.1b. These oscillations are known as Kiessig fringes, ${ }^{[21]}$ and their periodicity decreases, according to $2 \pi / d$, for increased film thicknesses as shown in Figure 5.3b. Due to the angle dependence of the penetration depth of the X-ray beam into the film, the oscillations are only observed at incident angles $\theta>\theta_{c}$.

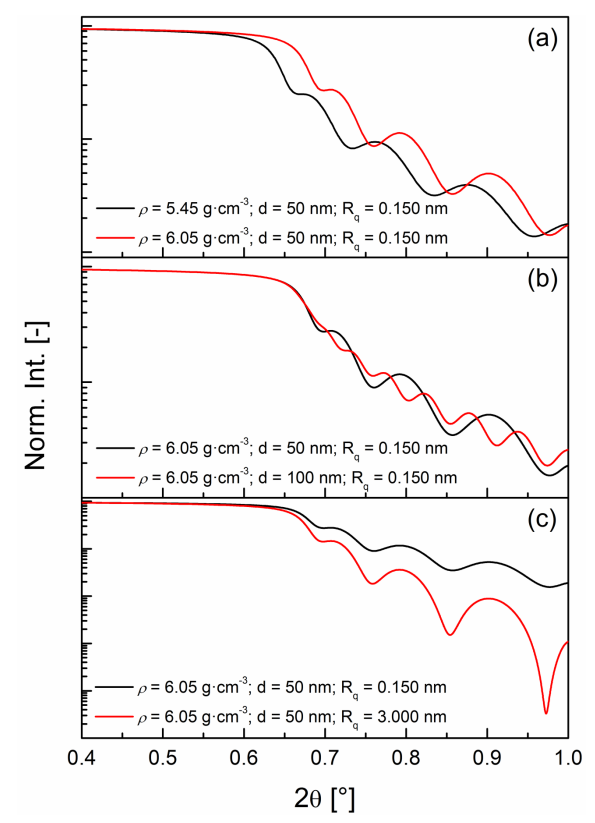

Figure 5.3 Influence of different fitting parameters on the X-ray reflectivity simulations, where $\rho, d$, and $\mathrm{R}_{\mathrm{q}}$ are the film density, thickness, and interfacial roughness, respectively. The simulated curves are based on a $3 \mathrm{~mol} \%$ yttria-stabilized zirconia (3YSZ) film deposited on a sapphire single crystal substrate: (a) at increased density, the reflectivity curve (and critical angle) shifts linearly to higher angles; (b) at increased film thickness, the periodicity of the Kiessig fringes decreases according to $2 \pi / d$; (c) at increased interface roughness, a more rapid intensity drop is observed at angles $>\theta_{c}$.

Whereas at low incident angles the penetration depth is in the order of 1-5 nm (top surface information), the penetration depth increases rapidly to approximately 100-1000 
$\mathrm{nm}$ around the critical angle. For (ideal) smooth films and interfaces, Fresnel reflectivity is observed and the intensity decreases rapidly according to $1 / q^{4}=(4 \pi \lambda / \sin \theta)^{4} \cdot{ }^{[1]}$ As shown in Figure 5.3c, a more abrupt intensity drop is observed at increased interface roughness between the substrate and film. Since all surfaces have some degree of roughness, modifications of the Fresnel coefficients for microscopic surface roughness have been described by Névot-Croce: ${ }^{[2]}$

$$
r_{\text {rough }}=\left|r_{i d e a l} \cdot e^{-2 k_{r} k_{r}^{\prime} \sigma^{2}}\right|
$$

where $\sigma$ is the root mean square (RMS) value for the roughness, $r_{\text {rough }}$ the surface/interface modified with microscopic roughness, and $r_{i d e a l}$ the ideal smooth surface/interface, respectively. The Fresnel coefficients for rough film-substrate $\left(r_{1,2}\right)$ and air-film ( $\left.r_{0,1}\right)$ interfaces can thus be individually calculated and used in Eq. (5.13) and Eq. (5.14) to fully describe the investigated system. More information on X-ray reflectivity can be found in books by Birkholz et al., ${ }^{[1]]}$ Als-Nielsen and McMorrow, ${ }^{[12]}$ and Daillant and Gibaud. ${ }^{[13]}$

\subsection{Experimental Section}

\subsubsection{Chemicals and Materials}

Zirconium (IV) $n$-propoxide $\left(\mathrm{Zr}\left[\left(\mathrm{OC}_{3} \mathrm{H}_{7}\right)\right]_{4}\right), 70 \mathrm{w} / \mathrm{w} \%$ in propanol) and yttrium (III) nitrate hexahydrate $\left(\mathrm{Y}_{\left(\mathrm{NO}_{3}\right.}\right)_{3} \cdot 6 \mathrm{H}_{2} \mathrm{O}$, purity $\left.99.9 \%\right)$ were purchased from Alfa Aesar GmbH. Glacial acetic acid (99.8\%), 2-methoxyethanol (99.3\%) and 1-propanol (99.9\%) were acquired from Sigma-Aldrich. All chemicals were used as-received from the suppliers without any further purification. Due to its high reactivity, the zirconium (IV) npropoxide was stored and handled in a water-free environment $\left(<0.1 \mathrm{ppm} \mathrm{H}_{2} \mathrm{O}\right)$.

\subsubsection{Sol-Gel Precursor Preparation}

A $1.0 \mathrm{~mol} \cdot \mathrm{dm}^{-3}$ solution of zirconium (IV) $n$-propoxide in 2-methoxyethanol was made in a glove box and stirred for $24 \mathrm{~h}$ under nitrogen atmosphere. After addition of glacial acetic acid, the reactants were allowed to mix for 5 min; subsequently, an yttrium (III) nitrate hexahydrate solution in 1-propanol was added, resulting in a final $[\mathrm{Zr}]=0.6$ 
$\mathrm{mol} \cdot \mathrm{dm}^{-3}$. The amount of yttrium (III) was equivalent to $3 \mathrm{~mol} \% \mathrm{Y}_{2} \mathrm{O}_{3}$ to $\mathrm{ZrO}_{2}$, i.e. to form 3 YSZ.

\subsubsection{Substrate Preparation}

Prior to thin film deposition, single crystal sapphire $\left(10 \mathrm{x} 10 \mathrm{x} 0.5 \mathrm{~mm}^{3}\right.$, (1 $\left.\overline{1} 02\right)$ orientation; Crys'Tec) substrates were cleaned with a jet of pressurized $\mathrm{CO}_{2}$ on a hot plate at $250{ }^{\circ} \mathrm{C}$ and subsequently treated with oxygen plasma (Harrick Plasma, Ithaca, USA) operating at $24 \mathrm{~W}$ for $150 \mathrm{~s}$ to remove organic residues attached to the surface. The substrates were used directly after this surface treatment. As a reference for a fully dense film $\left(\rho_{\text {rel }}=100 \%\right)$, sapphire and zinc oxide single crystal substrates $\left(10 \times 10 \times 0.5 \mathrm{~mm}^{3}\right.$, (1ฐ̄02) and (0001) orientation, respectively; Crys'Tec) were measured as received.

\subsubsection{Thin Film Preparation}

Thin films were prepared by spin-coating the sol-gel precursor using a Laurell spincoater (Model WS-400B-6NPP/LITE/AS/OND). Substrates were held in place using a vacuum stage and the deposition chamber was continuously purged with dry nitrogen gas. All films were obtained by rotating the samples for $40 \mathrm{~s}$ at $3000 \mathrm{rpm}$. Directly after thin film deposition, the samples were placed on a hot plate at $150{ }^{\circ} \mathrm{C}$, on which they were allowed to dry for $1 \mathrm{~h}$. Subsequently, the samples were annealed for $1 \mathrm{~h}$ in a preheated microwave oven (MultiFAST, Milestone, Sorisole, Italy) at temperatures ranging from $650-1000{ }^{\circ} \mathrm{C}$.

\subsubsection{Thin Film Characterization}

X-ray powder diffraction (Bruker D2 Phaser, Bruker AXS, Karlsruhe, Germany) was used to confirm the formation of the 3 YSZ phase. The average film thickness of the samples was determined by high-resolution scanning electron microscopy (HR-SEM, $2.5 \mathrm{keV}$, Zeiss 1550, Zeiss, Sliedrecht, The Netherlands). To reduce image drift as a result of the non-conducting sapphire substrate, approximately $13 \mathrm{~nm}$ of Cr was deposited on the 3 YSZ thin film (RF sputtering). Cross-sections of at least 5 different areas were investigated. Atomic force microscopy (AFM; Dimension Icon, Bruker Nano, Santa Barbara, CA, USA) was used to determine the surface roughness of the thin films. Per sample, the RMS surface roughness was determined on three different locations with an area of $5 \times 5 \mu \mathrm{m}^{2}$, using the Gwyddion software package (version 2.25). RBS 
measurements were carried out as a reference method for the density determination by Detect99, Utrecht, The Netherlands. The measurements yielded the individual number of $(\mathrm{Y}+\mathrm{Zr})$ and $\mathrm{O}$ atoms per $\mathrm{cm}^{2}$ from which the average thin film density could be calculated.

\subsubsection{X-ray Reflectivity Measurements}

$\mathrm{X}$-ray reflectivity measurements were carried out using a Bruker D8 reflectometer (Bruker AXS, Karlsruhe, Germany). Samples were scanned under very low incident angles using $\mathrm{Cu} \mathrm{K} \alpha$ irradiation $\left(\lambda=1.5418 \mathrm{~nm}\right.$ ), from $2 \theta=0.4-1.0^{\circ}$ (step sizes of 0.001 $1.5 \mathrm{~s}$ per step; $0.2 \mathrm{~mm}$ slits) with an acceleration voltage and current of $45 \mathrm{kV}$ and 40 $\mathrm{mA}$, respectively. All samples were measured and re-aligned at least 5 times to determine the average measurement error.

\section{Sample Alignment}

All samples were aligned and measured according to the following procedure, see Figure 5.4 for a schematic representation. (1) Prior to starting the measurements, the detector (20 axis) was aligned with respect to the direct beam within a $0.001^{\circ}$ error margin. (2) Spin-coated samples often show height variation at the edges of the substrate, the $\mathrm{x}$ and $y$-axis of the sample were therefore aligned at the center of the sample. (3) The sample surface was aligned in the center of the direct beam using a z-axis scan. Subsequently, the maximum intensity in a rocking curve was selected. (4) The sample was aligned below the surface with a second z-axis scan, and subsequently (5) a chi-scan was executed to remove a possible tilt from the sample mounting. (6) Again the sample surface was aligned in the center of the direct beam using a z-axis scan, and finally (7) a second rocking curve was measured (at $2 \theta=0.4^{\circ}$ ), and the maximum peak intensity was selected to correct for sample tilt.

\section{X-ray Reflectivity Simulations}

Reflectivity curves of thin 3YSZ films on sapphire substrates were simulated using the DIFFRACplus LEPTOS software package (version 7.03). Fitting parameters (Table 5.2) such as layer thickness and surface roughness were obtained from results of HRSEM and AFM analyses, respectively. Simulation curves of 3 YSZ thin films with differ- 


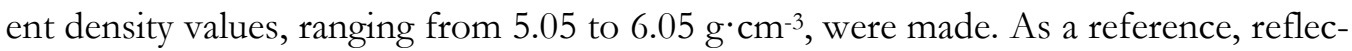
tivity curves of $\mathrm{Al}_{2} \mathrm{O}_{3}\left(\rho=3.984 \mathrm{~g} \cdot \mathrm{cm}^{-3}\right.$; RMS roughness $\left.0.150 \mathrm{~nm}\right)$ and $\mathrm{ZnO}(\rho=5.655$ $\mathrm{g} \cdot \mathrm{cm}^{-3}$; RMS roughness $0.150 \mathrm{~nm}$ ) single crystal substrates were simulated.

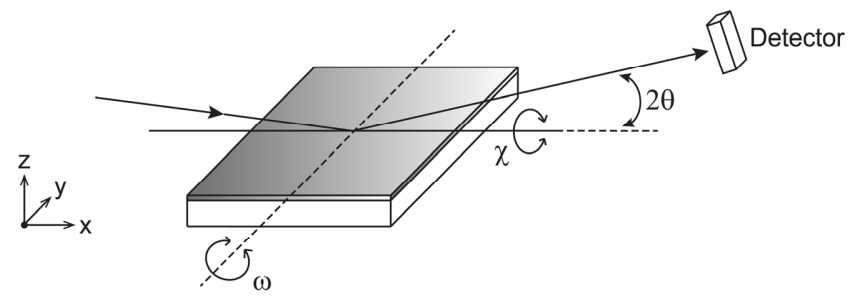

Figure 5.4 Schematic representation of the sample alignment. The $\mathrm{x}$ - and $\mathrm{y}$-axis are aligned at the center of the sample. Subsequently, the height of the sample is aligned at the center of the direct X-ray beam by changing the z-axis. Finally, possible sample tilt perpendicular and parallel to the beam path is corrected with a $\chi$ - and $\omega$-scan, respectively.

\subsection{Results and Discussion}

\subsubsection{Method for Thin Film Density Determination}

From Figure 5.2 it is apparent that critical angle determination becomes increasingly difficult for increasingly imperfect films or interfaces (higher $\beta / \delta$ value). Although the critical angle for all simulated reflectivity curves is equal, the $2 \theta$ position of the inflection point (where the rapid intensity decrease is observed) changes. In order to accurately determine the density of my sol-gel derived thin films, the following steps were carried out: (1) Reflectivity curves with different layer thickness and surface roughness, representing my real samples, were simulated for different thin film densities. The simulation parameters are shown in Table 5.2. The results were also compared to simulations with under- and overestimated interface roughness and density, to verify the method's robustness. (2) A pseudo-critical angle $\left(\theta_{\mathrm{pc}}\right.$; inflection point) was accurately derived (numerically, see section below) from both the measured and simulated reflectivity curves. (3) The thin film density of the measured samples was directly determined by comparing the $2 \theta$ position of its pseudo-critical angle with a calibration curve obtained via the simulations. The calibration curve was obtained by plotting the inflection points $(2 \theta$ position) of the simulated reflectivity curves versus its manually changed densities. 
Table 5.2 Parameters for the X-ray reflectivity simulations.

\begin{tabular}{lccc}
\hline & $\begin{array}{c}\text { Thickness } \\
{[\mathrm{nm}]}\end{array}$ & $\begin{array}{c}\text { RMS roughness } \\
{[\mathrm{nm}]}\end{array}$ & $\begin{array}{c}\text { Density } \\
{\left[\mathrm{g} \cdot \mathrm{cm}^{-3}\right]}\end{array}$ \\
\hline $3 \mathrm{YSZ}$ & $50-300$ & $0-2.000$ & $5.05-6.05$ \\
$\mathrm{Al}_{2} \mathrm{O}_{3}$ substrate & $\infty$ & 0.150 & 3.984 \\
\hline
\end{tabular}

\section{Determination of the pseudo-Critical Angle}

The pseudo-critical angle was numerically calculated for the simulated reflectivity curves using the Origin Pro 8.1 software package, by determining the first minimum of the $3^{\text {rd }}$ derivative (see Figure 5.5). I chose this procedure since it yields a reproducible value very close to the real critical angle while systematic errors between the pseudo-critical angle and the real critical angle are cancelled out via the calibration curve. The $1^{\text {st }}$ derivative of the intensity is not suitable to determine $\theta_{\mathrm{pc}}$, since it is located where the steep intensity drop $>\theta_{c}$ occurs (see Figure 5.5b). Changes in sample/interface roughness significantly influence the slope in this regime, and thus a correct determination of the position of $\theta_{\mathrm{pc}}$ is not possible. The simulations are based on the assumption of an infinitely large sample. Thus, no effect of the beam footprint is observed below the critical angle, i.e. $I_{r} / I_{0}=1$. For these simulations, the $2^{\text {nd }}$ derivative would be suitable to reliably estimate $\theta_{\mathrm{pc}}$ (see Figure 5.5c). However, when small 'real' samples are being measured, the intensity increase caused by the beam footprint (most pronounced for sample sizes smaller than approximately $5 \mathrm{~cm}^{2} ;[11]$ see Figure 5.5a) might easily influence the reliability of the determination of the pseudo-critical angle. I therefore used the $3^{\text {rd }}$ derivative to get a value for $\theta_{\mathrm{pc}}$, because its first minimum was not influenced by the size, thin film thickness or roughness of the samples. Significant changes in sample thickness $(50-300 \mathrm{~nm})$ and thin film roughness $(0.0-2.0 \mathrm{~nm})$, had no influence on the position of this experimentally determined pseudo-critical angle. Thus, the effect of minor deviations within a batch of samples can be neglected.

Because my results are compared with simulations of imperfect films (the real surface/interface roughness of both sample and substrate taken were into account), shifts of the pseudo-critical angle can only be caused by changes in the density. The observed shifts are thus equal to the shifts observed for the real critical angle, demonstrating that my method is independent of sample size or roughness, and thus applicable to various thin film deposition techniques. 


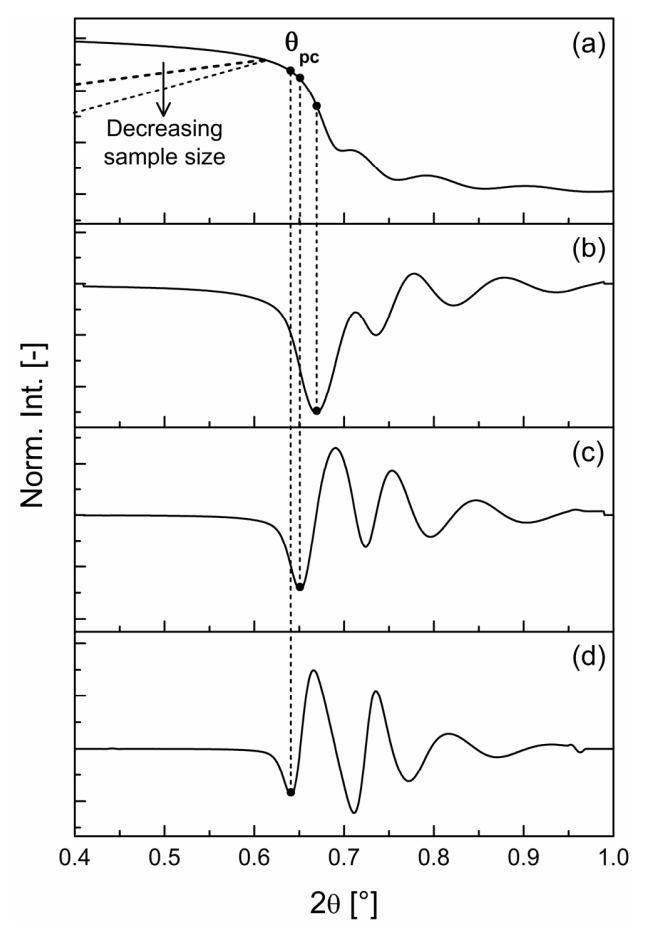

Figure 5.5 Numerical calculation of the pseudo-critical angle used for the density determination of thin films: (a) simulated X-ray reflectivity curve of a $50 \mathrm{~nm}$ thin 3 YSZ film $\left(\rho=6.05 \mathrm{~g} \cdot \mathrm{cm}^{-3}\right.$; $\left.\mathrm{R}_{\mathrm{q}}=0.500 \mathrm{~nm}\right)$ on a $\mathrm{Al}_{2} \mathrm{O}_{3}$ single crystal substrate $\left(\mathrm{R}_{\mathrm{q}}=0.150 \mathrm{~nm}\right)$. The dashed black lines show the steep intensity increase at angles $<\theta_{c}$ observed for samples of decreasing size (i.e. beam footprint). (b) $1^{\text {st }}$ derivative; (c) $2^{\text {nd }}$ derivative; and (d) $3^{\text {rd }}$ derivative of the calculated XRR curve. The first minimum of the $3^{\text {rd }}$ derivative determines the $p$ seudo-critical angle. No differences are observed in the calculation of this point as a result of decreasing sample size.

\subsubsection{X-ray Reflectivity of Single Crystal Substrates}

Single crystal substrates of sapphire and zinc oxide were used to quantify the accuracy and experimental error of the proposed method. The pseudo-critical angles of simulated reflectivity curves for different densities were determined for both materials, with relative densities ranging from $\rho_{\text {rel }}=90-100 \%$. Figure 5.6 shows the $2 \theta$ values of the calculated $\theta_{\mathrm{pc}}$ plotted versus the simulated densities; calibration curves were obtained using linear curve fits (dashed lines; $\left.\mathrm{R}^{2}>0.995\right)$. The average measurement error was estimated to be within $1.0 \%$. As expected, a 100\% theoretical density for both single crystal substrates was found within the error margin of the measurement: $\mathrm{Al}_{2} \mathrm{O}_{3} 100.7 \pm 1.0 \%$ 
and $\mathrm{ZnO} 99.9 \pm 1.0 \%$. The accuracy is thus comparable or even higher than methods such as RBS and ellipsometry, without the need for complex models or calculations.

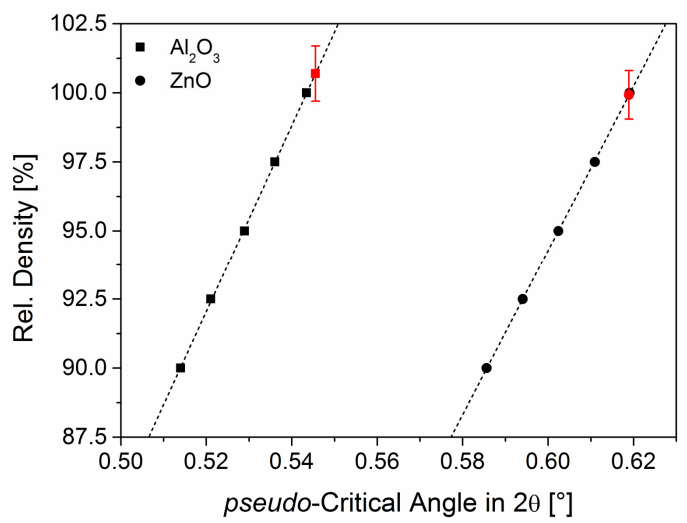

Figure 5.6 Reflectivity curves for both $\mathrm{Al}_{2} \mathrm{O}_{3}$ and $\mathrm{ZnO}$ single crystals were simulated at different densities, and plotted versus the calculated psendo-critical angle. The calibration curve was obtained by using a linear curve fit (dashed line). The single crystal substrates were measured five times; the average value and error bars were plotted (red square/dot and bars, respectively).

\subsubsection{X-ray Reflectivity of Thin Films on a Substrate}

Prior to simulating the reflectivity curves and preparing the calibration curves, test samples were made. The influence of the annealing temperatures on the surface roughness (by AFM) and the average film thickness (by SEM) were determined. For samples annealed at 650,850 , and $1000{ }^{\circ} \mathrm{C}$, the average RMS surface roughness was approximately $0.3,0.5$, and $0.9 \mathrm{~nm}$, respectively. Since the layer thickness of the film is determined presumably by only a few particles, the observed exponential increase in surface roughness is closely related to the particle growth at increasing temperatures. ${ }^{[2]}$ The average film thickness of samples annealed between 650 and $1000{ }^{\circ} \mathrm{C}$ was determined, and ranged from approximately 75 to $65 \mathrm{~nm}$, respectively. All calibration curves were simulated using an average film thickness of $70 \mathrm{~nm}$. The changing surface roughness with increasing annealing temperature was taken into account, however.

Cross-sectional SEM was used to verify the homogeneous distribution of particles in the deposited films. A homogeneous layer is important, because with XRR the density information is extrapolated from the derived density of the top-layer. For solgel-derived films, the densification is rather difficult to control due to strain caused by the substrate, by crystal growth, or by homogeneous and heterogeneous crystallization 
in the bulk and at the interface, respectively. ${ }^{[8,25]}$ All these phenomena can cause different densification behavior in the thin film or at the thin film-substrate interface (density gradient), which may lead to deviations in the XRR curves, and thus in the calculated densities. For such films, more parameters are needed in the simulations, and a density gradient should be taken into account (available in the software). ${ }^{[17]}$

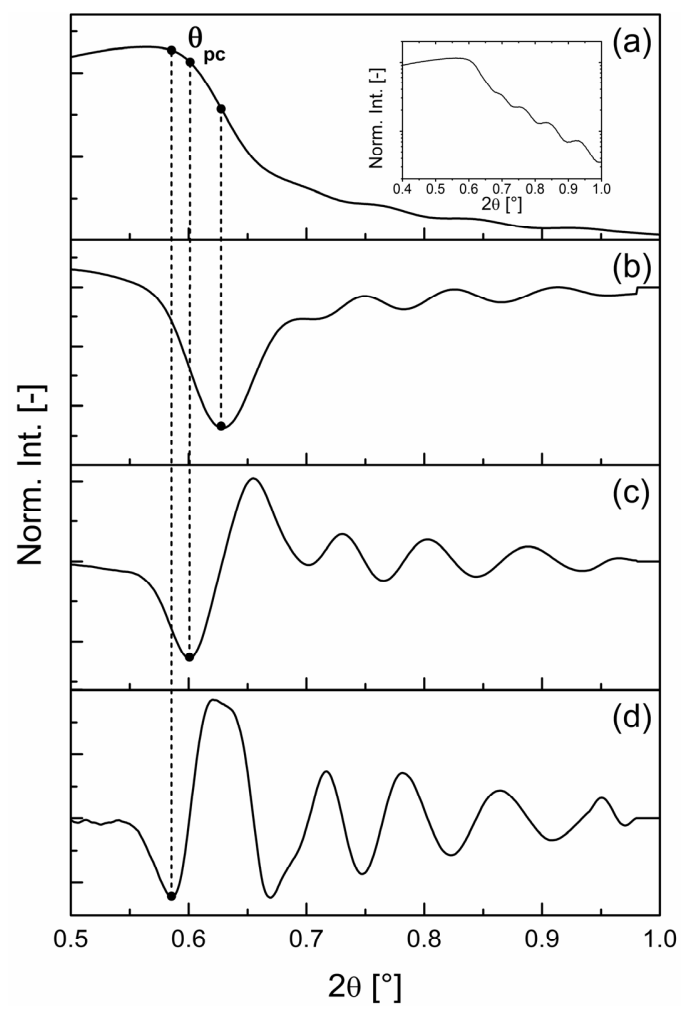

Figure 5.7 Determination of the pseudo-critical angle for a 3YSZ thin film on a single crystal $\mathrm{Al}_{2} \mathrm{O}_{3}$ substrate annealed for $1 \mathrm{~h}$ at $850^{\circ} \mathrm{C}$ in air, by using the first minimum of the numerically calculated $3^{\text {rd }}$ derivative. (a) the measured reflectivity curve, and its (b) $1^{\text {st }}$ derivative; (c) $2^{\text {nd }}$ derivative; and (d) $3^{\text {rd }}$ derivative. When the measured reflectivity curve is plotted with a logarithmic intensity scale, the Kiessig fringes at higher angles are more pronounced, see inset in (a).

Figure 5.7 schematically shows how the XRR method was used for a thin film annealed at $850{ }^{\circ} \mathrm{C}$. First, an XRR curve was recorded, and the $\theta_{\mathrm{pc}}$ was determined by the first minimum of the $3^{\text {rd }}$ derivative (Figure $5.7 \mathrm{~d}$ ). The density was then determined by the corresponding position of the $\theta_{\mathrm{pc}}$ in the calibration curve (Figure 5.8). All heat treated samples were measured at least five times. For the annealing temperatures 650, 850, and 
$1000{ }^{\circ} \mathrm{C}$, the density was determined to be $83.7 \%, 89.6 \%$, and $91.6 \%$, respectively (Figure 5.9). The observed trend (dashed line) in densification coincides well with what is generally expected for sintering.

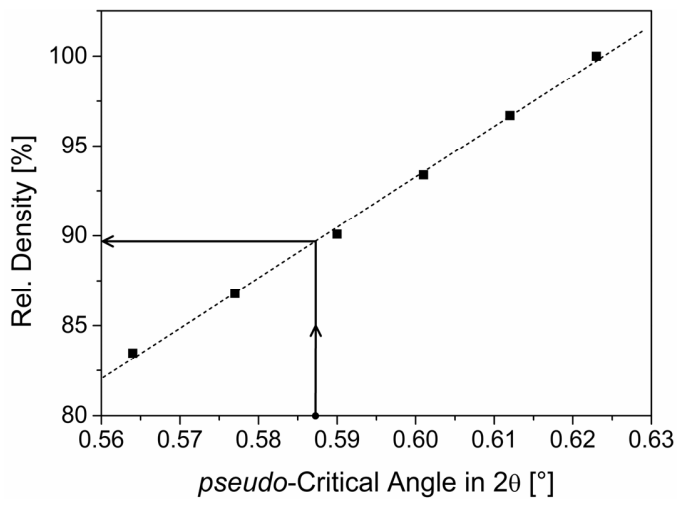

Figure 5.8 The relative density of a $3 \mathrm{YSZ}$ thin film on a single crystal $\mathrm{Al}_{2} \mathrm{O}_{3}$ substrate annealed for $1 \mathrm{~h}$ at $850^{\circ} \mathrm{C}$ in air $\left(\rho_{\text {rel }}=89.6 \%\right)$ is calculated in the calibration curve by using the $\theta_{\mathrm{pc}}$ determined in Figure 5.7. The data points of the calibration curve are based on simulations of thin 3YSZ film with a film thickness of $70 \mathrm{~nm}$, a RMS surface roughness of $0.500 \mathrm{~nm}$, and densities ranging from $\rho=5.05-6.05 \mathrm{~g} \cdot \mathrm{cm}^{-3}$.

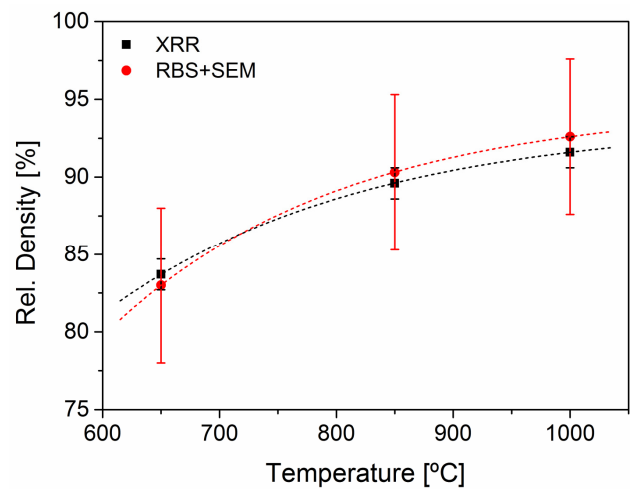

Figure 5.9 Comparison between derived thin film density of the proposed XRR method and the combined RBS and SEM analysis, as a function of the annealing temperature. The results obtained via the XRR method are well within error margin of the established techniques. The dashed lines are exponential fits to guide the eye.

\section{Validation Results with RBS \& SEM analysis}

To check the validity of my method, the density of the abovementioned samples was verified by a combination of RBS and SEM cross-sectional analysis. RBS analysis 
yielded the total concentration of $(\mathrm{Zr}+\mathrm{Y})$ atoms ${ }^{\cdot} \mathrm{cm}^{-2}$, from which the mass ${ }^{\cdot} \mathrm{cm}^{-2}$ could be calculated. The mass per volume ratio was calculated from the sum of the individual atoms, according to:

$$
\frac{m}{A}=\sum \frac{X_{i} \cdot M W_{i}}{\mathrm{~N}_{\mathrm{A}}}
$$

where $m / A$ is the total mass per area, $X_{i}$ and $M W_{i}$ are the total number of atoms and the molecular weight of species type $i$, respectively, and $N_{\mathrm{A}}$ is Avogadro's number. In combination with the film thickness derived from cross-sectional SEM analysis, the density of the samples was determined with a combined error of both techniques of approximately $5.0 \%$, due to elemental inaccuracy, and statistical and systematic errors.

The results are summarized in Table 5.3. As shown, the total YSZ mass deposited on the three samples is almost equal, indicating that the sol-gel deposition method is very reproducible, and batch-to-batch errors can be neglected. The differences in the density are thus only determined by shrinkage of the sol-gel film during heat treatment. Figure 5.9 summarizes the results obtained using the XRR method and a combination of RBS and SEM. The density values determined using the XRR method are well within the error margin of the established analytical techniques. Also, the densification behavior of the thin film follows the same trend. These results clearly demonstrate that my method is a fast, simple and accurate method to determine the density of sol-gel derived materials.

Table 5.3 Thin film densities of spin-coated 3YSZ films on sapphire substrates calculated by a combination of RBS and SEM analysis.

\begin{tabular}{ccccccccc}
\hline & \multicolumn{3}{c}{ RBS } & & \multicolumn{2}{c}{ SEM } & \multicolumn{2}{c}{ Density } \\
\hline $\begin{array}{c}\text { Temp. } \\
{\left[{ }^{\circ} \mathrm{C}\right]}\end{array}$ & $\mathrm{Zr}$ & $\mathrm{E}$ & $\mathrm{O}$ & \multicolumn{2}{c}{ Total } & Thickness & Abs. & Rel. \\
\hline 650 & $1.7 \cdot 10^{17}$ & $1.1 \cdot 10^{16}$ & $3.6 \cdot 10^{17}$ & $5.3 \cdot 10^{17}$ & $3.66 \cdot 10^{-5}$ & 73.1 & 5.022 & $83.0 \pm 5 \%$ \\
850 & $1.7 \cdot 10^{17}$ & $1.1 \cdot 10^{16}$ & $3.6 \cdot 10^{17}$ & $5.4 \cdot 10^{17}$ & $3.68 \cdot 10^{-5}$ & 67.4 & 5.461 & $90.3 \pm 5 \%$ \\
1000 & $1.7 \cdot 10^{17}$ & $1.1 \cdot 10^{16}$ & $3.6 \cdot 10^{17}$ & $5.4 \cdot 10^{17}$ & $3.68 \cdot 10^{-5}$ & 65.7 & 5.603 & $92.6 \pm 5 \%$ \\
\hline
\end{tabular}




\subsection{Conclusions}

I have successfully demonstrated a simple and fast approach to determine the density of sol-gel derived ceramic thin films using XRR. The method shows no apparent effect of changing sample size, interface roughness, or film thickness of different samples on the final determined density, and has an average measurement error of only $1 \%$. A psendo-critical angle was determined from the first minimum of the $3^{\text {rd }}$ derivative of the reflectivity curves. Simulations of films of various densities were used to obtain calibration curves, where the calculated $\theta_{\mathrm{pc}}$ was plotted versus the material density. Subsequently, the experimental thin film density was determined using these calibration curves according to the position of the determined pseudo-critical angle. The method was validated by determining the density of single crystal $\mathrm{Al}_{2} \mathrm{O}_{3}$ and $\mathrm{ZnO}$ substrates $\left(\rho_{\text {rel }}\right.$ $=100 \%$ ) within $1 \%$ of the expected value. The density of ceramic thin YSZ films heat treated at 650,850 , and $1000^{\circ} \mathrm{C}$ were calculated using XRR, and validated using a combination of well-established techniques such as RBS and SEM analysis. The density values obtained using the XRR method were well within the error margin of the combined RBS and SEM analysis, and the same trend in densification was observed. The XRR method can be used to study the impact of sintering temperature and substrate strain on densification behavior of sol-gel derived ceramics. Also the densification of amorphous gels, as a result of dehydroxylation and surface contraction during drying can be studied, since XRR does not rely on diffraction. Thus, new possibilities emerge to follow the sol-gel process in depth from the liquid phase (precursor solution), via gel formation to the final crystalline ceramic film. 


\subsection{Bibliography}

[1] X. Wang; A. Atkinson, Microstructure evolution in thin zirconia films: Experimental observation and modelling. Acta Materialia 2011, 59, (6), 2514-2525.

[2] M.G.H.M. Hendriks; M.J.G.W. Heijman; W.E. van Zyl; J.E. ten Elshof; H. Verweij, Solid state supercapacitor materials: Layered structures of yttria-stabilized zirconia sandwiched between platinum/yttria-stabilized zirconia composites. Journal of Applied Physics 2001, 90, (10), 5303-5307.

[3] B. Butz; H. Störmer; D. Gerthsen; M. Bockmeyer; R. Krüger; E. Ivers-Tiffée; M. Luysberg, Microstructure of nanocrystalline yttria-doped zirconia thin films obtained by sol-gel processing. Journal of the American Ceramic Society 2008, 91, (7), 2281-2289.

[4] M. Gaudon; E. Djurado; N.H. Menzler, Morphology and sintering behaviour of yttria stabilised zirconia (8-YSZ) powders synthesised by spray pyrolysis. Ceramics International 2004, 30, (8), 2295-2303.

[5] R. Swanepoel, Determination of the thickness and optical constants of amorphous silicon. Journal of Physics E: Scientific Instruments 1983, 16, (12), 1214-1222.

[6] A. Díaz-Parralejo; R. Caruso; A.L. Ortiz; F. Guiberteau, Densification and porosity evaluation of $\mathrm{ZrO} 2-3$ mol.\% Y $2 \mathrm{O} 3$ sol-gel thin films. Thin Solid Films 2004, 458, (1-2), 92-97.

[7] M. Jerman; Z. Qiao; D. Mergel, Refractive index of thin films of SiO2, ZrO2, and HfO2 as a function of the films' mass density. Applied Optics 2005, 44, (15), 3006-3012.

[8] G.W. Scherer, Sintering of Sol-Gel Films. Journal of Sol-Gel Science and Technology 1997, 8, (13), 353-363.

[9] C.J. Brinker; G.W. Scherer, Sol-gel science: the physics and chemistry of sol-gel processing. Academic Press, Inc: San Diego, CA, 1990.

[10] G.E. Jellison Jr, Spectroscopic ellipsometry data analysis: Measured versus calculated quantities. Thin Solid Films 1998, 313-314, 33-39.

[11] M. Birkholz; P.F. Fewster; C. Genzel, Thin film analysis by X-ray scattering. Wiley-VCH Verlag GmbH: Weinheim, 2006.

[12] J. Als-Nielsen; D. McMorrow, Elements of modern X-ray physics. John Wiley \& Sons: Chichester, West Sussex, 2011.

[13] J. Daillant; A. Gibaud, X-ray and neutron reflectivity: principles and applications. Springer-Verlag: Berlin Heidelberg, 2009.

[14] S. Vives; C. Meunier, Densification of amorphous sol-gel TiO2 films: An X-ray reflectometry study. Thin Solid Films 2010, 518, (14), 3748-3753. 
[15] P. Lenormand; A. Lecomte; D. Babonneau; A. Dauger, X-ray reflectivity, diffraction and grazing incidence small angle X-ray scattering as complementary methods in the microstructural study of sol-gel zirconia thin films. Thin Solid Films 2006, 495, (1-2), 224-231.

[16] S.L. Morelhão; G.E.S. Brito; E. Abramof, Nanostructure of sol-gel films by X-ray specular reflectivity. Applied Physics Letters 2002, 80, (3), 407-409.

[17] Bruker, DIFFRACphs LEPTOS 7 User Manual. Bruker AXS GmbH: Karlsruhe, Germany, 2009.

[18] A.H. Compton, A Quantum Theory of the Scattering of X-rays by Light Elements. Physical Review 1923, 21, (5), 483-502.

[19] E. Prince, International Tables of Crystallography, Volume C: Mathematical, physical and chemical tables. Springer Netherlands: 2006.

[20] L.G. Parratt, Surface studies of solids by total reflection of x-rays. Physical Review 1954, 95, (2), 359-369.

[21] H. Kiessig, Interferenz von Röntgenstrahlen an dünnen Schichten. Annalen der Physik 1931, 402, (7), 769-788.

[22] L. Nevot; P. Croce, Characterization of Surfaces by Grazing X-Ray Reflection - Application to Study of Polishing of some Silicate-Glasses. Revue De Physique Appliquee 1980, 15, (3), 761-779.

[23] S.A. Veldhuis; A. George; M. Nijland; J.E. ten Elshof, Concentration Dependence on the Shape and Size of Sol-Gel-Derived Yttria-Stabilized Zirconia Ceramic Features by Soft Lithographic Patterning. Langmuir 2012, 28, (42), 15111-15117.

[24] S.J.L. Kang, Sintering: densification, grain growth, and microstructure. Butterworth-Heinemann: Oxford, 2005.

[25] R.W. Schwartz, Chemical solution deposition of perovskite thin films. Chemistry of Materials 1997, 9, (11), 2325-2340. 


\title{
Rapid Densification of Sol-Gel Derived Yttria-Stabilized Zirconia Thin Films*
}

\begin{abstract}
A method based on X-ray reflectivity was used to study the densification behavior of 8 mol\% yttria-stabilized zirconia for use in solid oxide fuel cells. Sol-gel derived thin electrolyte films were prepared via spin coating. Subsequent microwave-assisted rapid thermal annealing at $650-1000{ }^{\circ} \mathrm{C}$ resulted in crack-free $70 \mathrm{~nm}$ thin films. A maximum density of approximately $95 \%$ was achieved within 5 min at $1000{ }^{\circ} \mathrm{C}$. X-ray photoelectron spectroscopy depth analysis on the thin films showed that the shorter annealing times, as opposed to conventional heating, resulted in lower Si concentrations at the top surface and at the substrate interface.
\end{abstract}

\footnotetext{
* This chapter has been submitted to an international peer-reviewed scientific journal.
} 


\subsection{Introduction}

Yttria-stabilized zirconia (YSZ) is one of the most commonly used electrolyte materials in solid oxide fuel cells (SOFC). Due to the thermal activation of ionic conduction through the electrolyte membrane, fuel cells mostly operate at high temperatures (800$\left.1000{ }^{\circ} \mathrm{C}\right)$. The high operational temperatures result in long start-up times, high material costs, and material degradation, which contributes to a reduced life time of the cell.

A reduction of the operating temperature to intermediate temperatures (400$700{ }^{\circ} \mathrm{C}$ ) would enable the use of cheaper materials (e.g. stainless steel supports), and concurrently reduce the thermal stresses in the system. ${ }^{[1]}$ A major problem, however, is that the reduced temperature leads to an increased Ohmic resistance in the electrolyte membrane, and thus to a reduction of the overall ionic conductivity. This can be compensated by decreasing the electrolyte film thickness. It has been shown that a decrease of film thickness from $15 \mu \mathrm{m}$ to $500 \mathrm{~nm}$ for a $10 \mathrm{~mol} \%$ YSZ electrolyte allowed for the reduction of the operational temperature from 700 to $525{ }^{\circ} \mathrm{C}$ (for an area-specific resistance of $\left.0.15 \Omega \cdot \mathrm{cm}^{2}\right) .{ }^{[2]}$ Thin electrolyte films are currently prepared using a wide array of deposition techniques, like e.g. pulsed laser deposition (PLD), ${ }^{[3,4]}$ spin coating, ${ }^{[5]}$ spray casting, ${ }^{[6]}$ and sputtering techniques. ${ }^{[7]}$

The fabrication of micro-SOFCs based on thin film electrolytes for portable power generation has received considerable attention due to their high power output, exceeding $200 \mathrm{~mW} \cdot \mathrm{cm}^{-2}$ at temperatures $<600{ }^{\circ} \mathrm{C} \cdot{ }^{[8-10]}$ Micro-electro mechanical systems (MEMS) technology based on Si supports and back-etching procedures is often employed for their fabrication. ${ }^{[7,9,11,12]}$ However, the use of $\mathrm{Si}$ in the fabrication procedure may lead to the formation of undesirable glassy siliceous phases. ${ }^{[13-15]}$ These phases segregate at the grain boundaries and severely impede the ionic conduction through the electrolyte. ${ }^{[16]}$ The high temperatures necessary to form dense membranes may thus be problematic due to the high mobility of Si. Consequently, fast densification may be an advantageous approach to achieve high density, while impeding the Si mobility.

Here, I describe the densification behavior of $8 \mathrm{~mol} \%$ YSZ thin films on $\mathrm{SiO}_{2} / \mathrm{Si}(001)$ and $\mathrm{Al}_{2} \mathrm{O}_{3}(0001)$ single crystalline substrates by microwave-assisted rapid thermal annealing (RTA) and conventional heating. The thin film density was determined by using the X-ray reflectivity (XRR) method described in the previous chapter. Thin films with a density of approximately $95 \%$ were obtained within 5 min at $1000{ }^{\circ} \mathrm{C}$ when RTA was employed. 
The short times at high temperatures, resulted in less siliceous phases in the thin films compared to films annealed by conventional heating. In addition, the usefulness of the $\mathrm{XRR}$ method for thin film density determination is illustrated in the presented densification study.

\subsection{Experimental Section}

\subsubsection{Chemicals and Materials}

Zirconium (IV) $n$-propoxide $\left(\mathrm{Zr}\left[\left(\mathrm{OC}_{3} \mathrm{H}_{7}\right)\right]_{4}\right), 70 \mathrm{w} / \mathrm{w} \%$ in propanol) and yttrium (III) nitrate hexahydrate $\left(\mathrm{Y}\left(\mathrm{NO}_{3}\right)_{3} \cdot 6 \mathrm{H}_{2} \mathrm{O}\right.$, purity $\left.99.9 \%\right)$ were purchased from Alfa Aesar GmbH. Glacial acetic acid (99.8\%), 2-methoxyethanol (99.3\%) and 1-propanol (99.9\%) were acquired from Sigma-Aldrich. All chemicals were used as-received from the suppliers without any further purification. Due to its high reactivity, zirconium (IV) npropoxide was stored and handled in a water-free environment $\left(<0.1 \mathrm{ppm} \mathrm{H}_{2} \mathrm{O}\right)$.

\subsubsection{Sol-Gel Precursor Preparation}

A $1.0 \mathrm{~mol} \cdot \mathrm{dm}^{-3}$ solution of zirconium (IV) $n$-propoxide in 2-methoxyethanol was made in a glove box and stirred for $24 \mathrm{~h}$ under nitrogen atmosphere. After addition of glacial acetic acid, the reactants were allowed to mix for 5 min; subsequently, an yttrium (III) nitrate hexahydrate solution in 1-propanol was added. The sol was hydrolyzed by addition of water, and further diluted with 2-methoxyethanol to a final concentration $[\mathrm{Zr}]$ $=0.6 \mathrm{~mol} \cdot \mathrm{dm}^{-3}$. The amount of yttrium (III) was equivalent to $8 \mathrm{~mol} \% \mathrm{Y}_{2} \mathrm{O}_{3}$ to $\mathrm{ZrO}_{2}$, i.e. to form $8 \mathrm{YSZ}$.

\subsubsection{Substrate Preparation}

Prior to thin film deposition, $10 \mathrm{~nm}$ thermally oxidized $\mathrm{SiO}_{2} / \mathrm{Si}(001)$ and single crystal sapphire (10x10x0.5 mm³, (0001) orientation; CrysTec) substrates were cleaned with a jet of pressurized $\mathrm{CO}_{2}$ on a hot plate at $250{ }^{\circ} \mathrm{C}$ and subsequently treated with oxygen plasma (Harrick Plasma, Ithaca, USA) operating at $24 \mathrm{~W}$ for $150 \mathrm{~s}$ to remove organic residues attached to the surface. The substrates were used directly after this surface treatment. 


\subsubsection{Thin Film Preparation}

Thin films were prepared by spin-coating the sol-gel precursor using a Laurell spincoater (Model WS-400B-6NPP/LITE/AS/OND). Substrates were held in place using a vacuum stage and the deposition chamber was continuously purged with dry nitrogen gas. All films were obtained by rotating the samples for $40 \mathrm{~s}$ at $3000 \mathrm{rpm}$. Directly after thin film deposition, the samples were placed on a hot plate at $150{ }^{\circ} \mathrm{C}$, on which they were allowed to dry for $1 \mathrm{~h}$. Subsequently, the samples were annealed for $1 \mathrm{~h}$ in a preheated microwave oven (MultiFAST, Milestone, Sorisole, Italy) or $12 \mathrm{~h}$ in a conventional oven at temperatures ranging from $650-1000^{\circ} \mathrm{C}$.

\subsubsection{Thin Film Characterization}

X-ray powder diffraction (X'Pert Pro MRD, PANalytical, Almelo, The Netherlands) was used to confirm the formation of the YSZ phase. Atomic force microscopy (AFM; Dimension Icon, Bruker Nano, Santa Barbara, CA, USA) was used to determine the surface roughness of the thin films. Per sample, the RMS surface roughness was determined on three different locations with an area of $5 \times 5 \mu \mathrm{m}^{2}$, using the Gwyddion software package (version 2.25).

\section{Density Determination}

The thin film density was determined using the method based on X-ray reflectivity, as discussed in Chapter 5. ${ }^{[18]} \mathrm{X}$-ray reflectivity measurements were carried out using an X'Pert Pro MRD diffractometer (PANalytical, Almelo, The Netherlands). Samples were scanned under very low incident angles using $\mathrm{Cu} K \alpha$ irradiation $(\lambda=1.5418 \mathrm{~nm})$, from $2 \theta=0.4-1.0^{\circ}$ (step sizes of $0.002^{\circ} ; 1.5 \mathrm{~s}$ per step; $1 / 16^{\circ}$ slits) with an acceleration voltage and current of $45 \mathrm{kV}$ and $40 \mathrm{~mA}$, respectively.

\section{X-ray Photoelectron Spectroscopy}

X-ray Photoelectron Spectroscopy (XPS) was used to determine the atomic concentration of $\mathrm{Si}$ in thin films annealed using rapid thermal annealing and conventional heating. Spectra were acquired using a Quantera SXM scanning probe XPS (Physical Electronics) with a monochromatic $\mathrm{Al} \mathrm{K} \alpha \mathrm{X}$-ray at $1486.6 \mathrm{eV}$. The data were further analyzed using the PHI Multipak (version 9.4.0.7) software package. A depth profile was created by sputtering with an $\mathrm{Ar}$ ion beam at $3 \mathrm{kV}$ in an area of $3 \times 3 \mathrm{~mm}^{2}$. 


\subsection{Results and Discussion}

One of the main requirements for electrolyte membranes in fuel cells applications is a high film density (i.e. gas impermeable). Knowledge of the grain growth, thin film density, and the densification behavior will enable optimized processing conditions, in which e.g. the times at high temperatures can be minimized. This is especially important for the fabrication of micro-SOFCS and the integration in Si-based MEMS technology. Due to the high mobility of $\mathrm{Si}$, fast densification is necessary to limit the segregation in the electrolyte's grain boundaries.

\subsubsection{Crystallite Growth}

Samples were annealed for $t=0,5,15,30$ and $60 \mathrm{~min}$ in a pre-heated microwave oven at temperatures ranging from 650 to $1000{ }^{\circ} \mathrm{C}$, where $t=0$ is defined as the time that was required to heat the oven to the desired temperature after heat loss due to opening of the microwave oven after loading samples. After the heat treatment, the crystallite sizes were determined by analyzing the XRD peak broadening of the (111) peak of YSZ using Scherrer's equation, see Figure 6.1. The figure shows that irrespective of the substrate's choice, the crystallites grew from approximately 6.6 to $17 \mathrm{~nm}$ after annealing at 650 and $1000^{\circ} \mathrm{C}$, respectively. Scherrer et al. found significantly different crystallite sizes for samples deposited on $\mathrm{Al}_{2} \mathrm{O}_{3}$ and $\mathrm{Si}$ substrates. ${ }^{[16]}$ After annealing for $20 \mathrm{~h}$ at 1000 ${ }^{\circ} \mathrm{C}$, the average crystallite sizes were approximately 130 and $48 \mathrm{~nm}$, respectively. Silicon is known to impede the grain growth of YSZ even in very low concentrations, ${ }^{[19,20]}$ due to segregation in the grain boundaries (GB) and the subsequent reduction of GB mobility. Segregation of Si was already observed after heat treatment for $5 \mathrm{~h}$ at $800{ }^{\circ} \mathrm{C} .{ }^{[21]}$ However, due to the different heating profiles (i.e. thermal shock) and the annealing temperatures of our samples, strain from the substrate played a more important role. Instead, crystallite growth may be inhibited due to compressive strain exerted by the substrate, since the thermal expansion coefficient of $8 Y S Z\left(10.8 \cdot 10^{-6} \mathrm{~K}^{-1}\right)^{[22]}$ is significantly higher than that of $\mathrm{Si}\left(2.6 \cdot 10^{-6} \mathrm{~K}^{-1}\right)^{[23]}$ and $\mathrm{Al}_{2} \mathrm{O}_{3}\left(5.5 \cdot 10^{-6} \mathrm{~K}^{-1}\right.$; from datasheet Crystec $\mathrm{GmbH})$, respectively. 


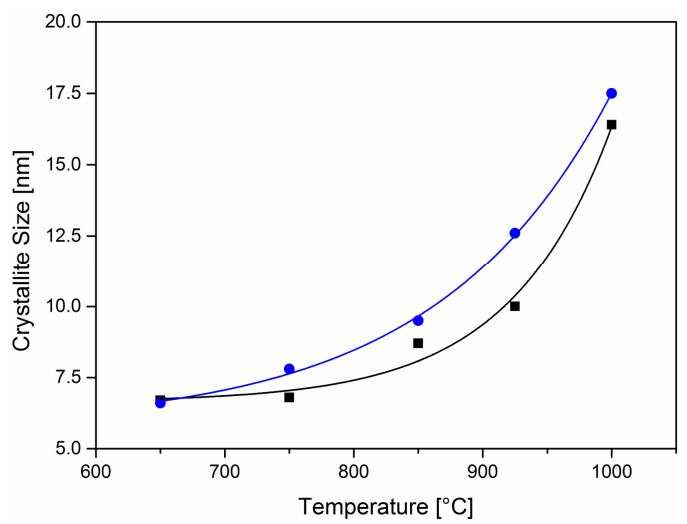

Figure 6.1 Crystallite sizes of an 8YSZ thin film after microwave-assisted rapid thermal annealing for $1 \mathrm{~h}$ at $650-1000{ }^{\circ} \mathrm{C}$ on a $\mathrm{SiO}_{2} / \mathrm{Si}$ (black) and $\mathrm{Al}_{2} \mathrm{O}_{3}$ (blue) substrate.

\subsubsection{X-ray Reflectivity Method}

The densification behavior of the 8YSZ thin films was monitored by using the X-ray reflectivity (XRR) method described in Chapter $5 .{ }^{[18]}$ With XRR in general, samples are measured under very low incident beam angles. The material's density is directly related to the critical angle of external reflection, which is ideally marked by a sudden drop of intensity. For more real films, however, the determination of the critical angle becomes increasingly difficult because the critical angle cannot be determined easily. The used method is based on the determination of a so-called pseudo-critical angle, defined as the $3^{\text {rd }}$ derivative of the XRR curve versus angle. ${ }^{[18]}$ The measured samples are then compared with a calibration curve, from which the thin film density can be calculated. The calibration curve is based on simulations of the investigated samples (Figure 6.2a-b) with manually adjusted densities. For each simulated density, the pseudo-critical angle was determined. Figure 6.2c shows typical experimental XRR curves for thin films deposited on $\mathrm{SiO}_{2} / \mathrm{Si}$ and $\mathrm{Al}_{2} \mathrm{O}_{3}$ substrates. The pseudo-critical angle for both curves was located at $2 \theta \sim 0.6^{\circ}$. Beyond this angle, a rapid intensity drop and Kiessig fringes ${ }^{[24]}$ (i.e. oscillations) were observed, which are associated with the interface roughness and film thickness, respectively. 
(a)

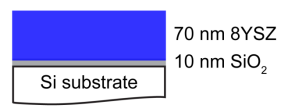

(b)
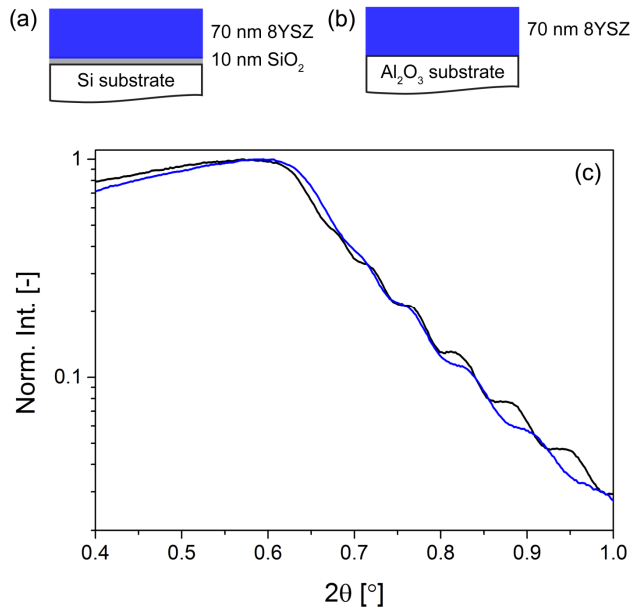

Figure 6.2 Schematic representation of the investigated system: a $70 \mathrm{~nm} 8 \mathrm{YSZ}$ film on (a) 10 $\mathrm{nm} \mathrm{SiO} 2 / \mathrm{Si}(001)$; (b) $\mathrm{Al}_{2} \mathrm{O}_{3}$ (0001). (c) Typical X-ray reflectivity curves of thin films annealed for $1 \mathrm{~h}$ at $1000{ }^{\circ} \mathrm{C}$ on $\mathrm{SiO}_{2} / \mathrm{Si}$ (black) and $\mathrm{Al}_{2} \mathrm{O}_{3}$ (blue), respectively.

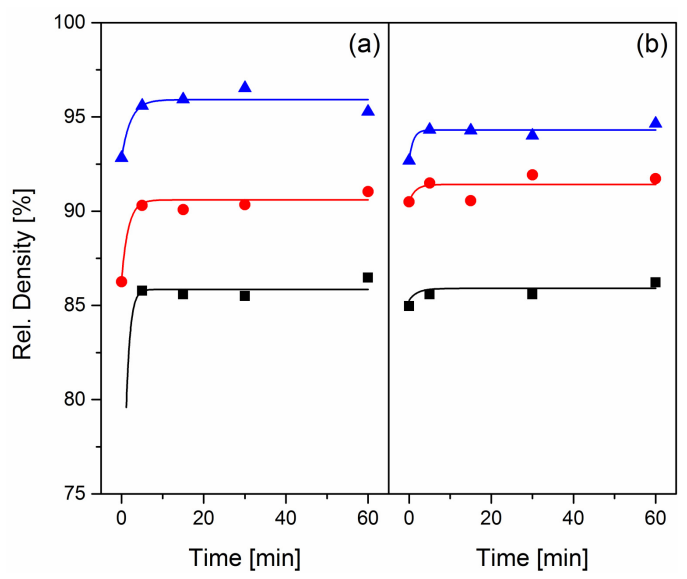

Figure 6.3 Densification behavior of $8 \mathrm{YSZ}$ films on (a) $\mathrm{Al}_{2} \mathrm{O}_{3}$ (0001) and (b) $\mathrm{SiO}_{2} / \mathrm{Si}(001)$ substrates at $650{ }^{\circ} \mathrm{C}$ (black), $850{ }^{\circ} \mathrm{C}$ (red), and $1000{ }^{\circ} \mathrm{C}$ (blue), respectively. The absolute measurement error is $\sim 1 \%$.

\subsubsection{Thin Film Densification}

The results obtained from analysis using the XRR method are presented in Figure 6.3. It clearly illustrates that the thin film densification by rapid thermal annealing proceeded very fast. A maximum density was achieved within 5 minutes of isothermal heating, 
irrespective of annealing temperature. In addition, the choice of substrate had no significant effect on the final density. Maximum densities of approximately 86.3, 91.4, and $95.0 \%$ were achieved after annealing at 650,850 , and $1000{ }^{\circ} \mathrm{C}$, respectively. Scanning electron microscopy images showed that the resulting films were crack-free, smooth and consisted of fine grained crystallites (see Figure 6.4).

In order to achieve a film density of $c a .95 \%$ using a conventional oven, a dwell time of $12 \mathrm{~h}$ at $1000{ }^{\circ} \mathrm{C}$ (heating/cooling rates $5{ }^{\circ} \mathrm{C} \cdot \mathrm{min}^{-1}$ ) was necessary. Naturally, such a long time at elevated temperature increases the susceptibility of $\mathrm{Si}$ to diffuse into the thin film, and segregate at the GBs. Furthermore, the average crystallite sizes after conventional heat treatment were approximately 2 times larger than after RTA.

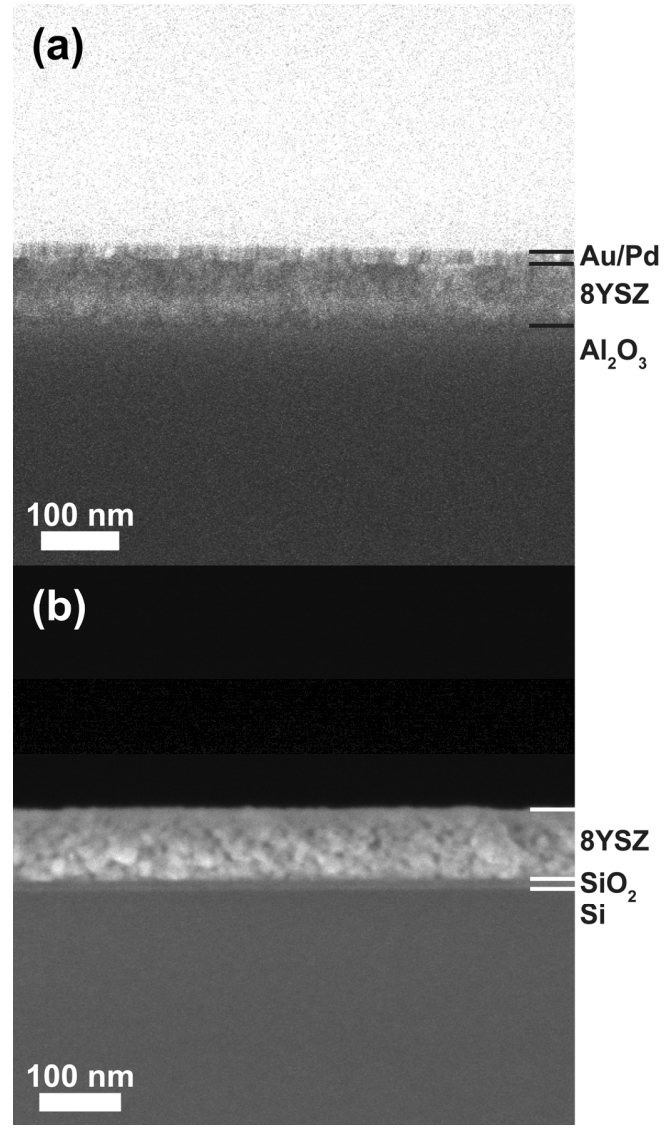

Figure 6.4 Scanning electron microscopy cross-sections of 8YSZ films annealed for $1 \mathrm{~h}$ at 1000 ${ }^{\circ} \mathrm{C}$ in a microwave oven on (a) $\mathrm{Al}_{2} \mathrm{O}_{3}(0001)$ and (b) $\mathrm{SiO}_{2} / \mathrm{Si}$ (001) substrates, respectively. For better imaging stability, sample (a) was tilted and a $\sim 15 \mathrm{~nm} \mathrm{Au} / \mathrm{Pd}$ layer was deposited on top of the 8YSZ film. 


\subsubsection{Thin Film Chemistry}

$\mathrm{X}$-ray photoelectron spectroscopy was used to investigate the composition of the surface and bulk region of the thin films. Segregation of Y and Si species in YSZ electrolytes is a well-known problem. The lowering of the interfacial energy is the driving force of segregation, and results in the tendency to transport the segregated species from the bulk to the surface. ${ }^{[25]}$ Theunissen et al. showed with Auger electron spectroscopy (AES) that independent of the bulk Y concentration, the surface layer (2-4 nm) consisted up to $36 \mathrm{at} \% \mathrm{Y} \cdot{ }^{[13]}$ De Ridder et al. used low-energy ion scattering (LEIS) and observed concentrations in a $5 \AA$ top-layer ranging from 36 to 60 at $\%$ Y for $3 \mathrm{YSZ}$ and 10YSZ, respectively. ${ }^{[14]}$ Secondary ion mass spectroscopy (SIMS) experiments between 800 and $1400{ }^{\circ} \mathrm{C}$ showed that at $1000{ }^{\circ} \mathrm{C}$, the highest $\mathrm{Y}$ enrichment was found, irrespective of oxidizing or reducing atmosphere. ${ }^{[25]} \mathrm{It}$ was postulated that the effect of temperature on segregation results from a competition between thermodynamic and kinetic factors.

Figure 6.5 shows the depth profiles of thin film (on $\mathrm{SiO}_{2} / \mathrm{Si}$ substrates) annealed in a microwave and a conventional oven. Although the $\mathrm{Y}$ concentration is fairly constant throughout both films, differences in Si concentrations at the top surface and substrate interface were observed. Samples annealed for $12 \mathrm{~h}$ at $1000{ }^{\circ} \mathrm{C}$ showed a Si concentration of $c a .4 .1 \mathrm{at} \%$ at the top surface, compared to $1.1 \mathrm{at} \%$ for the sample annealed in the microwave oven. In the interior of both films, the $\mathrm{Si}$ concentration remained $<0.5 \mathrm{at} \%$. This is consistent with the values found by Scherrer and co-workers. ${ }^{[16]}$ They found a surface and bulk concentration of approximately 9 and 1.1 at $\%$, respectively, for thin films deposited on $\mathrm{SiO}_{2}$ single crystal substrates, after annealing for $20 \mathrm{~h}$ at $1000{ }^{\circ} \mathrm{C}$. Near the film-substrate interface, significant differences in Si concentrations were observed between the two heating protocols. Especially for the conventionally heat treated sample, the Si concentration increased rapidly at approximately $15 \mathrm{~nm}$ distance from the substrate interface. For a fast annealed sample, the increase was only observed at $c a .8 \mathrm{~nm}$ from the substrate.

The effect of RTA on the surface and bulk composition of an 8YSZ film deposited on $\mathrm{Al}_{2} \mathrm{O}_{3}$ is presented in Figure 6.6. The major advantage of using sapphire substrates is that $\mathrm{Si}$ diffusion does not play a role in the densification and film composition. No Si was found at the surface, and the film interior showed an average Si concentration of $<0.3 \mathrm{at} \%$. The minor impurities may arise from impurities from the used chemicals. The $\mathrm{Y}$ enrichment at the surface was reduced to $\sim 3$ at $\%$. 


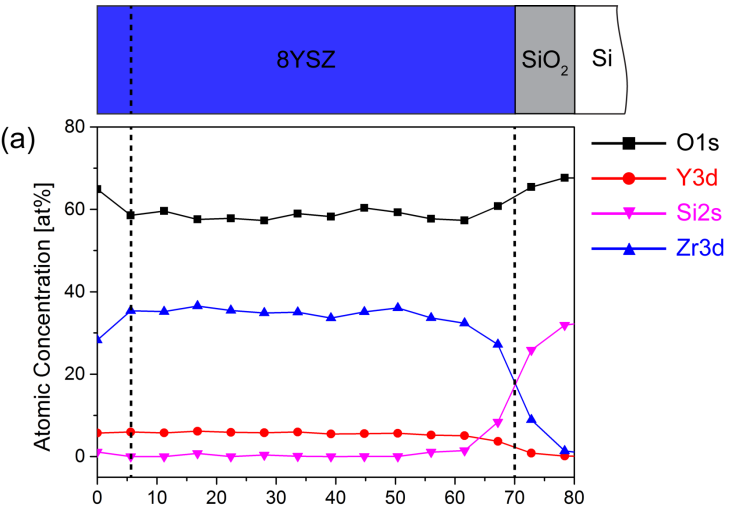

(b)

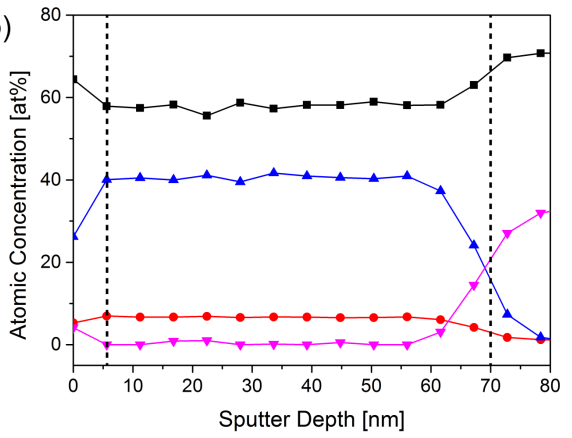

Figure 6.5 Elemental depth profile from XPS for a $70 \mathrm{~nm}$ 8YSZ thin film on a $\mathrm{SiO}_{2} / \mathrm{Si}(001)$ substrate, annealed in a (a) microwave oven for $1 \mathrm{~h}$ at $1000{ }^{\circ} \mathrm{C}$; (b) conventional oven for $12 \mathrm{~h}$ at $1000^{\circ} \mathrm{C}$.

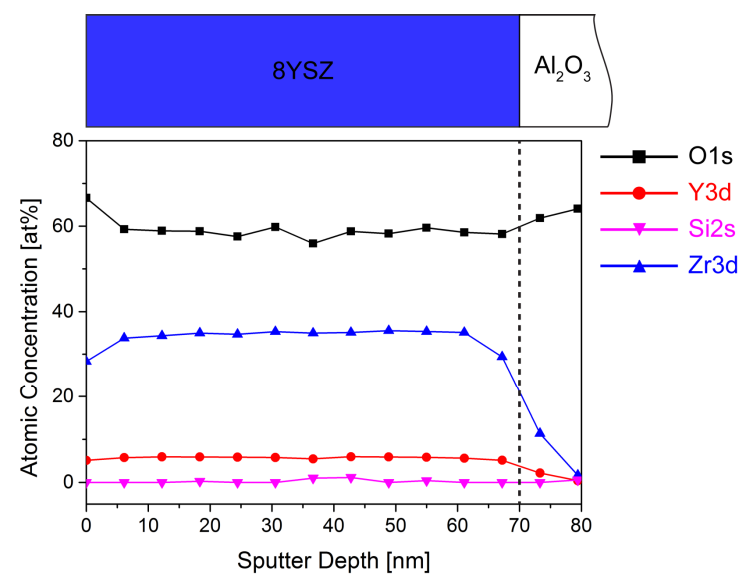

Figure 6.6 Elemental depth profile from XPS for a 70nm 8YSZ thin film on an $\mathrm{Al}_{2} \mathrm{O}_{3}(0001)$ substrate, annealed in a microwave oven for $1 \mathrm{~h}$ at $1000{ }^{\circ} \mathrm{C}$. 
To summarize, the results show that the rapid thermal annealing can be effectively used to obtain dense electrolyte films within several minutes. Faster annealing seems to reduce the degree of Si diffusion, and may allow for improved fabrication of micro-SOFCs based on MEMS technology. Two-step sintering techniques may be explored to further exploit the difference between grain boundary diffusion and migration. ${ }^{[26]}$

\subsection{Conclusions}

A method for the density determination of sol-gel derived 8YSZ thin films was used to study the densification behavior on various substrates. Microwave-assisted rapid thermal annealing was employed to form dense films in the temperature range of 650 to $1000{ }^{\circ} \mathrm{C}$. A maximum relative density of approximately $95 \%$ was reached after annealing for $1 \mathrm{~h}$ at $1000^{\circ} \mathrm{C}$. However, no significant densification was observed after $5 \mathrm{~min}$. The shorter annealing times at high temperature, as opposed to long conventional heating procedures, resulted in lower Si concentrations at the top surface of the films and at the substrate interface. Rapid thermal annealing in combination with sol-gel derived electrolyte thin films may prove a good alternative for Si-based micro-SOFC devices. 


\subsection{Bibliography}

[1] J. W. Fergus, Electrolytes for solid oxide fuel cells. J. Power Sources 2006, 162, 30-40.

[2] B. C. H. Steele, A. Heinzel, Materials for fuel-cell technologies. Nature 2001, 414, 345-352.

[3] X. Chen, N. J. Wu, L. Smith, A. Ignatiev, Thin-film heterostructure solid oxide fuel cells. Appl. Phys. Lett. 2004, 84, 2700-2702.

[4] H. S. Noh, H. Lee, B. K. Kim, H. W. Lee, J. H. Lee, J. W. Son, Microstructural factors of electrodes affecting the performance of anode-supported thin film yttria-stabilized zirconia electrolyte $(\sim 1 \mu \mathrm{m})$ solid oxide fuel cells. J. Power Sources 2011, 196, 7169-7174.

[5] K. Chen, Z. Lü, N. Ai, X. Huang, Y. Zhang, X. Xin, R. Zhu, W. Su, Development of yttriastabilized zirconia thin films via slurry spin coating for intermediate-to-low temperature solid oxide fuel cells. J. Power Sources 2006, 160, 436-438.

[6] P. Charpentier, P. Fragnaud, D. M. Schleich, E. Gehain, Preparation of thin film SOFCs working at reduced temperature. Solid State Ionics 2000, 135, 373-380.

[7] H. Huang, M. Nakamura, P. Su, R. Fasching, Y. Saito, F. B. Prinz, High-performance ultrathin solid oxide fuel cells for low-temperature operation. J. Electrochem. Soc. 2007, 154, B20-B24.

[8] Z. Shao, S. M. Haile, J. Ahn, P. D. Ronney, Z. Zhan, S. A. Barnett, A thermally self-sustained micro solid-oxide fuel-cell stack with high power density. Nature 2005, 435, 795-798.

[9] M. Tsuchiya, B. K. Lai, S. Ramanathan, Scalable nanostructured membranes for solid-oxide fuel cells. Nat. Nanotechnol. 2011, 6, 282-286.

[10] U. P. Muecke, D. Beckel, A. Bernard, A. Bieberle-Hütter, S. Graf, A. Infortuna, P. Müller, J. L. M. Rupp, J. Schneider, L. J. Gauckler, Micro solid oxide fuel cells on glass ceramic substrates. Adv. Funct. Mater. 2008, 18, 3158-3168.

[11] P. C. Su, F. B. Prinz, Nanoscale membrane electrolyte array for solid oxide fuel cells. Electrochem. Commun. 2012, 16, 77-79.

[12] A. Evans, A. Bieberle-Hütter, J. L. M. Rupp, L. J. Gauckler, Review on microfabricated micro-solid oxide fuel cell membranes. J. Power Sources 2009, 194, 119-129.

[13] G. S. A. M. Theunissen, A. J. A. Winnubst, A. J. Burggraaf, Segregation aspects in the ZrO2Y2O3 ceramic system. J. Mater. Sci. Lett. 1989, 8, 55-57.

[14] M. De Ridder, R. G. Van Welzenis, A. W. D. Van Der Gon, H. H. Brongersma, S. Wulff, W. F. Chu, W. Weppner, Subsurface segregation of yttria in yttria stabilized zirconia. J. Appl. Phys. 2002, 92, 3056-3064.

[15] K. V. Hansen, K. Norrman, M. Mogensen, TOF-SIMS studies of yttria-stabilised zirconia. Surf. Interface Anal. 2006, 38, 911-916. 
[16] B. Scherrer, A. Rossi, J. Martynczuk, M. D. Rossell, A. Bieberle-Hütter, J. L. M. Rupp, R. Erni, L. J. Gauckler, Impact of substrate material and annealing conditions on the microstructure and chemistry of yttria-stabilized-zirconia thin films. J. Power Sources 2011, 196, 7372-7382.

[17] S. A. Veldhuis, A. George, M. Nijland, J. E. ten Elshof, Concentration Dependence on the Shape and Size of Sol-Gel-Derived Yttria-Stabilized Zirconia Ceramic Features by Soft Lithographic Patterning. Langmuir 2012.

[18] S. A. Veldhuis, P. Brinks, T. M. Stawski, O. F. Göbel, J. E. Ten Elshof, A facile method for the density determination of ceramic thin films using X-ray reflectivity. J. Sol-Gel Sci. Technol. 2014, 71, 118-128.

[19] J. Zhao, Y. Ikuhara, T. Sakuma, Grain growth of silica-added zirconia annealed in the cubic/tetragonal two-phase region. J. Am. Ceram. Soc. 1998, 81, 2087-2092.

[20] M. Aoki, Y. M. Chiang, I. Kosacki, L. J. R. Lee, H. Tuller, Y. Liu, Solute segregation and grain-boundary impedance in high-purity stabilized zirconia. J. Am. Ceram. Soc. 1996, 79, 1169-1180.

[21] A. Bernasik, K. Kowalski, A. Sadowski, Surface segregation in yttria-stabilized zirconia by means of angle resolved X-ray photoelectron spectroscopy. J. Phys. Chem. Solids 2002, 63, 233-239.

[22] H. Hayashi, T. Saitou, N. Maruyama, H. Inaba, K. Kawamura, M. Mori, Thermal expansion coefficient of yttria stabilized zirconia for various yttria contents. Solid State Ionics 2005, 176, 613-619. [23] P. Becker, P. Scyfried, H. Siegert, The lattice parameter of highly pure silicon single crystals. Z. Physik B - Condensed Matter 1982, 48, 17-21.

[24] H. Kiessig, Interferenz von Röntgenstrahlen an dünnen Schichten. Annalen der Physik 1931, 402, 769-788.

[25] M. A. Idris, T. Bak, S. Li, J. Nowotny, Effect of segregation on surface and near-surface chemistry of yttria-stabilized zirconia. Journal of Physical Chemistry C 2012, 116, 10950-10958.

[26] I. W. Chen, X. H. Wang, Sintering dense nanocrystalline ceramics without final-stage grain growth. Nature 2000, 404, 168-171. 



\title{
Concentration Dependence on the Shape and Size of Sol-Gel Derived Yttria-Stabilized Zirconia Ceramic Features using Soft Lithographic Patterning*
}

\begin{abstract}
Surface areas of typically $5 \times 5 \mathrm{~mm}^{2}$ were patterned with high aspect ratio micron- and submicron-sized structures of yttria-stabilized zirconia using a combination of micromolding in capillaries and sol-gel chemistry. The influence of precursor solution concentration and mold geometry on the final shape and dimensions of the patterned structures was investigated. At a precursor concentration $[\mathrm{Zr}]=0.724 \mathrm{~mol} \cdot \mathrm{dm}^{-3}$, isolated objects - due to controlled cracking of patterned films - such as crosses (height $1.4 \mu \mathrm{m}$; width $6.0 \mu \mathrm{m}$ ) and 'dog-bones' (height $800-900 \mathrm{~nm}$; width $900 \mathrm{~nm}$ ) or patterned films (height $450 \mathrm{~nm}$ ) were obtained, depending on the mold geometry. Lower precursor concentrations led to differently sized and shaped structures, with changes in dimensions of more than an order of magnitude. Employing a precursor concentration $[\mathrm{Zr}]=0.036 \mathrm{~mol} \cdot \mathrm{dm}^{-3}$ yielded isolated rings (height $100-150 \mathrm{~nm}$; line width $20 \mathrm{~nm}$ ) and squares (height $40 \mathrm{~nm}$; line width $40 \mathrm{~nm}$ ). A better understanding of the relationship between precursor concentration, mold geometry and the observed coherent crack patterns in as-dried sol-gel structures may lead to new techniques to pattern isolated features.
\end{abstract}

\footnotetext{
* This chapter has been published in: S.A. Veldhuis, A. George, M. Nijland, and J.E. ten Elshof, Langmuir 2012, 28, (42), 15111-15117.
} 


\subsection{Introduction}

Yttria-stabilized zirconia (YSZ) is a high performance and technologically important ceramic material, due to its outstanding properties such as high mechanical strength, chemical resistance, high ion conductivity and biocompatibility. For instance, YSZ is used in (oxygen) sensors ${ }^{[1]}$ as catalyst and catalyst support, ${ }^{[2]}$ as electrolyte material in solid oxide fuel cells (SOFC), ${ }^{[3]}$ and in thermal barrier coatings. ${ }^{[4]}$

Structuring of YSZ films on the micro and nanoscale could be a very beneficial method to fabricate electrolyte monoliths for micro-SOFC and oxygen sensor technology. Furthermore, an increase of interfacial surface area between the electrodes and the electrolyte could lead to decreased oxygen ion transport resistance through the interface, and thus to improved performance of the fuel cell. The large surface area of the patterned structures could also be beneficial when exploited in sensing devices.

Extensive research has been done on the patterning of nanostructures and thin films from functional metal oxides. ${ }^{[5-9]}$ Micropatterned titanium dioxide $\left(\mathrm{TiO}_{2}\right)$ and zinc oxide $(\mathrm{ZnO})$ have attracted significant attention due to their application in (dye-sensitized) solar cells, ${ }^{[10]}$ semiconductors ${ }^{[11]}$ and light-emitting diodes. ${ }^{[12]}$ The patterning of thin film zirconium oxide $\left(\mathrm{ZrO}_{2}\right)$ has also attracted considerable attention and new routes towards nanopatterns and thinner films have been explored. ${ }^{[13-15]}$ Although these routes provide good control over the size and shape of the patterns, they often make use of expensive production techniques.

To my knowledge, no reports have been published on the micropatterning of YSZ. I describe here the patterning of arrays of isolated YSZ structures by a combination of micromolding in capillaries (MIMIC $)^{[14]}$ and sol-gel processing. Both are known for their low cost, technical simplicity and flexibility regarding shape and composition. In contrast to what is demonstrated in this study, MIMIC normally allows only the formation of continuous features and micropatterns. The aim of this research is to investigate the influence of the metal alkoxide precursor concentrations and PDMS mold geometry on the final shape and dimensions of the patterned YSZ structures. The solgel process comprises the hydrolysis and condensation of a stabilized metal alkoxide precursor into an amorphous gel and its crystallization after subsequent heat treatment. Since I was aiming at realizing microstructures with relatively high aspect ratios, i.e. $\sim 1$ or higher, high precursor concentrations are beneficial as they lead to reduced volume shrinkage during solidification. ${ }^{[7]} \mathrm{I}$ employed concentrated solutions in which the di- 
meric $\mathrm{Zr}$-clusters ${ }^{[16]}$ of the zirconium (IV) $n$-propoxide precursor solution were stabilized by ligand exchange, the bidentate binding of 2-methoxyethanol, ${ }^{[17]}$ and coordination number expansion of the $\mathrm{Zr}$-atom. ${ }^{[17,18]}$ The $\mathrm{pH}$ of the precursor solution was decreased by addition of glacial acetic acid (HAc). At low $\mathrm{pH}$ values yttrium is mostly present as $\mathrm{Y}^{3+}$ ions. Acetic acid can also act as a chelating agent and further stabilize the Zr-clusters.

(a)

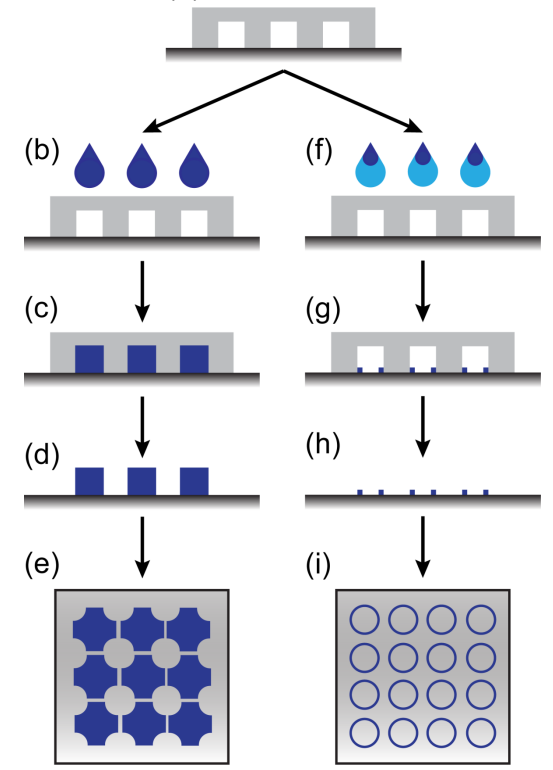

Figure 7.1 Schematic overview of the MIMIC patterning, (a) a plasma-treated mold is gently placed on a Si-substrate; (b) a drop of concentrated sol is placed at the openings of the microchannels; (c) capillary forces drag the precursor solution into the microchannels; the solution is subsequently dried in the mold at $60{ }^{\circ} \mathrm{C}$ for $1 \mathrm{~h}$; (d) the mold is gently released from the substrate, leaving a pattern of amorphous YSZ gel; (e) top view of the obtained structures; (f-h) same as step $\mathrm{b}$ to $\mathrm{d}$ for a diluted sol-gel precursor solution; (i) top view of the obtained structures at lower concentration.

Figure 7.1 shows a schematic diagram of the patterning process. An elastomeric mold with a micropatterned relief structure is brought into conformal contact with a substrate. When the sol-gel precursor is placed at the side entrances of the thus formed microchannels, capillary forces drag the sol-gel precursor into the microchannels of the mold, where it dries. During drying, the solvent(s) of the sol-gel precursor solution diffuse(s) into the elastomeric mold due to its natural porosity. The shrinkage of the patterned amorphous materials in the channels of the mold can be attributed to physical 
loss of solvent by evaporation. In the final stage of drying, the percolation threshold is reached and an infinite network (an amorphous gel) is formed by condensation of surface hydroxyl and alkoxy groups, i.e. $\mathrm{Zr}$-OR, where $\mathrm{R}=\mathrm{H}$ or $\left(\mathrm{CH}_{2}\right)_{2} \mathrm{OCH}_{3}$, respectively, causing contraction and loss of mass. As I will show below and is illustrated in Figure 7.1, the equivalent solids concentration in the precursor solution has a large effect on the final shapes that are obtained in the patterning process. After removal of the mold and subsequent heat treatment, solidified structures of desired composition and shape are obtained. I employed rapid thermal annealing (RTA), which causes surface modification and expels the liquid phase, trapped in the pores, from the gel. The main advantage of RTA over conventional thermal processing is that materials can be heated so quickly that densification is favored over crystallization and crystal growth is inhibited or postponed to higher temperatures than when lower heating rates are employed, ${ }^{[19]}$ yielding higher density films and patterns.

\subsection{Experimental Section}

\subsubsection{Chemicals and Materials}

Zirconium (IV) $n$-propoxide $\left(\mathrm{Zr}\left[\left(\mathrm{OC}_{3} \mathrm{H}_{7}\right)\right]_{4}\right), 70 \mathrm{w} / \mathrm{w} \%$ in propanol) and yttrium (III) nitrate hexahydrate $\left(\mathrm{Y}\left(\mathrm{NO}_{3}\right)_{3} \cdot 6 \mathrm{H}_{2} \mathrm{O}\right.$, purity $\left.99.9 \%\right)$ were purchased from Alfa Aesar GmbH. Glacial acetic acid (99.8 \%), 2-methoxyethanol (99.3\%) and 1-propanol (99.9 $\%$ were acquired from Sigma-Aldrich. All chemicals were used as-received from the suppliers without any further purification. Due to its high reactivity, zirconium (IV) npropoxide was stored and handled in a water-free environment $\left(<0.1 \mathrm{ppm} \mathrm{H}_{2} \mathrm{O}\right)$. Due to the toxic nature of 2-methoxyethanol, all experiments that require the handling of this material were carried out inside a fume hood or in a place with proper ventilation.

\subsubsection{Sol-Gel Precursor Preparation}

A $1.0 \mathrm{~mol} \cdot \mathrm{dm}^{-3}$ solution of zirconium (IV) $n$-propoxide in 2-methoxyethanol was made in a glove box and stirred for $24 \mathrm{~h}$ under nitrogen atmosphere. After addition of glacial acetic acid, the reactants were allowed to mix for 5 min; subsequently an yttrium (III) nitrate hexahydrate solution in 1-propanol was added. The amount of yttrium (III) was equivalent to $3 \mathrm{~mol} \% \mathrm{Y}_{2} \mathrm{O}_{3}$ to $\mathrm{ZrO}_{2}$, commonly described as $\left(\mathrm{ZrO}_{2}\right)_{0.97}\left(\mathrm{Y}_{2} \mathrm{O}_{3}\right)_{0.03}$ or 
3YSZ. The sol was allowed to mix for $5 \mathrm{~min}$ and hydrolyzed with distilled water. The molar ratios in the sol were $\mathrm{Zr}: \mathrm{HAc}: \mathrm{H}_{2} \mathrm{O}=1: 4: 5$, with $[\mathrm{Zr}]=0.724 \mathrm{~mol} \cdot \mathrm{dm}^{-3}$. Slow hydrolysis of the stabilized zirconium precursor solution by addition of water caused the formation of aqueous zirconium (IV) species. Further condensation of these species leads to the formation of an amorphous $\mathrm{Zr}-\mathrm{O}-\mathrm{Zr}$ network. The sols were diluted 20 times to $[\mathrm{Zr}]=0.036 \mathrm{~mol} \cdot \mathrm{dm}^{-3}$ by addition of 2 -methoxyethanol.

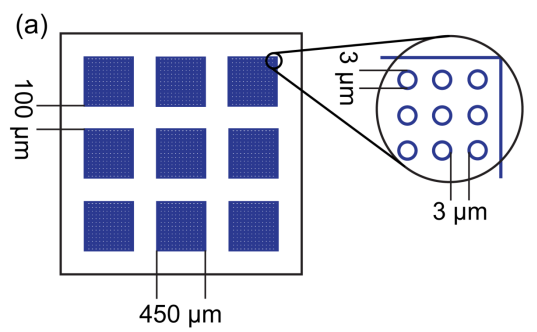

(b)

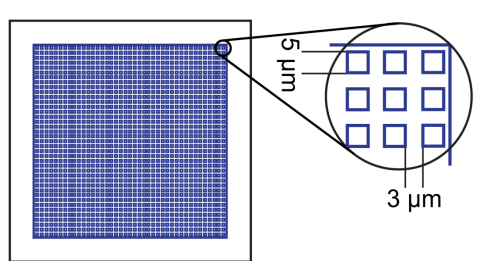

Figure 7.2 Schematic overview of the different PDMS molds, (a) areas of $450 \mathrm{x} 450 \mu \mathrm{m}^{2}$ of circular protruding pillars with a diameter, height and spacing of $3 \mu \mathrm{m}$. Patterned areas are intersected with wide channels of $100 \mu \mathrm{m}$ width; (b) whole patterned area consist of square protruding pillars with a diameter of $5 \mu \mathrm{m}$ and height and spacing of $3 \mu \mathrm{m}$.

\subsubsection{PDMS Mold Preparation}

Poly(dimethylsiloxane) (PDMS) prepolymer and a curing agent (Sylgard ${ }$ 184, Dow Corning Corporation) were mixed in a mass ratio 10:1 and subsequently poured onto a micropatterned silicon master. PDMS was left to polymerize at $70{ }^{\circ} \mathrm{C}$ for $48 \mathrm{~h}$. After curing, the PDMS mold was removed from the silicon master and cut into $5 \times 5 \mathrm{~mm}^{2}$ pieces. Prior to patterning, the PDMS molds were treated in an oxygen plasma chamber (Harrick Plasma, Ithaca, USA) operating at $24 \mathrm{~W}$ for $150 \mathrm{~s}$, to increase the hydrophilic nature of the mold. The molds that were used consisted of an array of circular or square protruding pillars with differences in the diameter, spacing and height. A schematic representation of the shapes and dimensions of the used molds are shown in Figure 7.2. 


\subsubsection{Substrate Preparation}

Silicon substrates (100) were cleaned with a jet of pressurized $\mathrm{CO}_{2}$ on a hot plate at 250 ${ }^{\circ} \mathrm{C}$ and subsequently with oxygen plasma for $150 \mathrm{~s}$ to remove organic residues attached to the surface. The substrates were used directly after this surface treatment.

\subsubsection{Pattern Fabrication}

3YSZ structures were prepared by means of MIMIC. An oxygen-plasma treated micropatterned PDMS mold was gently placed on a clean silicon substrate. To promote adhesion, the mold was softly pressed to ensure the conformal contact with the substrate (Figure 7.1a). A drop of freshly prepared 3YSZ sol was placed at the openings of the microchannels formed between the mold and the substrate. Due to the capillary suction of the microchannels, the sol was forced into the channels and filled them (Figure 7.1b$\mathrm{c}$ and $1 \mathrm{f}-\mathrm{g})$. After complete filling of the microchannels, the substrate and mold were placed on a hot plate at $60^{\circ} \mathrm{C}$ for $1 \mathrm{~h}$ to dry the sol-gel precursor. After drying, the mold was gently released from the substrate, leaving behind a large array of uniformly-sized structures (Figure 7.1d-e and 1g-i). The patterned substrates were then thermally annealed in a pre-heated microwave oven (MultiFAST, Milestone, Sorisole, Italy) at 850 ${ }^{\circ} \mathrm{C}$ for $1 \mathrm{~h}$.

\subsubsection{Characterization}

Samples were measured with X-ray powder diffraction (XRD) to confirm the formation of 3YSZ, using a diffractometer with a Cu anode and a Ni filter (Philips PW1830, PANalytical, Almelo, The Netherlands). Samples were investigated by high-resolution scanning electron microscopy (HR-SEM, $2.0 \mathrm{keV}$, Zeiss 1550, Zeiss, Sliedrecht, The Netherlands) and Atomic Force Microscopy (AFM; Veeco Dimension Icon, Bruker AXS, Wormer, The Netherlands) to determine the surface morphology and height profile of the patterns. The AFM data were further analyzed using the Gwyddion (version 2.25) software package. 


\subsection{Results and Discussion}

\subsubsection{Phase Determination and Microstructure}

$\mathrm{X}$-ray diffraction (Figure 7.3) confirmed that the patterned structures were of the crystalline $3 \mathrm{YSZ}\left(3 \mathrm{~mol} \% \mathrm{Y}_{2} \mathrm{O}_{3}\right.$ ) phase after annealing. ${ }^{[2]}$ No other crystalline phases formed during heat treatment. The sharp peaks at $2 \theta \sim 37.8^{\circ}$ and $44.2^{\circ}$ can be attributed to the $\mathrm{Al}$ holder on which the sample was placed. Sintering in amorphous materials to eliminate porosity, such as in sol-gel derived structures, is driven by viscous flow. Due to the porous nature of gels, the driving force is large enough for sintering to occur at much lower temperatures than for bulk materials, ${ }^{[17]}$ and therefore small crystallite sizes are expected. Crystallite sizes were calculated using the Scherrer equation. On average, the cross-shaped structures contained crystallites of $\sim 9 \mathrm{~nm}$ size $\left(\mathrm{FWHM} \approx 1.0^{\circ}\right.$ for the (111) peak at $2 \theta \sim 30.4^{\circ}$ ), from which I can conclude that densification occurred rapidly, without significant crystallite growth.

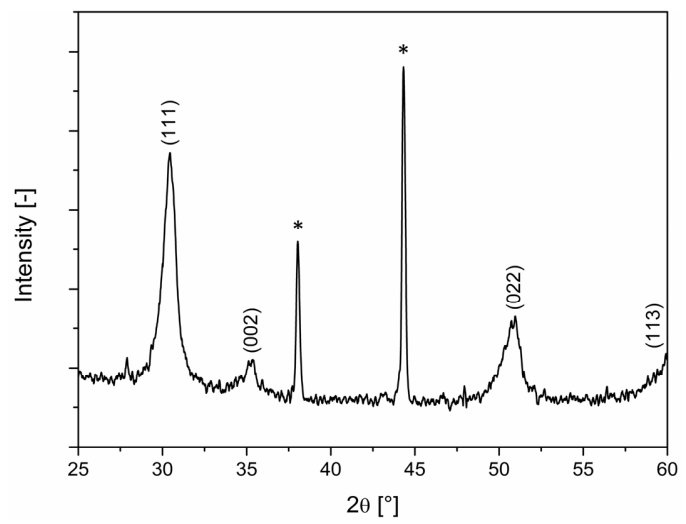

Figure 7.3 XRD pattern of $3 \mathrm{YSZ}$ measured from $2 \theta=25$ to $60^{\circ}$. The substrate was mounted on an $\mathrm{Al}$ disk (denoted with an asterisk).

\subsubsection{Influence of Precursor Concentration}

\section{High Concentration - Formation of Cross-shaped Structures}

During the MIMIC process, the rate at which the microchannels of the mold are filled with liquid sol-gel precursor is inversely proportional to the viscosity of the liquid phase $\eta$. Liquid is dragged into the microchannels due to capillary forces. The interfacial free energies of the precursor, PDMS mold and substrate play an important role: 


$$
\frac{d z}{d t}=\frac{R \cdot \gamma_{\mathrm{LV}} \cdot \cos \theta}{4 \cdot \eta \cdot z}=\frac{R \cdot\left(\gamma_{\mathrm{SV}}-\gamma_{\mathrm{SL}}\right)}{4 \cdot \eta \cdot z}
$$

Here $z$ is the penetration length of the capillary, and $R$ the hydraulic radius of the channel. $\gamma_{\mathrm{LV}}, \gamma_{\mathrm{SV}}$ and $\gamma_{\mathrm{SL}}$ are the surface tensions of sol precursor and air, PDMS wall and air and PDMS wall and sol precursor, respectively, and $t$ is time.

The solubility of nonpolar solvents such as dichloromethane ${ }^{[22]}$ and $\mathrm{C}_{5}-\mathrm{C}_{7}$ alkanes $^{[22,23]}$ in the micropores of PDMS is high, and can give rise to enormous swelling, making PDMS unsuitable as a mold material. Polar solvents such as 2-methoxyethanol and water are also soluble in PDMS, but do not swell the matrix, and are therefore much more suitable. On the other hand, polar solvents are repelled by the hydrophobic PDMS surface and do not have a favorable contact angle $\theta$ to allow capillary infiltration in micrometer-scale channels. However, the hydrophilicity of the PDMS mold surface can be increased by oxygen plasma treatment, thus enhancing the capillary infiltration of the microchannels by solvents, while not affecting the solubility of the solvents in the PDMS matrix. Metal alkoxides, ${ }^{[22]}$ or stabilized metal oxide clusters are dragged along with the solvent matrix into the microchannels, but they have more difficulties to diffuse into the micropores of the PDMS walls upon drying than the small solvent molecules. I may therefore assume that the micropores of the PDMS walls are primarily infiltrated by solvent and not by the stabilized zirconium $n$-propoxide clusters used here. At 60 ${ }^{\circ} \mathrm{C}$, the rate of evaporation of 2 -methoxyethanol (bp. $124-125{ }^{\circ} \mathrm{C}$, vapor pressure $\sim 88$ mbar) is low compared to water (bp. $100{ }^{\circ} \mathrm{C}$, vapor pressure $\sim 199 \mathrm{mbar}$ ). Thus, the drying and shrinkage of the sol-gel precursor under a mold can be attributed to the diffusion of solvent into the PDMS mold rather than to evaporation.

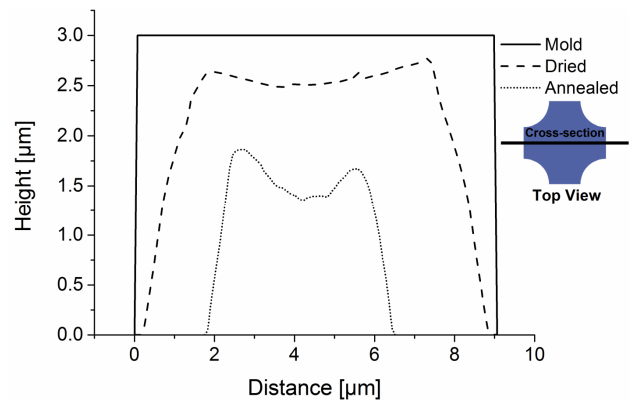

Figure 7.4 Cross sections of PDMS mold (solid line), as-dried gel structure, $60{ }^{\circ} \mathrm{C}$ for $1 \mathrm{~h}$ (dashed line), and the annealed crystalline 3 YSZ structure, $850^{\circ} \mathrm{C}$ for $1 \mathrm{~h}$ (dotted line). 
The cross-sectional view in Figure 7.4 of a dried cross-shaped structure shows a plateau height of $c a .2 .6 \mu \mathrm{m}$. The peak formation on the edges of the patterned structures resulted from a more rapid drying of the precursor sol in the corners of the mold, since the corner areas have a much higher surface area-to-volume ratio than elsewhere under the mold. ${ }^{[24]}$ The variation in gel times can be partially overcome by lowering the temperature during drying, or by replacing the square edges by curved ones. ${ }^{[2]}$ The deposits act as a point for pinning ${ }^{[25]}$ during evaporation or solvent loss via infiltration into the PDMS matrix. The solid phase thus grows from the PDMS interface towards the interior of the channel. In the final stages of drying, the microchannels are no longer completely filled by liquid and the remaining precursor solution accumulates in the center between four protruding pillars, see Figure 7.5a. Due to high local stresses around the protruding pillars, as illustrated by the high local density of force lines in Figure 7.5b-c and the low cohesive strength of the formed gel, the as-formed structures cracked, resulting in isolated cross-shaped structures (Figure 7.6a-b). The cracking phenomena occurred in an entirely homogenous fashion over the entire patterned surface area. Since the interfacial free energy of the PDMS mold $\left(\gamma_{\mathrm{SV}}=21.6 \mathrm{mN} \cdot \mathrm{m}^{-1}\right)^{[21]}$ is much lower than the Si-substrate $\left(\gamma_{\mathrm{SV}}=72.0 \mathrm{mN} \cdot \mathrm{m}^{-1}\right),{ }^{[21]}$ the gelled structures adhere preferentially to the substrate and the patterned structures remain intact upon mold removal. Further heat treatment in a microwave oven at $850{ }^{\circ} \mathrm{C}$ resulted in more shrinkage and crystallization of the amorphous structures. On average, the patterning technique yielded uniformly sized and shaped structures over the whole patterned area, with an average plateau height of approximately $1.4 \mu \mathrm{m}$ (Figure 7.4). This corresponds to $\sim 46.2 \%$ shrinkage in vertical direction, compared to the height of the initial as-dried structure.
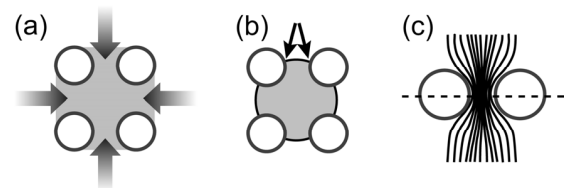

Figure 7.5 Schematic overview of formation of cross-shaped structures. The blue circles represent the protruding pillars of the mold; (a) precursor is continuously dragged into the microchannels, accumulating the solid content of the precursor at the center of four pillars. To simplify the actual flow of precursor, the flow from the depicted area into an identical neighboring area is not shown; (b) In the final drying stage, a viscous gel-structure has formed, and due to high local stresses around the circular protruding pillars the gelled structures crack at the locations as pointed out by arrows; (c) densification of force lines around the circular protruding pillars. The dashed line represents the location and direction in which the crack is observed. 
I calculated the maximum mass of precursor material in case of complete filling of the microchannels by precursor solution and its subsequent transformation into crystalline 3YSZ.

Remarkably, my calculations showed that approximately $750 \%$ more solid material had accumulated in the channels than is present in the equivalent volume of liquid precursor solution. I suggest that this significant accumulation is explained by the high permeability of 2-methoxyethanol into the micropores of the wall of the PDMS mold, which enables new precursor solution from the outside of the mold to be continuously dragged into the microchannels. In view of Equation (7.1), the existence of $100 \mu \mathrm{m}$ wide channels intersecting the patterned areas (Figure 7.2a) facilitate a low resistive transportation route for larger volumes of precursor material than the individual pillar spacing of $3 \mu \mathrm{m}$. Consequently, more precursor material is able to penetrate further into the interior of the mold in a shorter period of time.

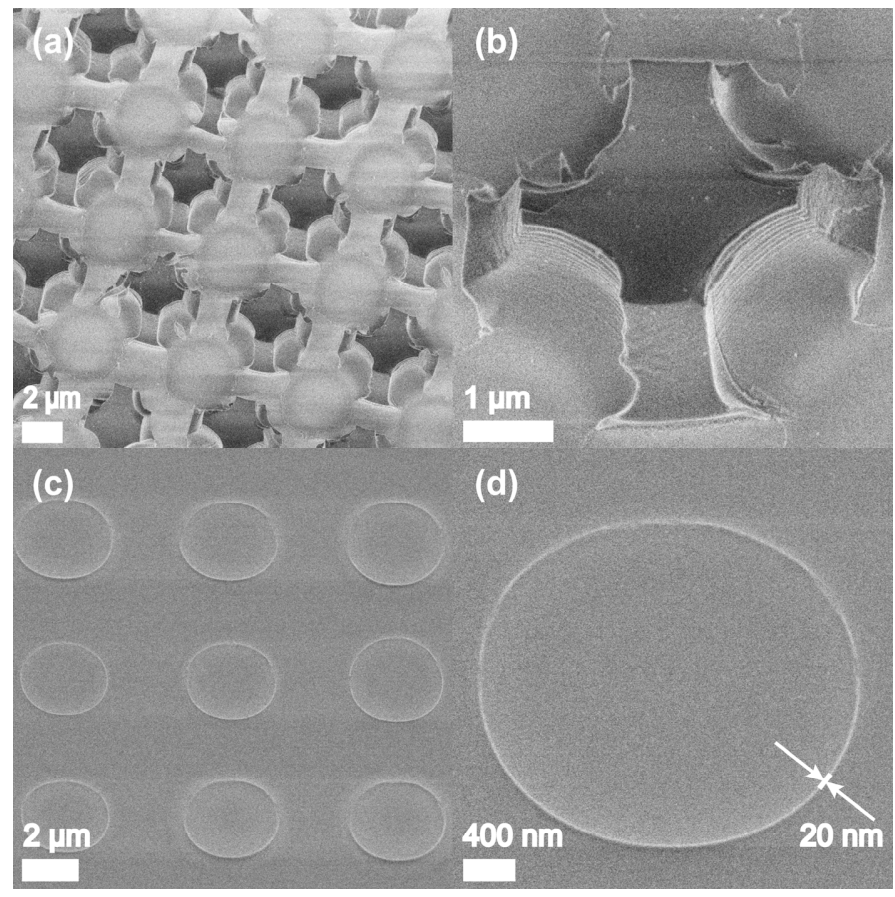

Figure 7.6 HR-SEM pictures of cross- and ring-shaped structures after annealing at $850{ }^{\circ} \mathrm{C}$ for $1 \mathrm{~h}$; (a) overview of a larger patterned area of cross shapes; (b) cross pattern at higher magnification. Pictures (a-b) were taken in-lens at $2.0 \mathrm{kV}$ for higher topographical resolution; (c) overview of a larger patterned area of ring shapes; (d) ring pattern at higher magnification. Pictures (c-d) were taken with secondary electrons at $2.0 \mathrm{kV}$. 


\section{Evolution of Pattern Formation - From Cross- to Ring-shaped Patterns}

Occasionally, patterns near the edges of the PDMS mold showed different structures than the interior parts, e.g. due to the presence of less precursor material at the edges, the effect of faster drying, blocked microchannels, and/or a lower degree of conformal contact between the stamp and the substrate. These different structures provide important information of the various stages of pattern formation. The stages were found not only to be concentration dependent, but also a mass dependency was found. For example, when only a small volume of the concentrated precursor solution was used to create a pattern, ring structures were obtained instead of cross shapes. Figure 7.7 shows the gradual evolution of ring formation from cross-shaped structures by AFM upon lowering the supply of solids.

(a)

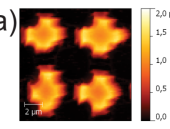

(d)

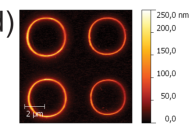

(b)
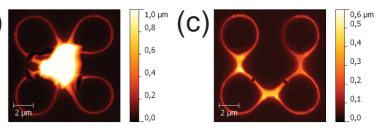

Figure 7.7 AFM height images of different stages of structure formation, from cross-shaped to ring-shaped structures; (a) complete filling of microchannels at high precursor concentration, cross formation; (b) lower mass of solids present, cross shapes (1.0 $\mu \mathrm{m}$ height) and small rings (10 nm height) were formed concurrently; (c) further reduction of the amount of solid mass in the precursor solution led to the patterning of rings connected via solid 'necks'; (de) a further mass decrease resulted in ring formation with decreasing line width.

At high precursor concentration and after complete filling of the channels, the whole patterned area was filled with cross-shaped structures (Figure 7.7a). At locations where a smaller mass of solids was present, high aspect ratio cross- and ring-shaped structures were formed concurrently, with heights of approximately $1.0 \mu \mathrm{m}$ and $10 \mathrm{~nm}$, respectively (Figure 7.7b). A further reduction of supplied mass resulted in ring-shaped structures connected with three solid 'necks'; no cross-shaped structures were observed (Figure 7.7c). Neck formation is a result of Rayleigh-Plateau instability during the final stages of drying, and depends on the rate of loss of solvents and/or the formation of polymer networks of higher molecular mass (gelling). ${ }^{[7,26]}$ As the amount of liquid precursor in the microchannels decreased, droplets are formed to reduce the total surface energy of the system. Further shrinkage of the droplets as a result of solvent diffusion into the 
PDMS increases the instability, and will eventually cause the droplet to collapse. I always observed the formation of three solid 'necks' connecting the rings as result of this collapse. At lower concentrations, no necks were observed and only ring-shaped structures with decreasing line widths were obtained (Figure $7.7 \mathrm{~d}-\mathrm{e}$ ). The formation of these rings is discussed in the next section.

\section{Low Concentration - Formation of Ring-shaped Structures}

Dilution of the precursor to $[\mathrm{Zr}]=0.036 \mathrm{~mol} \cdot \mathrm{dm}^{-3}$ caused a drastic change in the obtained structure sizes and geometry, as schematically shown in Figure 7.1f-i. HR-SEM pictures of an array of uniformly sized and shaped rings (Figure 7.6c-d) are shown, with a diameter of approximately $3.5 \mu \mathrm{m}$ and a line width of roughly $20 \mathrm{~nm}$. Differences between individual rings of $c a .25 \%$ in height and line thickness were observed with AFM measurements (Figure 7.8b). These differences, however, were not observed with HR-SEM (Figure 7.6c-d). They are most likely AFM scanning artifacts resulting from the small feature width $(\sim 20 \mathrm{~nm})$ and high aspect ratio of the rings. The rate of diffusion of 2-methoxyethanol into the micropores of PDMS is most rapid in the square corners of the mold, and the zirconia precursor was initially deposited there.
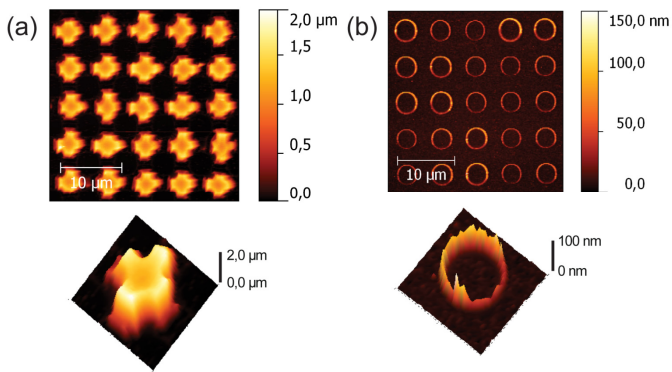

Figure 7.8 AFM height images $\left(30 \times 30 \mu \mathrm{m}^{2}\right.$ area) of: (a) cross-shaped structures, annealed in air at $850{ }^{\circ} \mathrm{C}$ for $1 \mathrm{~h}$; (b) ring-shaped structures from diluted sol, annealed in air at $850{ }^{\circ} \mathrm{C}$ for $1 \mathrm{~h}$. Three-dimensional representations of both structures are shown $\left(7 \times 7 \mu \mathrm{m}^{2}\right.$ area $)$ from the highlighted areas (dashed squares).

Since gravitational forces are negligible at this length scale, deposition of solids on the walls of the less preferential protruding PDMS pillars takes place as well. At the end of the drying stage, as the flux of precursor material into the microchannels has ceased, the PDMS (side) walls are covered with as-gelled zirconia precursor. 
After mold removal, only the solids deposited near the PDMS-Si interface remain attached to Si due to the higher interfacial free energy of the Si-substrate compared to PDMS. ${ }^{[21]}$ Shi et al. reported a similar mechanism for the formation of $\mathrm{TiO}_{2}$ ring structures from dilute colloidal solutions in ethanol. ${ }^{[27]}$ For similar concentrations and drying temperatures $\left(45^{\circ} \mathrm{C}\right)$ as reported here, they obtained rings with a height and line width of approximately 170 and $185 \mathrm{~nm}$, respectively. Although the height of the rings is quite similar to my findings, the line width is an order of magnitude larger. This significant difference can be explained by the fact that most precursor material was deposited on the PDMS side walls, and not on the Si-substrate. Furthermore, the crystallite sizes of sol-gel derived materials have much smaller dimensions than the sizes of the used colloidal $\mathrm{TiO}_{2}$ particles.

A three-dimensional representation (Figure 7.8b) clearly shows a lower height in parts of the ring-shaped structure. Rayleigh-Plateau instability in the final drying stage caused the decreasing precursor droplets to collapse (as explained in the previous paragraph), and material was locally expelled and deposited elsewhere on the same ring. The direction of the collapse is related to the position inside the PDMS mold, i.e. different directions were observed for the corners, sides and center of the mold (Figure 7.9). Moreover, the side with the lower height was always directed towards the interior region of the mold. A lower partial pressure outside the mold forces the drying precursor material to move towards the edges during the drying stage; random collapse directions were observed for ring structures in the center of the mold.

\subsubsection{Effect of Mold Geometry}

The mold geometry plays an important role in the final shape and size of the patterned structures. In order to show the importance, the geometry was carefully changed and continuous patterns and aligned isolated structures were obtained. A mold with square protruding pillars (mold features: $5 \mu \mathrm{m}$ diameter, $3 \mu \mathrm{m}$ spacing and $3 \mu \mathrm{m}$ height; Figure $7.2 \mathrm{~b})$ was used successfully.

\section{Square-shaped Patterns}

The channels of the PDMS mold were completely filled with the concentrated sol precursor. Unlike the circular patterned mold, the dried structure did not crack and a patterned film was formed, as illustrated by the RTA annealed patterns in Figure 7.10a-b. 
It appears that the quality of the patterned film was influenced by the shape of the protruding pillars. In particular, stress accumulation around the pillars during the drying of as-gelled structures plays an important role as was noted above. But unlike the significant densification of force lines around the circular protruding pillars (Figure 7.5c), the more evenly distributed force lines around the edges of the square protruding pillars dissipate the stress more efficiently. Consequently, the rigid as-dried pattern remained intact. No cracks were observed even after RTA. Also, a lower overall pattern thickness reduces the vertical shrinkage during drying and sintering, and thus the formation of cracks. ${ }^{[24]}$ Similar to the cross-shaped structures, peak formation on the edges was also observed here in the patterned film. Figure 7.10a-b clearly show that the procedure yielded a high quality pattern with an average height of $c a .450 \mathrm{~nm}$. The features are uniformly sized and shaped with sharp edges.

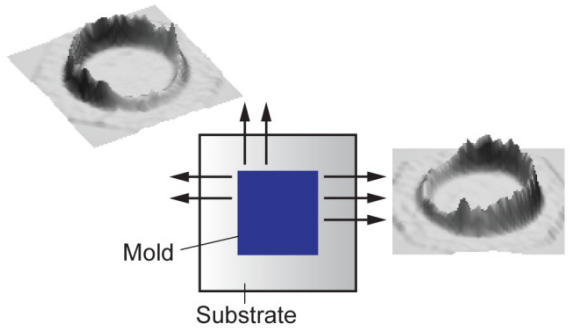

Figure 7.9 Schematic representation of ring collapse in the amorphous structures during the drying stage. Evaporation of the sol precursor is directed towards the edges of the mold (as indicated with the arrows). The places where the rings collapsed (lower height) were always directed to the interior of the mold. However, the direction became more random when the rings were located further away from the edges.

The significant difference in height between the cross-shaped structures and the patterned film by more than a factor of 3 is caused by the geometry of the mold: the mold with square protruding pillars lacks the $100 \mu \mathrm{m}$ wide channels in between patterned areas (Figure 7.2), so that the rate at which liquid precursor accumulates in the microchannels is lower. Moreover, instead of accumulation of solids in isolated features, all precursor material was distributed equally throughout the patterned film, yielding patterns with lower average heights. Dilution of the sol to $[\mathrm{Zr}]=0.036 \mathrm{~mol} \cdot \mathrm{dm}^{-3}$ led to the formation of squares, with solid material only deposited on the edges (Figure 7.10c-d). 


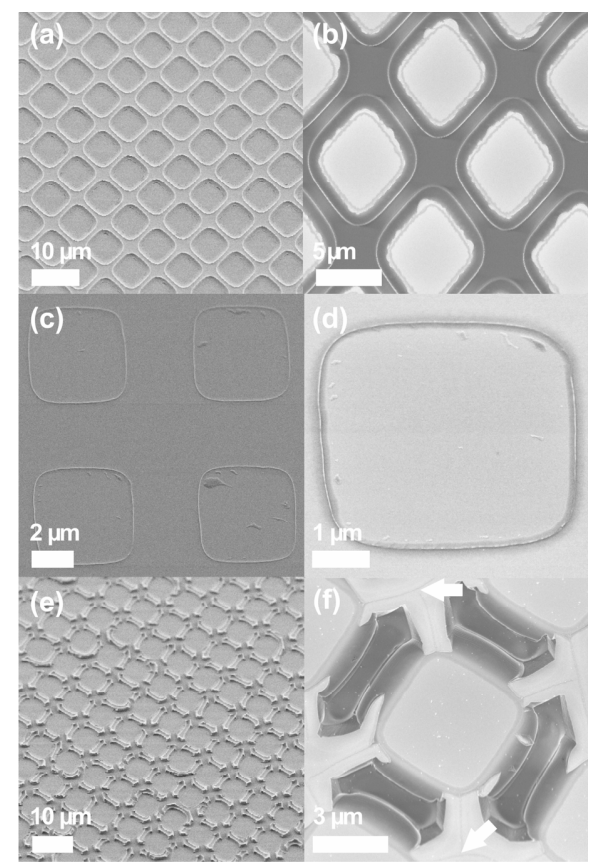

Figure 7.10 HR-SEM pictures of patterns obtained from square-shaped molds. All images were taken after heat treatment at $850^{\circ} \mathrm{C}$ for $1 \mathrm{~h}$ in air; (a) overview of patterned, crack-free film; (b) patterned film at higher magnification. Sharp edges and uniform size and shape of patterned film are clearly visible; (c-d) square line-patterns from diluted sols $([\mathrm{Zr}]=0.036$ $\left.\mathrm{mol} \cdot \mathrm{dm}^{-3}\right)$. Some PDMS residue is visible; (e) overview of patterned area with 'dog bone' shapes. The patterned film was deliberately cracked by addition of extra precursor sol during the drying stage; (f) 'dog bone' shaped structure at higher magnification. The location of crack formation is clearly visible (as indicated with the arrows) and the shape of the structure follows the curvature of the crack. Pictures a, c and e were taken with secondary electrons at 1.3 $\mathrm{kV}$. Pictures b, $\mathrm{d}$ and $\mathrm{f}$ were taken in lens at $1.3 \mathrm{kV}$ for higher topographical resolution.

\section{Re-filling of the Square-shaped Patterns}

To increase the height of the patterned film, new precursor solution was placed at the openings of the mold's channels after 10 min of drying. Although the final pattern height increased from 450 to approximately $800-900 \mathrm{~nm}$ after annealing for $1 \mathrm{~h}$ at 850 ${ }^{\circ} \mathrm{C}$, the patterned film could not be kept intact. This could be either the result of an increased pattern height-to-width ratio, ${ }^{[2]}$ or possible stress accumulation as a result of solvent retention. Diffusion of solvent, retained in the first deposited pattern, into the micropores of the PDMS may be impeded after the microchannels were re-filled with new precursor material.

Interestingly, the cracking occurred in a completely orderly fashion, and re- 
sulted in uniformly sized 'dog bone' shaped structures (Figure 7.10e-f). Moreover, the 'dog bone' shaped structures did not show the typical double peak profile on the edges; ${ }^{[24]}$ flat top surfaces were obtained. The HR-SEM image (Figure 7.10f) clearly shows that the cracks formed and propagated from the center point where four squares pillars meet. The arrows point to locations where cracks initiation took place. The shape of the structure follows the curvature of these cracks. Thus, by deliberately inducing cracks in the patterned film, a large array of uniformly sized isolated structures was obtained.

\subsection{Conclusions}

I have successfully demonstrated the patterning of high aspect ratio 3YSZ structures by combining micromolding in capillaries and sol-gel chemistry. This technique resulted in structures of similar shape and dimensions over the whole patterned area. When circular protruding pillars were used, cross-shaped structures with an average plateau height of $\sim 1.4 \mu \mathrm{m}$ were obtained for concentrated precursor solutions $\left([\mathrm{Zr}]=0.724 \mathrm{~mol} \cdot \mathrm{dm}^{-3}\right)$. The shape was determined by the geometry of the mold, shrinkage, and cracking of the as-formed gel during the drying stage and subsequent heat treatment. Dilution of the precursor solution by 20 times $\left([\mathrm{Zr}]=0.036 \mathrm{~mol} \cdot \mathrm{dm}^{-3}\right)$ resulted in ring-shaped structures that were more than an order of magnitude smaller in dimension. Addition of new precursor solution during the drying stage induced cracks in the as-gelled structures, and 'dog bone' shaped structures were obtained over the whole patterned area. Changes in pillar geometry and density, or channel height can lead to unwanted effects such as cracking and/or the appearance of randomly shaped structures. The evolution of these cracks and the direction in which they propagate is not yet understood. Computer modeling might lead to a better understanding of the connection between the PDMS mold geometry and the cracking behavior of the sol-gel precursor solutions. Predictions of the cracking behavior of precursor solutions may lead to new patterning techniques based on adjusted mold geometries that facilitate controlled cracking in order to obtain isolated structures of preferred shape and dimensions. The cracking phenomenon allows the formation of isolated features by MIMIC, a soft patterning methodology which normally allows only continuous patterns to be formed. 


\subsection{Bibliography}

[1] Z.Y. Can; H. Narita; J. Mizusaki; H. Tagawa, Detection of carbon monoxide by using zirconia oxygen sensor. Solid State Ionics 1995, 79, (C), 344-348.

[2] P. Vernoux; M. Guth; X. Li, Ionically conducting ceramics as alternative catalyst supports. Electrochemical and Solid-State Letters 2009, 12, (7), E9-E11.

[3] J.W. Fergus, Electrolytes for solid oxide fuel cells. Journal of Power Sources 2006, 162, (1), 30 40.

[4] X.Q. Cao; R. Vassen; D. Stoever, Ceramic materials for thermal barrier coatings. Journal of the European Ceramic Society 2004, 24, (1), 1-10.

[5] J. Henzie; J.E. Barton; C.L. Stender; T.W. Odom, Large-area nanoscale patterning: Chemistry meets fabrication. Accounts of Chemical Research 2006, 39, (4), 249-257.

[6] Y. Xia; J.A. Rogers; K.E. Paul; G.M. Whitesides, Unconventional Methods for Fabricating and Patterning Nanostructures. Chemical Reviews 1999, 99, (7), 1823-1848.

[7] J.E. ten Elshof; S.U. Khan; O.F. Göbel, Micrometer and nanometer-scale parallel patterning of ceramic and organic-inorganic hybrid materials. Journal of the European Ceramic Society 2010, 30, (7), 1555-1577.

[8] C.R. Martin; I.A. Aksay, Submicrometer-scale patterning of ceramic thin films. Journal of Electroceramics 2004, 12, (1-2), 53-68.

[9] A. George; T.M. Stawski; S. Unnikrishnan; S.A. Veldhuis; J.E. ten Elshof, Micro and nanopatterning of functional materials on flexible plastic substrates via site-selective surface modification using oxygen plasma. Journal of Materials Chemistry 2012, 22, (2), 328-332.

[10] Q. Zhang; C.S. Dandeneau; X. Zhou; C. Cao, ZnO nanostructures for dye-sensitized solar cells. Advanced Materials 2009, 21, (41), 4087-4108.

[11] R. Janisch; P. Gopal; N.A. Spaldin, Transition metal-doped TiO2 and ZnO - Present status of the field. Journal of Physics Condensed Matter 2005, 17, (27), R657-R689.

[12] Ü. Özgür; Y.I. Alivov; C. Liu; A. Teke; M.A. Reshchikov; S. Doğan; V. Avrutin; S.J. Cho; H. Morko, A comprehensive review of $\mathrm{ZnO}$ materials and devices. Journal of Applied Physics 2005, 98, (4), 1-103.

[13] S.M.D. Watson; K.S. Coleman; A.K. Chakraborty, A new route to the production and nanoscale patterning of highly smooth, ultrathin zirconium oxide films. ACS Nano 2008, 2, (4), 643650.

[14] Y. Gao; Y. Masuda; K. Koumoto, Patterning of $\mathrm{ZrO} 2$ precursor through a gas-generated self-assembly route. Journal of Nanoscience and Nanotechnology 2006, 6, (6), 1842-1846. 
[15] H. Ridaoui; F. Wieder; A. Ponche; O. Soppera, Direct ArF laser photopatterning of metal oxide nanostructures prepared by the sol-gel route. Nanotechnology 2010, 21, (6).

[16] D. Peter; T.S. Ertel; H. Bertagnolli, EXAFS study of zirconium alkoxides as precursor in the sol-gel process: I. Structure investigation of the pure alkoxides. Journal of Sol-Gel Science and Technology 1994, 3, (2), 91-99.

[17] C.J. Brinker; G.W. Scherer, Sol-gel science: the physics and chemistry of sol-gel processing. Academic Press, Inc: San Diego, CA, 1990.

[18] B. Malic; I. Arcon; A. Kodre; M. Kosec, Homogeneity of Pb (Zr, Ti) O thin films by chemical solution deposition: Extended x-ray absorption fine structure spectroscopy study of zirconium local environment. Journal of Applied Physics 2006, 100, 051612.

[19] G.W. Scherer, Sintering of Sol-Gel Films. Journal of Sol-Gel Science and Technology 1997, 8, (13), 353-363.

[20] D.G. Lamas; N.E. Walsöe De Reca, X-ray diffraction study of compositionally homogeneous, nanocrystalline yttria-doped zirconia powders. Journal of Materials Science 2000, 35, (22), 5563-5567.

[21] E. Kim; Y. Xia; G.M. Whitesides, Micromolding in capillaries: Applications in materials science. Journal of the American Chemical Society 1996, 118, (24), 5722-5731.

[22] D.P. Brennan; A. Dobley; P.J. Sideris; S.R.J. Oliver, Swollen poly(dimethylsiloxane) (PDMS) as a template for inorganic morphologies. Langmuir 2005, 21, (25), 11994-11998.

[23] J.N. Lee; C. Park; G.M. Whitesides, Solvent Compatibility of Poly(dimethylsiloxane)-Based Microfluidic Devices. Analytical Chemistry 2003, 75, (23), 6544-6554.

[24] C.R. Martin; I.A. Aksay, Topographical evolution of lead zirconate titanate (PZT) thin films patterned by micromolding in capillaries. Journal of Physical Chemistry B 2003, 107, (18), 4261-4268.

[25] R.D. Deegan; O. Bakajin; T.F. Dupont; G. Huber; S.R. Nagel; T.A. Witten, Capillary flow as the cause of ring stains from dried liquid drops. Nature 1997, 389, (6653), 827-829.

[26] J.A. Wigenius; M. Hamedi; O. Inganäs, Limits to nanopatterning of fluids on surfaces in soft lithography. Advanced Functional Materials 2008, 18, (17), 2563-2571.

[27] G. Shi; N. Lu; L. Gao; H. Xu; B. Yang; Y. Li; Y. Wu; L. Chi, Fabrication of TiO2 arrays using solvent-assisted soft lithography. Langmuir 2009, 25, (17), 9639-9643. 


\title{
General Conclusions and Outlook
}

\begin{abstract}
In this chapter general conclusions and remarks regarding the conducted research are presented. In addition, various experimental ideas for possible future research are discussed, with a particular focus on the effect of the synthetic pathway and the resulting microstructure on the structural properties. Finally, it is emphasized that the future of sol-gel chemistry in industrial applications lies in the use of its possibilities, rather than its limitations.
\end{abstract}




\subsection{General Conclusions}

The work described in this thesis concerns various low-temperature synthesis and processing approaches to perovskite and fluorite-type nanoceramics. Throughout the chapters, sol-gel chemistry was used as a main 'tool' for the preparation of these inorganic oxides. The main focus lies on the relationship between the synthetic pathway (and processing conditions) and the resulting crystalline phase or microstructure and resulting properties.

At first glance, a sol-gel synthesis may appear as simply the mixing of precursors in the appropriate ratios, their subsequent gelling, and heat treatment to form a crystalline product. Dissecting the different elements of sol-gel, however, shows that in practice this is hardly the case. Unfortunately. Subtle changes in concentration, stirring speed, or even precursor volume may have severe consequences on the final stoichiometry and/or microstructure of the desired product. A full understanding of the role of modifying ligands, the stability of precursors, and the interactions with each other and the solvent is therefore necessary to fully control the synthesis from molecular precursor to final product. The results in Chapter 2 underline that the choice of solvent determines if a crystalline phase is formed or not, ${ }^{[1]}$ and also may control the extent to which the nanocrystals are allowed to grow.

Time-resolved small angle X-ray scattering (SAXS) was used to probe the local electron density variations occurring during $\mathrm{BaTiO}_{3}$ (BTO) nanocrystal formation in solution. The use of the scattering invariant method, based on the total scattered intensity of the system, allowed for a model independent analysis of the crystalline phase formation. The effect of variations in processing parameters on the amorphous-to-crystalline phase transition could be described, and rate-limiting regimes were discerned (Chapter 3). Advanced knowledge of the mechanism of crystal phase formation enabled the expansion of this synthesis method to other perovskite materials, and the introduction of dopants. In Chapter 4, the synthesis of phase-pure proton conducting Ydoped $\mathrm{BaZrO}_{3}$ is described. Although a dense nano-crystalline ceramic was obtained at much lower processing temperature than needed for the bulk material, the high temperature processing caused local inhomogeneities at the grain boundaries. In addition, the limited crystallite growth during sintering resulted in a high grain boundary contribution on the total proton conduction. Further optimization of the processing conditions is thus necessary to increase its performance. 
A method based on X-ray reflectivity is developed in Chapter 5. Its goal was to provide a simple methodology to accurately determine the density of ceramic thin films, and to utilize this method to study the effect of high temperature processing conditions on the density of thin yttria-stabilized zirconia (YSZ) films. In Chapter 6, it is demonstrated that the proposed method is an excellent tool for microstructural analysis of large sample quantities and optimization of annealing procedures. Achieving a high thin film density, while limiting the annealing time at high temperatures, may result in better quality films. By using microwave-assisted rapid thermal annealing instead of conventional heating, it was possible to reduce the annealing time at $1000{ }^{\circ} \mathrm{C}$ from $12 \mathrm{~h}$ to 5 min.

Soft lithographic patterning in combination with sol-gel chemistry was used for the large area patterning of high aspect ratio YSZ features (Chapter 7). Isolated features were obtained by a specific combination of precursor concentration and patterning mold geometry. Patterning of these isolated features on top of dense YSZ films, greatly enhances the total surface area, and may result in higher ionic conductivity.

\subsection{Outlook}

This section presents various experimental ideas for possible future research, in which the properties of the synthesized materials are the main focus of investigation. In particular, the effect of the synthetic pathway and the resulting microstructure on the structural properties are worth further investigation. The work described in this thesis can be used as an experimental framework for the production of high-quality nanoceramics with control over the subtle chemistry.

\subsubsection{Total Scattering Experiments}

Although much has been learned about the formation of BTO nanocrystals in benzyl alcohol (Chapter $\mathbf{2}$ and 3), the initial stage structure and the mechanism of crystallite formation (in-situ transformation or dissolution-precipitation) is still unknown. Total scattering experiments (using a synchrotron radiation source) allows to record a pair distribution function (PDF). It describes the distribution of distances of particles within a certain volume, and thus contains information on the short-, middle-, and long-range 
order in a material. Time-resolved total scattering measurements may help to answer the question which mechanism is predominant in the formation of BTO nanocrystals, and what the average structure (at various time intervals) really looks like.

\subsubsection{Improved Performance of Proton-conducting BZY}

\section{Spark plasma sintering}

Due to the refractory nature of BZY ceramics, typically very high sintering temperatures are necessary to obtain dense bodies (as outlined in Chapter 4). As a consequence, phase inhomogeneity as a result of dopant segregation or secondary phase formation may occur, resulting in lower proton conductivity. To circumvent long dwell times at high temperatures, spark plasma sintering (SPS) is often employed. ${ }^{[2]}$ Samples are sintered under a high dc current along with a uniaxially applied pressure. High density ceramics are typically formed after only several minutes at high temperature, resulting in much cleaner grain boundaries without phase segregation or dopant inhomogeneities. ${ }^{[3]}$

Sample BZY1* has been sintered for 5 min at $1600{ }^{\circ} \mathrm{C}$ by SPS (heating rate 100 $\left.{ }^{\circ} \mathrm{C} \cdot \mathrm{min}^{-1}\right)$ under a uniaxial load of $2.5 \mathrm{kN}$, resulted in a final relative density of approximately $95 \%$. X-ray diffraction confirmed that the as-sintered ceramic was phase-pure $\mathrm{BZY}$, and no secondary phases were observed. The average crystallite size was approximately 3 times larger than obtained after conventional sintering for $24 \mathrm{~h}$ at $1350{ }^{\circ} \mathrm{C}$, $120 \mathrm{~nm}$ versus $43 \mathrm{~nm}$, respectively. The proton conductivity of the as-sintered pellets was measured using electrochemical impedance spectroscopy between 450 and $600{ }^{\circ} \mathrm{C}$ in wet $\mathrm{H}_{2}$ atmosphere $\left(\mathrm{pH}_{2} \mathrm{O} 0.030 \mathrm{~atm}\right)$, see Figure 8.1. The initial results show that the proton conductivity of a spark plasma sintered pellet is ca. 3-6 times higher than what is achieved by conventional heating, as summarized in Table 8.1. A maximum conductivity of $4.2 \cdot 10^{-4} \mathrm{~S} \cdot \mathrm{cm}^{-1}$ was measured at $600{ }^{\circ} \mathrm{C}$. In addition, the activation energy of the total proton conductivity is much lower than for a sample sintered by conventional heating. In fact, it is much lower than the reported literature value of $\sim 0.65$ $\mathrm{eV} \cdot{ }^{[4,5]}$ Further investigation on the effect of longer $\mathrm{Zr}$ and $\mathrm{Y}$ precursor intermixing and dopant distribution at the grain boundaries is recommended.

\footnotetext{
* Sample BZY1 was prepared by mixing a Zr and Y alkoxide solution in benzyl alcohol for $4 \mathrm{~h}$ at $100^{\circ} \mathrm{C}$. After cooling to room temperature and subsequent $\mathrm{Ba}(\mathrm{OH})_{2} \cdot 8 \mathrm{H}_{2} \mathrm{O}$ addition, the reaction mixture was refluxed for $20 \mathrm{~h}$ at $150{ }^{\circ} \mathrm{C}$ (see Chapter 4.2.2 for more experimental details).
} 
Table 8.1 Comparison of the bulk, grain boundary, and total proton conductivity achieved by SPS and conventional heating.

\begin{tabular}{lcc}
\hline & SPS & Conventional Heating \\
\hline Bulk Conductivity & $5.5 \cdot 10^{-3} \mathrm{~S} \cdot \mathrm{cm}^{-1}$ & $9.4 \cdot 10^{-4} \mathrm{~S} \cdot \mathrm{cm}^{-1}$ \\
Grain Boundary Conductivity & $4.5 \cdot 10^{-4} \mathrm{~S} \cdot \mathrm{cm}^{-1}$ & $1.4 \cdot 10^{-4} \mathrm{~S} \cdot \mathrm{cm}^{-1}$ \\
Total Conductivity & $4.2 \cdot 10^{-4} \mathrm{~S} \cdot \mathrm{cm}^{-1}$ & $1.2 \cdot 10^{-4} \mathrm{~S} \cdot \mathrm{cm}^{-1}$ \\
Activation Energy & $0.43 \pm 0.02 \mathrm{eV}$ & $0.79 \pm 0.02 \mathrm{eV}$ \\
\hline
\end{tabular}

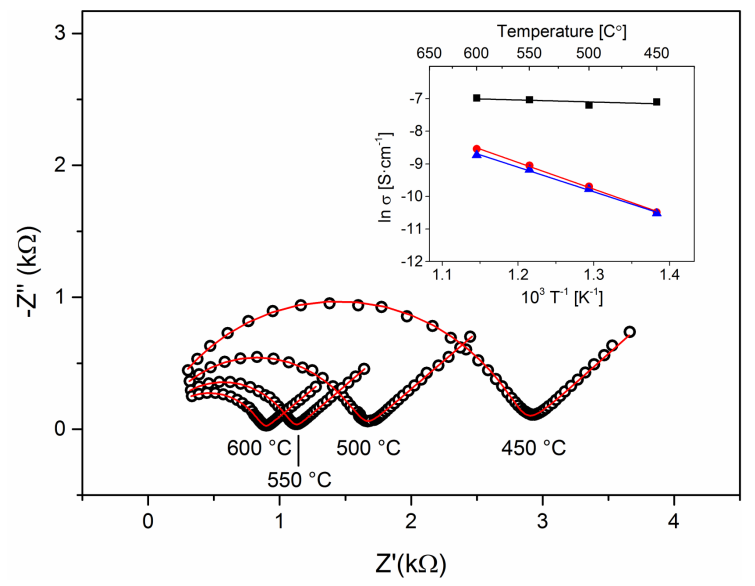

Figure 8.1 Impedance spectra of a spark-plasma sintered BZY pellet at $1600{ }^{\circ} \mathrm{C}$. Inset: Arrhenius representation of the bulk (black), grain boundary (red), and total (blue) proton conductivity, respectively.

\section{Synthesis of Single-source Zr-Y Precursors}

Alternatively, the preparation of a single-source precursor, as opposed to precursor intermixing, may help to achieve a more homogeneous dopant distribution. The synthesis of various heterometallic intermediates using $\mathrm{Zr}$ alkoxides in combination with less reactive lanthanide acetates has been described by Hubert-Pfalzgraf. ${ }^{[6]}$ Initial results show that the use of benzyl alcohol, besides the reported use of toluene or 2-methoxyethanol, also resulted in the formation of a single-source precursor. The yttrium (III) acetate tetrahydrate powder was added to a $0.1 \mathrm{~mol} \cdot \mathrm{dm}^{-3}$ solution of zirconium (IV) $n$-propoxide, and subsequently the mixture was heated for $>20 \mathrm{~h}$ at $100{ }^{\circ} \mathrm{C}$. Subsequently, $\mathrm{Ba}(\mathrm{OH})_{2} \cdot 8 \mathrm{H}_{2} \mathrm{O}$ was added to the as-formed precursor, and the reaction mixture was refluxed for $24 \mathrm{~h}$ at $150{ }^{\circ} \mathrm{C}$, yielding a phase-pure BZY powder. Interestingly, the yttrium acetate tetrahydrate only dissolves in benzyl alcohol in the presence of the $\mathrm{Zr}$ alkoxide precursor. 


\subsubsection{Effect of Microstructure on Ionic Conductivity of YSZ Thin Films}

The optimized annealing conditions, as described in Chapter 6, can be utilized to investigate: (1) the ionic conductivity of dense YSZ thin films, and (2) the effect of additional surface area (see Figure 8.2). An increased surface area may be achieved by e.g. the deposition of an additional porous film, or alternatively, by (soft lithographic) patterning of YSZ features (as described in Chapter 7).

In addition, a columnar microstructure in the thin films may be achieved by the deposition of multiple very thin layers by using strongly diluted sols (Figure 8.3). This method has been successfully used for the preparation of e.g. BTO thin films with columnar crystallites. ${ }^{[7]}$ For a granular microstructure, the total ionic conductivity is mainly determined by the grain boundary contribution (Figure 8.3a), whereas for columnar grains the ionic transport is only limited by the grain interior (Figure 8.3b). An increased ionic conductivity of approximately 2 orders of magnitude is expected, ${ }^{[8]}$ which may lead to a further decrease in SOFC operating temperatures.

(a)

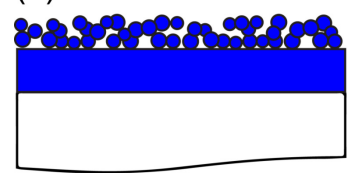

(b)

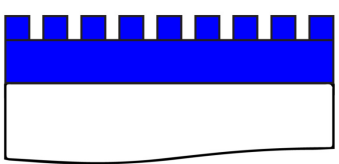

Figure 8.2 Schematic overview of thin film electrolytes with increased surface area: (a) a dense/porous film; (b) dense/patterned film.
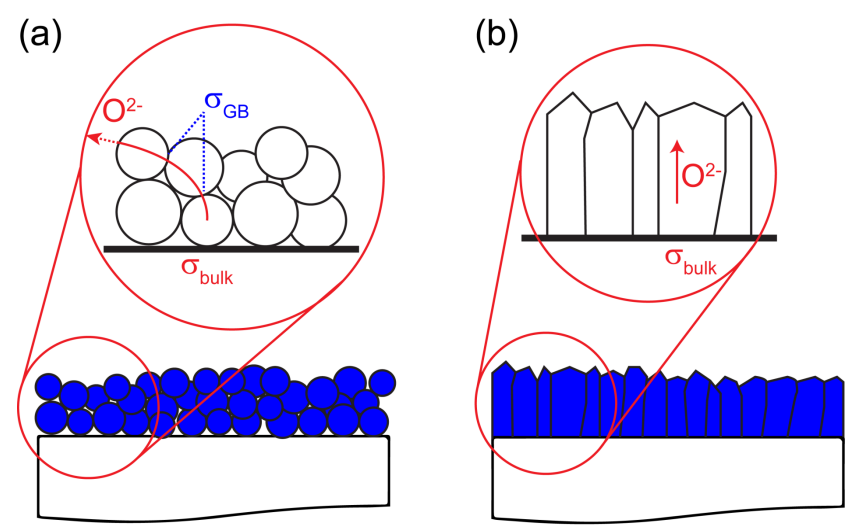

Figure 8.3 Schematic representation of the microstructural effect on the bulk and grain boundary conductivity in thin YSZ films, for (a) a granular structure, and (b) a columnar structure. 


\subsection{Final Remarks}

The work described in this thesis undoubtedly showed that sol-gel chemistry can be used as a cheap, and facile approach to high-quality ceramic materials. A better understanding of the sol-gel process will lead to an improved control over the desired crystalline phase and resulting microstructure. Although control on a molecular level can be exerted, sol-gel processing is not often used in industrial applications. Perhaps a shift in the perspective on how 'we' look at sol-gel chemistry is necessary to increase its use to a larger platform. A perspective in which the focus lies on the possibilities of the technique, rather than on the limitations. 


\subsection{Bibliography}

[1] T. M. Stawski, S. A. Veldhuis, O. F. Göbel, J. E. Ten Elshof, D. H. A. Blank, Effects of reaction medium on the phase synthesis and particle size evolution of BaTiO3. J. Am. Ceram. Soc. 2010, 93, 3443-3448.

[2] Z. A. Munir, U. Anselmi-Tamburini, M. Ohyanagi, The effect of electric field and pressure on the synthesis and consolidation of materials: A review of the spark plasma sintering method. Journal of Materials Science 2006, 41, 763-777.

[3] X. J. Chen, K. A. Khor, S. H. Chan, L. G. Yu, Overcoming the effect of contaminant in solid oxide fuel cell (SOFC) electrolyte: Spark plasma sintering (SPS) of $0.5 \mathrm{wt} \% \%$ silica-doped yttriastabilized zirconia (YSZ). Mater. Sci. Eng., A 2004, 374, 64-71.

[4] Z. Khani, M. Taillades-Jacquin, G. Taillades, M. Marrony, D. J. Jones, J. Rozière, New synthesis of nanopowders of proton conducting materials. A route to densified proton ceramics. J. Solid State Chem. 2009, 182, 790-798.

[5] S. Ricote, N. Bonanos, H. J. Wang, B. A. Boukamp, Conductivity study of dense BaZr0.9Y0.1O(3- $\delta$ ) obtained by spark plasma sintering. Solid State Ionics 2012, 213, 36-41.

[6] L. G. Hubert-Pfalzgraf, Heterometallic aggregates as intermediates on the molecular routes to multicomponent oxides. MRS Proceedings 1992, 271, 15-25.

[7] T. M. Stawski, W. J. C. Vijselaar, O. F. Göbel, S. A. Veldhuis, B. F. Smith, D. H. A. Blank, J. E. Ten Elshof, Influence of high temperature processing of sol-gel derived barium titanate thin films deposited on platinum and strontium ruthenate coated silicon wafers. Thin Solid Films 2012, 520, 4394-4401.

[8] M. V. F. Schlupp, B. Scherrer, H. Ma, J. G. Grolig, J. Martynczuk, M. Prestat, L. J. Gauckler, Influence of microstructure on the cross-plane oxygen ion conductivity of yttria stabilized zirconia thin films. Physica Status Solidi (A) Applications and Materials Science 2012, 209, 1414-1422. 


\section{Summary}

In Chapter 1, an introduction to the low-temperature wet-chemical approach to various perovskite and fluorite-type materials is presented. The main focus of the research described in this thesis is to control the material's synthesis route from liquid precursor to ceramic oxide powder or thin film; while understanding its formation mechanism. In addition, the synthetic approaches should be compatible with deposition techniques that allow for the upscaling to larger deposited surface areas. The scope of the thesis is presented at the end of the chapter.

In Chapter 2 and 3 the reaction mechanism of the low-temperature $\left(23-78^{\circ} \mathrm{C}\right)$ one-pot synthesis of $\mathrm{BaTiO}_{3}$ (BTO) is described. In Chapter 2, the formation of the crystalline phase was studied by investigating the stability and interaction of the precursors with each other and the solvent. Additional computational models could explain the experimental data well, showing that the phenylmethoxy ligand (from the parent alcohol) enhanced the stability of the Ti precursor by steric hindrance, and inhibited the growth of the BTO by forming a dense 'capping layer' on the surface of the crystallites.

The influence of temperature, water amount, and precursor concentration and stoichiometry on the BTO formation kinetics are described in Chapter 3. Time-resolved small-angle X-ray scattering (SAXS), X-ray diffraction (XRD), and high-resolution transmission electron microscopy (HR-TEM) were used to gain insight in nucleation, growth, and crystallization phenomena. The amount of water in the system (released from the barium hydroxide octahydrate precursor) was found to predominantly determine the rate of hydrolysis and consequently the rate of crystallization. At high precursor concentrations, crystallization followed the apparent zero-th order dehydration kinetics of the $\mathrm{Ba}$ precursor. Lower precursor concentrations constituted a decreased water availability, and resulted in impeded crystallization times. 
Careful adjustments of the total water concentration and precursor stoichiometry enabled to discern three rate-limiting regimes for the crystal phase formation.

The knowledge gained from the previous two chapters was used to expand this facile approach for the synthesis of other perovskite ceramics, and the incorporation of dopants. In Chapter 4 the synthesis of proton-conducting yttrium-doped barium zirconate ( $\left.\mathrm{BZY} ; \mathrm{BaZr}_{\mathrm{x}} \mathrm{Y}_{1-\mathrm{x}} \mathrm{O}_{3-\delta}\right)$ is presented. The formation of nano-crystalline $\mathrm{BZY}$ powders enhanced the sintering temperature, and dense, phase pure, ceramic bodies were obtained at significantly lower temperatures than necessary for bulk materials. The proton conductivity of the prepared BZY ceramic was mainly determined by the grain boundary contribution to the total resistance. The existence of ultrafine BZY grains after sintering (i.e. lack of grain growth) contributed to an enhanced grain boundary area, which negatively enhanced the proton conduction.

A method to measure the thin film density of sol-gel derived YSZ is described in Chapter 5. This facile approach is based on X-ray reflectivity (XRR) in which electron density of the material is determined by the critical angle (of total external reflection). The method describes the mathematical calculation of a so-called pseudo-critical angle. Calibration curves, illustrating the correlation between simulated XRR curves and their corresponding pseudo-critical angles, were used to determine the density of the prepared thin films. The method was validated by determining the thin film density of single crystal substrates and by using a combination of Rutherford backscattering (RBS) and high-resolution scanning electron microscopy (HR-SEM).

In Chapter 6, the aforementioned method was applied to investigate the densification behavior of YSZ thin films. In particular, the effect of annealing temperatures and substrate choice on the final density was studied. A final thin film density approximately $95 \%$ was achieved after annealing for only 5 min. Dense thin films are the key requirement for fuel cell applications, since fuel and oxidant need to be separated by the electrolyte membrane. Underlining, once more, the necessity of the method described in Chapter 5.

The soft-lithographic patterning of ionically conducting YSZ patterns is described in Chapter 7. A combination of sol-gel chemistry and micromolding in capillaries (MIMIC) was used to obtain (isolated) features with aspects ratios of $\sim 1$. The influence of the mold geometry and precursor concentration on the final patterned structures was investigated. At high precursor concentration, the use of a circular mold yielded micrometer-sized isolated features through crack formation during drying, whereas a square mold resulted in a continuous patterned structure. The use of diluted 
precursor solutions resulted in ring-shaped structures more than an order of magnitude smaller. The soft lithographic patterning of YSZ structures results in an increased electrolyte surface area. The combined knowledge of Chapter 5, 6, and 7 may result in a cost-effective fabrication method for gas-impermeable thin films with increased electrolyte surface area, and present a step towards improved economic feasibility and implementation of solid oxide fuel cell (SOFC) technology.

In Chapter 8, general conclusions are drawn. It is stated that sol-gel chemistry can be used as a cheap, and facile approach for the synthesis of high-quality nanoceramics. Although it is often described as an easy-to-use technique, subtle changes often have major consequences. Therefore, a full understanding of relevant synthesis parameters, e.g. the role of modifying ligands, precursor stability, and water concentration, is necessary to fully control the process from molecular precursor to final product. A change in perspective on how sol-gel chemistry is perceived, focusing on possibilities rather than on limitations, may contribute to a larger industrial platform. In addition, various experimental strategies, for future research are described, with a clear focus on the influence of synthesis parameters on the material's properties. 



\section{Samenvatting}

In Hoofdstuk 1 beschrijf ik, hoe ik getracht heb de verschillende keramisch materialen (van de perovskiet en fluoriet kristalstructuur) via nat-chemische syntheses te maken. Het liefst, bij een zo laag mogelijke temperatuur. De belangrijkste focus ligt hierbij op het controleren èn begrijpen van het gehele proces, van precursors (grondstoffen die de benodigde chemische elementen bevatten) en oplosmiddelen tot keramisch poeder of dunne laag. Tevens is geprobeerd de syntheses zodanig te ontwikkelen, dat deze makkelijk opgeschaald kunnen worden. Aan het einde van het hoofstuk worden de kernonderwerpen van dit proefschrift beschreven.

In Hoofdstuk 2 en 3 wordt het reactie mechanisme van barium titanaat $\left(\mathrm{BaTiO}_{3}\right.$; $\left.\mathrm{BTO}\right)$ beschreven. Deze reactie is uitgevoerd in slechts één stuk glaswerk (ook wel één-pots reactie genoemd), bij temperaturen tussen 23 en $78^{\circ} \mathrm{C}$; een barium zout is toegevoegd aan een oplossing van een titaniumhoudend molecuul in benzyl alcohol. In Hoofdstuk 2 is de formatie van de kristallijne* fase bestudeerd, door de interactie van de precursors met elkaar en het oplosmiddel te onderzoeken. De computermodellen die hiervoor ook gebruikt zijn, konden de verkegen experimentele data goed verklaren. Er is aangetoond dat de chemische groepen van het titaniumhoudend molecuul (titanium precursor) zich uitwisselen met het oplosmiddel. Dit wordt ook wel ligandenuitwisseling genoemd. Door de sterische hinder van de uitgewisselde oplosmiddel moleculen is de stabiliteit van de titanium precursor verhoogd. Tevens vormen deze ligand moleculen een dunne laag op het oppervlak van de nanodeeltjes, waardoor de groei van deze deeltjes geremd wordt.

* De atomen in een kristallijn materiaal zijn periodiek gerangschikt in 3 dimensies. Het tegenovergestelde is een amorf materiaal. 
De invloed van temperatuur, de hoeveelheid water, en de precursor concentratie en stoichiometrie op de barium titanaat formatiesnelheid is beschreven in Hoofdstuk 3. Tijdsafhankelijke kleine-hoek röntgen verstrooiing (SAXS; bij ESRF in Grenoble), röntgen diffractie (XRD), en hoge-resolutie transmissie elektronen microscopie (HR-TEM) zijn gebruikt om inzicht te krijgen in de nucleatie (het onstaan van de deeltjes), groei, en kristallisatie fenomenen. De hoeveelheid water die aanwezig is in het systeem (vrijgelaten door het barium zout) blijkt grotendeels de snelheid van hydrolyse, en daardoor, de kristallitie te beïnvloeden. Bij hoge barium precursor concentraties kristalliseren de barium titanaat deeltjes even snel als dat het barium zout dehydrateert. Bij lagere precursor concentraties (en dus bij lagere beschikbare hoeveelheden water) wordt de kristallisatie vertraagd. Door het voorzichtig aanpassen van de totale hoeveelheid water en de precursor stoichiometrie (de verhouding tussen de precursors), konden drie verschillende reactie-limiterende regimes van kristalformatie worden onderscheiden.

De verkregen kennis van de vorige twee hoofdstukken, is gebruikt om deze makkelijke synthetische route uit te breiden naar de productie van andere keramische perovskieten èn om de materiaaleigenschappen te veranderen door deze te doterent. In Hoofdstuk 4 is de synthese van protonengeleidend yttrium-gedoteerd barium zirconaat (BZY; $\mathrm{BaZr}_{\mathrm{x}} \mathrm{Y}_{1-\mathrm{x}} \mathrm{O}_{3-\delta}$ ) gepresenteerd. De vorming van nano-kristallijne BZY deeltjes verandert de sintertemperatuur zodanig, dat compleet verdichte, zuivere, keramische pellets gevormd worden bij significant lagere temperaturen dan gebruikelijk voor bulk materialen. De protonengeleiding van het geproduceerde keramiek is voornamelijk bepaald door de contributie van de korrelgrenzen op de totaal gemeten weerstand in het materiaal. De aanwezigheid van de zeer kleine BZY korrels na het sinteren (d.w.z. geen deeltjesgroei) draagt bij aan een vergroot korrelgrensoppervlak, en daarmee, helaas, aan een lagere protonengeleiding.

Een methode om de dichtheid van dunne lagen $¥$ yttrium-gestabiliseerd zirconia (YSZ) te bepalen, is beschreven in Hoofdstuk 5. Deze makkelijke aanpak is gebaseerd op de reflectie van röntgenstralen (XRR), waarbij de elektronendichtheid van een materiaal (en daarmee de materiaaldichtheid) wordt bepaald door de kritische hoek van totale externe reflectie. De methode beschrijft de mathematische berekening van een zogeheten pseudo-kritische hoek.

\footnotetext{
† Doteren is het inbrengen van 'onzuiverheden' om materiaaleigenschappen te veranderen.

$\ddagger$ Deze dunne lagen zijn verkregen door een sol-gel oplossing op een snel roterend oppervlak te deponeren ('spin coaten').
} 
Kalibratiecurves, die de correlatie tussen gesimuleerde XRR curves en de overeenkomende pseudo-kritische hoek laten zien, zijn gebruikt om de dichtheid van de geproduceerde dunne films te bepalen.

In Hoofdstuk 6, wordt de bovengenoemde methode gebruikt om de verdichtingseigenschappen van dunne YSZ lagen te bestuderen. Met name, het effect van de sintertemperatuur en substraatkeuze op de uiteindelijke dichtheid is onderzocht. De maximale laagdichtheid van $95 \%$ is bereikt in slechts 5 minuten verhitting bij $1000{ }^{\circ} \mathrm{C}$. Verdichte lagen zijn de belangrijkste vereiste voor gebruik in een brandstofcel, omdat de oxidant (lucht) en brandstof ten allen tijde gescheiden moet worden door het elektrolytmembraan (de YSZ laag). Dit laat nogmaals de noodzaak van een methode voor dichtheidsbepaling, zoals beschreven in Hoofdstuk 5, zien.

De formatie van ionengeleidende YSZ patronen met behulp van zachte elastomere stempels is beschreven in Hoofdstuk 7. Een combinatie van sol-gel chemie en zogeheten 'micromolding in capillaries' (MIMIC) is gebruikt om geïsoleerde patronen met een aspect ratio van $\sim 1$ te fabriceren. De invloed van de stempelgeometrie en de precursorconcentratie op de uiteindelijke structuren is onderzocht. Bij hoge concentraties, resulteerde het gebruik van een cirkelvormige stempels in micrometergrote geïsoleerde structuren, die gevormd zijn door het scheuren tijdens het drogingsproces. Een vierkante stempel daarentegen, resulteerde in een continu gepatroneerde structuur. Het gebruik van lagere concentraties resulteerde in ringstructuren die meer dan een ordergrootte $\$$ kleiner waren dan bij het gebruik van hoge concentraties. De patronering van YSZ structuren met behulp van zachte stempels, zorgde voor een vergroting van het totale oppervlak. De kennis verkregen van Hoofdstuk 5, 6, en 7 kan mogelijk bijdragen aan een goedkopere, kostenefficiënte fabricage methode voor gasondoordringbare dunne elektrolyt lagen, met een vergroot oppervlak. En kan zodoende een stap zetten richting de economische haalbaarheid en implementatie van vaste oxide brandstofcel (SOFC) technologie.

In Hoofdstuk $\mathbf{8}$ worden algemene conclusie getrokken. Er wordt beschreven hoe sol-gel chemie gebruikt kan worden als een goedkope en makkelijke route voor de synthese van hoogwaarde keramische producten (op nanoschaal). Ondanks dat het vaak beschreven wordt als een makkelijk-te-gebruiken techniek, zijn het de kleine, subtiele veranderingen tijdens de synthese die grote gevolgen hebben op de eigenschappen van het uiteindelijke product.

$\checkmark$ Een orde van grootte is een term die gebruikt wordt om de vermenigvuldiging met een factor 10 aan te duiden. 
Daarom is het noodzakelijk om de invloed van bijvoorbeeld de ligandenuitwisseling, de precursor stabiliteit en de waterconcentratie te begrijpen, om het process van begin tot einde te kunnen controleren. Een verandering van de manier waarop men tegen sol-gel chemie aankijkt, één die uitgaat van mogelijkheden in plaats van beperkingen, kan mogelijk bijdragen aan een breder gebruik binnen het industriele platform. Als laatste, worden verscheidene experimentele strategiën voor mogelijk vervolgonderzoek beschreven. De focus ligt hierbij vooral op de invloed van synthese parameters op de uiteindelijke materiaaleigenschappen. 


\section{List of Publications}

[15] S. A. Veldhuis, P. Brinks, J.E. Ten Elshof, Rapid densification of sol-gel derived yttria-stabilized zirconia thin films. Submitted.

[14] S. A. Veldhuis, W. J. C. Vijselaar, T. M. Stawski, J. E. Ten Elshof, The formation of nanocrystalline barium titanate in benzyl alcohol at room temperature. Inorg. Chem. 2014, 53, 13188-13196. [13] A. W. Maijenburg, J. Veerbeek, R. de Putter, S. A. Veldhuis, M. G. C. Zoontjes, G. Mul, J. M. Montero-Moreno, K. Nielsch, H. Schafer, M. Steinhart, J. E. ten Elshof, Electrochemical synthesis of coaxial TiO2-Ag nanowires and their application in photocatalytic water splitting. Journal of Materials Chemistry A 2014, 2, 2648-2656.

[12] S. A. Veldhuis, P. Brinks, T. M. Stawski, O. F. Göbel, J. E. Ten Elshof, A facile method for the density determination of ceramic thin films using X-ray reflectivity. J. Sol-Gel Sci. Technol. 2014, 71, 118-128.

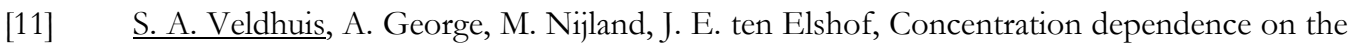
shape and size of sol-gel-derived yttria-stabilized zirconia ceramic features by soft lithographic patterning. Langmuir 2012, 28, 15111-15117.

[10] A. George, T. M. Stawski, S. Unnikrishnan, S. A. Veldhuis, J. E. ten Elshof, Micro and nanopatterning of functional materials on flexible plastic substrates via site-selective surface modification using oxygen plasma. J. Mater. Chem. 2012, 22, 328-332.

[9] T. M. Stawski, S. A. Veldhuis, R. Besselink, H. L. Castricum, G. Portale, D. H. A. Blank, J. E. Ten Elshof, Nanostructure development in alkoxide-carboxylate-derived precursor films of barium titanate. Journal of Physical Chemistry C 2012, 116, 425-434.

[8] T. M. Stawski, R. Besselink, S. A. Veldhuis, H. L. Castricum, D. H. A. Blank, J. E. ten Elshof, Time-resolved small angle X-ray scattering study of sol-gel precursor solutions of lead zirconate titanate and zirconia. J. Colloid Interface Sci. 2012, 369, 184-192. 
Electron microscopy study of intragranular nanoporosity and the occurrence of local structural disorder in cubic $\mathrm{BaTiO} 3$ nanopowders from alkoxidehydroxide precipitation process. Ceram. Int. 2012, 38, 6911-6917.

[6] T. M. Stawski, W. J. C. Vijselaar, O. F. Göbel, S. A. Veldhuis, B. F. Smith, D. H. A. Blank, J. E. ten Elshof, Influence of high temperature processing of sol-gel derived barium titanate thin films deposited on platinum and strontium ruthenate coated silicon wafers. Thin Solid Films 2012, 520, 43944401.

[5] T. M. Stawski, S. A. Veldhuis, R. Besselink, H. L. Castricum, G. Portale, D. H. A. Blank, J. E. Ten Elshof, Erratum: Nanoscale structure evolution in alkoxide-carboxylate sol-gel precursor solutions of barium titanate (Journal of Physics Chemistry C (2010) 115 (20449-20459) DOI: 10.1021/jp206572q). Journal of Physical Chemistry C 2011, 115, 24028.

[4] T. M. Stawski, S. A. Veldhuis, R. Besselink, H. L. Castricum, G. Portale, D. H. A. Blank, J. E. Ten Elshof, Nanoscale structure evolution in alkoxide-carboxylate sol-gel precursor solutions of barium titanate. Journal of Physical Chemistry C 2011, 115, 20449-20459.

[3] T. M. Stawski, S. A. Veldhuis, H. L. Castricum, E. G. Keim, G. Eeckhaut, W. Bras, D. H. A. Blank, J. E. Ten Elshof, Development of nanoscale inhomogeneities during drying of sol-gel derived amorphous lead zirconate titanate precursor thin films. Langmuir 2011, 27, 11081-11089.

[2] O. F. Göbel, T. E. Branfield, T. M. Stawski, S. A. Veldhuis, D. H. A. Blank, J. E. T. Elshof, Stacks of functional oxide thin films patterned by micromolding. ACS Applied Materials and Interfaces 2010, 2, 2992-2994.

[1] T. M. Stawski, S. A. Veldhuis, O. F. Göbel, J. E. Ten Elshof, D. H. A. Blank, Effects of reaction medium on the phase synthesis and particle size evolution of BaTiO3. J. Am. Ceram. Soc. 2010, 93, 3443-3448. 


\section{Acknowledgments}

After hundreds of reflux syntheses, over a thousand deposited thin films, and other successful and unsuccessful attempts, I finally arrive to writing the fun part of my thesis. To address those who contributed - knowingly and unknowingly - to the completion of this work. Firstly, I'd like to thank André ten Elshof, Dave Blank, and Guus Rijnders for hiring me as a research technician (and for starting this journey). I absolutely loved the job! Especially, the freedom to learn and explore: no boundaries. It turned out to be the catalyst for four wonderful extra years in the Inorganic Materials Science group. André, I'd like to thank you for the opportunity and for believing I could do it. The discussions we've had were always very constructive and always accompanied with encouraging words. It helped me to structure my thoughts and work. Thank you for creating the perfect atmosphere for science and fun.

Secondly, I'd like to thank Tomek. We've started working together, about 7 years ago, when I was 'your' technician. We've had tons of fun, but also a very fruitful collaboration. It made me realize I also wanted to start a $\mathrm{PhD}$. In addition, many thanks to Antony and Maarten for kick-starting my research. Your introduction to 'why not?' helped me to think out-of-the-box, which added tremendously to my creative thinking.

The pleasant and collegial atmosphere in the IMS group was very enjoyable and often ended in $2 \mathrm{~h}$ coffee breaks filled with interesting discussions on topics ranging from trivial to (slightly) less trivial. I'd like to thank everyone in the IMS group for creating this stimulating environment, and the staff to so be actively involved in promoting it: André, Bernard, Guus, Gertjan, Mark, Dave, Henk, Dominic, Marion, José, Laura, Kees, and Gerrit. Furthermore, a special thanks to Henk and Dominic for their technical support, and their often simple (but brilliant) approach to my daily-life lab problems. 
Marion and José, thank you for taking care of a lot of 'invisible' work regarding administration and finances, it made my life a lot easier!

Also, I'd like to thank all my former and present room-mates: Tomek, Nicolas, Michiel, Pablo, Gerard, Antony, Ronald, and Karin for the fun, discussions, and brainstorm sessions in the office. And of course my fellow chemical brothers and sisters: Tomek, Ole, Antony, Maarten, Rogier, Wouter, Wouter V., Pablo, Gerard, Huiyu, Alessandro, Ronald, Sajid, Petra, Roy, Bahruz, Vera, Maarten, Tom, Michiel, Nicolas, Suresh and the whole batch of MSc and BSc students I've forgot to mention (my apologies). Your input given at the Friday morning work meetings were invaluable, and regularly resulted in the direct implementation and testing of it after the meeting. André and Bernard, also thank you for all your critical questions and positive remarks during these meetings! Also, a big thank you for my students Wouter V. Sander, and Wouter B. for their hard work, thoughts, and ideas.

In the 7 years I've worked at the university, I had the pleasure to work with many wonderful colleagues. Thank you chemical brothers and sisters (again), Nirupam, Alim, Kurt, Anirban, Ben, Tjeerd, Rik, Brian, Michelle, Bouwe, Xin, Evert, Hajo, Tom, Werner, Muhammad, Debakanta, Zhaoliang, Lin, Özlem, Ron, Jung, Kenan, Anuj, Tülin, Melanie, Josee, Willem, Jeroen, Hans, Oktay, Minh, Matthijn, Joska, Peter de V., Frank!, Gerwin, Bas, Louis, and Frank. Also the expertise and help of Rico Keim, Mark Smithers and Gerard Kip at the Nanolab is kindly acknowledged.

I'm grateful for the scientific contribution of the co-authors of my published (and unpublished) work: Antony, Maarten, Tomek, Ole, Wouter V., Peter, Pablo, Gerard, Bernard, Bas, Louis Winnubst, Sophie Guillemet, and Liane Benning. It was impossible without your input.

And, how can I forgot the numerous trips to the synchrotron in Grenoble. In particular, the impossible (ever-changing) planning, the 5 am beers after yet another 20 $\mathrm{h}$ shift, corny tiredness, 'paranoia', the walks in(to) town or to the Bastille. As tiring as every trip was, I'm going to miss it! A special thanks to the SAXS-clan: Tomek, Rogier, Hessel, Pablo, Huiyu, Roy, Suresh, and Sajid. And of course the staff of the DUBBLE BM26, in particular Giuseppe Portale, Daniel Hermida Merino, Fabian Ledrappier, and Wim Bras.

It was wonderful to work with so many cool colleagues; always ready to help, or to share an idea, or just for a plain fun (e.g. Friday afternoon experiments). But more importantly, the fact that some of you were not just colleagues but also very good friends. Thank you Tomek \& Kasia (and Maja), Nicolas \& Marian, Michiel, Antony \& 
Meegha, Rogier, Pablo \& Joanna, Gerard \& Niloofar, Wouter, Alessandro, Ronald, and Wouter V. for the countless drinks, dinners, concerts, games, trips, and one broken coat hanger. You've made this an unforgettable time!

I'd like to thank my friends Chris and Annabelle (and little Coralie) for - unknowingly - always choosing the perfect moment for a good braai, concert or weekend break. It always helped me clear my mind and start afresh.

Many thanks to my family, in particular my parents, for their unlimited support throughout my life, and the opportunities that were given to me to become who I am now. Dad (or Henk at work), I never would've thought we were going to be colleagues, but it was really nice. Thank you!

Last, but definitely not least, I'd like to thank my wife Coralie for her unconditional love and support, especially near the end. I know it wasn't always easy having me in the house. Thanks love, I couldn't have done it without you! I'm ready for our next adventure, bring it on! 



\section{Dankwoord}

$\mathrm{Na}$ honderden reflux syntheses, meer dan duizend gedeponeerde dunne films, en vele andere succesvolle en minder succesvolle pogingen, kan ik eindelijk het leukste deel van mijn proefschrift schrijven. Om de mensen te bedanken die - bewust en onbewust hebben bijgedragen aan de voltooiing van dit werk. Allereerst zou ik graag André ten Elshof, Dave Blank en Guus Rijnders willen bedanken voor mijn aanstelling als onderzoekstechnicus (en daarmee de start van dit avontuur). Het was een geweldige baan! Vooral de vrijheid om te leren en ontdekken kende geen grenzen. Dit alles bleek de katalysator voor vier prachtige extra jaren in de Inorganic Materials Science groep. André, bedankt voor deze mogelijkheid en het vertrouwen in me. Onze discussies waren altijd constructief en gingen altijd gepaard met bemoedigende woorden. Het heeft me geholpen om structuur te geven aan mijn gedachten(gang) en werk. Bedankt voor het creeëren van de perfecte atmosfeer voor wetenschap en plezier.

Vervolgens zou ik graag Tomek willen bedanken. We begonnen onze samenwerking ongeveer 7 jaren geleden, toen ik 'jouw' technicus werd. We hebben niet alleen ontzettend veel lol gehad, maar het was ook een ontzettend productieve samenwerking. Ik realiseerde me daardoor snel dat ik ook wilde promoveren. Antony en Maarten, bedankt voor het kickstarten van mijn onderzoek. Jullie 'why not?'-principe heeft geholpen om 'out-of-the-box' te denken en heeft enorm bijgedragen aan mijn creatief denken.

De gemoedelijke en collegiale atmosfeer in de IMS groep was heel aangenaam, en eindigde vaak in 2 uur durende koffiepauzes, die gevuld werden met interessante discussies over onzin of andere belangrijke dingen. Via deze weg zou ik graag iedereen binnen de IMS groep willen bedanken voor het creeëren van deze stimulerende werkomgeving, en de stafleden voor jullie actieve rol in het stimuleren hiervan: André, Bernard, Guus, Gertjan, Mark, Dave, Henk, Dominic, Marion, José, Laura, Kees en 
Gerrit. Een speciaal woord van dank voor Henk en Dominic voor hun technische support en de soms kinderlijk eenvoudige (maar briljante) oplossingen voor mijn allerdaagse lab problemen. Marion en José, bedankt voor het uit handen nemen van veel 'onzichtbaar' werk m.b.t. administratie en financiën; het heeft mijn leven een stuk makkelijker gemaakt!

Mijn voormalige en huidige kamergenoten voor alle lol, discussies en brainstorm sessies in het kantoor: Tomek, Nicolas, Michiel, Pablo, Gerard, Antony, Ronald en Karin. Natuurlijk wil ik ook mijn chemische broeders en zusters bedanken: Tomek (wederom), Ole, Antony, Maarten, Rogier, Wouter, Wouter V., Pablo, Gerard, Huiyu, Alessandro, Ronald, Sajid, Petra, Roy, Bahruz, Vera, Maarten, Tom, Michiel, Nicolas, Suresh en de vele MSc en BSc studenten die ik vergeten ben te benoemen (mijn excuses hiervoor). Jullie input tijdens de vrijdagochtend vergaderingen was van onschatbare waarde voor mij. Het leidde vaak tot de het testen van jullie opmerkingen direct na de vergadering. André en Bernard, jullie ook bedankt voor alle kritische vragen en commentaar tijdens deze vergaderingen! Mijn studenten Wouter V., Sander en Wouter B. bedankt voor jullie harde werk en ideeën.

In de 7 jaren die ik op de UT gewerkt heb, heb ik het voorrecht gehad om met vele geweldige collega's samen te werken. Bedankt mijn chemische broeders en zusters (nogmaals), Nirupam, Alim, Kurt, Anirban, Ben, Tjeerd, Rik, Brian, Michelle, Bouwe, Xin, Evert, Hajo, Tom, Werner, Muhammad, Debakanta, Zhaoliang, Lin, Özlem, Ron, Jung, Kenan, Anuj, Tülin, Melanie, Josee, Willem, Jeroen, Hans, Oktay, Minh, Matthijn, Joska, Peter de V., Frank!, Gerwin, Bas, Louis en Frank. Ook de expertise en hulp van Rico Keim, Mark Smithers en Gerard Kip, van het Nanolab, is zeer op prijs gesteld.

Ik ben de co-auteurs van mijn gepubliceerde (en niet-gepubliceerde) werk dankbaar voor de wetenschappelijke contributie die zijn geleverd hebben: Antony, Maarten, Tomek, Ole, Wouter V., Peter, Pablo, Gerard, Bernard, Bas, Louis Winnubst, Sophie Guillemet en Liane Benning. Het was onmogelijk zonder jullie input.

En hoe kan ik de vele reisjes naar de synchrotron in Grenoble vergeten. Met name de onmogelijke (continu veranderende) planning, de biertjes om 5 uur's ochtends na weer een 20 uur durende werkdag, de melige moeheid, 'paranoia', de wandelingen in/naar het centrum of de Bastille. Hoe vermoeiend elke trip ook was, ik ga het missen! Een speciaal woord van dank voor de SAXS-clan die dit mogelijk heeft gemaakt: Tomek, Rogier, Hessel, Pablo, Huiyu, Roy, Suresh en Sajid. En natuurlijk ook de staf van DUBBLE BM26, met name Giuseppe Portale, Daniel Hermida Merino, Fabian Ledrappier en Wim Bras. 
Het was geweldig om samen te werken met zoveel leuke collega's, die altijd bereid waren om te helpen, of om ideeën uit te wisselen, of gewoon voor alle lol (bijv. de vrijdagmiddag experimenten). Maar belangrijker nog, het feit dat sommige van jullie niet alleen collega's waren, maar ook goede vrienden. Bedankt voor deze geweldige tijd Tomek \& Kasia (en Maja), Nicolas \& Marian, Michiel, Antony \& Meegha, Rogier, Pablo \& Joanna, Gerard \& Niloofar, Wouter, Alessandro, Ronald en Wouter V. voor de ontelbare drankjes, etentjes, concerten, spelletjes, tripjes en niet te vergeten, één kapotte kapstok. Jullie hebben het een onvergetelijke tijd gemaakt!

Ik wil ook graag mijn vrienden Chris en Annabelle (en kleine Coralie) bedanken omdat ze - onbewust - altijd het juiste moment wisten te kiezen voor een goede braai, een concert, of gewoon een lekker weekend weg. Het heeft me altijd geholpen mijn hoofd te legen en een frisse start te maken.

Veel dank gaat uit naar mijn familie, met name mijn ouders, voor de onbegrensde steun en mogelijkheden die jullie me altijd gegeven hebben, zodat ik kon worden wie ik nu ben. Pa (of Henk op het werk), ik had nooit gedacht dat we ooit collega's zouden worden, maar het was echt geweldig. Bedankt!

Tot slot, wil ik graag mijn vrouw Coralie bedanken voor haar onvoorwaardelijke liefde en steun, met name op het laatst. Ik weet dat het niet altijd makkelijk was met mij in huis. Bedankt schat, ik had het niet zonder jou kunnen doen! Ik ben klaar voor ons volgende avontuur! 
